\title{
Seagrass mapping and monitoring along the coasts of Crete, Greece
}

\author{
by Lemenkova Polina
}

March 2011 


\section{Course Title}

Geo-Information Science and Earth Observation for Environmental Modelling and Management

\section{Level}

Master of Science (MSc)

Course Duration:

September 2009 - March 2011

\section{Consortium partners:}

* University of Southampton, School of Geography (UK)

* Lund University, GIS Centre (Sweden)

* University of Warsaw, Faculty of Geography and Regional Studies (Poland)

* University of Twente, Faculty of Geo-Information Science and Earth Observation (ITC) (The Netherlands)

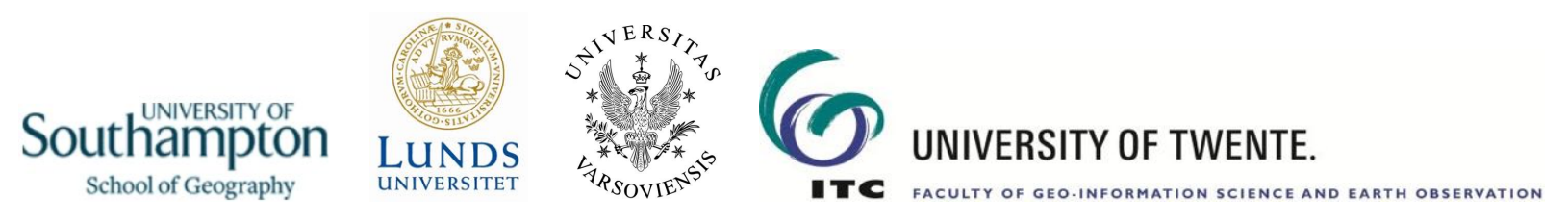




\title{
Seagrass mapping and monitoring along the coasts of Crete, Greece
}

\author{
by Lemenkova Polina
}

Thesis submitted to the University of Twente, Faculty of Geo-Information Science and Earth Observation (ITC), in partial fulfillment of the requirements for the degree of Master of Science in Geo-information Science and Earth Observation for Environmental Modelling and Management.

Thesis Assessment Board:

* Chair: Prof. Dr. Andrew K. Skidmore

* External Examiner: Dr. Matgorzata Roge-Wiśniewska

* First supervisor: Mr. Valentijn Venus

* Second supervisor: Dr. Albertus G. Toxopeus

17C FACULTY OF GEO-INFORMATION SCIENCE AND EARTH OBSERVATION 


\section{Contents}

$\begin{array}{ll}\text { Front Page } & \text { i }\end{array}$

Course Title $\quad$ i

Supervisory Committee ii

Table of Content

Dedication $\quad$ vi

Acknowledgements

Disclaimer $\quad$ viii

$\begin{array}{ll}\text { Abstract } & \text { ix }\end{array}$

Keywords $\quad$ ix

$\begin{array}{lc}\text { Document Outline } & \mathbf{x} \\ & \end{array}$

List of Acronyms

List of Tools $\quad$ Xv

$\begin{array}{ll}\text { List of Figures } & \text { xvi }\end{array}$

List of Tables $\quad$ xxiii

1 Introduction $\quad 1$

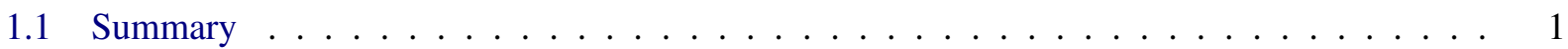

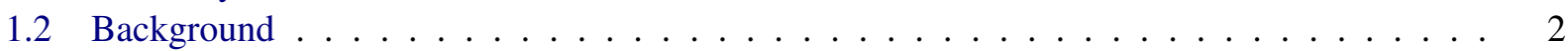

1.2.1 Global distribution of the seagrasses . . . . . . . . . . . . . . . 2

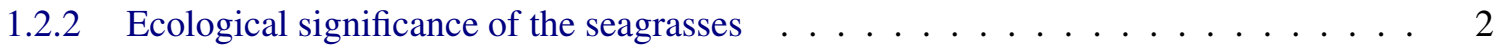

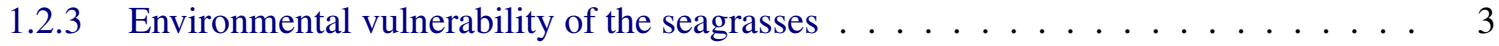

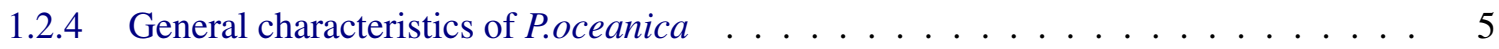

Morphology of P.oceanica . . . . . . . . . . . . . . . . 5

Phenology of P.oceanica . . . . . . . . . . . . . . . . 6

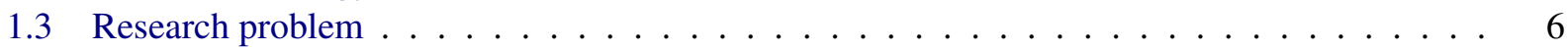

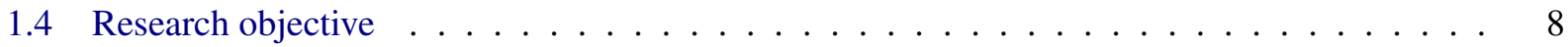

1.4 .1 General objective . . . . . . . . . . . . . . . . . . . . . . 9

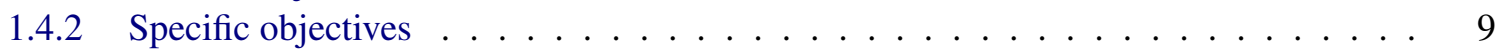

1.5 Research questions $\ldots \ldots \ldots \ldots \ldots \ldots$ 


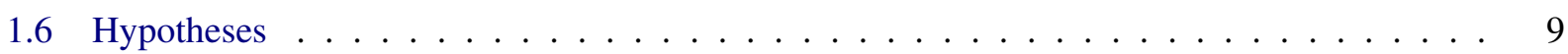

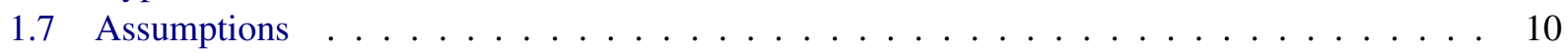

1.8 Research approach . . . . . . . . . . . . . . . . . . . 11

2 Seagrass monitoring: overview of literature and research resources 13

2.1 Seagrass global monitoring: history and perspectives . . . . . . . . . . . . 13

2.2 Measuring optical properties of benthic vegetation: hyperspectral radiometers . . . . . . . 14

2.3 Radiative Transfer Models (RTM) for the simulation of water optical properties: a brief

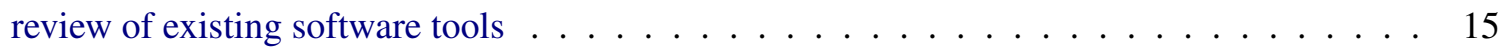

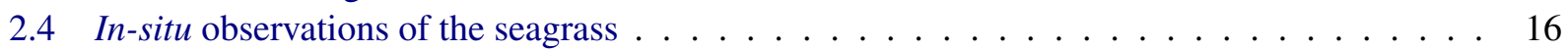

2.5 Application of the remote sensing data towards seagrass mapping . . . . . . . . . . . 17

2.5.1 Review of multispectral imagery used for seagrass mapping . . . . . . . . . . 20

2.5.2 Review of hyperspectral imagery used for seagrass mapping . . . . . . . . . . . . 22

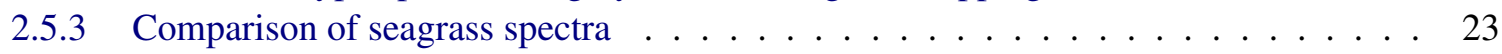

3 Materials and methods $\quad 24$

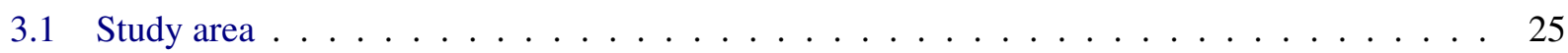

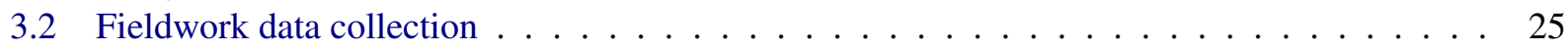

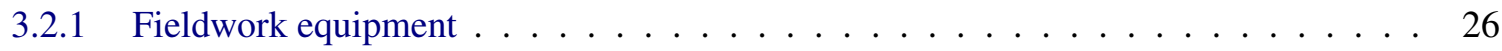

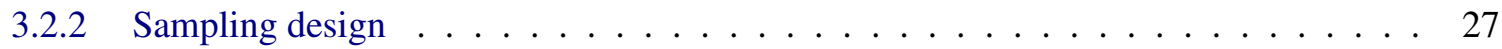

3.3 Review of the collected data . . . . . . . . . . . . . . . . . . . . . 29

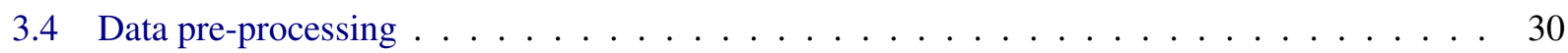

3.4 Auxiliary data: spectral dataset . . . . . . . . . . . . . . . . . 30

3.4 .2 Modelling method: WASI water colour simulator . . . . . . . . . . . 31

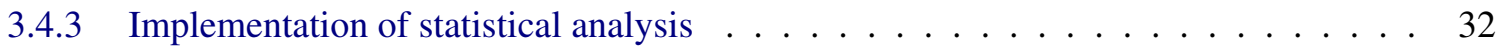

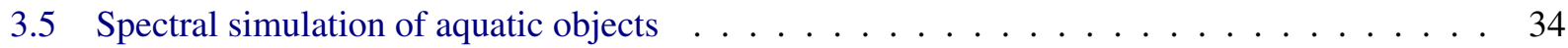

3.5.1 Model parameters: depth and bottom cover fraction . . . . . . . . . . . . . 35

3.6 Google Earth aerial imagery . . . . . . . . . . . . . . . . . . . . 36

3.7 Image processing using Erdas Imagine $\ldots \ldots \ldots \ldots$

4 Results $\quad 38$

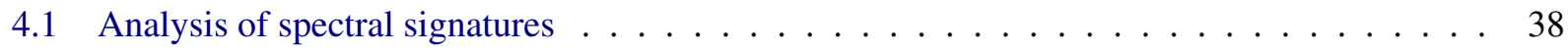

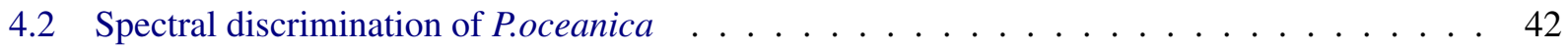

4.2.1 Statistical analysis of the observational data and hypothesis testing . . . . . . . . . 44

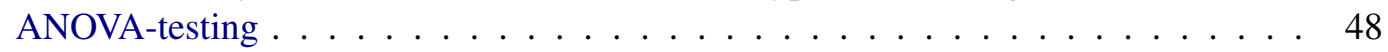

4.2 .2 Remote sensing application $\ldots \ldots \ldots \ldots \ldots \ldots$

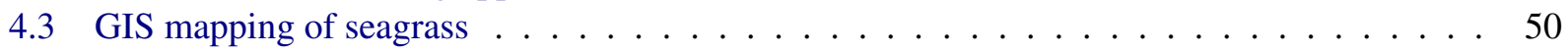

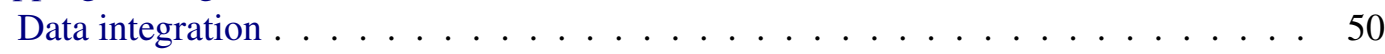

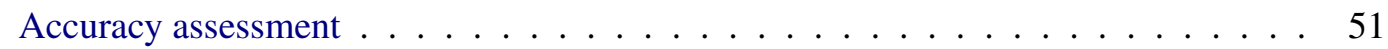

5 Discussion $\quad \mathbf{5 2}$

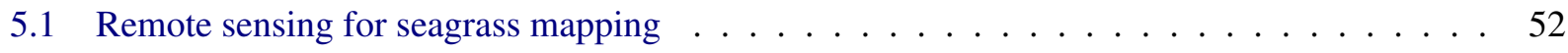

5.2 Upscale mapping of the seagrass landscapes $\ldots \ldots \ldots \ldots 5$

6 Conclusion $\quad 57$ 
A appendices

A.1 Capturing aerial imagery from the Google Earth . . . . . . . . . . . . . . i

A.2 Illustrations of remote sensing principles used for seagrass monitoring $\ldots \ldots \ldots$. . . . ii

A.3 Instrumental adjustment and tuning: Trios-RAMSES setup . . . . . . . . . . . v

A.4 Types of seagrass structural patterns: Ligaria beach, Crete . . . . . . . . . . . . . vii

A.5 Results of videographic measurements: seafloor types on Crete island . . . . . . . . . . viii

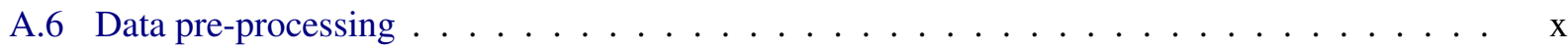

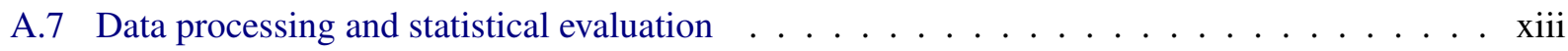

A.7.1 Data processing and statistical evaluation: P.oceanica . . . . . . . . . . xix

A.7.2 Data processing and statistical evaluation: carbonate sand . . . . . . . . . x xli

A.8 Satellite and aerial images covering research area of Crete Island: selected examples _ . . . xlvii

A.9 Analysis and classification of the satellite and aerial images . . . . . . . . . . . . . 1

A.10 Accuracy assessment . . . . . . . . . . . . . . . . liii

A.11 Research general workflow $\ldots \ldots \ldots \ldots \ldots \ldots \ldots$ lv $\ldots \ldots \ldots$

A.12 Some snapshots of the working process $\ldots \ldots \ldots \ldots \ldots$ lvi

Bibliography

Index of People

$\begin{array}{lc}\text { Index of Concepts } & \text { o }\end{array}$ 


\section{Dedication}

To My Elder Brother AND Best Friend, Peter LEMenkov 


\section{Acknowledgements}

This research was carried out at the University of Twente, Faculty of Geo-Information Science and Earth Observation (ITC), Enschede, the Netherlands, under the financial support of the EU Erasmus Mundus Scholarship.

I thank my scientific supervisors, Dr. Albertus G.Toxopeus and Mr. Valentijn Venus from the ITC, Department of Natural Resources, for our successful scientific collaboration, help and discussions of my research work. I also express them my most sincere appreciations for our fieldwork on Crete.

Besides scientific routine, we had an unforgettable time spent together.

Personally, I would like to mention that I have visited Greece the first time in my life, and I will always remember my Cretan period-2010 and Ligaria beach.

I extend my gratitude to the staff of the Museum of Natural History, Department of Zoology of the University of Crete, especially to Dr.Petros Lymberakis and his colleagues, for their assistance during our fieldwork, providing us with all necessary equipment (e.g. SCUBA gear diving, instruments for underwater measurements, etc). I also appreciate their very warm, personal attitude and interest towards our research.

My sincere gratitude goes again to Mr.Valentijn Venus for his generous providing me with a lot of spatial data relevant to my research (e.g. such as digital vector layers of Crete island, raster georeferenced maps for the whole island for my GIS project, Excel spreadsheets, etc). Without these vital data the implementation of this project would have hardly been possible. I am also thankful to him for the technical help in Google Earth imagery capturing, using GDAL technologies and assistance during the fieldwork (videometric underwater footage, consultancies in seagrass observation and monitoring, driving boat, etc).

My special thank to his personal, friendly support in various situations on Crete.

I am thankful to Dr.rer.nat.Peter Gege, the software developer from the Earth Observation Centre of the German Space Agency, for his generous consultancies concerning the technical question about WASI that arose during my work. I am thankful for all his explanations and articles given to me via e-mail

My special thanks are addressed to my elder brother, Mr.Peter Lemenkov, the software developer from the ipPort, for his priceless numerous advices and constant professional support throughout my career. He encouraged me to use various very useful software and tools, always gave me necessary recommendations and precious help, thus highly contributing to my professional growth.

My special thank for his help with Python scripting.

I am also heartfelt thankful to him for his personal friendship and support.

I am grateful to Mr.Willem Nieuwenhuis, the software developer from the ITC, Department of Natural Resources, for shared technology of Google Earth aerial imagery grabbing and for his consultancy with ASTER imagery.

I thank Dr. Ir. Cornelis A.J.M. de Bie from the Department of Natural Resource, ITC, for his patient sharing of iPAQ knowledge during my Polish fieldwork in summer 2010. I used this skills on Crete.

Many thanks for Dr. Dingtian Yang from the South China Sea Institute of Oceanology, our colleague in problem of seagrass monitoring and research, for his handing over the data of spectral reflectance of Thalassia seagrass, which enabled to compare spectra of various seagrass types. 


\section{Disclaimer}

This document describes work undertaken as part of a programme of study at the University of Twente, Faculty ITC. All views and opinions expressed therein remain the sole responsibility of the author, and do not necessarily represent those of the university.

I herewith certify that although I conferred with other researchers while preparing this document, and used a range of various research and literature resources, cited in the text, the content of this MSc Thesis document remains my own, original work, written by me personally.

Signed................................(Lemenkova Polina)

Enschede, The Netherlands.

18th February 2011. 


\section{Abstract}

The seagrasses, a unique group of aquatic plants, create complex, extremely diversified and productive ecological systems in the littoral coastal zones. The only flowering plant in the world that is able to live completely submerged, seagrasses play vital role in the marine ecosystems of the World Ocean. Seagrasses are the most important component in the environmental food chain of the coastal ecosystems, being a vital food source for various marine species (e.g. fish, dugongs, turtles, swans), and a producer of organic matter, which is the very basis of the food web.

The P.oceanica seagrass is an endemic for the Mediterranean region, and a main species in the marine coastal environment of Greece. Meadows of P.oceanica are subjected to the human activities, because they occur in coastal areas, where they are affected both by anthropogenic and by climatic and environmental factors. Nowadays P.oceanica is in the alarming state of regression, because of the deterioration of the environment in the Mediterranean Sea. Due to these reasons, P.oceanica is a protected species since 1988 in some European countries (France). Monitoring P.oceanica is therefore an important contribution to the saving and protecting the environment of Mediterranean region.

The current MSc thesis focuses on the monitoring of seagrass P.oceanica along the northern coasts of Crete Island, Greece, and investigates the application of the remote sensing techniques for the seagrass mapping. This research was articulated in two parts, where the first one involves an ecological approach to the seagrass distribution in various regions around the globe and the experience of seagrass monitoring nowadays. The second part of this work has technical character and investigates the application of the remote sensing techniques towards seagrass mapping. It, furthermore, focuses on the optical properties of the P.oceanica and other seafloor cover types, and studies distinguishability of various seafloor cover types. Studies of the optical characteristics of separate seafloor cover types were made with purpose to clarify, whether their spectral properties change with varying environmental conditions.

Special attention has been drawn on the role of environmental factors on the distribution of P.oceanica along the coasts of Crete, and in particular, how the optical properties of the seafloor cover types, i.e. spectral reflectance, are being changed under varying external conditions, e.g. water column, amount of suspended particles and sediments in the seawater, and water temperature. For this purpose we studied differences in the spectral reflectance of P.oceanica and other bottom cover types at three distinct depths. The diverse spectral values entail variations in optical properties of the seafloor cover types at changing environmental conditions. We applied WASI Water Color Simulator (WASI) simulation techniques for the modelling of the optical parameters of various seafloor cover types by various spaceborne imaging spectrometers (MEdium Resolution Imaging Spectrometer (MERIS), Sea-viewing Wide Field-of-view Sensor (SeaWiFS), Coastal Zone Color Scanner (CZCS) and MODerate resolution Imaging Spectroradiometer (MODIS)), in order to understand their suitability and possible limitations for the seagrass mapping.

Fieldwork research sites were presented by separate locations on the northern coast of Crete region (Ligaria, Agia Pelagia, Xerocampos). The additional measurements of the reflectance spectra of the seawater with and without sediments have been made in aquarium tank in 2009 by means of Trios-RAMSES spectroradiometer. Parallel to the collection of spectra signatures, we captured the imagery for the seagrass mapping, which consists of the aerial images from the Google Earth website and the satellite Landsat TM and ETM+ scenes.

\section{Keywords}

P.oceanica, seagrass monitoring, spectral reflectance, remote sensing, WASI, Google Earth, Crete 


\section{Document Outline}

Chapter 1: Introduction is an introductory section. It describes general background of the research problem, outlines the need and actuality of the problem (including the environmental vulnerability of the seagrasses), and highlights limitations and possibilities of the remote sensing application for the current work. In this chapter we also set up research objectives, put research questions for hypothesis testing and sketch research approach for the proposed work.

In Chapter 2: Seagrass monitoring: overview of literature and research resources we review the existing literature and reported research experience on the similar problem: studies of spectral separability of various seafloor types, limitations and advantages of the remote sensing techniques applied for seagrass mapping seagrass ecology and mapping seagrass environment. We considered not only the Mediterranean environment, but also papers from Australian and Chinese scientists, because seagrass monitoring is most actively developed in the southern regions of our planet. The review of the existing RTM algorithms for the retrieval of the optical parameters, as well as description of various tools for the spectrometric measurements - are given in the same Chapter as well. More close attention has been given to the imaging hyperspectral radiometer Trios RAMSES, used for the data collection.

Chapter 3: Materials and methods deals with the methods and materials used in current work. We start our discussion from the fieldwork area location and describe tools and instruments used during the fieldwork, as well as sampling design. Procedures of the data pre-processing and capturing imagery from the Google Earth are also presented in the same chapter.

Chapter 4: Results presents to the reader the main results of the current MSc work, obtained during the processing fieldwork and other collected data. It starts from the review of the collected data from different sources, then describes the modelling component of the research, namely WASI colour simulation and plotted resulting graphs. We also discuss here the particularities of various sensors, suitable enough for deriving radiometric information to discriminate sand from the seagrass. Furthermore, this chapter includes analysis of the spectral signatures of various seafloor cover types in conditions of changing environment, possibility and limitations for P.oceanica spectral discrimination, statistical analysis of the data sets and mapping based on images processing.

Cahpter 5: Discussion discusses research results, reported in detail in a previous chapter, comes to the research insights and discusses relevance of this work in scientific context.

Chapter 6: Conclusion summarizes and highlights the final research outcomes and main results.

Finally, we suggest some recommendations for any further research focusing on the seagrass environment along the coasts of Crete (or other Mediterranean areas) in the final Recommendations.

A lot of plotted graphs, statistical outcomes, tables, auxiliary (yet relevant to our research) pictures and images, illustrating our work - are collected in the appendices. Due to the standard editorial limitations of the current MSc work, it was not possible to include all them to the main chapters. However, we tried to make the structure of the Appendices most clear and easy-readable as possible, by dividing the Appendices into 10 various sub-sections and referencing to them from the main text where necessary.

The References section includes literature and internet resources used for the current work. The crossreferencing and web hyper-referencing are used in the whole document to make reading more quick, effective and informative.

All persons mentioned in the current document are listed in the Index of People.

An Index of Concepts is placed in the end of the Document to help the reader find what he is looking for. 


\section{List of Acronyms ${ }^{1}$}

6SV1 Second Simulation of a Satellite Signal in the Solar Spectrum Version1 .

ASCII American Standard Code for Information Interchange $\ldots \ldots \ldots \ldots \ldots \ldots \ldots \ldots \ldots \ldots \ldots \ldots$

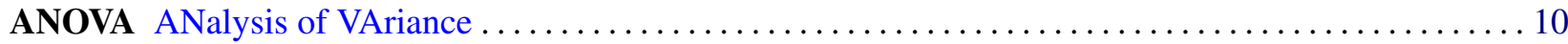

ASTER Advanced Spaceborne Thermal Emission and Reflection Radiometer ..................21

BRDF Bidirectional Reflectance Distribution Function $\ldots \ldots \ldots \ldots \ldots \ldots \ldots \ldots \ldots \ldots \ldots \ldots \ldots \ldots$

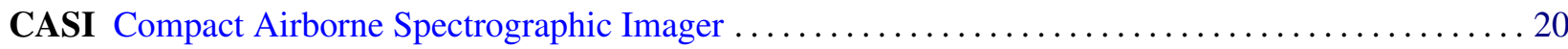

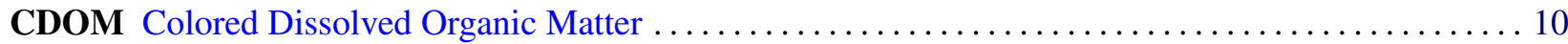

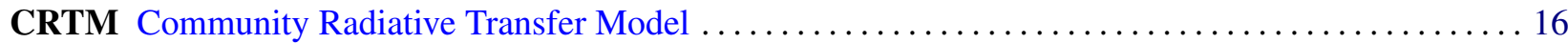

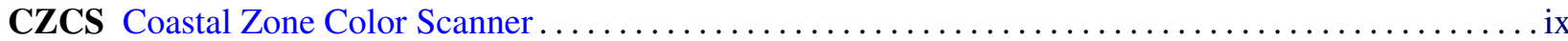

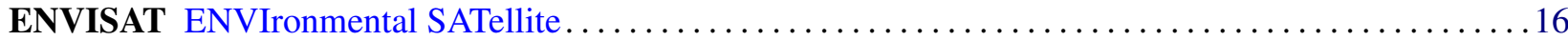

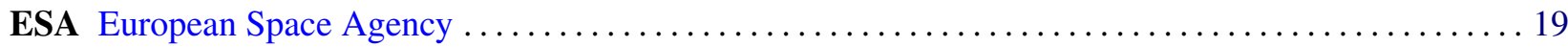

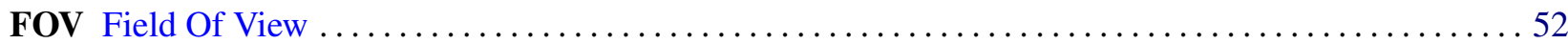

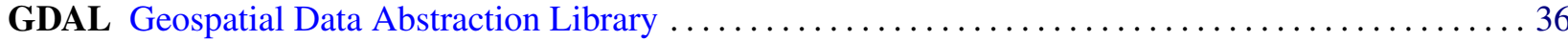

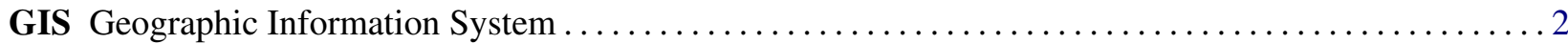

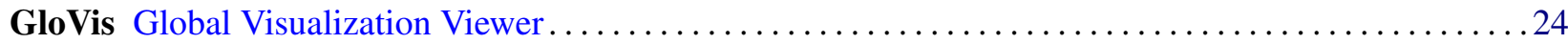

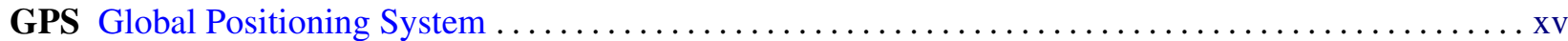

\footnotetext{
${ }^{1}$ The page is given where the glossary is first entered and defined
} 
GRASS Geographic Resources Analysis Support System $\ldots \ldots \ldots \ldots \ldots \ldots \ldots \ldots \ldots \ldots \ldots \ldots \ldots$

GRETL GNU Regression, Econometrics and Time-series Library $\ldots \ldots \ldots \ldots \ldots \ldots \ldots \ldots \ldots \ldots 44$

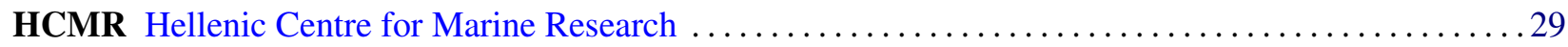

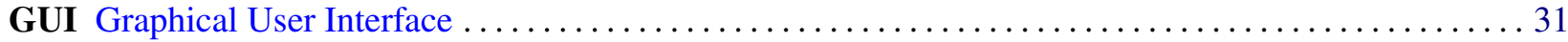

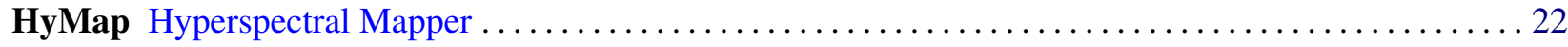

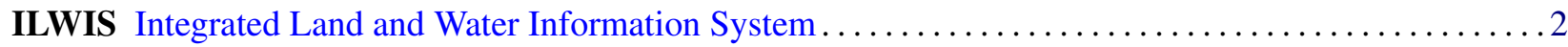

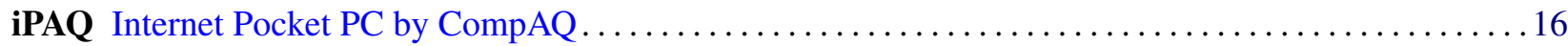

KOPRA Karlsruhe Optimized and Precise Radiative transfer Algorithm . . . . . . . . . . . . . . . 16

LAD Least Absolute Deviations . ......................................... 45

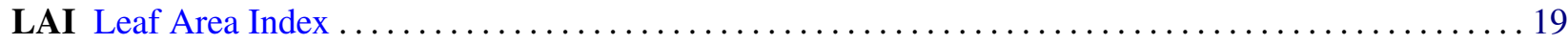

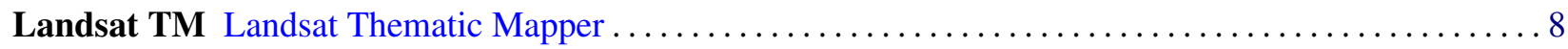

Landsat ETM+ Landsat Enhanced Thematic Mapper Plus $\ldots \ldots \ldots \ldots \ldots \ldots \ldots \ldots \ldots \ldots \ldots$

MERIS MEdium Resolution Imaging Spectrometer $\ldots \ldots \ldots \ldots \ldots \ldots \ldots \ldots \ldots \ldots \ldots \ldots \ldots \ldots \ldots \ldots \ldots \ldots$

MIPAS Michelson Interferometer for Passive Atmospheric Sounding $\ldots \ldots \ldots \ldots \ldots \ldots \ldots \ldots \ldots \ldots \ldots$

MODIS MODerate resolution Imaging Spectroradiometer $\ldots \ldots \ldots \ldots \ldots \ldots \ldots \ldots \ldots \ldots \ldots \ldots$ ix

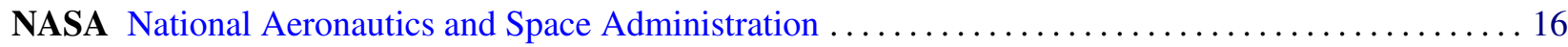

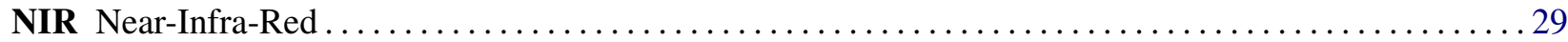


NOAA National Oceanic and Atmospheric Administration

OBC On Board Calibration

OLS Ordinary Least Squares 45

Olympus ST Olympus Stylus Tough 8

RRTM Rapid Radiative Transfer Model . 16

RTTOV-9 Radiative Transfer for TIROS (Television and InfraRed Observation Satellite) Operational Vertical Sounder

RTM Radiative Transfer Model. 1

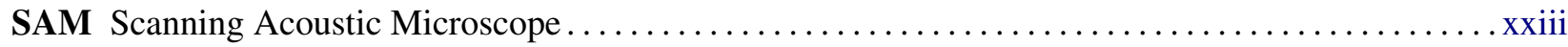

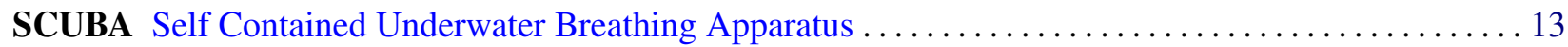

SeaWiFS Sea-viewing Wide Field-of-view Sensor $\ldots \ldots \ldots \ldots \ldots \ldots \ldots \ldots \ldots \ldots \ldots \ldots \ldots \ldots \ldots \ldots \ldots$

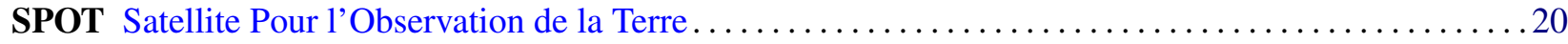

SPSS Statistical Package for the Social Sciences..................................

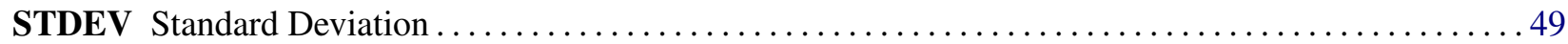

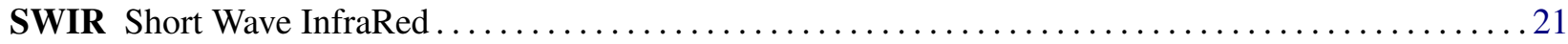

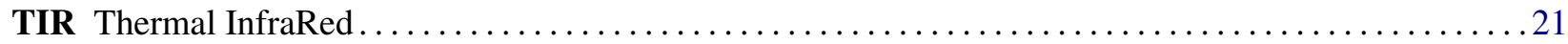

Trios-RAMSES RAdiance Measurement SEnSor $\ldots \ldots \ldots \ldots \ldots \ldots \ldots \ldots \ldots \ldots \ldots \ldots \ldots \ldots \ldots \ldots \ldots$

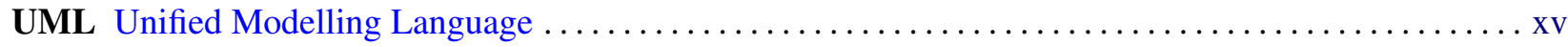




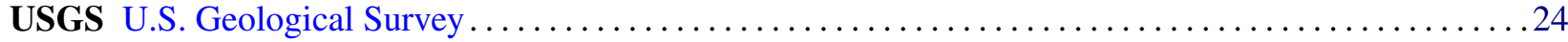

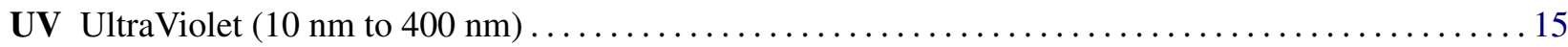

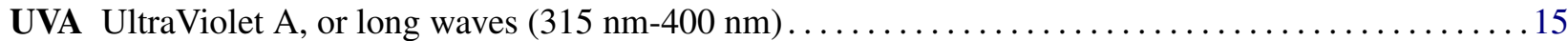

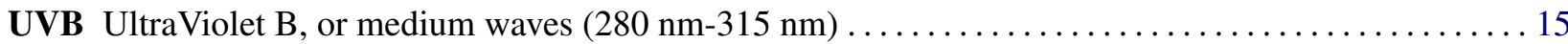

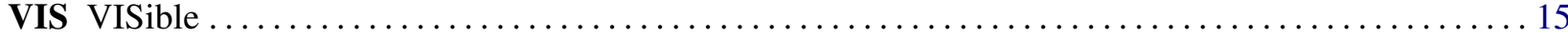

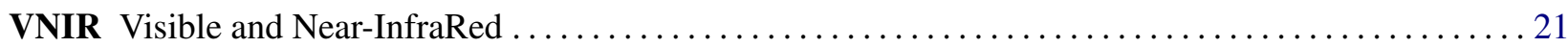

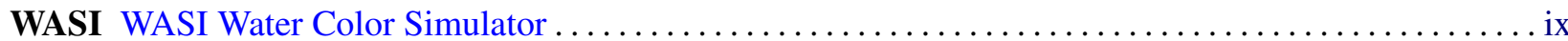

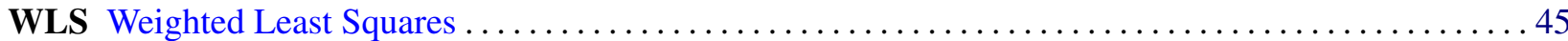




\section{List of Tools}

\section{Software and utilities used in the current work:}

\section{Main Tools:}

- ArcGIS 10.0: mapping, data integration and spatial analysis

- ILWIS, Erdas Imagine: imagery processing and classification

- WASI Water Color Simulator, for modelling optical water properties under changing environment

- iPAQ and Global Positioning System (GPS) for data capture during the fieldwork

- $\mathrm{LTT}_{\mathrm{E}} \mathrm{X}$, for document typesetting, formatting and performing pdf output

- BibTeX, for management of bibliography and reference database

- GNUplot for plotting graphs

- Gretl: GNU Regression, Econometrics and Time-series Library for statistic analysis

- Open Office: document typesetting, data pre-processing and preliminary statistical evaluation

- SPSS (PASW Statistics 18): statistical data edition and analysis

- FWTools: for operating images formats

- StarUML, Dia, ArgoUML: Unified Modelling Language (UML) diagram tool for creating flowcharts of work algorithms

\section{Auxiliary Tools:}

- LyX for exporting $\mathrm{ITT}_{\mathrm{E}} \mathrm{X}$ document to the Word .doc format via HTML

- Calc2LaTeX: converting spreadsheets into LATEXenvironment

- Python language, for writing ancillary scripts (e.g. raw data interpolation)

- OpenEV: used for raster Google Earth imagery viewing, visualisation and preliminary analysis

- Notepad++: ancillary text editing and raw data formatting

- Inkscape and Gimp: GNU Image Manipulation Program for drawing 


\section{List of Figures}

1.1 Seagrass Posidonia Oceanica. Pages: $<1>,<3>,<5>\ldots \ldots \ldots \ldots \ldots$

1.2 Distribution of seagrasses in the world. Source:[48]. Pages: $\langle 1\rangle,<2>\ldots \ldots \ldots$

1.3 Morphology of different types of seagrasses. Source: http://www.ozcoasts.org.au.

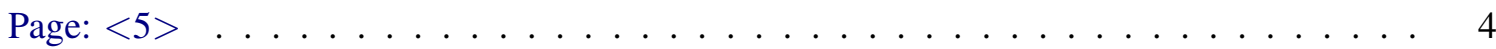

1.4 Distribution of seagrass in relation to mean ocean temperature. Source: [107]. Pages: $<2>$,

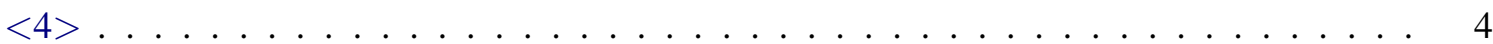

1.5 Geographical distribution of P.oceanica. Source: [12]. Pages: $\langle 4\rangle,\langle 5\rangle \ldots \ldots$

1.6 Morphology of P.oceanica. Page: $<5>\ldots \ldots \ldots \ldots$

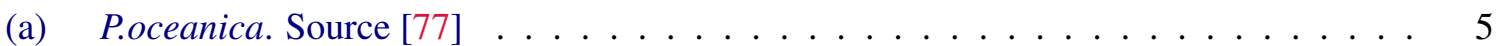

(b) Scheme of matte structure of P.oceanica. Source[116] . . . . . . . . . . . . 5

(c) Structure and components of P.oceanica. Source[28] . . . . . . . . . . . . 5

1.7 Spectra of the seagrass on different depths $(0-15 \mathrm{~m})$. Source [35]. Page: $<7>\ldots \ldots$

1.8 General methodological approach for the analysis of spectral signatures. ArgoUML, Gimp. Page: $<11>\ldots \ldots \ldots \ldots \ldots \ldots \ldots \ldots \ldots \ldots$

2.1 RAdiance Measurement SEnSor (Trios-RAMSES) Hyperspectral Sensors. Source: Trios. Pages: $\langle 14>,<15>,<19>\ldots \ldots \ldots \ldots \ldots \ldots \ldots \ldots$

(a) Trios-RAMSES-ACC-UV - Hyperspectral UVA/UVB Irradiance Sensor: 280-500 nm 14

(b) Trios-RAMSES-ARC - Hyperspectral UV-VIS Radiance Sensor: 320-950 nm. . . . . 14

2.2 In situ optical reflectance spectra of seagrass. Shaded areas - \% of spectra lying within the range of reflectance. White lines - mean spectra. Source: [57]. Pages: $<19>,<23>\ldots \ldots$

2.3 Difference between broadband multispectral and hyperspectral resolution of spectral signatures. Source: [23]. Page: $\langle 22>\ldots \ldots \ldots \ldots \ldots$. . . . . . . . . . . . 18

2.4 Band coverage of ASTER and Landsat channels on the e/m spectrum. Source:[66]. Pages:

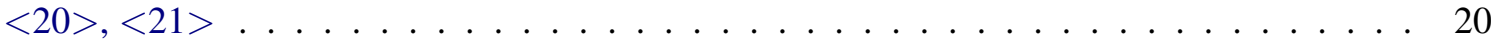

2.5 Multispectral vs. hyperspectral band coverage. Source: [125]. Pages: $\langle 22\rangle,\langle 20\rangle \ldots \ldots$

2.6 Reflectance spectra of Thalassia seagrass; Rrs(0-) - subsurface RS reflectance; Rrs b - the bottom reflectance. Source:[140]. Pages: $<23>,<24>,<57>\ldots \ldots \ldots$. . . . . 22

3.1 Study area: Crete island. Pages: $\langle 2>,<25>\ldots \ldots \ldots \ldots \ldots$

3.2 Study area: Ligaria beach, Crete island. Pages: $\langle 25>,<26>\ldots \ldots \ldots$

3.3 Fieldwork equipment. Pages: $\langle 17>,<26>,<27>,<28>,<28>\ldots \ldots \ldots$

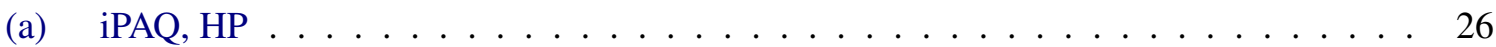

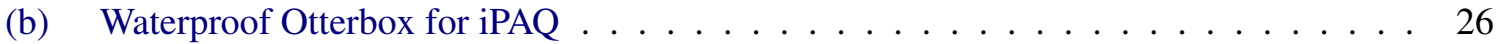




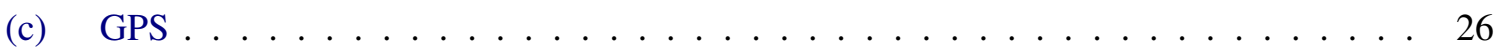

(d) Olympus waterproof camera . . . . . . . . . . . . . . . . 26

3.4 Boat used for the fieldwork measurements on Crete Island. 2010. Page: $<26>\ldots \ldots$

3.5 Scheme of the depths measurements; fieldwork on Ligaria beach. Page: $<28>\ldots 27$

3.6 Scheme of placements of the Olimpus cameras during the measurements. Pages: $<28>,<28>28$

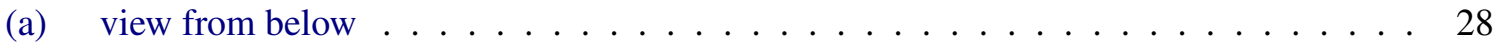

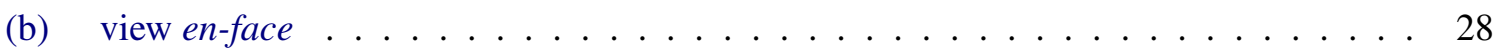

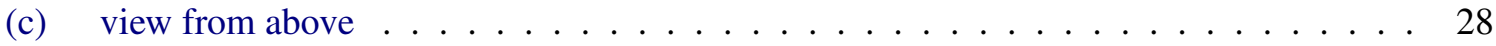

3.7 Work flow for the data acquisition, Dia display. Page: $<29>\ldots \ldots$. . . . . . . 30

3.8 Work Flowchart Diagram illustrating algorithm of the Statistical Analysis applied towards the observation dataset (StarUML). Page: $\langle 44>,<32>\ldots \ldots \ldots \ldots$. . . . . . . . 33

3.9 Sea water physical properties, modeled by WASI. Page: $<34>\ldots \ldots \ldots$. . . . . . 34

(a) Concentration of Gelbstoff at depths $0.58 .0 \mathrm{~m} \ldots \ldots \ldots$. . . . . . . . . . 34

(b) Bottom reflectance at depth $0.5-4.0$ meters . . . . . . . . . . . . . 34

3.10 Seafloor types of the Arina beach: P.oceanica, sand, rocks. Google Earth images. Page: $<55>37$

(a) small-scaled $(1: 54,000) \ldots \ldots \ldots \ldots \ldots \ldots \ldots$

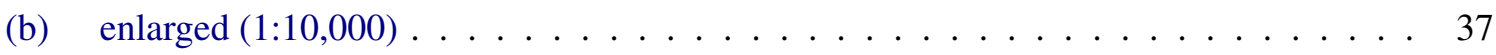

4.1 Statistical comparison of spectral reflectance of P.oceanica and carbonate sand. Selected measurements sets. Gnuplot graph. Pages: $<31>,<36>,<32>\ldots \ldots$. . . . . . 38

4.2 Optical properties of the sea water with sediments, measured in aquarium tank. Agia Pelagia district, Crete. Gnuplot. Pages: $<23>,<38>\ldots \ldots$. . . . . . . . . . . . 39

4.3 Multiplot showing spectral reflectance of the seawater with sediments, measured in aquarium tank, Agia Pelagia district, Crete. Gnuplot. Two complimentary graphs below show the results of the statistical analysis. Pages: $\langle 31>,<32>,<38>\ldots \ldots \ldots \ldots$

4.4 Combined plots of simulated remote sensing reflectance of P.oceanica at various sensors: MODIS, MERIS, SeaWiFS and CZCS, iterated over three depths, as stripes shown spectral bands covered by these sensors. Pages: $<23>,<24>,<40>,<50>\ldots \ldots \ldots \ldots$

4.5 Simulated remote sensing reflectance of P.oceanica at various depths. Pages: $<35>,<39>$. Vertical stripes show coverage of spectral bands by MERIS sensor . . . . . . . . . . . 42

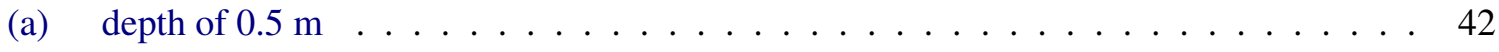

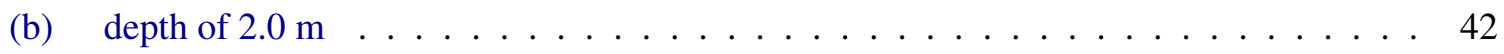

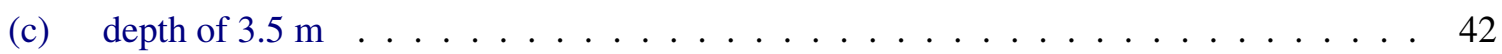

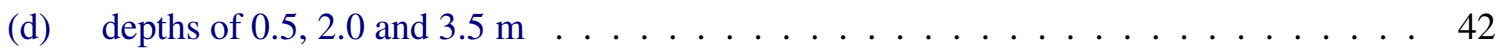

4.6 Statistical analysis of the spectral reflectance of P.oceanica: min-max, average values (red bold points), Q1-Q3 areas (green vertical dashed) and measured values (dotted): multiplot of measurement sets 200-300. Gnuplot. Pages: $<23>,<31>,<35>\ldots \ldots \ldots$

4.7 Bottom albedo of carbonate sand and P.oceanica, Agia Pelagia. Page: $<24>\ldots$. . . . . 43 


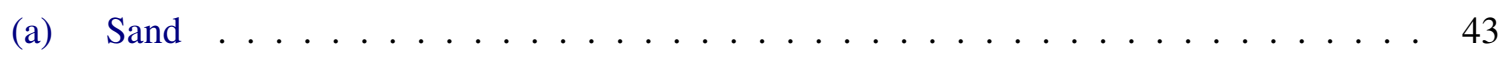

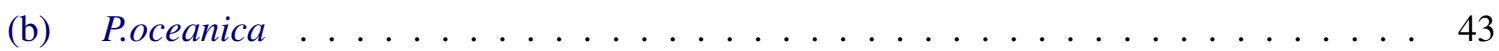

4.8 Multiplot of spectral reflectance of P.oceanica. Series 1-100. Shown mid-spread of the statistical quartiles Q1 and Q3 (vertical dashes) and mean value within the range (red bold

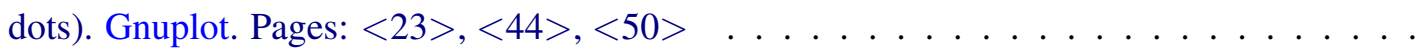

4.9 Multiplot of spectral reflectance of carbonate sand. Series 1-75. Shown mid spread of the statistical quartiles Q1 and Q3 (vertical dashes) and mean value within the range (red bold dots). Gnuplot. Pages: $<23>,<44>\ldots \ldots \ldots \ldots \ldots \ldots$

4.10 Multiplot of spectral reflectance of P.oceanica. Series 126-150. Shown mid-spread of the statistical quartiles Q1 and Q3 (vertical dashes) and mean value within the range (red bold dots). Gnuplot visualization. Pages: $\langle 42>,<50>\ldots \ldots \ldots \ldots \ldots$

4.11 Google aerial images incorporated into the GIS project: fragment of ArcGIS layout. Page:

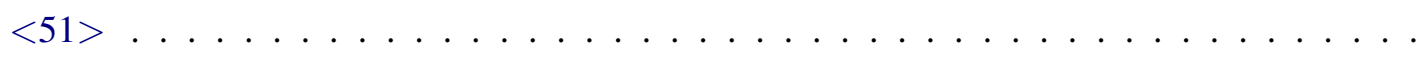

5.1 Spectral reflectance of P.oceanica and carbonate sand at different depths of 0.5-4.0m. Modelled by WASI water color spectral simulation. Pages: $\langle 34>,<38>,<31>,<49>\ldots$. . . 53

5.2 Variations in spatial structure of the seagrass landscapes. Page: $<55>\ldots \ldots 6$

(a) Meadows of the seagrass. Source: Google Earth . . . . . . . . . . . . . . 56

(b) Patches (mattes) of the seagrass. Source: in-situ videometric measurements . . . . . . 56

A.1 Capturing aerial imagery from the Google Earth: grabbing process. Page: $<36>\ldots$ i

A.2 Script command of FWTools enabling to reduce the size of the aerial images, from tif to .ecw format. Page: $<36>\ldots \ldots \ldots \ldots \ldots$ ii

A.3 Schematic illustration of the solar zenith angle and viewing zenith angle for observations from satellite-based instrument. Source: Support to Aviation Control Service (SACS). Page:

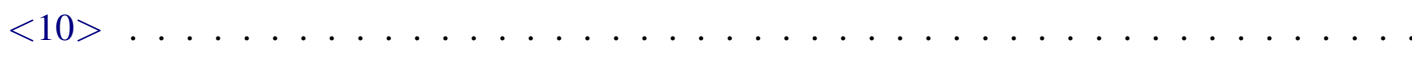

A.4 Absorbance spectra of free chlorophyll a (green) and b (red) in a solvent. The spectra of chlorophyll molecules are slightly modified in vivo depending on specific pigment-protein interactions. Source: Wikipedia.org. Page: $\langle 53>\ldots \ldots$. . . . . . . . iii

A.5 Example of sonar beam acoustic systems used for mapping seagrasses habitat boundaries. Source: Reef Research. Page: $<17>\ldots \ldots$. . . . . . . . . . . . iii

A.6 Example of wave backscattering from the vegetation. Source: Yoshio Inoue. Page: $\langle 11>$. . iv

A.7 BRDF is a ratio of reflected radiance along $\omega_{o}$ to the irradiance from direction $\omega_{i}$, all parameterized by azimuth angle $\phi$ and zenith angle $\theta$. Source: Wikipedia.org. Page: $\langle 11\rangle \ldots$ iv

A.8 Types of seagrass structural patterns, Ligaria beach, Crete. Pages: $<28>,<31>\ldots$. . . . vii

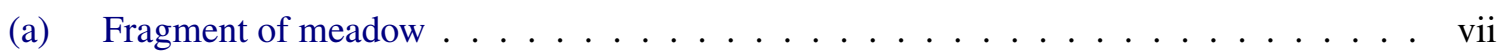

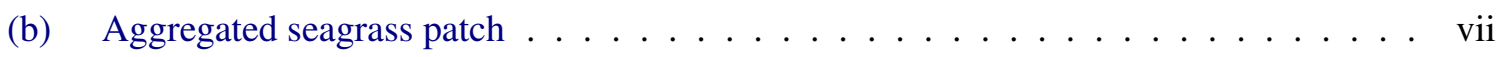

(c) Isolated patch of seagrass . . . . . . . . . . . . . . . vii

A.9 Locations of the video measurements and GPS tracklogs, Ligaria. Pages: $<27>,<28>\ldots$ vii 
A.10 Ligaria beach, Crete: seafloor types. Pages: $<31>,<42>\ldots \ldots$. . . . . . . . viii

A.11 Various seafloor types; Ligaria beach, Crete. Page: $<31>\ldots$. . . . . . . . . . . . viii

A.12 Measurement underwater equipment. Page: $<28>\ldots \ldots \ldots \ldots$. . . . . . ix

A.13 Script written on Python, for the interpolation raw data of the Trios-RAMSES measurements.

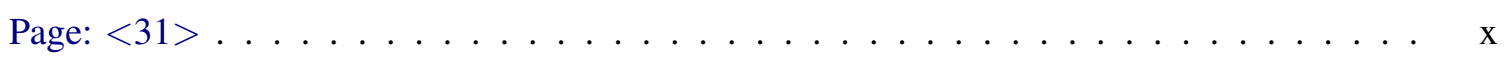

A.14 Fragment of Bottom.R file: values of spectral measurements of the seagrasses (various species), sand, silt and artificial spectrum of constant albedo. Page: $<31>\ldots \ldots \ldots$ xi

A.15 Interpolation of the spectral measurements by means of Open Office. Page: $<31>\ldots$. . . xii

A.16 Radiance of the seawater with sediments. Measured in aquarium tank. Bezier Interpolation.

Gnuplot. Pages: $<32>,<44>,<29>\ldots \ldots \ldots \ldots$. . . . . . . . . . . . . . . . .

A.17 Multiplot graph showing spectral reflectance of the seawater without sediments, measured in aquarium tank, Agia Pelagia district, Crete. Gnuplot. Two complimentary graphs below show the results of the statistical analysis. Pages: $<31>,<32>,<34>\ldots \ldots$. . . . xiv

A.18 Irradiance of the seawater, measured in aquarium tank. Smooth Splines interpolation. Visualization in Gnuplot. Page: $<38>\ldots \ldots \ldots$. . . . . . . . . . xiv

A.19 Irradiance of the seawater, measured in aquarium tank. Smooth Bezier interpolation. Visualization in Gnuplot. Pages: $<32>,<29>\ldots \ldots \ldots \ldots \ldots$. . . . . . . . . . . . .

A.20 Spectral reflectance of the seawater with sediments. Bezier interpolation. Mean value is shown by the vertical impulses linestyle. Gnuplot. Pages: $<32>,<38>\ldots \ldots$. . . . . xvi

A.21 Plot illustrating polynomial trend for spectral reflectance of seawater without sediments (Ligaria Beach), variable V15. Gretl modelling visualization. Page: $<32>\ldots$. . . . . . . xvi

A.22 Plot illustrating polynomial trend for spectral reflectance of seawater with sediments (Ligaria Beach), variable V15. Gretl modelling visualization. Page: $<32>\ldots \ldots$. . . . . . xvii

A.23 Exponential moving average of spectral reflectance of seawater with sediments (Ligaria Beach), variable V15. Gretl modelling visualization. Page: $<32>\ldots \ldots$. . . . . . xvii

A.24 Frequency normality test against gamma distribution: radiance of the seawater, measured in aquarium tank. Visualization in Gretl. Page: $<17>\ldots \ldots$. . . . . . . xviii

A.25 Frequency normality test against normal distribution: radiance of the seawater, measured in aquarium tank. Visualization in Gretl. Page: $\langle 17>\ldots \ldots \ldots$. . . . . . . . . . . . . . . . .

A.26 Values of spectral reflectances of seagrass P.oceanica (fragment). Pages: $<32>,<44>$. . . xix

A.27 Spectral reflectance of P.oceanica. Measurement series 401-420. Gnuplot. Pages: $<23>$, $<32>,<38>\ldots \ldots \ldots \ldots \ldots \ldots \ldots \ldots \ldots \ldots \ldots$ xix

A.28 Statistical analysis of the measurement data: spectral reflectance of the P.oceanica. Visualization of the interquartile ranging. Example of data set 401-420. Shown mid-spread of statistical quartiles Q1 and Q3, min and max values within the range. Gnuplot. Pages:

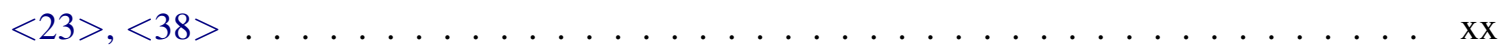


A.29 Enlarged fragment of the statistical analysis of the measurement data. Example of data set 401-420. Visualization of the interquartile ranging and plotted together with measurement data. Gnuplot. Page: $<38>\ldots \ldots \ldots \ldots$. . . . . . . . . . . xx

A.30 Fragment of the statistical analysis of the P.oceanica reflectance. Example of data set 401420. Visualization of the measured data together with statistical values: interquartile ranging, medians, means. Gnuplot. Pages: $<23>,<32>,<29>\ldots \ldots \ldots$. . . . . . xxiii

A.31 Partial correlation analysis of the measurement set 1-16 of the spectral reflectance of P.oceanica (15.X.). Visualization in SPSS. Page: $<45>\ldots \ldots \ldots$. . . . . . . . xxix

A.32 Autocorrelation analysis of the measurement set 1-16 of the spectral reflectance of P.oceanica (15.X.). Visualization in SPSS. Page: $<45>\ldots \ldots \ldots \ldots$. . . . . . . . . . . . . .

A.33 Spectral reflectance of the seawater without sediments. Interpolation graph. Gnuplot display.

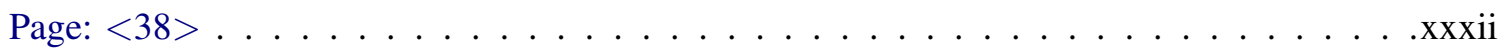

A.34 WASI-simulated remote sensing reflectance of P.oceanica at various sensors. Pages: $<40>$,

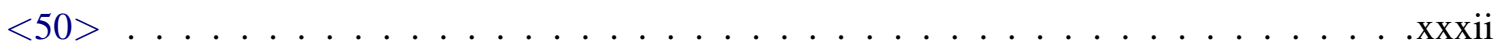

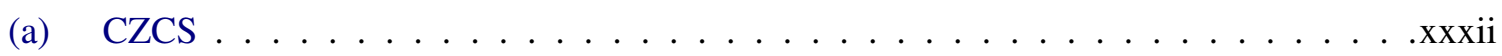

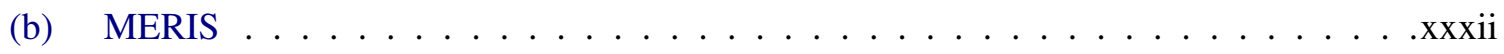

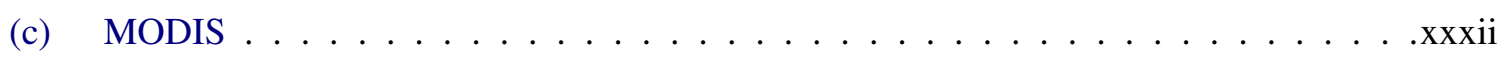

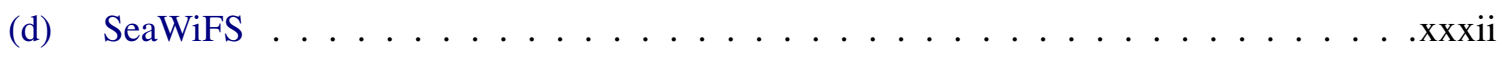

A.35 Spectral reflectance of P.oceanica. Measurement series 25-50. Gnuplot display. Pages:

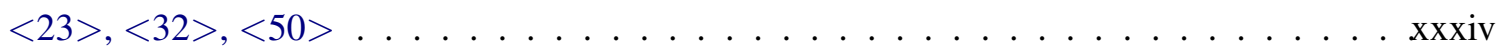

A.36 Remote sensing reflectance of P.oceanica. Series 1-25. Shown midspread of the statistical quartiles Q1 and Q3 (vertical dashes) and mean value within the range. Gnuplot. Page:

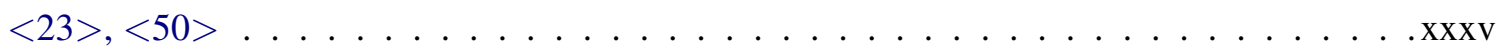

A.37 Multiplot of spectral reflectance of P.oceanica. Series 151-200. Shown mid-spread of the statistical quartiles Q1 and Q3 (vertical dashes) and mean value within the range (red bold dots). Gnuplot visualization. Pages: $<31>,<42>\ldots \ldots \ldots$. . . . . . . . xxxix

A.38 Normal Q-Q plot: estimated versus observed values of the measurement of carbonate sand, variable 27. Series 51-75. Gretl modelling visualization. Page: $\langle 45\rangle \ldots \ldots$. . . . . . . xli

A.39 Spectral reflectance of carbonate sand on A.Pelagia beach. Results of single measurement set made by spectroradiometer Trios-RAMSES. Gnuplot. Pages: $<31>,<42>\ldots$. . . . . xliv

A.40 Plot illustrating periodogram for v30 from measurements of carbonate sand, series 51-75.

Gretl modelling visualization. Page: $\langle 45>\ldots \ldots \ldots$. . . . . . . . xlvi

A.41 Graph of the autocorrelation analysis of the measurements of carbonate sand. Series 51-75, variable 27. Gretl visualization. Page: $\langle 44>\ldots \ldots \ldots$. . . . . . . xlvi

A.42 Locations of selected measurements, visualization on Google Earth. Page: $<36>$. . . . . xlvii A.43 Random mosaic of selected aerial Google Earth images. Pages: $<29>,<36>\ldots$. . . . . . xlvii A.44 Landsat imagery, Crete Island. Previews. Page: $<29>\ldots \ldots$. . . . . . . . . . xlix 
(a) Landsat 2006-11-07-TM . . . . . . . . . . . . . . . . . . xlix

(b) Landsat-2005-04-09 . . . . . . . . . . . . . . . . . . . . . xlix

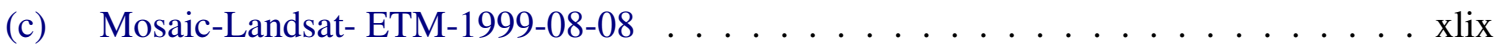

(d) Landsat 2000-07-09 ETM . . . . . . . . . . . . . . . . . . . . . xlix

(e) Landsat 2000-06-30 ETM . . . . . . . . . . . . . . . . . . . . . xlix

(f) Landsat 1987-06-10-TM . . . . . . . . . . . . . . . . . . . . xlix

(g) Landsat-2005-05-04-ETM . . . . . . . . . . . . . . . . . . . xlix

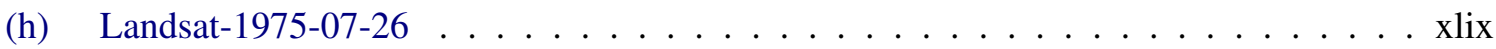

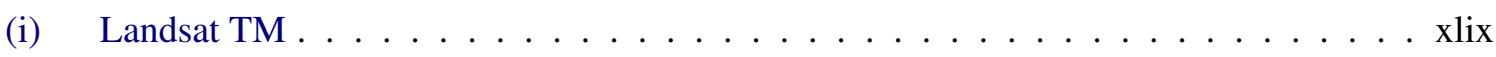

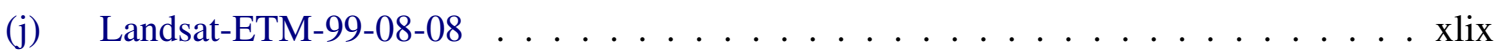

A.45 The point querying shows the selected points and their coordinates within the area of seagrass meadow (green). OpenEV.Page: $\langle 29>\ldots \ldots \ldots \ldots \ldots$

A.46 Logarithmic Enhancement to Raster, applied to the aerial Google Earth image: the seagrass meadow seen as a bright spot of purple color. OpenEV. Page: $<29>\ldots \ldots$. . . . . . . . 1

A.47 Raster properties dialog: visualization and spatial info about the image (projection UTM, zone 35, datum WGS-84, etc.) OpenEV). Page: $<29>\ldots \ldots$. . . . . . . . . . li

A.48 Color composite image composed of 3 images of Cretan shelf, Google Earth. ILWIS. Page:

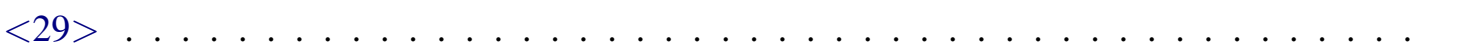

A.49 Results of the image unsupervised classification of the seafloor cover types and land structure, Agia Pelagia; raster layer read into the ArcGIS project. Page: $\langle 55>\ldots$. . . . . . . . lii

A.50 Results of the image supervised classification in Erdas Imagine: seagrass distribution in Bali area, Crete. Pages: $<55>,<$ liv $>\ldots \ldots \ldots \ldots$. . . . . . . . . . . . . . . .

A.51 General methodological research approach. Inkscape. Page: $<11>\ldots \ldots \ldots \ldots$. . . . lv

A.52 Google Earth aerial imagery grabbing, Heraklion, the University of Crete. Pages: $<36>$, $<11>\ldots \ldots \ldots \ldots \ldots \ldots \ldots \ldots \ldots \ldots \ldots \ldots \ldots \ldots$

A.53 Adjusting waterproof Olympus cameras for underwater seafloor videometric measurements. Dr. Petros Lymberakispeople]Lymberakis, P. (left) and Dr. Bert Toxopeuspeople]Toxopeus, A.G. (right). Pages: $<27>,<28>\ldots \ldots \ldots \ldots \ldots \ldots \ldots$. . . . . . . . . . . . . . .

A.54 SCUBA gear diving equipment necessary for seagrass monitoring. Source: Aquanauts.com.

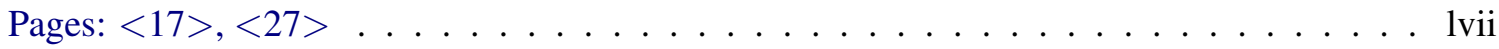

A.55 ...and it's me, learning diving skills on Ligaria beach, Crete, 2010. On the photo: left. Page: $<27>$

A.56 Sticking marker into the sea bottom in matte of P.oceanica for depth measurements. Page:

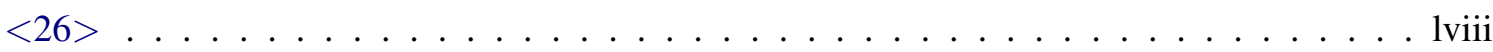

A.57 Placing the $0.5 \mathrm{~m}$ circle and depth marker in the mattte of P.oceanica for photo capture. Page:

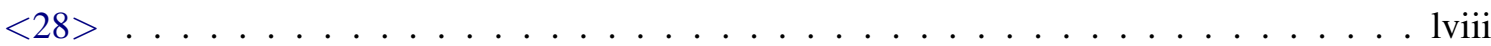


A.58 Monitoring different seafloor cover types: matte of P.oceanica vs carbonate sand. Ligaria beach. Page: $<28>\ldots \ldots \ldots \ldots \ldots$. . . . . . . . . . . . . . . . . . . 


\section{List of Tables}

2.1 Characteristics of selected ocean-colour sensors. Pages: $<50>,<36>\ldots \ldots$

3.1 Model-specific parameters of water WASI adjusted to simulate environment of the Mediterranean Sea along Crete. Pages: $<10>,<34>\ldots \ldots \ldots \ldots$

4.1 Statistical analysis of the measurements of spectral reflectance of P.oceanica (fragment). Page: $<44>\ldots \ldots \ldots \ldots \ldots \ldots \ldots \ldots \ldots$

A.1 Attributes of the Trios-RAMSES hyperspectral radiometer and Scanning Acoustic Microscope (SAM) during measurement sets. Selected examples (14. X, set 1 and 15.X, set 4). Page: $<29>\ldots \ldots \ldots \ldots \ldots \ldots \ldots \ldots \ldots$

A.2 Attributes of the Trios-RAMSES hyperspectral radiometer during measurement sets. Selected examples (15. X, set 1 and 14.X, set 4). Page: $<29>\ldots \ldots \ldots$. . . . . . . vi

A.3 Basic mathematical formulae used for statistical analysis of the measurement set of the spectral reflectance. Page: $\langle 44>\ldots \ldots \ldots \ldots \ldots$. . . . . . . . . . . . . . . . . . .

A.4 Robust estimation of the seawater radiance (measured in aquarium tank, Heraklion): results of the least absolute deviation (LAD), Series:V16. Gretl. Page: $<45>\ldots \ldots$. . . . . . . . . xv

A.5 Results of the statistical analysis of spectral reflectance of P.oceanica, with average values (for sets 1 - 350). Generalisation up to step $20 \mathrm{~nm}$. Pages: $<44>,<49>\ldots$. . . . . . . . xxi

A.6 Model summary of the regression analysis: curve estimation and ANOVA table tested for single observations within one measurement set: spectral reflectance of P.oceanica. Statistical Package for the Social Sciences (SPSS). Page: $<45>\ldots \ldots$. . . . . . . . xxii

A.7 ANOVA table: exponential curve estimation in the regression analysis, tested for single observations within one measurement set: spectral reflectance of P.oceanica. SPSS. Pages:

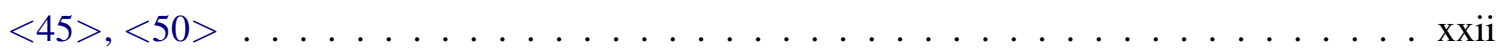

A.8 Coefficients of the regression analysis (exponential curve estimation) of the spectral reflectance of P.oceanica. SPSS. Page: $<45>\ldots \ldots \ldots$. . . . . . . . xxii

A.9 Results of the ANOVA one-way analysis: results of the single factor (depth) testing of the radiance of P.oceanica at various depths: $0.5,1.5$ and 2.5 meters. SPSS. Page: $<31>\ldots$ xxiii

A.10 Summary of the ANOVA one-way analysis: results of the single factor (depth) testing of the radiance of P.oceanica at various depths: $0.5,1.5$ and 2.5 meters. SPSS. Page: $<31>\ldots$ xxiv

A.11 Results of the statistical analysis of spectral reflectance of P.oceanica, sets 1-350). Wavelength step: $3 \mathrm{~nm}$. Measured on Agia Pelagia beach, 15th October. Pages: $<31>,<44>$,

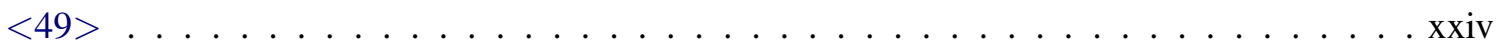


A.12 Nonlinear model: results of the logistic analysis of the seawater radiance with sediments (15.X.), Series:V16. Gretl. Page $<44>\ldots \ldots \ldots$. . . . . . . . . xxviii

A.13 Results of the autocorrelation analysis of the measurement set 1-16 of the spectral reflectance of P.oceanica (15.X.), Series:V3. SPSS. Page $<45>\ldots \ldots \ldots$. . . . . xix

A.14 Results of the partial autocorrelation analysis of the measurement set 1-16 of the spectral reflectance of P.oceanica (15.X.), Series:V3. SPSS. Page: $<44>\ldots \ldots$. . . . . . . xxx

A.15 Ordinary Least Squares: results of the OLS analysis of the measurement set 326-350 of the spectral reflectance of P.oceanica (15.X.). Gretl. Page: $<45>\ldots \ldots$. . . . . . . xxxi

A.16 Summary statistics of measurements set: 301-325. Example of selected variables 12-22.

Gretl. Page: $<44>\ldots \ldots \ldots \ldots \ldots \ldots$. . . . . . . . . . . . . . . . . . . . . . . . . . . .

A.17 Summary of the table with values of the spectral reflectance of P.oceanica measured on three different depths, R. Page: $<31>\ldots \ldots \ldots$. . . . . . . . . . xxxiv

A.18 Two-Stage Least Squares: results of the TSLS analysis of the measurement set 1-191 of the spectral reflectance of P.oceanica (15.X.). Gretl. Page: $<44>\ldots$. . . . . . . . . xxxvi

A.19 Initial Cluster Centers: results of the $K$-means analysis of the measurement set 201-236 of the spectral reflectance of P.oceanica (15.X.). SPSS. Pages: $<29>,<44>\ldots \ldots$. . . . xxxvi

A.20 Iteration History(a): results of the K-means analysis of the measurement set 201-236 of the spectral reflectance of P.oceanica (15.X.). SPSS. Page: $<44>\ldots \ldots$. . . . . . . xxxvii

A.21 Number of Cases in each Cluster: results of the K-means analysis of the measurement set 201-236 of the spectral reflectance of P.oceanica (15.X.). SPSS. Page: $<44>\ldots$. . . . . xxxvii

A.22 Final Cluster Centers: results of the K-means analysis of the measurement set 201-236 of the spectral reflectance of P.oceanica (15.X.). SPSS. Page: $<45>\ldots \ldots$. . . . . . . . xxxvii

A.23 Results of the tobit analysis with censored dependent variable (2) from the selected dataset Series 151-175 of the s.reflectance of P.oceanica. Gretl. Page: $<44>\ldots$. . . . . . . xxxviii

A.24 Results of the Prais-Winsten estimation applied towards variables 15 from the selected dataset 151-175 of the spectral reflectance of P.oceanica. Gretl. Page: $<44>\ldots$. . . . . . . . .xxxviii

A.25 Results of the Principal Components Analysis: measurement variables 1-7 from the selected dataset 301-325 of the spectral reflectance of P.oceanica (15.X.). Gretl. Page: $<44>$. . . xxxix

A.26 Results of the Weighted Least Squares Analysis applied towards variables 12-20 from the selected dataset 301-325 of the spectral reflectance of P.oceanica. Gretl. Page: $<45>\ldots$. . . xl

A.27 Results of the autocorrelation analysis of the measurement set 51-75 of the spectral reflectance of carbonate sand, Gretl. Page: $<44>\ldots \ldots$. . . . . . . . . . . . xli

A.28 Results of the statistical analysis of spectral reflectance of carbonate sand, with average values (for sets 1-3). Wavelength step: $3 \mathrm{~nm}$. Measured on Agia Pelagia beach, 14th October. Pages: $\langle 44>,<49>\ldots \ldots \ldots \ldots$. . . . . . . . . . . xlii

A.29 Results of the Quantile estimates: measurements 51-75 of the spectral reflectance of carbonate sand, Gretl. Page: $\langle 44>\ldots \ldots \ldots$. . . . . . . . . . . . xliv 
A.30 Results of the periodogram for v30 of the measurement set 51-75 of the spectral reflectance of carbonate sand, Gretl. Page: $<45>\ldots \ldots$. . . . . . . . . . . . . xlv

A.31 Available broadband Landsat satellite images covering the research area of Crete Island.

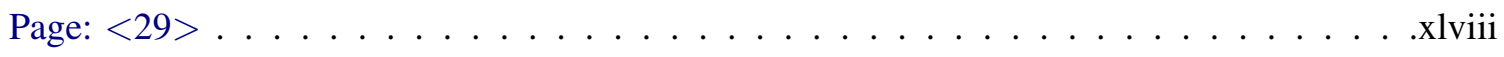

A.32 Confusion Matrix-1, between the classified Google Earth aerial image and fieldwork data, for Fig.A.49. Page: $<51>\ldots \ldots \ldots$. . . . . . . . . . . liii

A.33 Confusion Matrix-2, between the classified Google Earth aerial image and fieldwork data, for Fig.A.50. Page: $<51>\ldots \ldots \ldots \ldots \ldots \ldots$ liv 


\section{Introduction}

\subsection{Summary}

The seagrasses, a unique group of aquatic plants growing submerged in the sea water, with root-like structures (rhizoms) buried in the sediments and vertical elongate leaves. A flowering plant, completely adapted to the marine environment, they are however, more closely related to the lily family (Liliaceae) than to the true grass, despite their name seagrass, caused by the ribbon-like, grassy leaves [90]. Seagrasses create unique, complex, extremely diversified and productive ecological systems in the littoral coastal zones between 0-50 meters in shallow waters all over the world [58], and serve as valuable environmental indicators for the marine ecosystems health. Seagrasses are closely connected and linked with complex interactions to other vegetation types, e.g. mangroves, coral reefs, etc. An important constructing component of littoral ecosystems, seagrass contributes significantly to their structure and functioning.

The adaptation to the salt waters is evidently influenced the global distribution of the seagrasses (Fig.1.2), limiting it to shallow coastal areas. A number of critical conditions determine growth of the seagrass, including general climatic characteristics of the area, i.e.temperature, day length, geological and geomorphological conditions, e.g. soft type of sediments (sand or mud), shallow depths, as well as chemical and physical parameters of the water: salinity, waves [85]. The seagrass Posidonia oceanica (further P.oceanica) is a key species to inhabit littoral of the Mediterranean Sea, see Fig.1.1 ${ }^{2}$
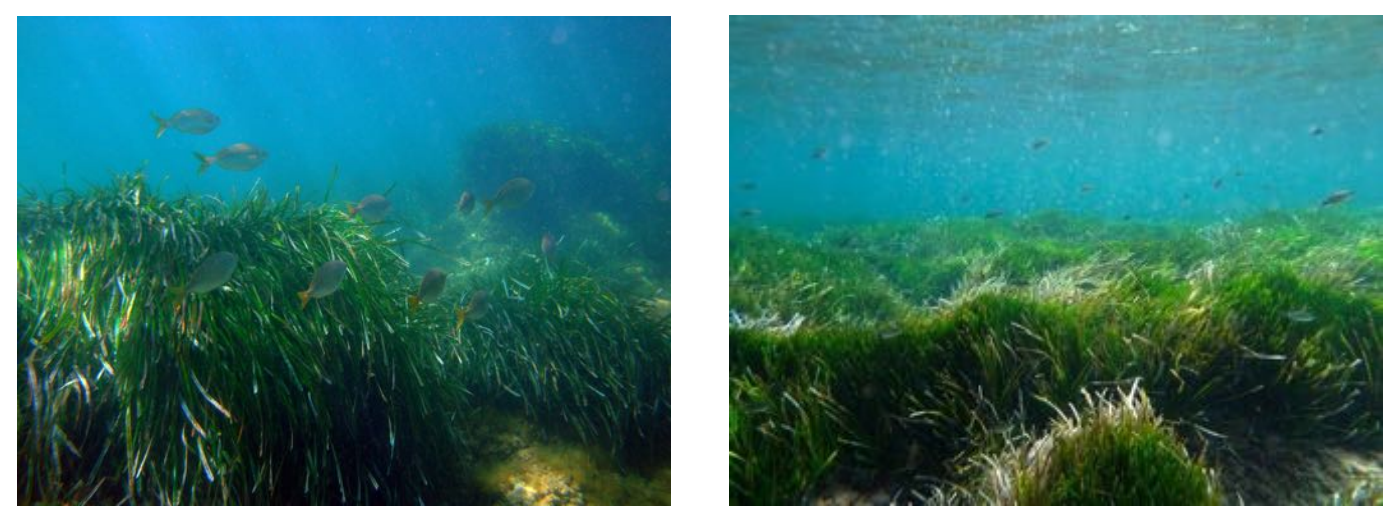

Figure 1.1: Seagrass Posidonia Oceanica. Pages: $<1>,<3>,<5>$

and is widely spread along the coasts of Crete [33] . It plays an important role in a number of geomorphological and ecological processes. Namely, it is a source of food for herbivorous fauna as well as shelter zones for fish and other marine organisms; it contributes to the nutrient recycling; it provides sediments stability by reducing the degree of water movements, etc [40].

The purpose of current MSc research work aims to apply methods of remote sensing analysis, including

\footnotetext{
${ }^{2}$ The page where the illustration is explained in the main text of MSc thesis is given in angle brackets (e.g., Page: $<44>$
} 
Radiative Transfer Model (RTM), Geographic Information System (GIS)-based spatial analysis, processing and classification of satellite and aerial photos, as well as videometric underwater footage, towards mapping and environmental monitoring of seagrass $P$. oceanica along the selected locations of the northern coasts of Crete island, Greece (Fig.3.1). The technical implementation is based on WASI RTM software, GIS (Integrated Land and Water Information System (ILWIS), Erdas Imagine and ArcGIS), using aerial and satellite images and the results of the underwater videometric measurements.

\subsection{Background}

\subsubsection{Global distribution of the seagrasses}

Globally, there are 58 recognized and described seagrass species (Fig.1.2, Fig.1.4), belonging to two orders (Hydrocharitales and Najadales), four families (Hydrocharitaceae, Posidoniaceae, Cymodoceaceae and Zosteraceae), and 12 genera (Enhalus, Thalassia, Halophila, Posidonia, Syringodium, Halodule, Cymodocea, Amphibolis, Thalassodendron, Zostera, Heterozostera and Phyllospandix) [71].

The distribution of the seagrasses is strongly influenced by several environmental factors, which include climate (mostly, tropical and temperate areas, Fig.1.4), bathymetry (shallow shelf zones), hydrological particularities (chemical content of water, nutrient availability and turbidity of waves), and geological characteristics sedimentation and cover types of the seafloor [88].

There are four European seagrass species in Mediterranean area [12]: Zostera marina, Zostera noltii, Cymodocea nodosa and P.oceanica. In Greece the common species are P.oceanica (L.) Delile, Cymodocea no-

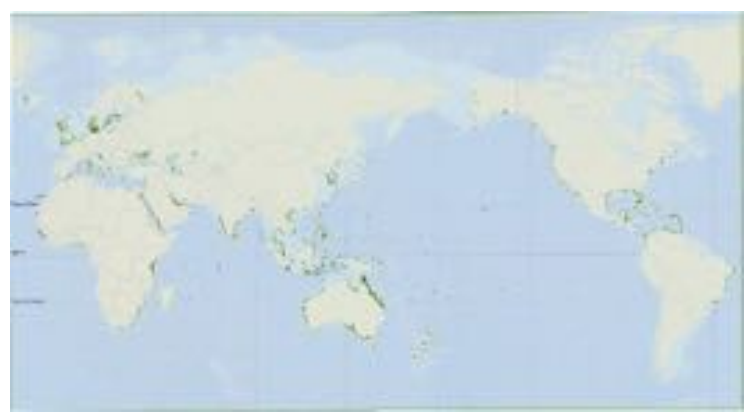

Figure 1.2: Distribution of seagrasses in the world. Source:[48]. Pages: $<1>,<2>$ dosa (Ucria) Ascherson, Zostera noltii Hornemann and Halophila stipulacea [3]. These species differ in morphological and phenological features (Fig. 1.3) as well as in structure and dynamics. Thus, Cymodocea nodosa is considered the pioneer species of P.oceanica beds, the latter species forming the last stage. When P.oceanica beds regresses, C.nodosa often replaces them [53]; as a result, P.oceanica, C.nodosa, and Z.noltii do not form mixed persistent stands [16].

\subsubsection{Ecological significance of the seagrasses}

Seagrass plays vital role in the marine ecosystems of the world ocean. Seagrasses are the only flowering plant in the world that is able to live completely submerged. Seagrass is a habitat for numerous marine fish species [103], source of primary production and food for fish, turtles and other organisms, which gives them special environmental value [104].

Seagrass meadows produce enormous quantities of organic matter (leaves, epiphytes), which constitutes the 
basis of the food web both within and outside the ecosystem [45]. Finally, seagrasses are an important component in the environmental "food chain" of the coastal ecosystems, being the food source for dugongs, turtles, swans and various fish [18]. Due to their wide distribution, meadows size, easy collection and abundance, sensitivity to the modifications of the coastal zone and their important role in maintaining coastal water quality and clarity, seagrass is perfect indicator and descriptor of the environmental health of marine ecosystems, and is highly suitable for the environmental monitoring [118].

Being often confused with marine "algae", "seagrasses" are vastly different from them. There are fundamental differences between both marine organisms, which we briefly mention below:

* first, seagrasses are true plants with root system and leaves which photosynthesis, have complex structure and create landscape-similar vast formations on the colonized seafloor areas with soft sediment, whereas algae are simple organisms that can only holdfast;

* secondly, seagrasses are complex vascular plants with reproductive mechanism such as fruits, seeds and spores, while algae are primitive organisms with simple cell structure, spores and gametes;

* finally, seagrasses uptake nutrient through the root system, while algae nourish directly from the water column [31].

There are other nuances and details of difference between the "seagrasses" and "algae", but their discussion would go beyond the scope of this work.

\subsubsection{Environmental vulnerability of the seagrasses}

Meadows of $P$. oceanica (Fig.1.1) are subjected to the human activities, as they occur in coastal areas, where they can be affected both directly [92] or indirectly, through the impact on the quality of waters and sediments [32]. As P.oceanica is a long-living plant with a slow growth rate, the anthropogenic modifications of the coastal zone, happening more rapidly than the capacity of the plant to adapt to these changes, reduce its distribution area [95]. One of the main drivers of seagrass decline is, for instance, the location of the fish farming near the seagrass meadows. The negative effects of the sedimentation of waste particles in the farm vicinities on P.oceanica meadows are diverse and complex, and may cause benthic deterioration, accumulation of organic matter and seagrass decline [60]. Seagrasses are subject to anthropogenic nutrient (N and P) loading [21], [74], which may occasionally casue morphological (e.g. leaf length) and physiological (e.g. chlorophyll and nitrogen content of the leaves) responses towards changed environmental conditions $[72,73]$. The detailed research of the fish farm-induced decline of the seagrass meadows [29]reports the relationships of fish farm organic and nutrient content in the sediments with dynamics of the key seagrass species (P. oceanica) in the Mediterranean Sea. Nowadays P.oceanica is in the alarming state of regression due to the deterioration of the environment in the Mediterranean Sea [122]. Due to these reasons, P.oceanica is a protected species since 1988 in some European countries [40], and its presence serves as an indicator of a stable healthy environment. Among other negative factors, affecting both growth and status of the seagrasses 
the environmental contaminants can be mentioned, e.g. thermal, sewage, dredging and chemical pollution as well as any other kind of maritime works, e.g. trawling and anchoring of boats [122]. Other human activities that cause degrading of the seagrass are recreational boating, commercial overexploitation of coastal resources, eutrophication [88].

Besides anthropogenic factors, various biochemical, climatic and environmental processes can cause negative influence on seagrass distribution. Seagrass is exposed to threats from the global climate and environmental change, i.e. increases in sea surface temperature; sea level rise; increased frequency and intensity of storms and waves; local decrease of water quality, increased sedimentation, contamination and nitrification; desiccation; salinity fluctuations; nutrient changes; suspended sediments [11]. These stress-drivers can alone result in large-scale seagrass degradation, but often seagrass undergo simultaneous affects from several of these factors together. It naturally increases the environmental pressing to drastic loss of

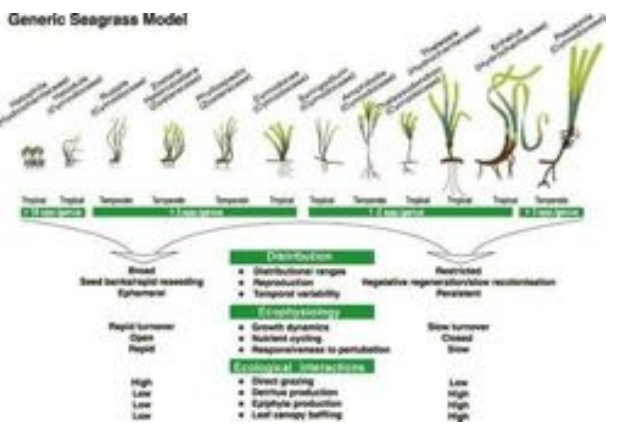

Figure 1.3: Morphology of different types of seagrasses. Source: http:// www. ozcoasts.org.au. Page: $<5>$ very large areas of seagrass globally [107]. In tropical areas, where most of seagrasses are located (Fig.1.4), seagrasses are subject to catastrophic extinction and loss, due to the cyclones, typhoons, storms, regular floods and increased rainfalls. Recovery from such events can take up to several years and often it is only possible by means of the seed reserves from the local environmental surveys [89]. Other threats for seagrasses are increased nutrient availability in the coastal zones [2], increased eutrophication and invasive macroalgae. These processes have strong affect on the status of the seagrass meadows, and often lead to their complete disappearance [59].

Other environmental threat for the seagrasses arises as a result of the environmental struggle and competition for existence among species. Thus, meadows of P.oceanica in the Mediterranean Sea (Fig.1.5) are presently facing invasion by alien algal species, particularly in areas where P.oceanica is already degrading, stressed, have gaps and patchy structure in meadows and show other signs of regression [97].

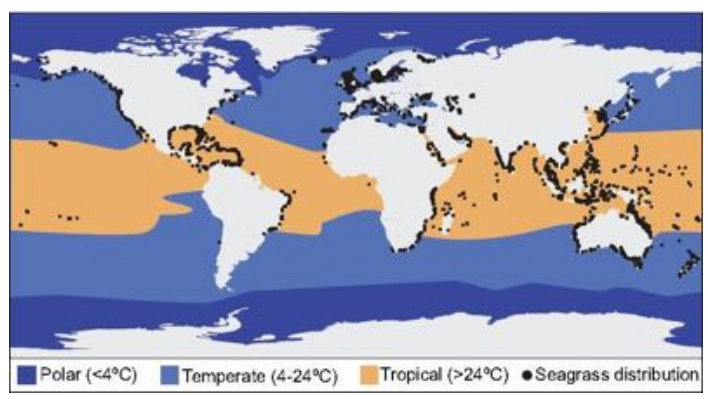
Seagrasses are vulnerable fragile species, important for the marine coastal ecosystems, especially for the

Figure 1.4: Distribution of seagrass in relation to mean ocean temperature. Source: [107]. Pages: $<2>,<4>$ protection of the beach structure. However, the facts about seagrass global degrading sound worrying: about $54 \%$ of the total seagrass meadows have lost any part of their area; the areas, where the seagrass ecosystems are degrading or lost, are not located in a specific area or continent, but registered globally; since 1980s global losses of the seagrasses on our planet is equal to two football fields per hour [94]. 


\subsubsection{General characteristics of P.oceanica}

Morphology of P.oceanica The endemic Mediterranean seagrass Posidonia oceanica (further P.oceanica), is a main species in marine coastal environment of Greece, forming, despite its slow growth, the largest, most widespread, homogeneous and dense meadows (Fig.1.1) in the Mediterranean Sea between 5 and $40 \mathrm{~m}$ depth [52].

The dominant and most productive coastal ecosystem of the Mediterranean, P.oceanica is spatially restricted to the Mediterranean area (Fig.1.5), with its extension limited by the western part of the Mediterranean Sea where cold Atlantic waters enter Gibraltar and mix with warm Mediterranean waters, thus decreasing its temperature. Morphologically, P.oceanica consists of long, 5-12 mm broad, hairy-like leaves, 3-4 mm thick roots and short rhizomes $(0.5-2.0 \mathrm{~mm})$, Fig.1.6, Fig.1.3. The leaves are, perhaps, the most particular characteristics of P.oceanica, making it highly recognizable and distinguishable

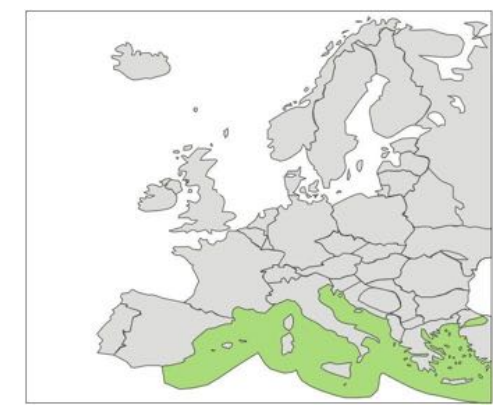

Figure 1.5: Geographical distribution of P.oceanica. Source: [12]. Pages: $<4>,<5>$ from other seagrasses (Fig.1.6(a)): having usual length of 20$40 \mathrm{~cm}$, in some cases they can reach up to $1 \mathrm{~m}$ [12] (Fig.1.6(c)). Growing P.oceanica make a meadows which, in turn, consist of smaller patches, called matte (Fig.1.6(b)), a monumental construction made by the growth of rhizomes and leaves with entangled roots and entrapped sediment [39].

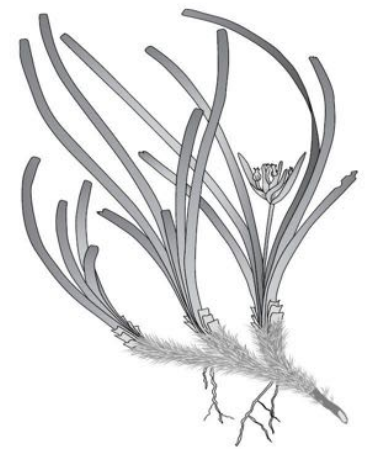

(a) P.oceanica. Source [77]

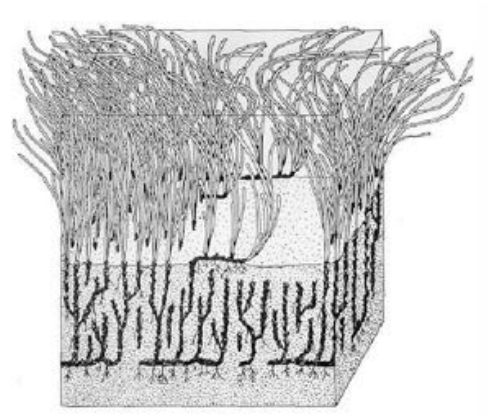

(b) Scheme of matte structure of P.oceanica. Source[116]

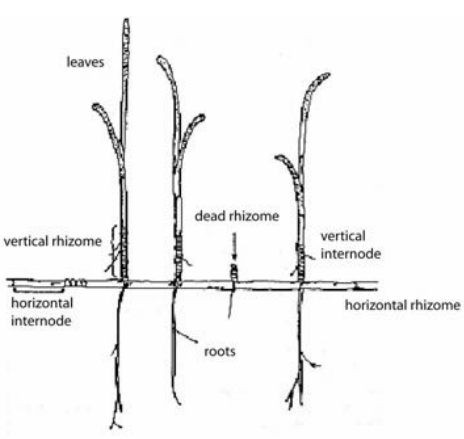

(c) Structure and components of P.oceanica. Source[28]

Figure 1.6: Morphology of P.oceanica. Page: $<5>$

Representing one of the most productive Mediterranean ecosystems, P.oceanica usually serves as a perfect biological indicator for the assessment of the quality of waters and environmental health [14]. Some authors $[49,96]$ used status and population dynamics of P.oceanica as indicators for the evaluation of the meadow health status. 
Phenology of P.oceanica There are several environmental factors, determining the growth of the P.oceanica. The adaptation to dry-summer subtropical climate reduces its extension to Mediterranean area only (Fig.1.5). Besides, the distribution of the seagrasses changes with water depth: it is noticed [34] that the highest flowering density is usually in the 4-7 m depth. P.oceanica flowers appeared in shallow stands in September while in November only in stands deeper than $15 \mathrm{~m}$. This time delay is caused by the different maximum summer temperatures at those depths [16]. The phenology of P.oceanica is also affected by the coastal bathymetry: in the isolated meadows in shallow waters plants have shorter and falciform leaves, compared to ones in the deeper and central areas [34]. In P.oceanica flower abundance is related to the structure of the meadow with the maximal flower density in the densest stands, while the occurrence of flowering is regulated by environmental factors [16]. Phenology of the P.oceanica undergoes modifications with varying seasons during the year: during the flowering period (ca 3 months long) the number of leaves on the flowering shoots decrease. Changes of the leaf growth also appear in the flowering shoots with longer oldest leaves and shorter and narrower leaves induced during the flowering [46].

\subsection{Research problem}

Monitoring of the marine benthic ecosystems of seagrasses is essential for the environmental assessment of the coastal zones. It increases our knowledge of the seagrass ecology, highlights threats to the seagrass and preventing them from possible losses and degrading and improves techniques and methods of the underwaterbased observations. Mapping the seagrass contributes to the evaluating of the seagrass current distribution, analysis of its dynamics and changes over time, as well as estimations of the degrading of seagrass meadows for the purpose of the coastal management.

Precise, correct and up-to-date information about the distribution of P.oceanica is necessary for the sustainable conservation of the marine environment and ecosystems in Mediterranean area, being an important contribution to the environmental coastal zone management [117]. However, mapping the seagrass has limitations due to the specific location and characteristics of the research object.

The remote sensing techniques have traditionally been widely used for the seagrass monitoring. The general overview of the application of various remote sensing data types (colour, infrared, and black and white images) for the seagrass monitoring shows its high suitability and potential as a research method [112, 84]. The using of the aerial photographs as base

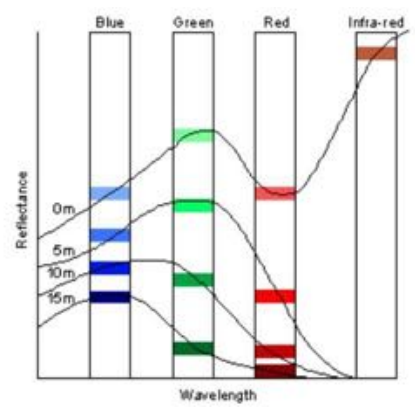

Figure 1.7: Spectra of the seagrass on different depths $(0-15 \mathrm{~m})$. Source [35]. Page: $<7>$ maps for the seagrass meadows mapping is, perhaps, the most traditional application $[86,68,111]$. The results of the image processing of colour aerial photographs for the monitoring of littoral environment with seagrass beds have been reported by several authors [67, 138, 47]. Satellite imagery processing has also being used for the seagrass monitoring, due to their accuracy, repeatability and 
information value as a source of data [27], enabling regular temporal coverage over the large remote areas and providing a cost-effective approach for the mapping of the remotely located feature, such as underwater vegetation [64]. Satellite images provide with detailed information on seagrass canopy and other environmental indicators [41]. Various research papers report successful application of the image processing for the seagrass mapping $[20,26,38,47,62,64,68,78,82,83,99,112,111,109,117,120,122,129,138]$.

The application of the remote sensing data towards seagrass mapping is based on the spectral reflectance characteristics of the P.oceanica seagrass, which enable its spectral discrimination from spectra of other seafloor types. It is proved [132] that the spectral signatures of different species of tropical seagrasses are well distinguishable from each other. The application of the methods of images classification for seagrass mapping is based on the classifying the pixels on the image according to their spectral reflectance values (Fig.1.7)[38], so that the seafloor can be divided into several types: sand, rock, P.oceanica, other vegetation, etc. Other example of monitoring of P.oceanica using remote sensing techniques [20] reports the application of the CZCS images towards the case study of the Italian coast and shows successful results of the neuralbased classification using Isodata method of supervised classification. In case of P.oceanica meadows aerial and satellite images are particularly suitable for the surveying shallow waters [110] enabling to distinguish seagrass formations and dynamics of the temporal evolution of seagrass meadows over the research area [112]. However, using space borne satellite imagery for the seagrass mapping has certain limitations, due to the uncertainties of the spectral signature of the seagrass at higher depths (Fig.1.7), as well as some optical particularities, e.g. light refraction under water, unevenness of the water surface, depths, etc. Some problems can also arise in the images interpretations, as quite different objects may have similar spectral reflectance, e.g. seagrass, dark-coloured bottom patches (mud), macroalgae. The in-situ fieldwork including underwater videographic measurements is an important part of the seagrass monitoring, and has been successfully applied towards seagrass mapping [51]. The underwater measurements are used to validate the results and to receive detailed, accurate and precise data for the selected locations. The underwater measurements cannot be applied for the whole research area, however it provides with detailed monitoring along the route of the boat. Therefore, in the selected locations it becomes a useful tool for the assessment of the distribution, density and coverage of the seagrass along the track log. Besides, the underwater observations using scuba diving equipment have been conducted for the measurements of depths. 


\subsection{Research objective}

The current MSc research aims to explore the environmental conditions for the spatial distribution of P.oceanica seagrass along the northern coast of Crete Island, based on the remote sensing and GIS techniques, knowledge about the coastal environment in Crete and integration of various data from the following sources :

i) spectra of P.oceanica, carbonate sand, silt and other seafloor types

ii) satellite imagery: Landsat Thematic Mapper (Landsat TM), Landsat Enhanced Thematic Mapper Plus (Landsat ETM+)

iii) aerial photos: Google Earth

iv) in-situ fieldwork data of underwater videographic measurements

v) vector GIS layers.

Although there are a variety of environmental factors that contribute to the spectral reflectance, the most important ones are water column height and seafloor fraction. It is because spectra of the seagrass P.oceanica vary qualitatively over the depths interval of $0.54 \mathrm{~m}$, and secondly, the content and cover fraction of the seafloor have the most distinctive effect on the spectral reflectance of the water. In the environmental conditions of Crete Island, P.oceanica may grow at depths up to six meters; however, the most usual depth is four meters, which caused our decision to focus on depths up to four meters, and use these depths for further WASI modelling. Therefore, in the current research we focus on these two major factors, and study the response of the water reflectance towards changing conditions of the water column depth and seafloor bottom cover fraction (seagrass P.oceanica and carbonate sand).

The research aims to explore the limitations of the application of the RTM and remote sensing techniques towards the study of the environmental properties of the P.oceanica meadows distribution over the selected locations of northern Crete. The main research objective is monitoring the seagrass P.oceanica in selected areas of Crete and analyzing the environmental conditions for the growth of P.oceanica.

This research is supported by the in-situ measurements in two selected locations of the northern coast of Crete (Ligaria beach in Agia Pelagia district and Xerocampos), using following methods of the remote sensing techniques: spectral modelling by means of the RTM WASI, underwater videometric measurements made by Olympus Stylus Tough (Olympus ST) camera, aerial Google Earth and satellite images from different sources, spatial GIS and statistical analysis. 


\subsubsection{General objective}

The main objective of this study is to analyse the optical properties of the seagrass P.oceanica and other seafloor types, and to apply the remote sensing techniques towards the investigation of the seagrass distribution in the selected locations along the northern coast of Crete. General objectives:

* Analysing spectral reflectance of the P.oceanica and other seafloor cover types means of radiative transfer model tools (RTMs), using WASI.

* Mapping spatial distribution of the seagrass P.oceanica over selected locations along the northern coasts of Crete Island

\subsubsection{Specific objectives}

1. To study narrow-band spectral reflectance properties of P.oceanica and other seafloor cover types (sand and silt) using WASI water colour simulation software

2. To use methods of the in situ diving observations and underwater videometric measurements by Olympus ST camera in order to receive large-scale imagery of the P.oceanica mattes

3. To apply remote sensing data (Google Earth aerial images, Landsat TM and Landsat ETM+ satellite images) for the monitoring of the seagrass meadows distribution

4. To perform supervised images classification for the thematic mapping of the P.oceanica seagrass distribution along the selected locations over the coasts of northern Crete.

\subsection{Research questions}

- Is P.oceanica spectrally distinct from carbonate sand with varying in-situ conditions ?

- Do broadband and hyperspectral sensors provide enough radiometric information for spectral discrimination of seagrass, and therefore, can be used for mapping of P.oceanica?

\subsection{Hypotheses}

A statistical testing will be used to compare between the spectral responses of the different seafloor cover types (i.e. sand and P. oceanica), whether it is spectrally distinct and at least one pair is statistically different at every spectral band.

For the Research Question 1 the Hypothesis $H_{o}$ claims: seagrass types are not spectrally distinct from other seafloor types with varying in-situ conditions, which means $H_{o}: \mu 1=\mu 2=\mu 3=\ldots=\mu n$.

The alternative Hypothesis $H_{a}$ claims the opposite statement: seagrass is spectrally distinct with varying in-situ conditions, $H_{o}: \mu 1 \neq \mu 2 \neq \mu 3 \neq \ldots \neq \mu$. 
For the Research Question 2 the Hypothesis $H_{o}$ claims: broadband and hyperspectral remote sensing data cannot be used for the mapping of P.oceanica, because they do not provide enough radiometric information to discriminate sand from seagrass, which means $H_{o}: \mu 1=\mu 2=\mu 3=\ldots=\mu n$.

The alternative Hypothesis $H_{a}$ claims the opposite statement: broadband and hyperspectral sensors do prove to provide enough radiometric information to discriminate sand from seagrass, $H_{o}: \mu 1 \neq \mu 2 \neq \mu 3 \neq \ldots \neq \mu$., and can therefore, be used for the seagrass mapping.

The distribution of the spectral responses at every spectral band is assumed to be normal as well as the equality of the statistical variances. The hypothesis testing is suggested to be carried out using the ANalysis of VAriance (ANOVA) statistical test. The purpose of ANOVA test is to visualize in an effective and quick way the spectral differences between seagrass species and their spatial distribution. Thus, the key hypotheses of the research will be tested to prove whether the results of the research are accurate, reasonable and correct.

\subsection{Assumptions}

The general research assumption, used in this work, in order to make feasible application of the remote sensing methods, includes some statements about the in-situ atmospheric conditions, viewing angle, wave backscattering and other optical properties of the environment. They all definitely play a certain role and impact final results of optical measurements, but for practical reasons we have chosen to ignore their contribution in the spectral separability of seafloor cover types. We briefly list below general research assumptions for the optical properties of the environmental variables used in this study.

Weather conditions for the measurements are assumed to be ideal: clear, sunny, windless day. Otherwise wind roughens water surface causing sun glitter, and values of spectral reflectance may contain disturbances. Sky radiance might be influenced by multiple reflectance between the sea surface albedo and the atmosphere and in general, sky radiance increases rapidly while viewing zenith angle is near to $90^{\circ}$ (i.e. in the evening hours). Therefore, ideally measurements should be done at noon, with as low zenith angle (Fig.A.3) as possible; otherwise, if the solar zenith angle is too high (e.g. approaching $60-70^{\circ}$ ), received data may contain noise. For WASI simulations reflection factor of sky radiance is taken as 0.0201 with simulated ideal conditions: viewing angle $\left(0^{\circ}=\right.$ nadir $)$. The interval of water temperature taken as default lies in the diapason $17-25^{\circ}$ as to simulate the conditions of the Mediterranean Sea. However, in real time conditions the sun zenith angle of $45^{\circ}$ has been accepted as suitable. The accepted model-specific parameters of the WASI simulator are shown in the Table 3.1.

The anisotropy factor of upwelling radiation or the quality (Q-) factor, showing the directionally dependency of the radiance, is taken as 5 . We accepted some values of model-specific optical parameters as default values at WASI simulator, which are shown in the Table 3.1. Thus, concentration of phytoplankton is accepted at the interval of $0.035-0.089 \mathrm{mg}^{-1}$ and concentration of large suspended particles is given to 8 . Reference wavelength for Colored Dissolved Organic Matter (CDOM), or Gelbstoff, absorption is equal to 440. The backscattering (Fig.A.6) is accepted to be $0.00144 m^{-1}$. The coefficient of attenuation remains equal to 
1.0546, as set up by default at WASI.

We also assume that concentration of non-chlorophyll particles (absorption at $\lambda_{0}$ ) as well as concentration of small suspended particles is equal to zero, so we do not count them in this work. Exponent of CDOM (Gelbstoff) absorption is accepted as 0.0140. Finally, the Bidirectional Reflectance Distribution Function (BRDF) of bottom reflectance (sand), which defines reflection of light is at an opaque surface (Fig.A.7), is assumed to be $0.318 s r^{-1}$.

\subsection{Research approach}

Seagrass consistent monitoring and mapping is necessary and important for the sustainable coastal development and conservation measures. Earlier, many seagrass meadows have been destroyed by human activities in the coastal zone, mainly due to the ignorance of their existence, because information on the seagrass bed exact location was not available [22]. Well-time seagrass observations and mapping enables precise control of its spatial distribution, detection of any changes in the seagrass landscapes, highlights potential environmental threats in the coastal zone (e.g. declining of meadows) before they become unmanageable for the coastal management services. Choosing the right and most effective approach method for the seagrass monitoring is essential. Remote sensing methods alone, though having evident advantages, are insufficient, because satellite images of underwater habitats are notoriously difficult to identify and interpret. The best research method should be based on the integrated approach, well described in various scientific works $[13,98,70]$, which includes combination of various techniques of the seagrass monitoring, i.e. remote sensing imagery classification of aerial and satellite images, GIS-based spatial analysis and ground in-situ surveys. The current study is based on the application of the remote sensing data, broadband satellite imagery, aerial images and the results of the underwater videographic measurements towards seagrass mapping (Fig.A.51). Image classification is based on the principle of the differentiation between the spectral signatures of various seafloor cover types (Fig.1.8). The spectrum of light coming up from the ocean surface in shallow waters keeps information on the optical properties of the seawater components and benthic substrate which can be read from their spectral signatures [139]. The pre-processing of the images includes imagery corrections for atmospheric noises and effects of the water column. Reflectance spectra of the seagrass canopy at different depths of the water-column are analysed for the discrimination of their spectral signatures, enabling to separate various seafloor types during classification. The results of the of imagery classification are analysed for the detection of the dynamics in P.oceanica seagrass distribution along the northern coasts of Crete. Aerial imagery from Google Earth with high spatial resolution (Fig.A.52), suitable for the large-scale detailed mapping of seagrass mattes, is used for the improvement of the accuracy of large seagrass meadows and separate mattes within the meadows. The in situ underwater videometric measurements of the seafloor are collected during the fieldwork in Crete, for the validation of the classification results and to determine the exact current distribution of the P.oceanica meadows. The image processing includes steps of the remote sensing techniques, i.e. calibration, masking from land and cloud, atmospheric correc- 
tion, sea surface glint and depth effects correction as recommended [83]. During the image classification working step the training sites for the supervised classification methods are designed, as well as its control and trials of different classification approaches (Unsupervised, K-means or Isodata; Supervised, Maximum Likelihood).

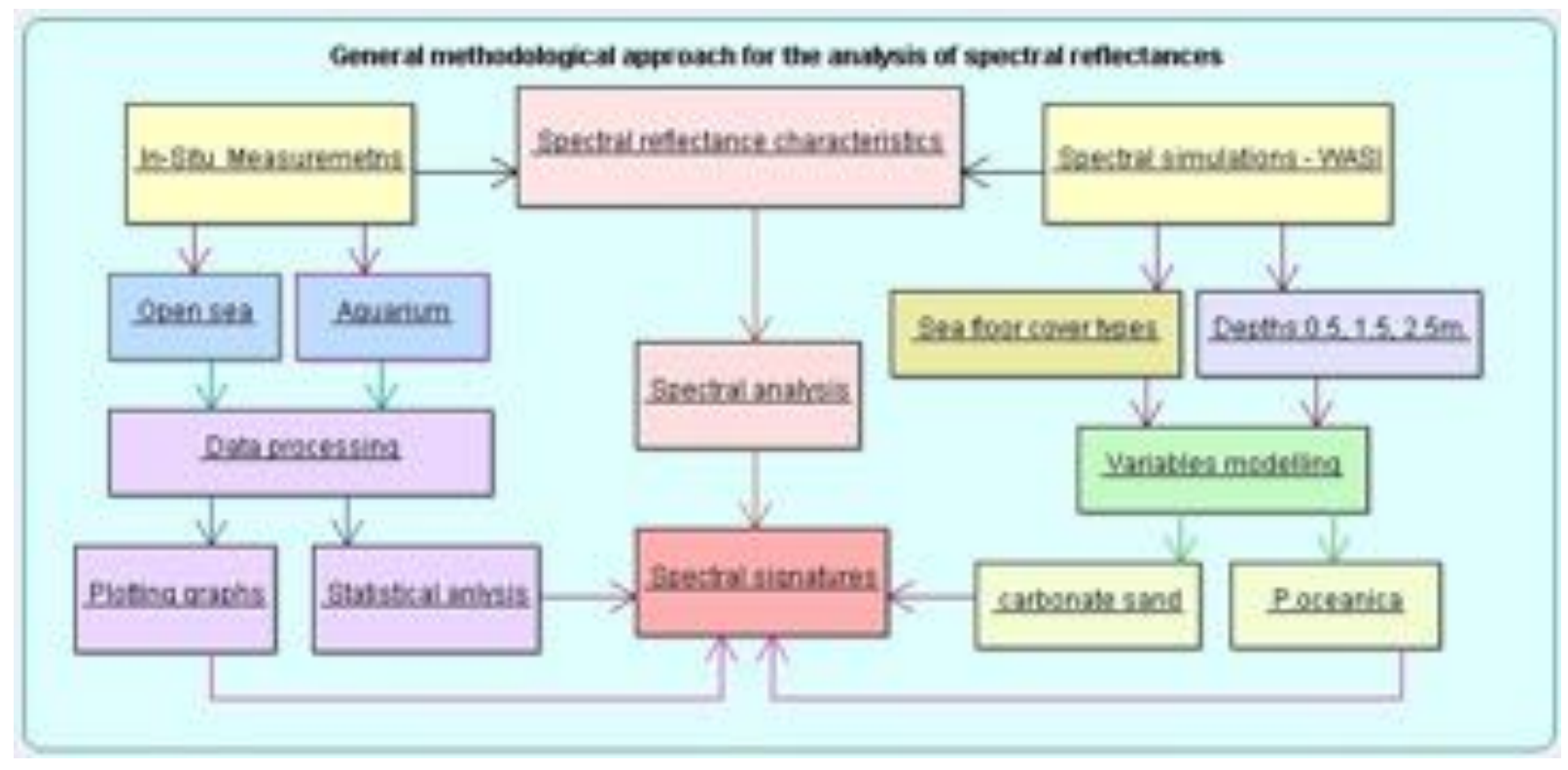

Figure 1.8: General methodological approach for the analysis of spectral signatures. ArgoUML, Gimp. Page: $<11>$ 
2 SEAGRASS MONITORING: OVERVIEW OF LITERATURE AND RESEARCH RESOURCES

\section{Seagrass monitoring: overview of literature and research resources}

\subsection{Seagrass global monitoring: history and perspectives}

Mapping and monitoring the seagrass is important for the environmental assessment of the marine ecosystems in coastal areas. Regular tracking of current distribution of seagrass meadows, based on correct information and cartographic visualization of seagrasses, is a preventive environmental management, which helps to analyse potential environmental risks of coastal areas, decrease of the number of species, loss of meadows and patches of the seagrasses. The tradition of global seagrass mapping though has not a very long history comparing to the terrestrial cartography, due to the technical difficulties of underwater observations. However, nowadays is has become a rapidly developing, increasingly popular and challenging research branch. Regular observations and monitoring of the seagrasses are known since 1960s, mainly in tropical regions (Australia). Since that time traditional methods of the seagrass monitoring and common recommendations are being elaborated. The development of the underwater Self Contained Underwater Breathing Apparatus (SCUBA) diving equipment (Fig.A.54) and devices enabled to conduct underwater detailed measurements and observations largely contributed to the improvement of the traditional in-situ observations of seagrass. From the other side, development of the remote sensing methods and data acquisition from space contributed to the new methods of seagrass mapping, using distance approach and generally based on images classification.

Various global seagrass survey organizations organize and provide regular monitoring of the seagrass species distribution, health and environmental sustainability.

We list below the most important and world-known scientific institutions focusing on seagrass research:

- Global-scaled: Global Seagrass Monitoring Network and the World Seagrass Association; The World Atlas of Seagrasses is published by the UNEP.

- Australian Seagrasswatch (perhaps, the best organization, regularly publishing informative reports)

- European: the Mediterranean association Seagrass-2000, the Mediterranean Institute for Advanced Studies and Seagrasses.org;

- US American seagrass recovery campaign by the Seagrassgrow, Seagrass Ecosystems Research Laboratory in South Florida, Seagrass.LI and Florida Seagrass organisation;

- Asian: UNEP/GEF South China Sea Project, Marine Conservation Cambodia and Sosmalaysia.org.

All these organizations aim at the global seagrass monitoring, providing with research results and reporting guidelines and manuals with standardized methods and recommendations, specific for the seagrass research and monitoring. There are also university marine centres and research institutes conducting seagrass monitoring and as a particular part of their research and reporting various approaches for the monitoring and 
mapping of the seagrasses, including remote sensing applications. Their reports and guidelines were used for references in the current research.

\subsection{Measuring optical properties of benthic vegetation: hyperspectral radiometers}

Among various research approaches for the seagrass mapping the most popular methods are based on application of the remote sensing techniques, enabling to detect and discriminate the substratum and various vegetation types growing on the seafloor. The application of the remote sensing data for seagrass mapping is based on our knowledge of the spectral reflectance properties of the target objects, and using it for the classification of these objects on the image. In case of seagrasses it is spectral reflectance of the seafloor cover types, which can be analyzed using measurements of optical properties of sea water: radiance and irradiance. Optical remote sensing methods can get through the clear waters to approximately $1530 \mathrm{~m} \mathrm{[102].}$ When sunlight enters the waters and goes down into the water column, parts of the electromagnetic energy are absorbed and scattered, which is determined by the optical and physical properties of the water, e.g. concentration of suspended particles, chlorofill, colored dissolved organic matter (gelbstoff) that make up the water content [1]. Besides, light is strongly dependent on wavelengths, i.e. it is greater in blue wavelengths $(400 \mathrm{~nm})$ than in others.

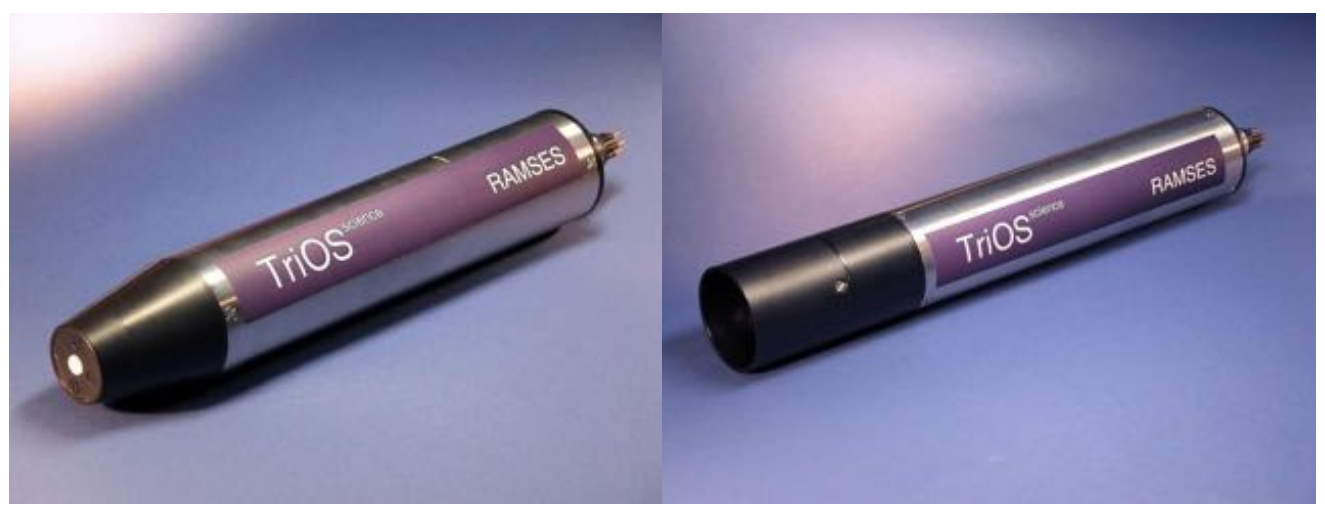

(a) Trios-RAMSES-ACC-UV - Hyperspectral UVA/UVB Irradiance Sensor: 280-500 nm

(b) Trios-RAMSES-ARC - Hyperspectral UV-

VIS Radiance Sensor: 320-950 nm.

Figure 2.1: Trios-RAMSES Hyperspectral Sensors. Source: Trios. Pages: $<14>,<15>,<19>$

The optical properties of the sea water vary with different environmental conditions and reflect current chemical content and physical specifics of the water, revealing the variability and distribution of color of the sea waters, determined by the material in the water, e.g. chlorophyll, as well as its physical properties, e.g. water absorption, attenuation, backscattering [80]. Shallow waters generally contain more dissolved substances and suspended particles, which directly influences the transparency and color of the waters of shelf zones [65]. Being highly dynamic environments, coastal waters experience a variety of processes which alter their optical properties incessantly. The effects of these processes influence application of the hyperspectral re- 
mote sensing and reinforce other processes [81]. Thus, waves and tides increase sedimentation processes, which in turn, may change micro relief properties and topology.

The optical properties of the water are best reflected in the values of its radiance and irradiance, which can be converted into spectral reflectance, or reflectivity. The spectral irradiance (E) is a radiant flux of the electromagnetic solar radiation energy, received per surface unit area in a given time $\left(W * m^{2} * n m^{1}\right)$, while radiance $(\mathrm{L})$ characterizes total emission or reflection that passes through or is emitted from a particular area $\left(W * s r^{1} * m^{2} * n m^{1}\right)$. Therefore, the spectral reflectance, or the reflectivity of the object, can be estimated by the direct mathematical division of these first two characteristics, and is expressed in percentage. The irradiance and radiance of the water thus should be measured, in order to estimate spectral reflectance of the various seafloor cover types.

The optical measurements of the irradiance and radiance of the sea water and bottom cover types of the seafloor can be received by the means of the optical sensors spectroradiometers. There are several companies producing radiometers with various characteristics and adjusted for different purposes, e.g. portable and miniature spectrometers from StellarNet, Hyperspectral Ocean Colour Radiometer (HyperOCR) sensor by Satlantic, traceable spectroradiometers by Orbotronix and lots of others. Among other radiometers there are ones designed by the Trios company producing optical sensors, GER-Series Field portable spectroradiometers from SpectraPartners, etc. Trios-RAMSES hyperspectral radiometers (Trios-RAMSES Hyperspectral UltraViolet A, or long waves (315 nm-400 nm) (UVA)/UltraViolet B, or medium waves (280 nm-315 nm) (UVB) Irradiance Sensor and Trios-RAMSES-ARC Hyperspectral UltraViolet (10 nm to 400 $\mathrm{nm}$ ) (UV)-VISible (VIS) Radiance Sensor), Fig.2.1 are small-sized, low power-consuming, flexible for fieldwork yet with high level of precision, specially calibrated for air and for water application as well as color measurements (Fig.2.1). These products have been used for the radiance and irradiance measurements in Agia Pelagia bay, Crete Island, 2009.

\subsection{Radiative Transfer Models (RTM) for the simulation of water optical properties: a brief review of existing software tools}

Understanding radiance distribution within a water column is necessary for the studies of the underwater visibility, because scattering properties of the water body naturally vary with changing depth, wavelength and environmental conditions. Simulation of the radiance quantities for natural water bodies enables to analyse seafloor color remote sensing properties. Therefore, the artificial modelling of the seawater optical properties by means of the RTM is used when water optics is studied under changing environment (e.g., depths, sun angle, suspended particles in water column).

In such cases a retrieval of water optical parameters from the remote measurements should be tested and analyzed.

We briefly discuss below the most effective RTM software and algorithms, suitable for underwater radiance simulations, from a range of various best-known up-to-date tools. 
* The Second Simulation of a Satellite Signal in the Solar Spectrum Version1 (6SV1) is a US atmospheric correction algorithm, developed in the University of Maryland; adjusted for the MODIS satellite imagery lookup tables. The $6 \mathrm{~S}$ algorithm has been implemented by the Geographic Resources Analysis Support System (GRASS) software for the atmospheric correction

* Another example of the RTM adjusted for a specific imagery is a German Karlsruhe Optimized and Precise Radiative transfer Algorithm (KOPRA), fitted for Michelson Interferometer for Passive Atmospheric Sounding (MIPAS) and ENVIronmental SATellite (ENVISAT) imagery.

* The HydroLight RTM commercial software is an advanced model for oceanic radiative transfer calculations, developed by the Sequoia Scientific, Inc., USA. It is designed to solve a wide range of problems in optical oceanography and limnology.

* The British Radiative Transfer for TIROS (Television and InfraRed Observation Satellite) Operational Vertical Sounder (RTTOV-9) is a radiative transfer model, developed for nadir viewing atmospheric sounders and imagers. It includes a number of useful tolls, e.g. can compute sea-surface emissivity for each channel, enables, to specify cloudiness for radiance calculations, etc. This program runs under Unix/Linux platforms and is open source.

* The Rapid Radiative Transfer Model (RRTM) is one more RTM freeware, designed in the USA, Massachusetts.

* The MODTRAN, a commercial software from Spectral Sciences Inc., is another example of the RTM. Among its newest updates is generation of atmospheric correction data; it also has an option to write spectral output in binary, and convert it to American Standard Code for Information Interchange (ASCII).

* The Community Radiative Transfer Model (CRTM) is designed by the (JCSDA, National Aeronautics and Space Administration (NASA)) and includes Surface Emissivity/Reflectivity Models, Cloud Absorption/Scattering Model and Gaseous Absorption Model.

For our purpose we have chosen the WASI RTM software, due to its effectiveness, adaptability for the Mediterranean environment, open source availability, coverage of necessary wavebands and clear, user friendly interface, enabling to adjust various environmental parameters.

\subsection{The in-situ observations of the seagrass}

The traditional methods of in-situ seagrass monitoring include in general the following standard scheme [87]. The seagrass is being sampled on the selected sites using transect lines, quadrant frame, single point markers, GPS, laptops with installed software (GIS), SCUBA equipment, Internet Pocket PC by CompAQ (iPAQ) and other auxiliary tools (Fig.3.3). The seagrass sampling is taken on the regular way with observation points 


\subsection{Application of the remote sensing data towards seagrass mapping OVERVIEW OF LITERATURE...}

covering the study area with normal distribution (Fig.A.25, Fig.A.24). During the measurement process, the vertical photograph of the measurements frame is taken, and the following points are traditionally estimated: percentage of the seagrass cover within the quadrate, species composition, sediment composition, canopy height, epyphyte abundance, algae percent cover, count of microfauna and a specimen of seagrass is being taken. This scheme, well described by McKenzie [87] is widely used and well-known among the marine biologists and seagrass researchers. Applications of the in-situ seagrass observations of the structuring epiphyte community composition in the P.oceanica ecosystems in Mediterranean Sea is, for example, described by Villegas [136]. Realization of traditional methods for mapping seagrass usually involves intensive and time-consuming in-situ observations during the fieldwork, as, for example, reported by Iverson and Bittaker [61]. The results of the in-situ measurements and observation are usually managed and treated using integrated GIS approach, as, e.g. reported by Schmieder [127].

Other methods of seagrass in-situ monitoring are based on the application of the active hydro-acoustic sonar sensors that send towards a sea floor a signal of energy and then collect the return echoes for the analysis (Fig.A.5).

One of the examples of the acoustic sonar sensor designed for seabed classification is the British RoxAnn system, which application for the seafloor mapping is very well described on the OzCoasts website.

However, the applications of the acoustic methods requires specialized expensive equipment and is mostly used in the deep open waters, combined with bathymetric measurements. Another limitation of the acoustic techniques is that, initially intended for the bathymetric surveying, acoustic equipment is mostly designed for the geomorphological and geological studies of the underwater substratum and are, therefore, more adjusted for the benthic habitat discrimination, and they are not effective for the identifying of the biological species composition or even the presence of aquatic vegetation such as seagrasses and seaweeds [139].

The current study is based on the application of the remote sensing optical measurement techniques, due to their effectiveness, non-destructive nature and availability of necessary tools: spectral radiometers and RTM.

\subsection{Application of the remote sensing data towards seagrass mapping}

Various methods and approaches have been applied towards mapping of the seagrasses, based on digitized aerial photographs, GPS data, remote sensing and SCUBA-based (Fig.A.54) fieldwork measurements. SCUBA-based in-situ observations, though providing high resolution and accuracy results in seagrass map- 


\subsection{Application of the remote sensing data towards seagrass mapping OVERVIEW OF LITERATURE...}

ping, is limited in application, because of their time consumption, weather-dependency and unsuitability for the case of monitoring large areas of water for small-scale mapping. The underwater videography with a GPS is a tool of seagrass monitoring which has certain advantages, i.e. high spatial and visual resolution, non-destructive sampling, effectiveness at all depths and rapid data collection in the field [128]. However, it cannot cover large areas for small-scale mapping. Remote sensing techniques offer clear advantages over other methods of in-situ field measurements and seagrass observations, mentioned above. Preference of the remote sensing methods consists in their weather-independence, cost-effectiveness, accuracy and spatial coverage, which enables periodic monitoring of the seagrass meadows and gives access to the distant and unapproachable areas. Integrated together with GIS vector layers and maps, remote sensing data enable historical mapping $[19,5]$ and assessment of change detection. However, application of the remote sensing techniques for mapping of submerged vegetation, seafloor cover types and benthic vegetation, inter alia seagrasses, are still in their development. Approaches and methods for the seagrass protection and monitoring still remain location-specific or, at least, nation-specific, depending to large extent on the tools available for the researchers [8], [93]. Universal, international, standardized methods for seagrass directly for seagrasses as such still should be developed. Various case studies have been performed, yet their mostly report methods adjusted for particular areas, without evaluating standard general algorithms that could be extrapolated towards other regions.

Application of the remote sensing towards seagrass mapping is generally based on the assumption that various types of the

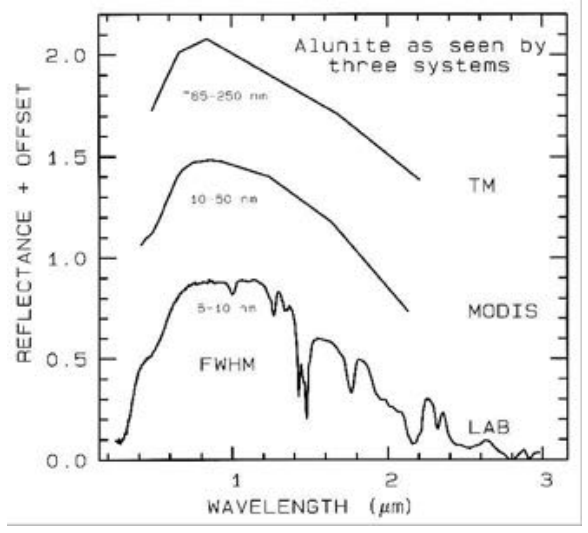

Figure 2.3: Difference between broadband multispectral and hyperspectral resolution of spectral signatures. Source: [23]. Page: $<22>$ seafloor bottom have different characteristics of the reflectivity, which is visually expressed in distinct colors of the objects [123]. In its turn, reflectivity of the sediments is affected by the water optical properties and content. For example, Stephens [131] prove that microalgae biomass and community structure affect hyperspectral reflectance of sediments, which enable to estimate total microalgae biomass from measurements of hyperspectral reflectance. Spectral measurements of the target objects are made by means of the radiometers (Fig.2.1), which receive and register the amounts of energy (radiance and irradiance) from the objects. Measuring optical properties of of the seawater allows to calculate spectra of the objects and to discriminate them on the aerial and satellite images. Thus, various scientists report success in spectral discrimination of submerged vegetation and other seafloor cover types on imagery using hyperspectral optical properties of the sea water for the assessment of benthic habitats [75, 76, 25, 139].

Studies of spectral reflectance of the different seagrass species comparing to the spectra of sand and other seafloor cover types [134] prove that spectra of green, brown and red benthic macroalgae differ from each other, as well as from sand and deep water reflectance spectra. These differences are well detectable by 
2.5 Application of the remote sensing data towards seagrass mapping OVERVIEW OF LITERATURE...

Table 2.1: Characteristics of selected ocean-colour sensors. Pages: $<50>,<36>$

\begin{tabular}{|c|c|c|c|c|c|c|}
\hline $\begin{array}{l}\text { Satellite Sen- } \\
\text { sor: }\end{array}$ & Landsat & SPOT & ENVISAT & Terra & GeoEye & Nimbus 7 \\
\hline Origin & USA & France & $\begin{array}{l}\text { Europe } \\
\text { (ESA) }\end{array}$ & $\begin{array}{l}\text { USA } \\
\text { (NASA) }\end{array}$ & USA & USA \\
\hline Instrument & $T M, E T M+$ & Pan, $X S$ & MERIS & $M O D I S$ & SeaWiFS & $C Z C S$ \\
\hline $\begin{array}{l}\text { Number } \\
\text { channels }\end{array}$ & 8 & 6 & 15 & 36 & 8 & 5 \\
\hline $\begin{array}{l}\text { Wavelength } \\
\text { coverage }\end{array}$ & $185-1700$ & $500-1750$ & $412.5-900$ & $469-1640$ & $412-865$ & $443-750$ \\
\hline $\begin{array}{l}\text { Ground reso- } \\
\text { lution (nadir), } \\
\text { m }\end{array}$ & $\begin{array}{l}15- \\
\text { pan,30(MS),60 } \\
\text { (TIR) }\end{array}$ & $\begin{array}{ll}2.5, & 5, \\
10,20 & \end{array}$ & $\begin{array}{ll}1.2 & \mathrm{~km} / 300 \\
\mathrm{~m} & \end{array}$ & $1.0 \mathrm{~km}$ & $1.13 \mathrm{~km}$ & $825 \mathrm{~m}$ \\
\hline $\begin{array}{ll}\text { Band } & \text { Width } \\
(\mathrm{nm}) & \\
\end{array}$ & $0.45-10.4$ & 10,20 & $\begin{array}{l}2.5,7.5,9,10 \\
14,20\end{array}$ & $\begin{array}{l}0.18,0.3,0.5,1 \\
-50\end{array}$ & 20,40 & 20,100 \\
\hline Launched & 1972,1999 & 1986 & 2002 & 1999 & 1997 & 1978 \\
\hline $\begin{array}{l}\text { Recurrent pe- } \\
\text { riod, days }\end{array}$ & 16 & 24 & 35 & 16 & 16 & 16 \\
\hline
\end{tabular}

the means of the remote sensing research methods. Comparing to the terrestrial plants, aquatic vegetation, inter alia seagrass, cannot be detected using red edge of the spectrum, as these wavelengths are significantly absorbed by water [69], as well as by scattering and absorption by phytoplankton. Some authors [30] also use spectrally based radiative transfer approach to quantitatively estimate shallow-water bathymetry and leaf area index (Leaf Area Index (LAI)) of the seagrass. The spectral reflectance in general is the result of the spectral absorption in different bands, typical for each target object. Spectral reflectance of the seagrass (Fig.2.2) is largely influenced by the water depth where it is located, and is generally decreasing in values by increasing depths. The most important spectral diapason for marine mapping of submerged vegetation and, particularly, for seagrass, is 350-800 $\mathrm{nm}$ [7]. Using airborne imagery for retrospective data (before 1970s) together with the most recent imagery allows to detect changes in seagrass distribution on over different years and to analyse dynamics of the seagrass distribution [6].

Another important advantage of the application of the remote sensing data for mapping of submerged aquatic vegetation has commercial nature: using remote sensing data and methods enables more low-cost and upto-date seagrass mapping [100], and is especially useful for the areas where the fieldwork data capturing is unavailable. Seagrass meadows may reach spatial scales from several up to hundreds of metres, therefore they are susceptible by the means of satellite imagery from remote sensors, both with moderate resolution (e.g., Landsat MSS, Landsat TM, Landsat ETM+, MERIS from European Space Agency (ESA), ASTER, MODIS) and high resolution as well (e.g., IKONOS, Quickbird, SPOT, CASI). The possibility of their application towards seagrass mapping varies and is limited by the technical characteristics (Table 2.1) and resolution of these sensors (Fig.2.3). In the next paragraphs (Review of multispectral imagery used for seagrass mapping and Review of hyperspectral imagery used for seagrass mapping) we will briefly discuss 
research experience of the application of satellite imagery towards seagrass mapping, its advantages and limitations, reported by various researchers.

\subsubsection{Review of multispectral imagery used for seagrass mapping}

Seagrass mapping using remotely sensed data from multispectral sensors is based on the classification and discrimination of the seafloor types using their spectral characteristics in different wavebands.

Perhaps, the most known imagery, widely used in the remote sensing mapping, is received from the group of Landsat sensors, known for its historical, pioneer role in the satellite industry. Being the longest running satellite system, lunched in 1972, Landsat is the only source of archival data going back to 1984 at a sufficient spatial resolution [27], which makes its data desirable for historical mapping or environmental analysis of change detection of the seagrass landscapes. The Landsat TM and Landsat ETM+ data, with the most recent from sensor Landsat 7 - an advanced and multispectral scanning,

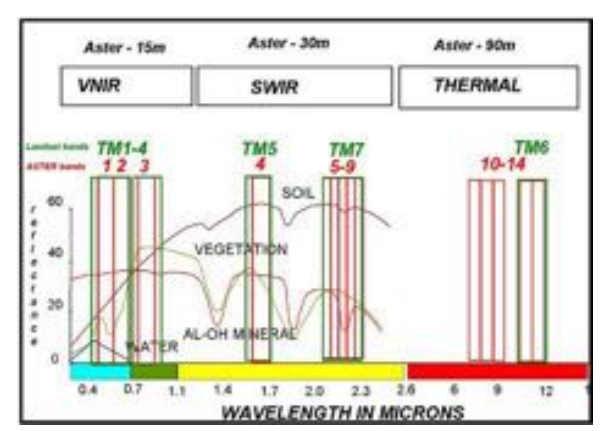

Figure 2.4: Band coverage of ASTER and Landsat channels on the e/m spectrum. Source:[66]. Pages: $<20>,<21>$ launched in 1999, prove to be feasible and useful for the mapping of submerged vegetation, such as seagrasses or coral reefs. The successful applications of the imagery Landsat TM towards the seagrass mapping, were reported in numerous research works [108, 50, 137, 10, 36, 121].

The Landsat data are particularly suitable for the case of change detection of seagrass landscapes at a decade scale, because being the main sensor onboard the Landsat satellites, the Thematic Mapper (TM) provides the longest time series available for change detection analysis over submerged vegetation [108]. Another wellknown multispectral sensor, Satellite Pour l'Observation de la Terre (SPOT) provides multispectral imagery with a spatial resolution of $10 \mathrm{~m}$ (Fig.2.4), covering covers a surface area of $3600 \mathrm{~km}(60 * 60 \mathrm{~km} \mathrm{swath})$, 26-day orbital repeat cycle for nadir viewing and imagery with a spatial resolution $20-2.5 \mathrm{~m}$ [106]. SPOT imagery was used for mapping beds of P.oceanica in the Mediterranean Sea [113] . The IKONOS, offering multispectral and panchromatic imagery, was the first to collect publicly available high-resolution imagery at 1- and 4-meter resolution from Geoeye. IKONOS imagery has been applied for the seagrass mapping due to its high resolution and accessibility. Thus, the results of image classification in case study of shallowwater marine environment [101] made using IKONOS, Landsat TM, and Compact Airborne Spectrographic Imager (CASI), show that in the blue part of the spectrum, the best results are achieved by the IKONOS and CASI, while Landsat TM has not high enough resolution. It may be caused to some extent by the loss of the radiance contrast, atmospheric Rayleigh scattering and defects of scattering. However, comparing between CASI and IKONOS, the same authors prove that CASI enable to receive still more accurate results of the 
classification than IKONOS [101].

Another comparative analysis of the application of CASI, Landsat and Quickbird imagery [119] demonstrates high suitability of CASI images for the fine-scale mapping of the seagrass landscapes. Thus, CASI and Quickbird-2 images enable to identify even separate seagrass species with small width and heterogeneous nature of the seagrass patches, which could not be detected using Landsat TM images with their 30*30m resolution. Advanced Spaceborne Thermal Emission and Reflection Radiometer (ASTER)), launched in 1999 on board Terra sensor, provides high-resolution images of the Earth in 15 different bands of the electromagnetic spectrum, ranging from visible to thermal infrared light (Fig.2.4). It has diverse subsystems for the Visible and Near-InfraRed (VNIR) with $15 \mathrm{~m}$ resolution, shortwave infrared Short Wave InfraRed (SWIR), and Thermal InfraRed (TIR) wavelength regions [66].

For each channel there is separate On Board Calibration (OBC) system, telescope with independent pointing and different detector technology [4]. This makes ASTER imagery especially suitable for the application towards detailed mapping of sur-

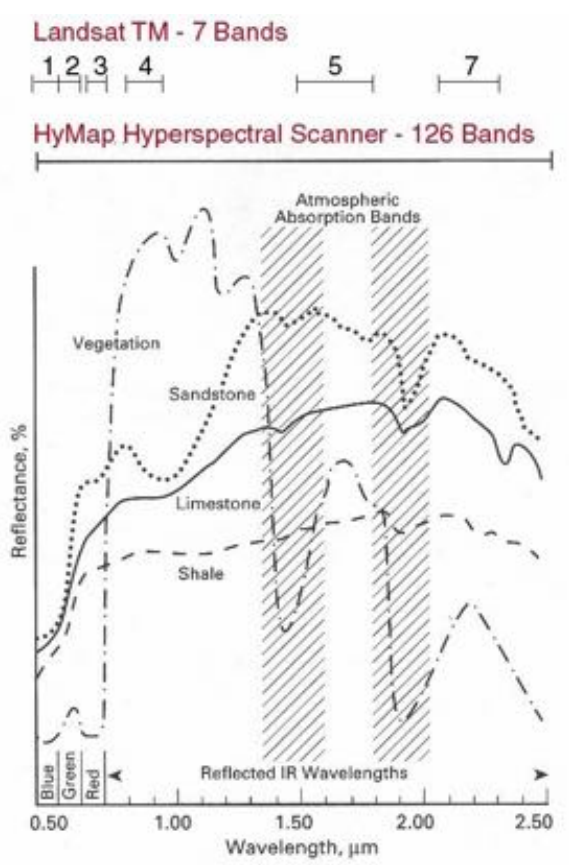

Figure 2.5: Multispectral vs. hyperspectral band coverage.

Source: [125]. Pages: $<22>,<20>$ face temperature, emissivity and reflectance of objects and bathymetric elevations as well (Fig.2.4). Successful application of the ASTER imagery towards mapping of submerged vegetation reported, for example, by Hirose [55]. Other multispectral images have also been used for the seagrass interpretation. For example, the success of using imagery from the multispectral airborne scanner Daedalus AADS1268 is reported by Heege et al [54] where they aim at classification of macrophytes in shallow waters of the Lake Constance. In regard to the methods chosen for the image interpretation, the supervised classifications proves to be the most worthy in a majority of case studies [108, 114]. While often methods of the unsupervised classification are used as a tool for classifying submerged object and features on the multispectral images and aerial imagery [37], it still does not provide common algorithms that can be applied to other images and regions. Thus, the strength of the optical signal coming from the various types of the seafloor is strongly influenced by the effects of the water column, its depth and chemical properties. Yet methods of the unsupervised classification overleap mixed spectral effects of the water column which shift the real values of the spectra, with the pure reflectance from the benthos; as a result, it may cause significant errors [30]. For the accurate assessments of various seafloor cover types, water column depth and its optical properties, methods of supervised classification should be preferably used as being more suitable in classification and interpretations of imagery. However, it is only true if spectrally distinct regions of the spectrum are covered by a space-born sensor and if the atmospheric distortion and viewing geometry is not degrading 


\subsection{Review of hyperspectral imagery used for seagrass mapping 2 OVERVIEW OF LITERATURE...}

the radiometric quality at essential wavelengths. While this and other studies [119] demonstrated the advantages and success of the application of multispectral imagery for the spectral discrimination of the seafloor cover types and mapping the submerged landscapes on the basis of pixels classification, the application of data from hyperspectral sensors has better potential due to their higher resolution (Fig.2.5).

\subsubsection{Review of hyperspectral imagery used for seagrass mapping}

The application of the hyperspectral sensors is most effective and provide more accurate classification results (Fig.2.5), due to their higher spectral resolution [15] with interval narrows to 10 nanometers, while broadband sensors are limited to the spectral width of ca $150 \mathrm{~nm}$ (Fig.2.3). Hyperspectral imagery is acquired through the simultaneous acquisition of images in many narrow, contiguous spectral bands from hyperspectral scanners (mostly) cover the 400- to 2500-nm spectral bands [126]. Perhaps, the most advantageous and general characteristics of hyperspectral imagery is its high spectral resolution, desirable for the case of seagrass monitoring. The most suitable scanner fit for detailed seagrass mapping would cover bands of 550-750 $\mathrm{nm}$ and have a spectrum resolution of 5-15 $\mathrm{nm}$ [42],

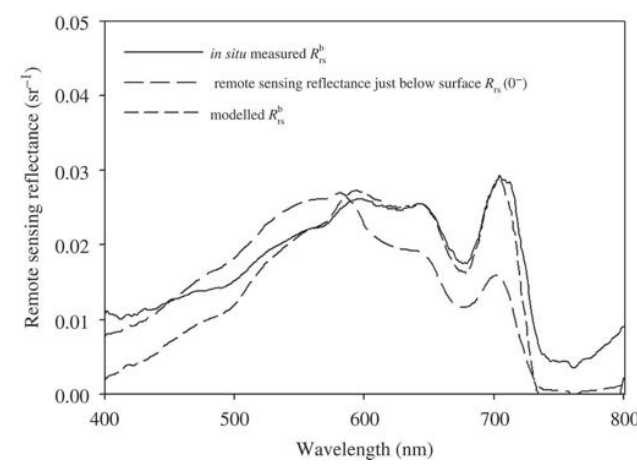

Figure 2.6: Reflectance spectra of Thalassia seagrass; Rrs(0-) - subsurface RS reflectance; Rrs b - the bottom reflectance. Source:[140]. Pages: $<23>,<24>,<57>$ which exactly characterizes typical airborne and hyperspectral satellite scanners. Important features may be detected in the narrow wavelengths of hyperspectral imagery, while this information can be lost in the broader wavelengths of other sensors. With its 126 spectral bands, Hyperspectral Mapper (HyMap) imagery enables to distinguish features of interest, i.e. seagrass types [115], which is the major advantage of the of hyperspectral data for mapping landscapes of the seagrasses. While comparing multispectral imagery with airborne hyperspectral, the last one showed higher overall accuracies [119]. Several, regular and narrow (10 $\mathrm{nm})$ spectral bands, specific for hyperspectral imagery, are strong tool enabling to detect even slight and subtle differences in the spectral reflectance between various seafloor types, e.g. different seagrass species at diverse depths, algae, corals, dark-coloured sands or other types of sediments [56]. Therefore, there is great potential of the application of hyperspectral remote sensing imagery towards seagrass mapping at species level, as long as they are distinguishable spectrally (Fig.2.6) which, for example, has been tested in the case study of Australian marine ecosystems by Fyfe [42]. Application of various classifications methods, inter alia maximum likelihood, minimum distance and means, towards hyperspectral imagery [114], combined with fieldwork measurements ensures accurate mapping results with the maximum likelihood methods producing the best results. Therefore, accurate mapping of the seagrass landscapes and other seafloor types using remote sensing approaches requires application of high-spatial resolution (higher than $5 \mathrm{~m}$ ) or hyperspectral imagery. Comparative analysis of the application of hyperspectral and multispectral imagery 
towards the seafloor types classification [56] demonstrates that coral, seagrasses and sand very well distinguishable in their spectra with an overall classification accuracy of $98 \%$. However, the use of data from various sensors, both hyperspectral and multispectral, is possible and reasonable, as soon as it meets the research specific objective. Thus, the use of multispectral imagery with high spatial resolution is preferable to using hyperspectral medium resolution data in case of mapping benthic vegetation in areas where the spatial heterogeneity is very high [135].

\subsubsection{Comparison of seagrass spectra}

The reflectance spectra from different seagrass species reported in various research works demonstrate diverse spectral signatures which are dependent on the mixture of environmental conditions as well as individual characteristics of the seagrass. In the current work we have compiled an extensive measurements dataset (up to 400 single spectral profiles) of the reflectance spectra from various seafloor cover types (P.oceanica and carbonate sand) in the coastal waters of Crete Island, which is partly visualized on the plotted graphs (Fig.4.2, Fig.4.6, A.27, A.28, A.30, A.35, A.36). Having analyzed reflectance spectra received in previous works by other researchers and compared them with our results, obtained in the current work, we noticed some general trends in the character of reflectance spectra of various seafloor cover types. We mention below some general conclusions and observed tendencies in the profiles and patterns of spectra of P.oceanica and carbonate sand (as for Crete Island). Measured remote sensing spectral reflectance is highly variable with changing environmental conditions, such as water physical content (amounts of suspended particles and organic matter, salinity, chemical content), water column depth, atmospheric conditions (e.g. sun zenith angle) and individual features on the plant, e.g. morphology and colour pigmentation of the leaves, differed in various plant's health and age conditions. The maximal values of the spectral reflectance of P.oceanica, received both in the current work and by previous researchers, lies in wavelength interval of 500-600 nm, as, for example, shown on Fig.2.2, Fig.2.6, and can be clearly seen in our results as well (Fig.4.2, Fig.4.6, Fig.4.8, A.35). Comparison of the remote sensing reflectance spectra of various seagrass species, e.g. P.oceanica (Fig. 4.4) and Thalassia testudinum (Fig.2.6), shows that P.oceanica is in generally brighter in the wavelength interval 500-600 nm which can be caused by various colour pigmentation. The plotted graphs with spectra of the seagrasses P.oceanica and Thalassia testudinum demonstrate that the dip in the spectral reflectance after ca $600 \mathrm{~nm}$ is more pronounced in case of P.oceanica seagrass beds (Fig.4.4) than in those with Thalassia testudinum (Fig.2.6), due to absorption caused by pigment of green leaves. The remote sensing of the bottom albedo of P.oceanica and carbonate sand (Fig.4.7) shows clear difference between the carbonate sand and P.oceanica, which is evidently much darker. To estimate and further analyze particularities of the P.oceanica remote sensing reflectance spectra over regions with different bathymetry $(0.5,1.5$ and 2.5 meters column depth) we used WASI RTM software, which incorporates measurements of the seafloor reflectance and water column optical properties. 


\section{Materials and methods}

In the section Seagrass monitoring: overview of literature and research resources we briefly discussed main existing cartographic methods and tools for seagrass mapping. In the current research we try to combine various techniques from mentioned above for the assessment of the seagrass distribution in the Mediterranean environment, for the case study of Crete. We mentioned in the List of Tools the software that we used for logically separated research sections, which required various approach. Thus, for example, spectral analysis and assessment of spectral signatures is technically based on WASI, statistical analysis of series of experimental raw data has been made by means of statistical software, such as Gretl and SPSS; mapping has been made using ArcGIS; images processing and classification were made using Erdas Imagine software by means of Google Earth and Landsat imagery. ArcGIS 10.0 software is used for the spatial analysis, general mapping and cartographic layout presentation; the raster processing techniques are applied for the detection of seagrass spatial distribution using supervised classification. The research data include Google Earth aerial images and scenes from the Landsat TM and Landsat ETM+ covering research period of 10 years in the same year time, taken from U.S. Geological Survey (USGS), Global Visualization Viewer (GloVis), National Oceanic and Atmospheric Administration (NOAA) and The Earth Science Data Interface. The satellite imagery provides vital information of the most recent changes in P.oceanica within the coastal areas, as well as the condition (poor or destroyed). The raster processing includes making mosaic-like covering for the whole research area. The Google Earth images are most appropriate for the detailed mapping than satellite than Landsat or ASTER enabling to produce accurate maps with correct results. Therefore, the main set of images for the current work is Google Earth aerial images. The Landsat images are used for the general overview. Besides aerial and satellite photographs, data acquired during the fieldwork (three weeks in September - October) are necessary addition to the mapping helping to solve problems of interpretation during the images classification [109]. Therefore, this work includes sampling of the in-situ measurements of the seagrass distribution. The sampling stations were located in two candidate places on the northern (Ligaria) and southern (Xerocampos) parts of Crete island, as these regions are well suitable for the seagrass, due to the annual mean water temperatures and geological factors, i.e. seafloor conditions and sediments. The field campaign has been carried out during the September-October period 2010. The information about the location of the seagrass (mostly represented by the P.oceanica species) is useful for the understanding of the relationship between the spatial distribution of the seagrass and the environment of the selected areas of Cretan beaches. The results of the videographic measurements are used for the seafloor types detection, because the objects represented on the photos can be well distinguished and classified according to the following well-known characteristics [17]: size (yet some measurements are necessary for the similar-looking objects); shape (the general form is most reliable evidence for identification); colour (common and reliable object indicator); texture (when changes in tone are too small to be distinguishable, texture may assist identification, e.g., stippled, granular, rough, smooth, etc.); associated features (those usually found near other objects, e.g., rocks and soil). 


\subsection{Study area}

General area: Island of Crete, Greece (Fig.3.1).

The study area of the current MSc research is located in the shallow areas of the Ligaria beach, Agia Pelagia and Xerocampos, Crete island, Greece (Fig.3.2). These shelf areas have maximal depth of four meters. Seagrass sampling has been performed at two stations at a depth of 4 meters, in the following selected areas:

1. Ligaria beach (Agia Pelagia district), $36^{\circ} 20^{\prime} N, 22^{\circ} 59^{\prime} E$

2. Xerokampos, $35^{\circ} 12^{\prime} N, 26^{\circ} 18^{\prime} E$

3. Agia Pelagia, $36^{\circ} 20^{\prime} N, 22^{\circ} 59^{\prime} E$.

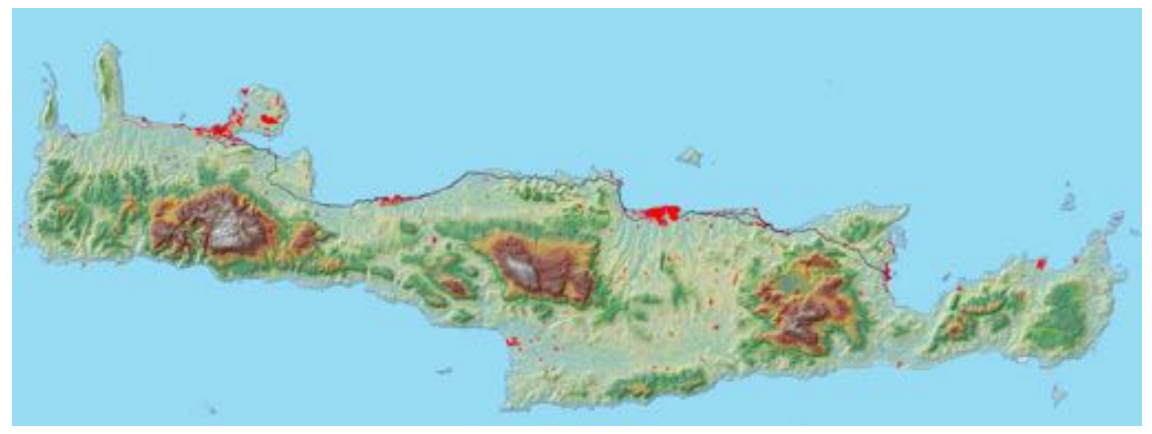

Figure 3.1: Study area: Crete island. Pages: $<2>,<25>$

\subsection{Fieldwork data collection}

Seagrass sampling has been performed at two research stations at Crete Island - Ligaria beach $\left(36^{\circ} 20^{\prime} N, 22^{\circ} 59^{\prime} E\right)$ and Xerocampos $\left(35^{\circ} 12^{\prime} N, 26^{\circ} 18^{\prime} E\right)$, at depths lesser than 4 meters.
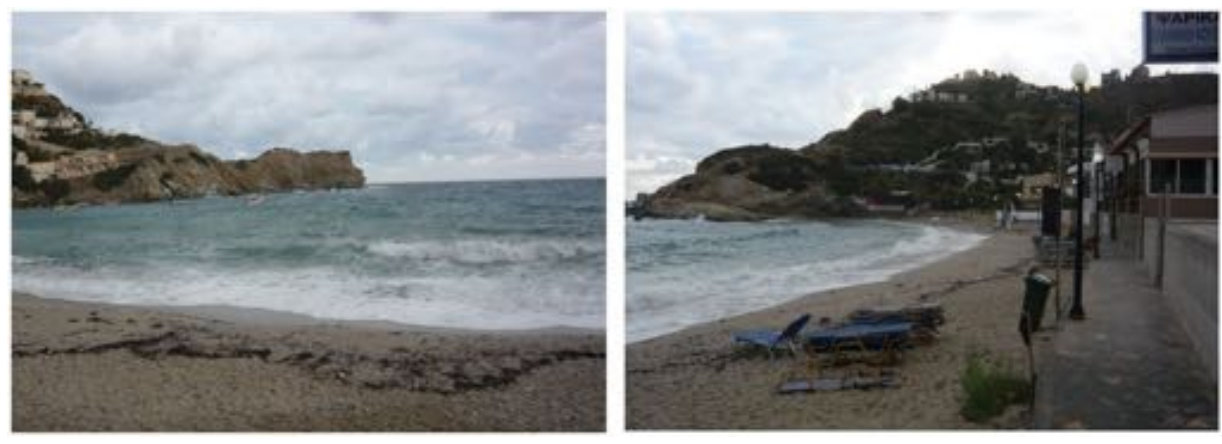

Figure 3.2: Study area: Ligaria beach, Crete island. Pages: $<25>,<26>$

The Ligaria Beach is a narrow, sandy and pebble beach (Fig.3.2), located ca 15 km north-west from Heraklion. The in-situ measurements were conducted during the fieldwork in the period 21.09.2010-11.10.2010. 
The fieldwork on seagrass monitoring included visual estimations and photo- and video footage of the aboveground seagrass patches, sediment seafloor cover types, species compositions, water depth and geographic locations recorded using GPS.

\subsubsection{Fieldwork equipment}

The research materials and equipment were provided by the Natural History Museum of Crete, the University of Crete and the ITC, and included the following items (Fig.3.3): 1) three iPAQs (Fig.3.3a); 2) three GPS (Fig.3.3c); 3) Three underwater video cameras, Olympus ST 8000 (Fig.3.3d), suitable for photographing

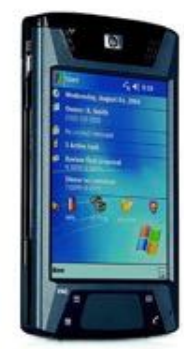

(a) $\mathrm{PAQ}, \mathrm{HP}$

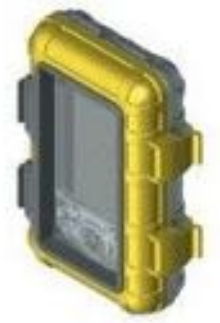

(b) Waterproof Otterbox for iPAQ

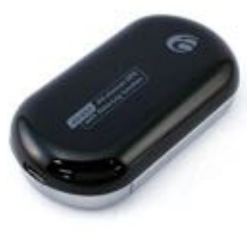

(c) GPS

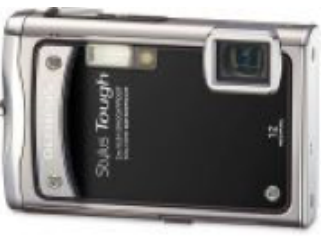

(d) Olympus waterproof camera

Figure 3.3: Fieldwork equipment. Pages: $\langle 17>,<26>,<27>,<28>,<28>$

up to up to 33 foot depths and high-resolution 12.0-Mpixel image sensor; 4) Markers and cords for the depths measurements (Fig.A.56); 5) Waterproof plastic Otterbox (Fig.3.3b) for keeping the iPAQ dry; 6) SCUBA Diving equipment, taken from the Ligaria Diving Center; 7) Boat (Fig.3.4);

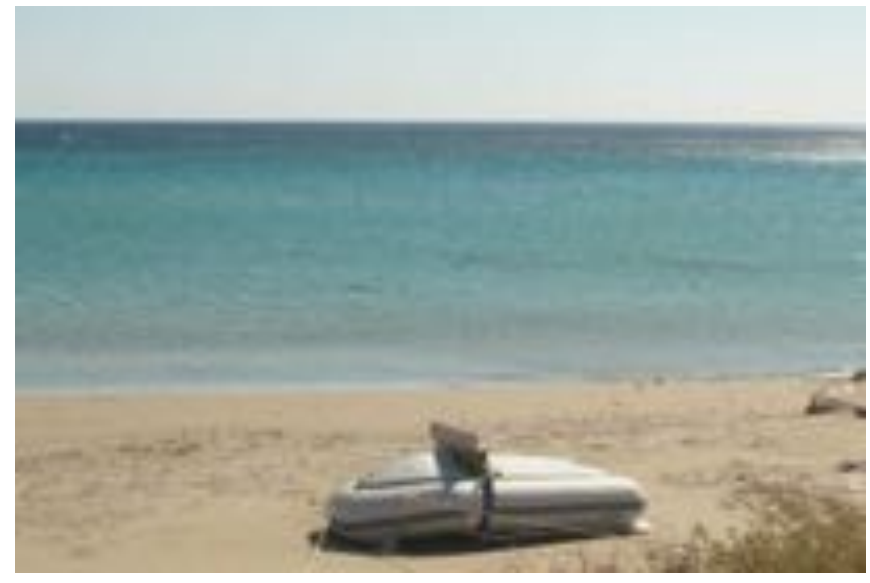

Figure 3.4: Boat used for the fieldwork measurements on Crete Island. 2010. Page: $<26>$

A GPS and iPAQ have been used for detection of the geodetic coordinates and keeping the tracklogs along the boat route for GIS project. 


\subsubsection{Sampling design}

The sampling design of the fieldwork was aimed at surveying of the spatial distribution of the meadows of P.oceanica, and spatial pattern of the seagrass meadows consisted from separate patches. The fieldwork included several routes of the boat in the Ligaria beach sampling site, nine routes in total, in the directions parallel to the coastline, ca 180-200 m long each one, thus enabling the course plot to cover the area of growing seagrass: shelf areas not deeper than four meters. The measurements of the seafloor cover types have been made using underwater video cameras Olympus ST 8010 (Fig.3.3(d)), mounted under the boat to capture video footage and imagery (Fig.A.53). The data records were made along each path using these cameras. A videographic approach, tested previously [105], was applied during the fieldwork on Crete island, for collecting information on benthic cover types and distribution of the seagrass patches from photo transects, in order to use for the calibration of mapping approaches. Three underwater video cameras, adjusted on the bottom of the boat (Fig.A.53), provided videometric measurements of the seafloor during the track (Fig.A.9), and resulted in a series of consequent overlapping images of the sea bottom under the boat path. The general locations of the sampling sites and routes were selected on the basis of the visual examination of the seagrass beds during snorkeling and SCUBA diving (Fig.A.54, Fig.A.55), recommendations from the Greek collaborators of the Natural History Museum of Crete, and available maps covering the research area. To ensure even and objective selection of sampling sites we used transect sampling method, i.e. photographs were taken along the research path.

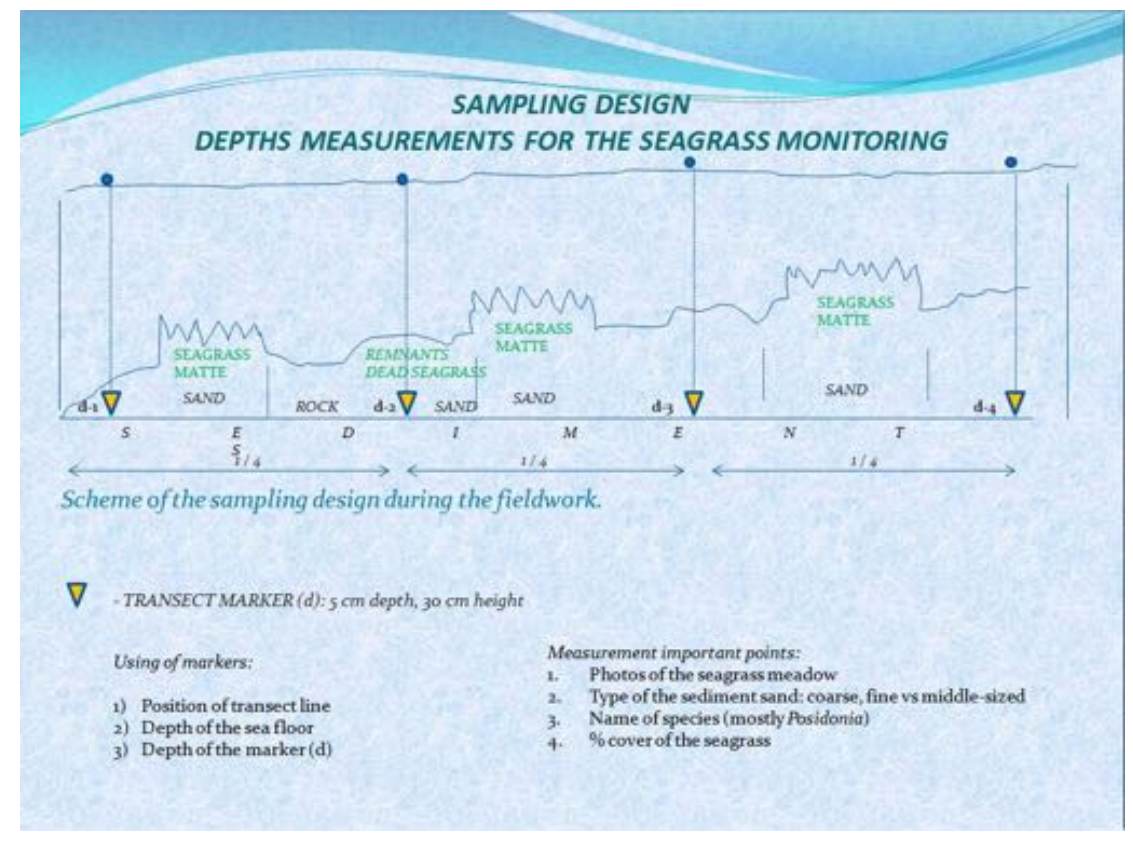

Figure 3.5: Scheme of the depths measurements; fieldwork on Ligaria beach. Page: $<28>$

Transect method (Fig.3.5) is a common sampling technique in studies of the seagrass monitoring [130], 
enabling the occurrences of the seagrass meadows to be recorded and counted in a systematic and accurate way, detect spatial distribution of the single seagrass mattes to be properly identified, without location bias (Fig.A.12).

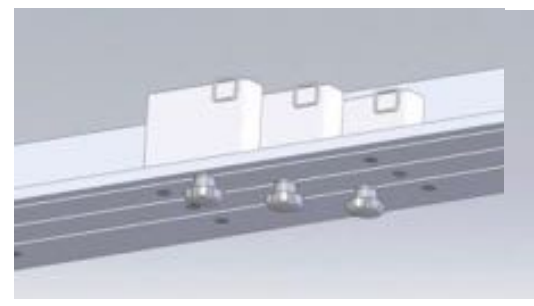

(a) view from below

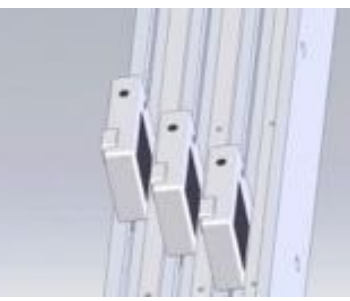

(b) view en-face

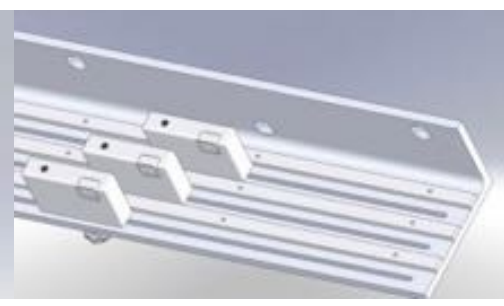

(c) view from above

Figure 3.6: Scheme of placements of the Olimpus cameras during the measurements. Pages: $<28>,<28>$

The videographic measurements and photos, enabling to detect types of the seafloor, were captured by means of three underwater digital video cameras Olympus ST 8000 (Fig.3.3d), at five minutes interval along the tracklog path (Fig.A.9). research sampling design also included measurements of depths (Fig. 3.5), because bathymetry is one of the most determining factors for the seagrass locations. Measurements of depths were performed during the fieldwork using cord, iPAQ, and markers (Fig.A.57) in order to assure that the videometric measurements are taken at depths not more than four meters, in the shelf area. As a result, nine transects were established of one $\mathrm{m}$ wide and $20 \mathrm{~m}$ long track, to cover seagrass beds with videographic measurements. The GPS allowed to capture measurement locations on the iPAQ, encapsulated in a plastic waterproof Otterbox (Fig 3.3b). The camera were adjusted horizontally by a leveler and mounted under the bottom of the boat Fig.A.53 to capture video footage and imagery (Fig.3.6). The data were taken at proper weather conditions: sunny, serene and cloud-free days with glassy sea state. The locations of the route were randomly selected in the areas of the Ligaria beach, to ensure most dense coverage of the seagrass meadows in the research area. The underwater measurements of the seagrass coverage were carried out by taking video footage and photos of ca $0.5 \mathrm{~m}^{2}$ size each (Fig.A.12, Fig.A.57). The results of the underwater videometric measurements include series of digital images helping to classify seafloor cover types (Fig.A.58) and seagrass meadows, according to the differences in the structure, colour, texture and shapes of the depicted objects.

There are several types of the seagrass landscapes alon Ligaria beach, namely, seagrass meadows continuously covering vast areas (Fig.A.8 (a)), aggregated seagrass patches, represented by separate mattes with short irregular channels between them (Fig.A.8 (b)) and isolated seagrass patches, or mattes, located separately from broad meadows (Fig.A.8 (c), Fig.A.58). The results of the underwater videometric measurements of the Olympus ST cameras made during the ship route include nine total tracklog routes in the selected research area, including series of consequent images, completely covering the area under the boat path. The received data contain information on seagrass presence within the study area, distribution of sea- 
grass P.oceanica meadows and nature of the seafloor cover types: rocks, sandy, mixed (Fig.A.11, Fig.A.10, Fig.A.8). Seagrass species on the Ligaria and Agia Pelagia beach consist of P.oceanica. The types of sediment on the Ligaria vary from coarse sand, P.oceanica patches, sand, mud, rock gravel and fine sand (Fig.A.11).

\subsection{Review of the collected data}

The remote sensing imagery was collected for the Crete island area covering the research period and area, enabling the field data to be used for the calibration and validation. The available aerial and satellite imagery are commonly used for the mapping of seagrass landscapes and their application is proven by various research papers. The imagery includes satellite multi-spectral imagery (Landsat-TM, ETM+) and aerial imagery from the Google Earth. The overview of the collected data enables to summarize their following types:

1. Optical spectra of P.oceanica, carbonate sand, seawater with sediments and seawater measured in aquarium tank, without sediments, at different environmental conditions (e.g., Fig. A.20)

2. Aerial imagery from the Google Earth

3. Satellite images from various open sources (e.g. Landsat, Tab A.19) (previews: Fig. A.43)

4. Results of underwater videometric measurements of the Olympus ST cameras made during the ship route

The available satellite imagery (Fig.A.44, Tab.A.31) and aerial images are read into the ArcGIS project. The available broadband and hyperspectral remote sensing data are used for the mapping of the seagrass in shelf areas no deeper than 4.0 meters (Fig.A.45, Fig.A.46, Fig.A.47, Fig.A.48), for the environmental monitoring in order to detect spatial distribution of the seagrass along Crete during the past ten years using different satellite images for 2000-2010 (Fig.3.7).

The spatial resolution of Landsat ETM+ image is $30 \mathrm{~m}$ in the visible and near infrared bands (bands 1-5 and 7); the spatial resolution of ASTER $15 \mathrm{~m}$ for the visible and near-infrared bands. IKONOS acquires data in 3 visible channels and Near-Infra-Red (NIR), with spatial resolution of 1-4 meters. ASTER and IKONOS images are suggested to be included as soon as available, in addition to the Landsat. The research includes fieldwork in-situ measurements of the seagrass distribution along the northern and south-eastern coasts of Crete in chosen locations.

The optical measurements of the irradiance and radiance of the sea water and bottom cover types of the seafloor have been received by the means of the optical sensors Trios-RAMSES Hyperspectral UVA/UVB Irradiance Sensor and Trios-RAMSES-ARC Hyperspectral UV-VIS Radiance Sensor (Fig. 2.1), both adjusted for the measurements of the irradiance and radiance (see appendices: Tab. A.1, Tab. A.2). These products have been used for the radiance and irradiance measurements in at the Hellenic Centre for Marine 


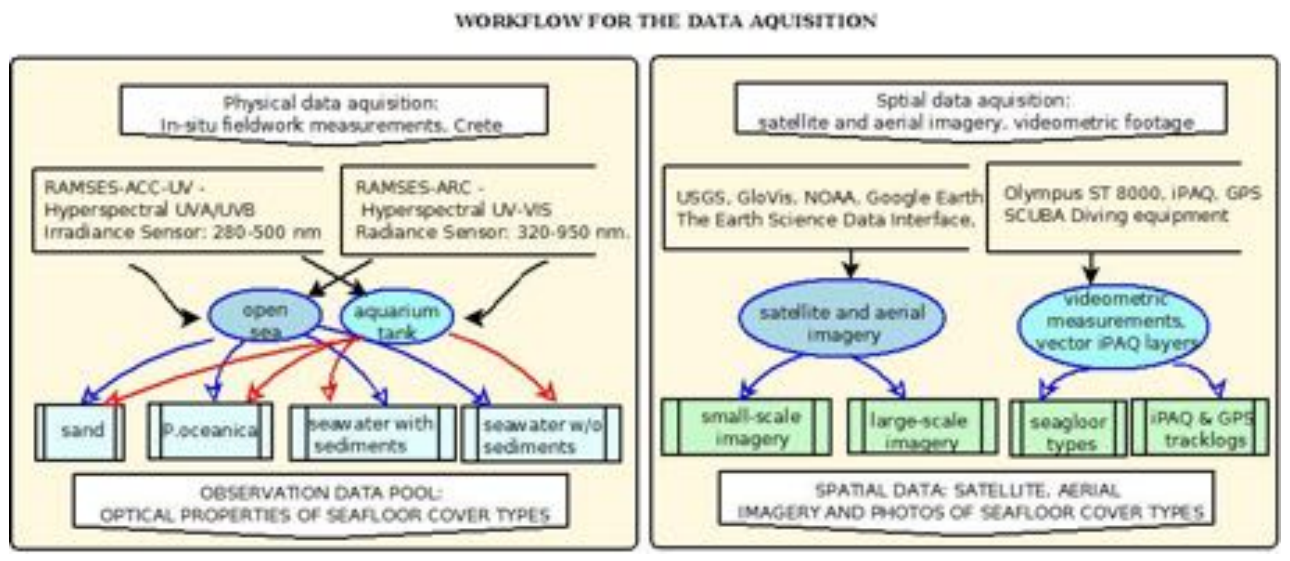

Figure 3.7: Work flow for the data acquisition, Dia display. Page: $<29>$

Research (HCMR) at the Institute of Aquaculture, Crete Island, 2009 by Ms Sylvia Noralez using following workflow. The spectrometer was adjusted for automatic measurements mode, with measurements taken as fast as possible. The spectrometer head was held submerged, and the sampling was controlled by an operator on the surface boat. The head of the sensor was pointed downward at an angle of $0^{\circ}$ (nadir) in order to capture the spatial discernibility in the radiance for the benthic cover types. The frame was held at $45^{\circ}$ angle in order to keep sensor looking down at $0^{\circ}$ (nadir view). A waterproof camera was attached to the platform to assist with the identification of the target object being measured ([104]). The highest measured values are located in the diapason of 410-730 $\mathrm{nm}$ for the water irradiance (Fig. A.19) and 430-650 for the water radiance (Fig.A.16). Afterwards, the measured values of the radiance and irradiance, respectively, have been used for the computation of the spectral reflectance properties of the sea water and bottom cover types (Fig.A.30). The spectral range of radiance cover diapason of 320-950 nm, and irradiance measurements are covered in the interval of 280-500 nm, which is suitable for characteristics of seagrass reflectance. Different curves on the reflectance, radiance and irradiance graphs for example, on Fig.A.27, or A.29, enlarged) represent several series of the measurements. The values of the spectral reflectance are received from the computations of these values using mathematical formulae. The graphs shown on Fig. 4.2, Fig. A.20, Fig. A.33, Fig. A.18 display values of the radiance and irradiance of the sea water in Agia Pelagia, with and without sediments and suspended particles, respectively. Graph on Fig A.28 displays statistical analysis of the measured sets of observations, i.e. shows the mid-spread of the statistical quartiles (Q1-Q3), mean and extreme values.

\subsection{Data pre-processing}

\subsubsection{Auxiliary data: spectral dataset}

A collection of visible spectra of two seafloor cover types - P.oceanica and carbonate sand - consist of multiple measurement sets of P.oceanica made by means of RAMSES hyperspectral radiometer: 1-350 for 15th October (fragment on Tab. A.11), 1-445 for 14th October for P.oceanica; 1-106 for water without 
sediments, measured in aquarium tank, 1-27 for seawater with sediments measured in aquarium tank; 1-75 for carbonate sand (Tab.A.17). Measurements of 2009 has been used for the database and statistical analysis, because 2010 data pool was not available. All these data have been analyzed and statistically tested. We measured mean, extreme values (min-max), median and statistical quartiles, in order to visualize distribution of the values at various spectral wavelengths. Carbonate sand was measured at wavelengths $402-750 \mathrm{~nm}$, while P.oceanica - at the interval 318-951 nm. We visualized the behavior of different spectra on relevant graphs (Fig. 4.3, A.39, A.37). The available collected data were tested for the spectral variability and separability under varying conditions of different environmental constituents (e.g. depth, water content, sun angle), in order to determine the potential that it may have on the approaches for further images processing and classification. Behavior of the spectra of P.oceanica have been tested using datasets for various depths: 0.5, 1.5 and 2.5 meters (Tab. A.9, Tab. A.10). The raw initial data of measurements of the spectral reflectance have been preprocessed and statistically analyzed thereafter with graphs visualizing mean spectra and Q1Q3 interval, instead of the series of single observations which is illustrated, for example, on Figures A.17, 4.6, 4.1). These data have been measured using different step of the wavebands: some measurements were made with $3 \mathrm{~nm}$ interval, while others using 4 and $1 \mathrm{~nm}$ step. Therefore, these data had to be interpolated (Fig. A.15) and standardized to one format, which is values of spectral reflectance with one nm step. For the interpolation we used script written on Python programming language that allowed receiving more detailed data by interpolating them from 3 and $4 \mathrm{~nm}$ step up to $2 \mathrm{~nm}$ (Fig.A.13). The interpolated data contained spectral measurements of the seagrass P.oceanica (measured at Agia Pelagia beach, Crete), sand (measured at Agia Pelagia beach, Crete), silt and default artificial spectrum of constant albedo at WASI (Fig.A.14).

\subsubsection{Modelling method: WASI water colour simulator}

To estimate and further analyze particularities of the P.oceanica remote sensing reflectance spectra over regions with different bathymetry (0.5, 1.5 and 2.5 meters column depth) we used WASI RTM software, which incorporates measurements of the seafloor reflectance and water column optical properties. We have chosen WASI RTM software among other aquatic RTM (2.3.Radiative Transfer Models (RTM) for the simulation of water optical properties: a brief review of existing software tools) due to its effective cognitive approach and because it is specifically adjusted and developed for the purpose of aquatic optical modelling. Consistency of simple and logical Graphical User Interface (GUI) (Fig.5.1) let the researcher to easily define model parameters, which can be changed directly in the main window tools menu, and to choose between forward or inverse calculations. Besides other important advantages of WASI we would mention its learnability: available documentation, supporting materials, learning curve with hints and tips, as well as its user-friendly GUI, enabling to learn this product in a most effective and prompt way in a tight schedule of MSc studies. Technically, WASI need for system memory is minimised and the installation is simple and easy.

To create sensor-specific reflectance spectra using WASI, spectral responses of MERIS, MODIS, CZCS and SeaWiFS sensors were applied for simulation of seagrass spectral signatures in full-resolution spectra. 
We also included measurements of other seagrass species - Thalassia seagrass (measured at Southern Chinese Sea by C.Yang and D. Yang [140] ) in order to compare spectral reflectance of different seagrasses under various environmental conditions. The most suitable wavebands for the seagrass monitoring usually lay between 400 and $700 \mathrm{~nm}$, which can be concluded by the visual examination, comparison and analysis of the different spectra of the seagrasses. Therefore, we chosen the spectra 400-750 as the most appropriate range for further research experiment. The results of the linear interpolation (Fig.A.39) demonstrate values of the sand spectral reflectance with $1 \mathrm{~nm}$ interval covering the wavelength diapason of 400-750 nm.

\subsubsection{Implementation of statistical analysis}

The initial measured data were stored in raw-oriented format, so that re-formatting them into the columnbased layout was done using transpose command in Open Office or Excel (Fig. A.26). The next step included calculation of the median, mean, quartiles and other statistical values at every data set (see appendices, Fig. A.35, Tab. A.17). After the preliminary analysis, the measured data were visualized using Gnuplot program, which enables fine plotting of various datasets together: Fig 4.3, Fig.A.17, Fig.4.1. The most acceptable method of interpolation was Bézier curve (Fig. A.19, Fig. A.16), as it has trend-friendly graph better showing the general behavior of the curves at different wavebands comparing to splines (see appendices for more results). Therefore, after several experiments with various interpolation techniques (Fig.A.30, Fig.A.20), we have chosen Bézier curves interpolation (Fig.A.19) which contains convex hulls made on its control points, and therefore is best suitable for our case: analysis of optical properties of seawater.

To analyze average values of spectral reflectance of P.oceanica by means of the measured sets we calculated mean values for the total set of measurements 1350 (15th October): mean of min and max values, mean of average for each waveband, mean for statistical quartiles for each wavelength and mean for median, respectively. The adjusted averages evaluate mean values of trend, needed for statistical analysis of the datasets (Fig.A.21). The outcome of this calculations is shown in the Tab.A.6 and Tab.A.7 (appendices).

As a result, we received mean values of spectral reflectance of P.oceanica for extreme, average (Fig.A.23, Fig.A.22), median and both quartiles, independent of the individual sets 1-350.

We used several statistical methods (Fig.3.8) to asses data received as a result of measurements. The Student$t$ test, one of the most commonly used techniques for testing a hypothesis on the basis of a difference between sample means, is used for the data analysis. In our case the Student t-test demonstrates, if the variation between two analyzed groups values of spectral reflectance of seagrass P.oceanica and sand - is significant. Therefore, we use Student t-test to compare two sets of quantitative data of spectral reflectance of P.oceanica and sand, respectively, with samples collected independently of one another. The Student-t test can be performed knowing just the means, standard deviation, and number of data points. Therefore, we used the data (appendices) of means of spectral reflectance of the both cover types within data sets, their standard deviation, and the number of data points. 


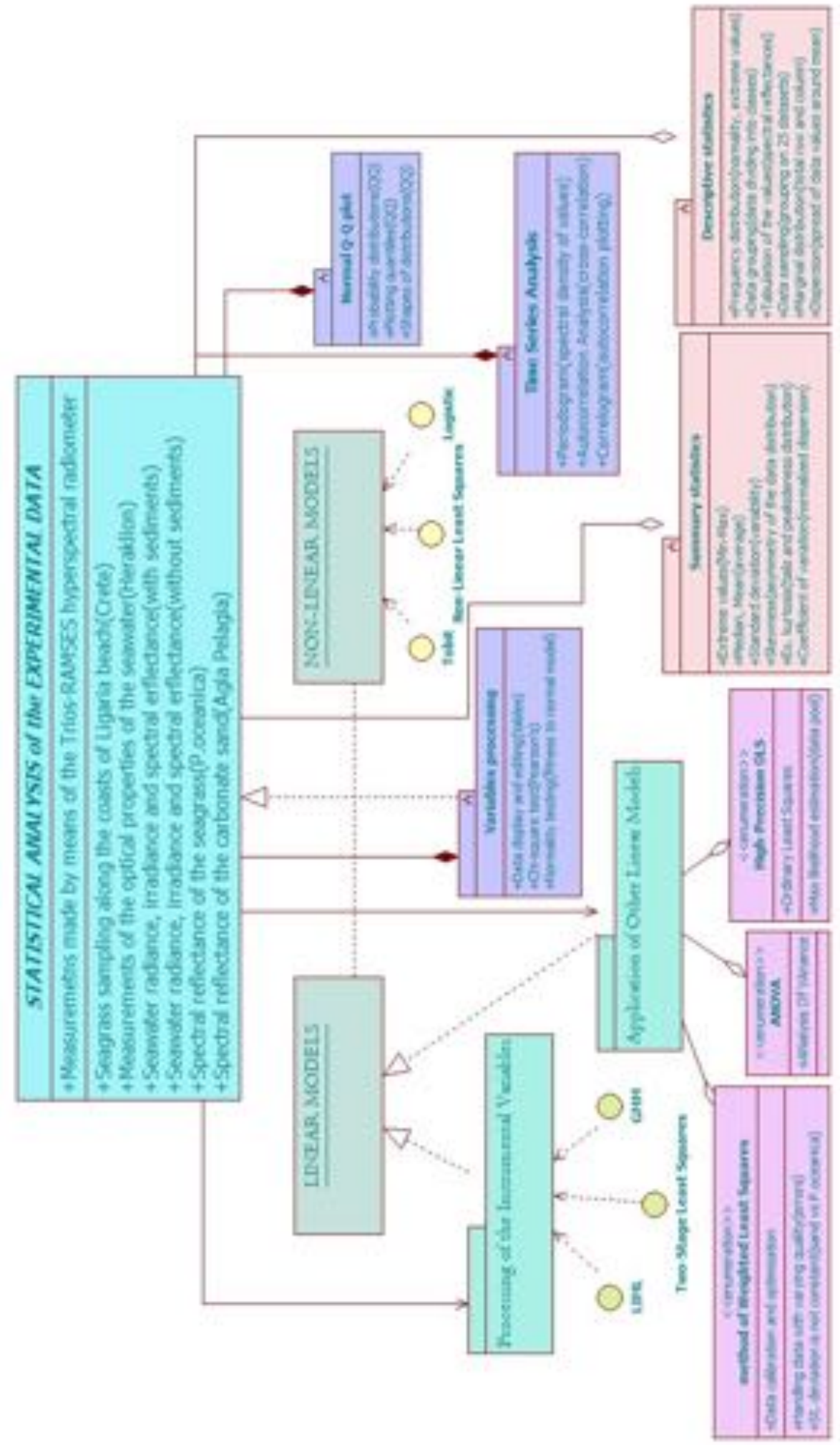

Figure 3.8: Work Flowchart Diagram illustrating algorithm of the Statistical Analysis applied towards the observation dataset (StarUML). Page: $<44>,<32>$ 


\subsection{Spectral simulation of aquatic objects}

The main aim of this part of research is to clarify if the bottom reflectance of the different seafloor types including patches of the seagrass P.oceanica meadows, silt and carbonate sand differ and can be clearly discriminated while mapping. A study is based on three seafloor types containing silt, carbonate sand and seagrass, as well as mixed types, where the spectral signatures were examined. WASI software (Fig.5.1) is used to simulate spectral reflectance and colour discrimination of water, affected by presence of P.oceanica and other factors, under various environmental conditions which influence its colour. The data provided with the model was determined at freshwater of the Boddensee [44], yet the model was adjusted for the marine environment, so that its parameters (concentration of chlorophyll, concentration of small particles, yellow substance, etc) now perfectly simulate the Mediterranean water conditions. The remote sensing reflectance has been compared under the conditions of different water depths and cover fraction of the seafloor, in order to assess spectral signatures of the seagrass and carbonate sand as major seafloor types. WASI enables to use forward or inverse calculation for the spectrum types at a diapason of 350-800 nm with a $1 \mathrm{~nm}$ spectral resolution. For the spectral analysis we applied forward calculations, i.e. a computing and plotting of series of spectra according to specified parameter settings, with exactly defined depths and cover fraction.

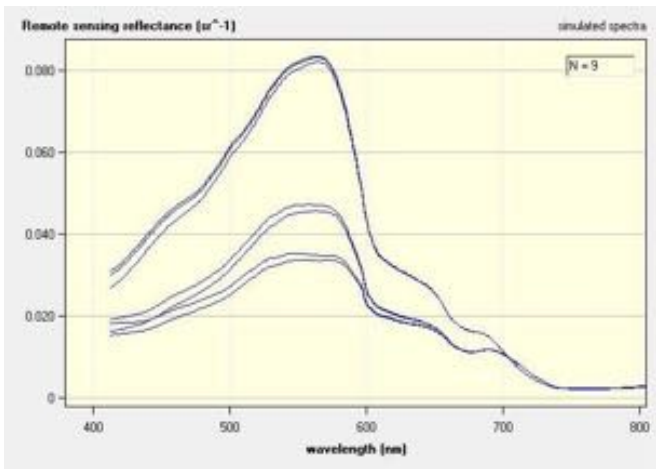

(a) Concentration of Gelbstoff at depths 0.5 $8.0 \mathrm{~m}$

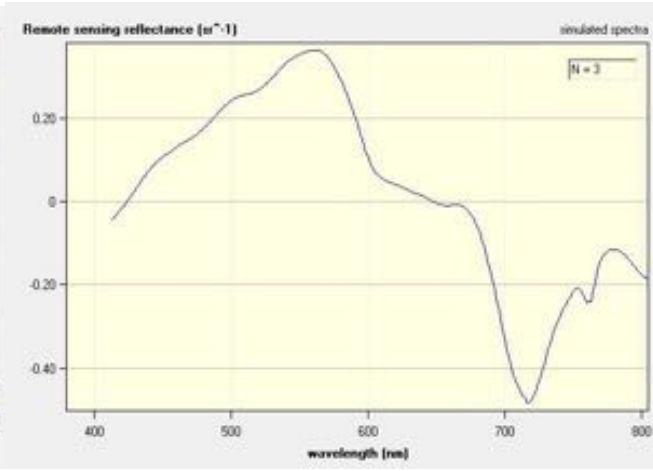

(b) Bottom reflectance at depth 0.5-4.0 meters

Figure 3.9: Sea water physical properties, modeled by WASI. Page: $<34>$

The specific parameters have been chosen for the simulation of the environmental conditions where seagrass grow. The adaptations to life in salt sea water requires various physical and chemical parameters which include salinity, temperature of $17-25^{\circ} \mathrm{C}$, light requirements with $10-20 \%$ on average, ranging from 4.4 $\%$ minimal up to $29 \%$ [91], so that the zenith angle is taken as $35-45^{\circ}$ and reflection factor 0.0201 . P.oceanica. These values, simulating the environment of the Mediterranean Sea, are fixed (Tab.3.1) among WASI user-defined parameters. The calculations are done for the spectrum 350-800 nm, covering the most important part of the RS spectrum: 1) Blue-green 0.45 - 0.5 m; 2) Green 0.5 - 0.6 m; 3) Red 0.6 - 0.7 m; 4) Red-NIR 0.7 - 0.8 m (Fig.3.9). 


\subsubsection{Model parameters: depth and bottom cover fraction}

Although seagrass P.oceanica can be found until depth limits down to $40 \mathrm{~m}$ depth [52], the most preferable limits of its distribution in the Mediterranean Sea are shallow waters until 4 meters of depth.

Table 3.1: Model-specific parameters of water WASI adjusted to simulate environment of the Mediterranean Sea along Crete. Pages: $<10>,<34>$

\begin{tabular}{|c|c|c|}
\hline $\begin{array}{l}\text { Parameter, } \\
\text { WASI }\end{array}$ & Name and description & Values \\
\hline C-L & Concentration of large suspended particles & 8 \\
\hline $\mathrm{C}(\mathrm{i}), \mathrm{i}=0 . .5$ & Concentration of Phytoplankton & $0.035-0.089 u g^{-1}$ \\
\hline $\mathrm{bbS}$ & Specific backscattering for small particles & $0.005 m^{2} g^{-1}$ \\
\hline $\mathrm{T}-\mathrm{W}$ & Temperature of water & $17-25^{\circ} \mathrm{C}$ \\
\hline $\mathrm{n}$ & Exponent of Backscattering by small particles & $0.005 m^{2} g^{-1}$ \\
\hline Q & $\begin{array}{l}\text { Anisotropy factor of upwelling radiation ("Q- } \\
\text { factor") }\end{array}$ & 5.00 \\
\hline sigma-L & Reflection factor of sky radiance & 0.0201 \\
\hline b1 & Backscattering coefficient of saline waters & $0.00144 m^{-1}$ \\
\hline 0 & $\begin{array}{l}\text { Reference Wavelength for CDOM (Gelbstoff) } \\
\text { absorption }\end{array}$ & 440 \\
\hline sun & Sun zenith angle & 45.0 \\
\hline $\mathrm{zB}$ & Bottom depth & 4.00 \\
\hline$f(i), i=0 \ldots 5$ & Areal fraction of bottom surface type number $n$ & $01 / 10 / 10$ \\
\hline K0 & Coefficient of Attenuation & 1.0546 \\
\hline view & Viewing angle $(0=$ nadir $)$ & 0 \\
\hline $\mathrm{C}-\mathrm{X}$ & $\begin{array}{l}\text { Concentration of non-chlorophyll particles (ab- } \\
\text { sorption at } \lambda_{0} \text { ) }\end{array}$ & 0 \\
\hline $\mathrm{S}$ & $\begin{array}{l}\text { Reference wavelength for scattering of small } \\
\text { particles }\end{array}$ & 500 \\
\hline $\mathrm{C}-\mathrm{S}$ & Concentration of small suspended particles & 0 \\
\hline$S$ & Exponent of CDOM absorption & 0.0140 \\
\hline $\mathrm{C}-\mathrm{Y}$ & $\begin{array}{l}\text { Concentration of CDOM Gelbstoff (absorption } \\
\text { at } \lambda_{0} \text { ) }\end{array}$ & 0.400 \\
\hline $\mathrm{Bn}$ & BDRF of bottom reflectance (sand) & $0.318 s r^{-1}$ \\
\hline
\end{tabular}

The increase of depths (zB) influences weakening of light and thus directly affects production of chlorophyll, because when light passes through the water and suspended particles, it is being largely modified through the absorption and scattering before it finally reaches plant canopy of the seagrass. Therefore, the most healthy and suitable areas for the seagrass grow are located at depths lesser than 4 meters (Fig.4.5). 


\subsection{Google Earth aerial imagery for the seagrass mapping}

Apart from the satellite imagery, the aerial photographs from the Google Earth provide a powerful tool for seagrass mapping, because they are important, reliable, detailed and up-to-date source of imagery. Perhaps, the clearest advantage of the Google Earth imagery is its high resolution (15 $\mathrm{m}$ in land areas and lower in the oceans). Obtained from the airborne platforms, Google Earth images have general spatial resolution of several meters (though varying in different areas), which allows very detailed habitat and seafloor types discrimination, comparing with images acquired from the space-borne satellite platforms.

The spatial coverage of the Google imagery is lesser comparing to spaceborne images, but this can be solved as well: while in general providing smaller area coverage than satellites images, the Google Earth images can be stitched to the composite maps of the acceptable spatial extent, using script written on Python (Fig.A.1) and Geospatial Data Abstraction Library (GDAL) technologies (Fig.A.2) for the Google Earth aerial imagery grabbing process (Fig.A.52) which allows multiple overlapping of single images over the flight paths into one swath, and generates imagery mosaics.

\subsection{Image processing using Erdas Imagine}

The analysis of the imagery of Cretan coasts is based on the images classification and is aimed to investigate the distribution of the seagrass P.oceanica within the research area. In the image processing part of the research supervised classification has been applied to the aerial and satellite images. Seagrass meadows and other seafloor cover types were evaluated through a detailed examination of the imagery.

Seagrass beds are clearly visible in color aerial Google Earth photographs (Fig.A.42, Fig.A.43), contrasting against slightly-yellow and brownish sand bottom. The seagrass areas are detected using different bands combinations, masked and studied for the estimation of the changes in the areas. The classification is based on the properties of the P.oceanica, such as brightness, colour, texture and structure of the seagrass mattes (Fig.3.10a). The raster-based mapping includes supervised classification with training sites of seagrasses (10-15 set areas) in different bands for each photograph by classification a series of polygons characteristic of each of the sea floor bottom types: sandy surface, seagrass bed for each species including P.oceanica (meadows), patchy seagrass bed and algae on rock, rocks, muddy surface, etc (Fig.3.10b). 


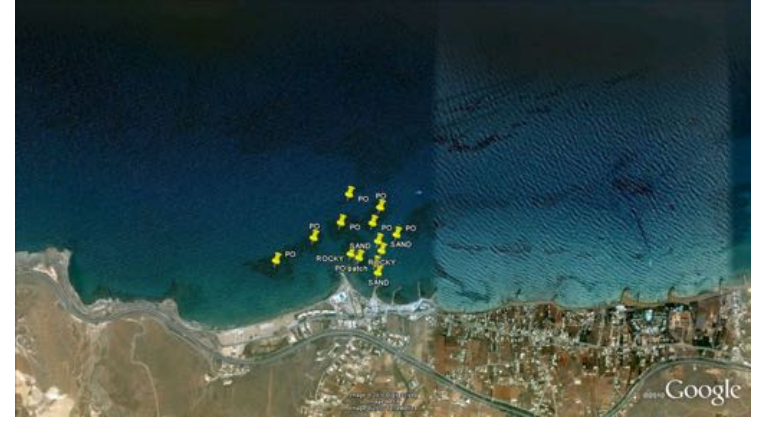

(a) small-scaled $(1: 54,000)$

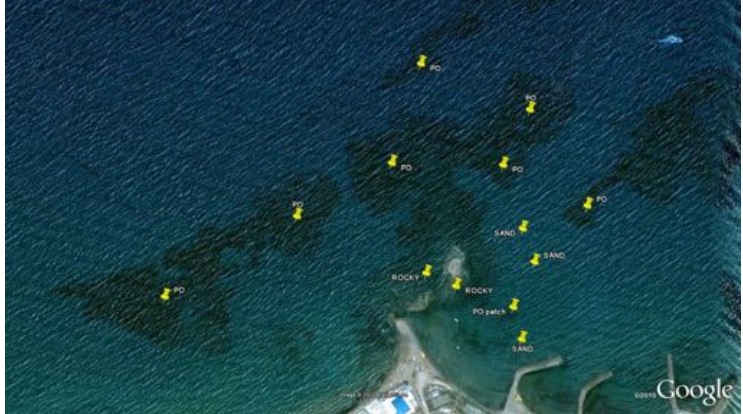

(b) enlarged (1:10,000)

Figure 3.10: Seafloor types of the Arina beach: P.oceanica, sand, rocks.

Google Earth images. Page: $<55>$

On the basis of the image processing and classification, applied to the northern coats of Crete, the marine bottom types between $10 \mathrm{~m}$ depth has been mapped, including the limit depths of the of the seagrass meadows provided on the basis of the available and collected field data. The classification has been completed using Erdas Imagine software. 


\section{Results}

\subsection{Analysis of spectral signatures}

The distinguishing spectral signatures for various seafloor types (e.g. seagrass species, coral reefs, various types of sand, mud, other sediments, (Fig.4.3) exist in well-defined and narrow $(10-20 \mathrm{~nm})$ wavelength ranges. The values of their spectral reflectance are accepted as constant. The results of spectral measurements enable to analyze, whether P.oceanica is spectrally distinct from other sea floor types with changing environmental conditions, using the differences in their spectral signatures on the graphs in a WASI software. The WASI, a software tool for analyzing and simulating the most common types of spectra [44], is highly suitable for the seagrass spectral analysis. There are several environmental characteristics, included in WASI interface (Fig.5.1), which influence the results of water spectral reflectance, e.g. different bottom depths, concentration of suspended particles in water column, water temperature, sun angle, concentration of Gelbstoff (CDOM), concentration of phytoplankton, aerosol scattering, exponent of backscattering by small particles [43].

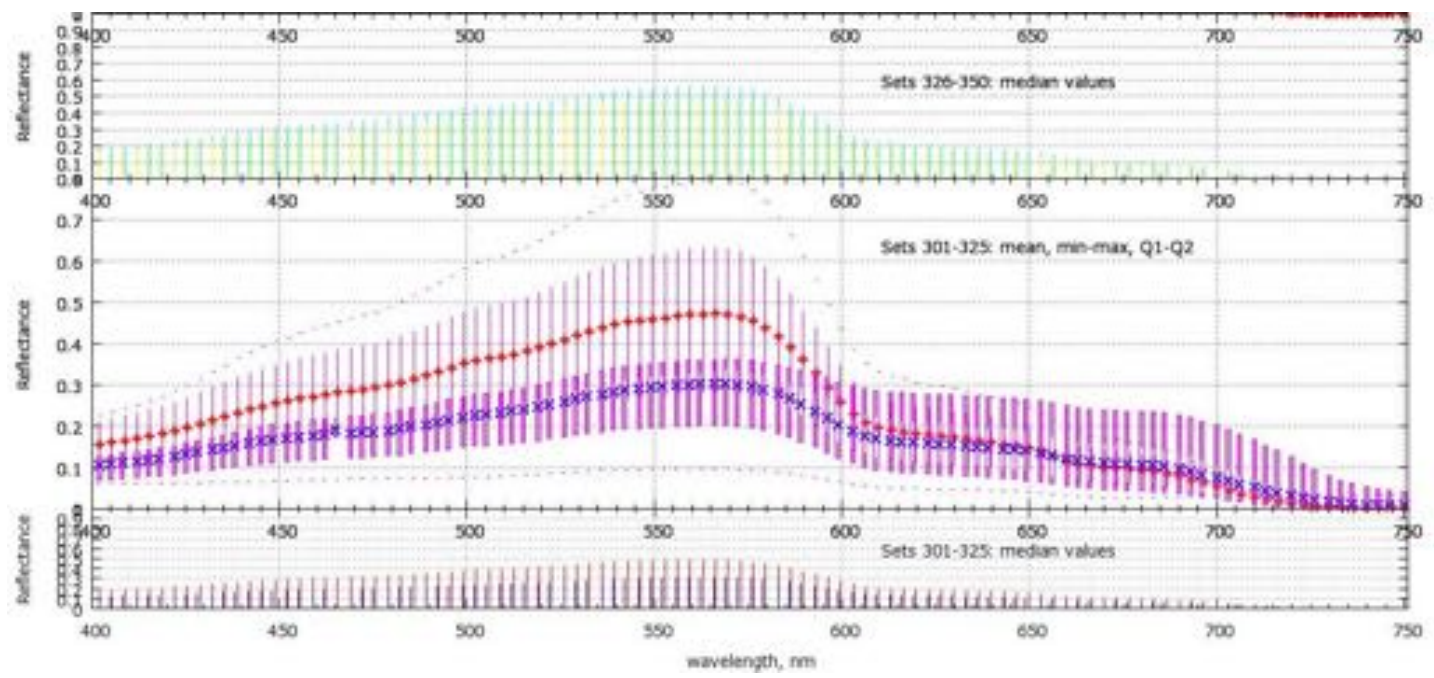

Figure 4.1: Statistical comparison of spectral reflectance of P.oceanica and carbonate sand. Selected measurements sets. Gnuplot graph. Pages: $<31>,<36>,<32>$ 

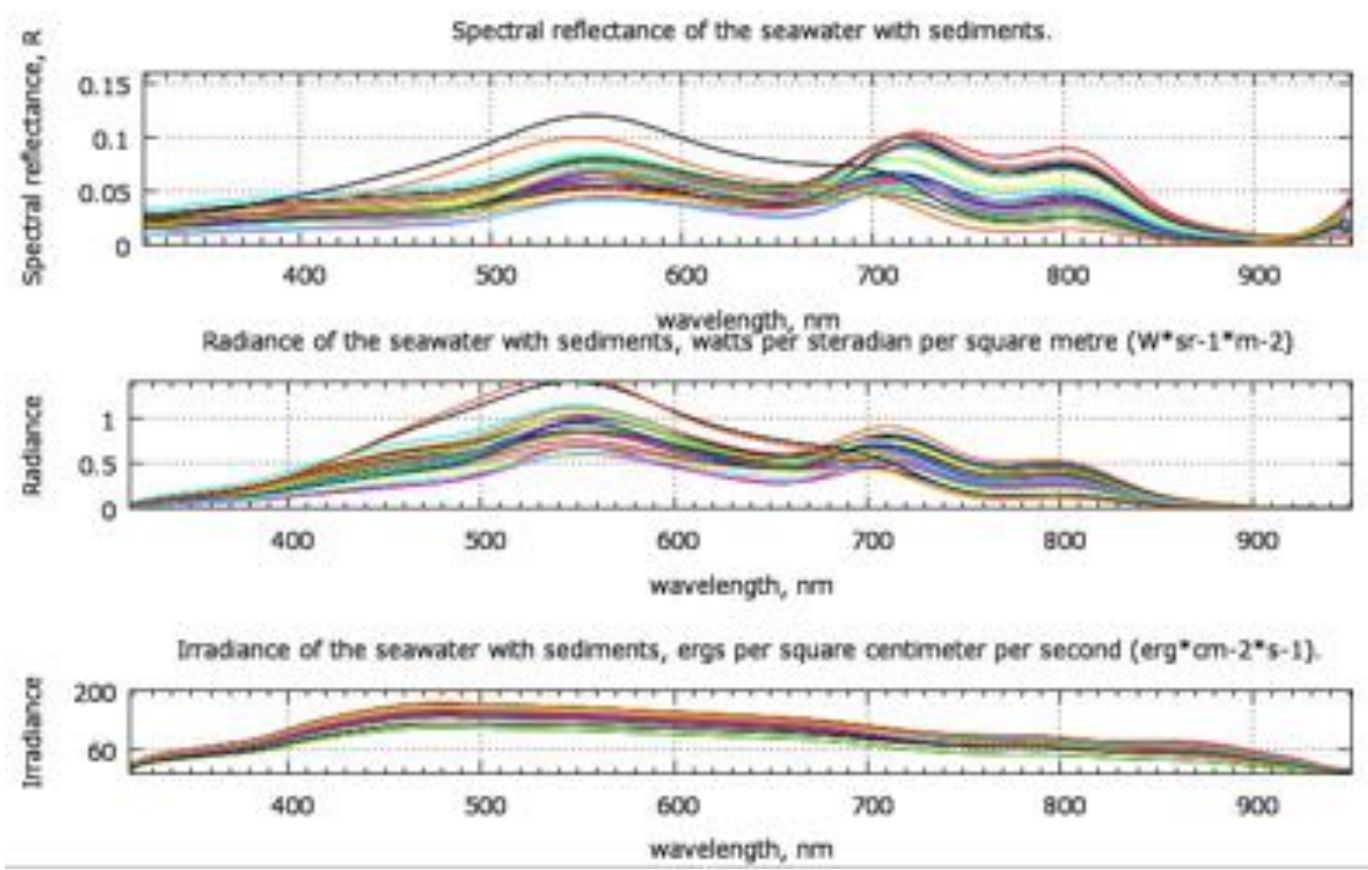

Figure 4.2: Optical properties of the sea water with sediments, measured in aquarium tank. Agia Pelagia district, Crete. Gnuplot. Pages: $<23>,<38>$

The backward-scattering coefficient (bb), also included in WASI, is a fundamental optical property which plays a central role in the ocean-color remote sensing, providing the remotely sensed optical signal, as well as suspended particle distributions, water clarity, and underwater visibility [79]. WASI enables simulation of backscattering of pure water, large and small particles. The values of all these parameters can be redacted and changed manually. However, the most important, major factors affecting the in-situ conditions are water depth (Fig.4.5) and cover fraction of the seafloor types: P.oceanica and carbonate sand. Seagrass P.oceanica can be mapped using remotely acquired spectral imagery, but only if it has distinctive reflectance signatures at different depths. Therefore, the depths of the shelf area are the first variable condition for this research question. The depths values chosen for the current research are lesser than 3.5 meters, covering shelf zone, and providing the best environmental conditions for the seagrass P.oceanica: 0.5, 2.0 and 3.5 meters with an interval of 1.5 meters. The $3.5 \mathrm{~m}$ depth limit was chosen based on the analysis of the separability of seagrass reflectance signatures, received by the means of previous in-situ measurements (year 2009) of the radiance and irradiance of water in Agia Pelagia bay, which indicated that P.oceanica seagrass could be only well separated within depths of $3.5 \mathrm{~m}$. A statistical analysis of WASI-simulated spectral reflectance has been used in order to answer the first research question: whether the P.oceanica spectra is spectrally distinct at varying environmental in-situ conditions, and if P.oceanica remains spectrally distinct with the increasing water column depth. To answer this research question, different seafloor cover types are discriminated using data of the broadband remote sensing. 


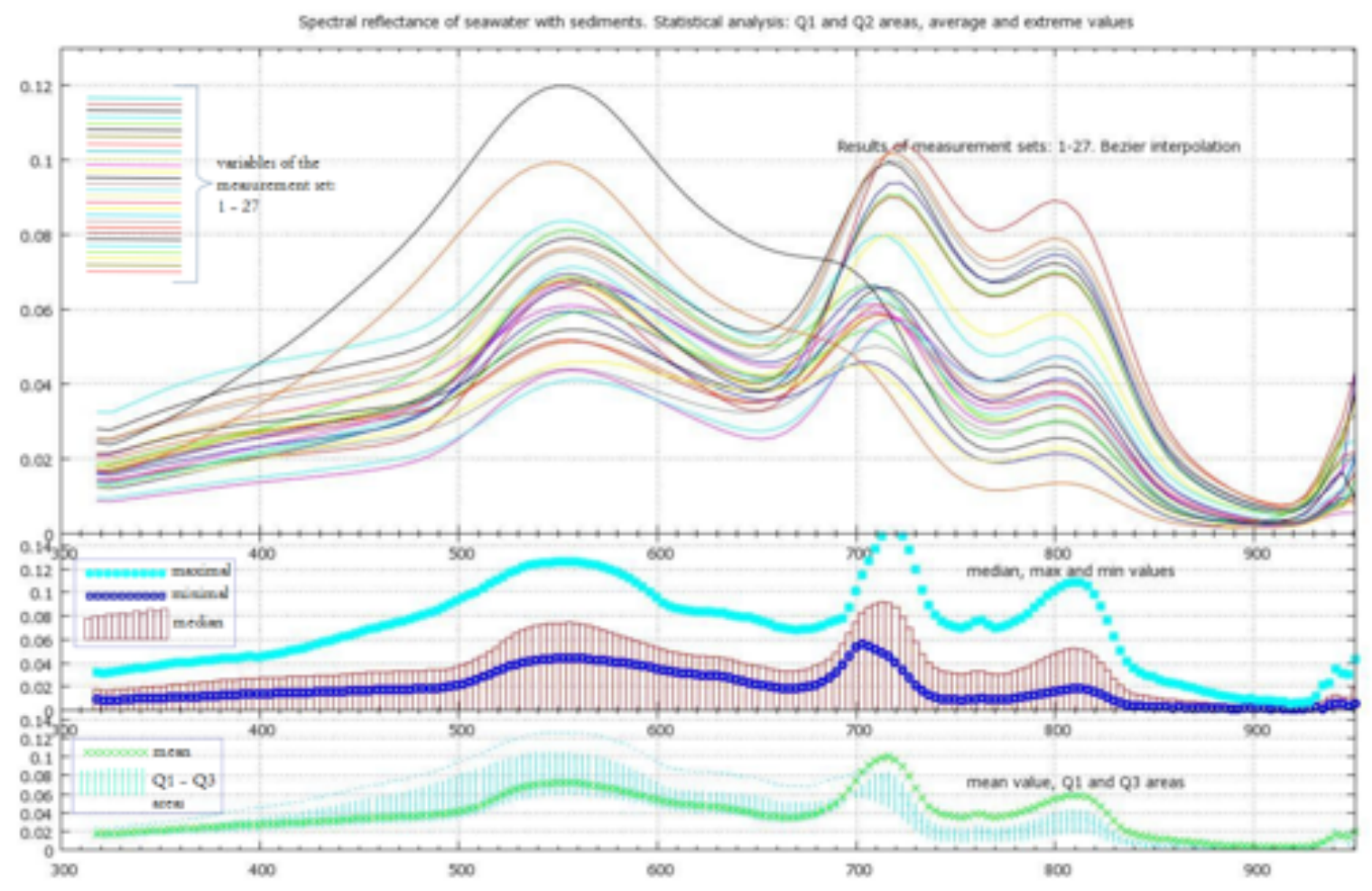

Figure 4.3: Multiplot showing spectral reflectance of the seawater with sediments, measured in aquarium tank, Agia Pelagia district, Crete. Gnuplot. Two complimentary graphs below show the results of the statistical analysis. Pages: $<31>,<32>,<38>$

The results enable to study reflectance properties of the seagrass and other seafloor types. Application of the optical radiative transfer model WASI is suggested to simulate remote sensing sensors (MODIS, ASTER, MERIS and SeaWiFS), (Fig.4.4, Fig.A.34). 
Simulated remote sensing reflectance of $\mathrm{P}$-oceanica at various sensors, iterated over three depehs $\{0.5,1.5$ and 2.5 meters)

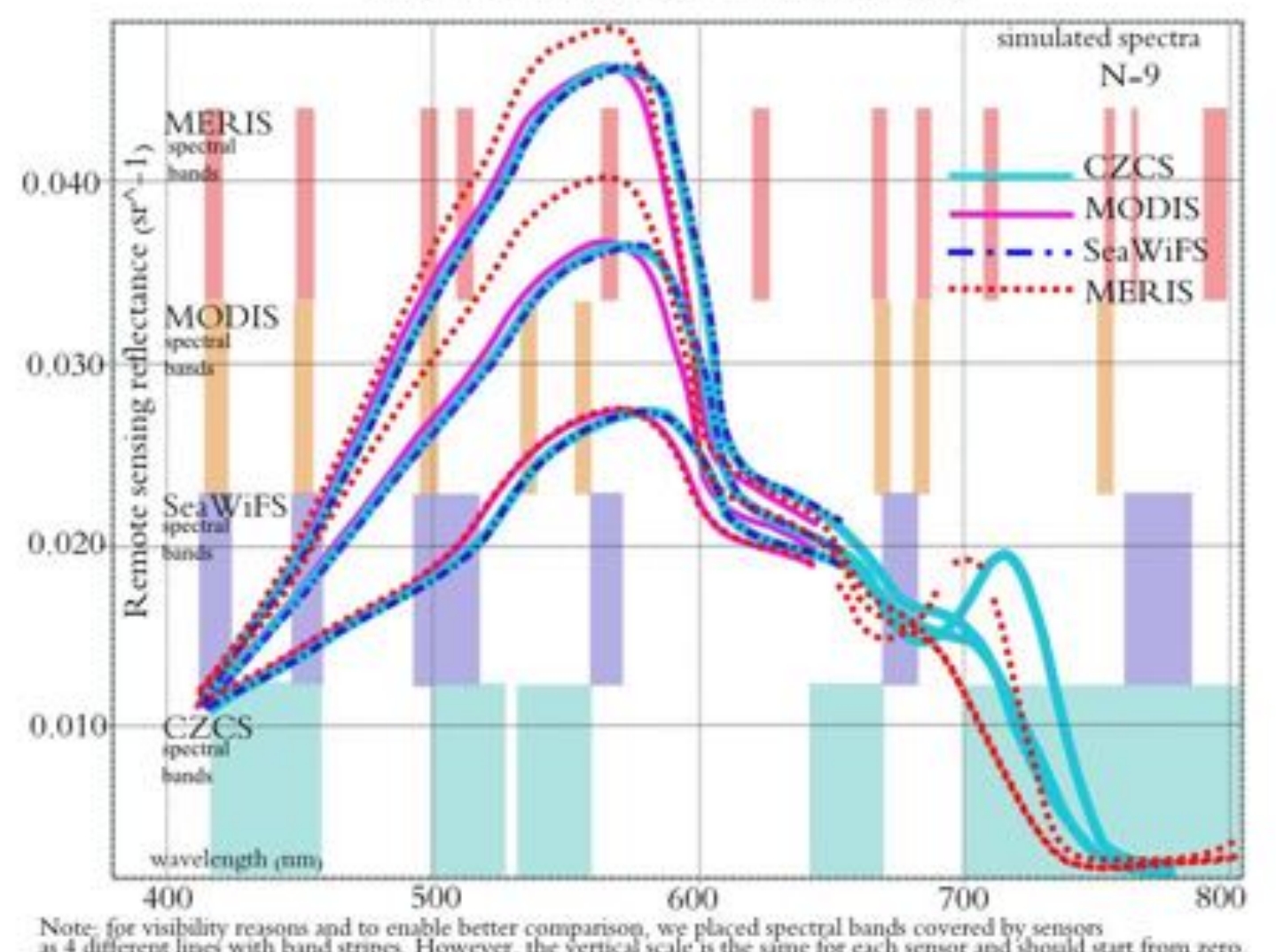

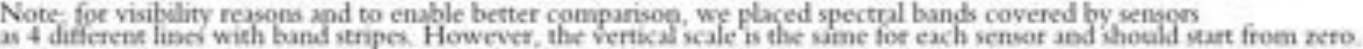

Figure 4.4: Combined plots of simulated remote sensing reflectance of P.oceanica at various sensors: MODIS, MERIS, SeaWiFS and CZCS, iterated over three depths, as stripes shown spectral bands covered by these sensors. Pages: $<23>,<24>,<40>,<50>$

In order to focus on the factors of primary importance, other and less influencing factors are excluded, i.e. sun angle, concentration of the suspected particles in the water column, content of gelbstoff, etc. For these factors default values of WASI are accepted. Under normal conditions by independent water colour sampling, values of the remote-sensing reflectance can vary by $12-24 \%$ [133], and these variations in the radiometric determinations are mainly caused by the variety of the environmental factors. Different factors influence colour and spectral reflectance of water, among which different bottom depths, concentration of suspended particles in water column, water temperature, sun angle, concentration of CDOM, concentration of phytoplankton, aerosol scattering, exponent of backscattering by small particles, cloudiness, viewing geometry and wind speed (which is, however, not the major source of uncertainty). All these environmental components increase the absorption and scattering of light which, in its turn, results in a complex relationship between their concentrations and the radiance of water that finally influence its spectral reflectance. 


\subsection{Spectral discrimination of P.oceanica}

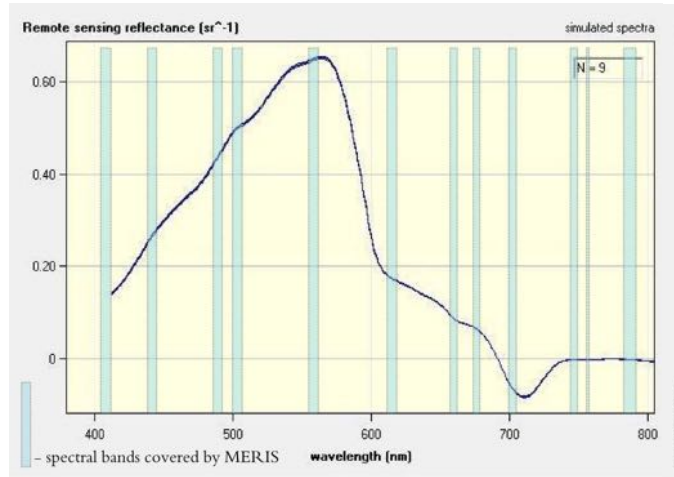

(a) depth of $0.5 \mathrm{~m}$

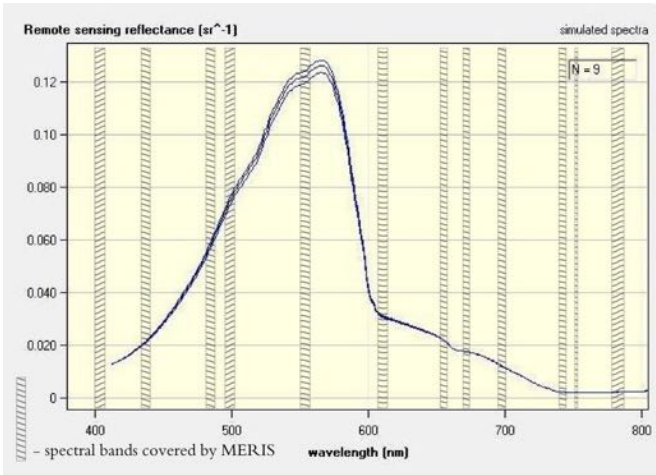

(c) depth of $3.5 \mathrm{~m}$

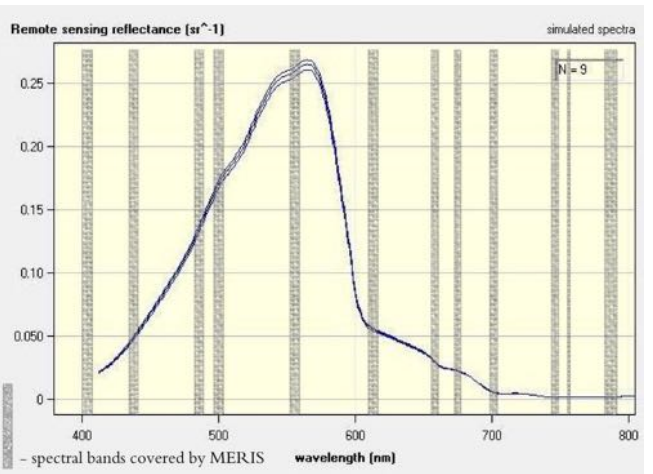

(b) depth of $2.0 \mathrm{~m}$

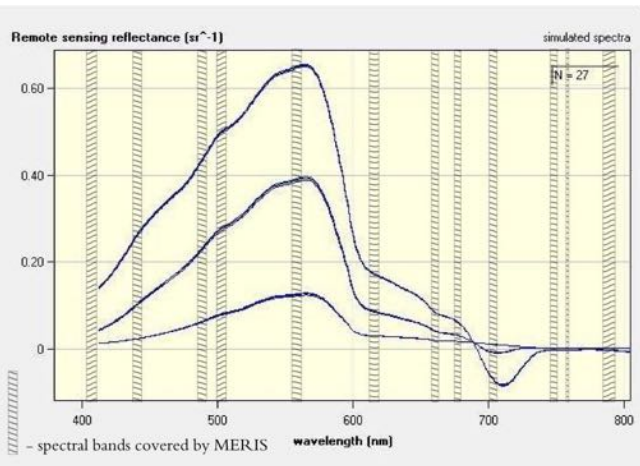

(d) depths of $0.5,2.0$ and $3.5 \mathrm{~m}$

Figure 4.5: Simulated remote sensing reflectance of P.oceanica at various depths. Pages: $<35>,<39>$. Vertical stripes show coverage of spectral bands by MERIS sensor

An analysis of the spectral reflectance of P.oceanica is done using the WASI simulations in order to determine, which wavebands can be still used to identify P.oceanica. The analysis of spectra shows that the appropriate wavebands for seagrass mapping lay between 500 and $600 \mathrm{~nm}$ and has also peaks at around $700 \mathrm{~nm}$, ca between 680 and $710 \mathrm{~nm}$ (Fig.4.6). The highest values of the bottom reflectance are at spectra of 500-600 nm. The most appropriate depths at which the spectral signatures of the seagrass could still be discriminated are lesser than 2.5 meters. The patches of white sandy bottoms of the seafloor, studied in the fieldwork in Ligaria beach, are much brighter than mattes of P.oceanica (Fig.A.11, A.10): seafloor types in Ligaria), which can be clearly seen at the graph comparing values of the spectral reflectance of the carbonate sand (Fig.A.39) and that of P.oceanica (Fig.A.37). 


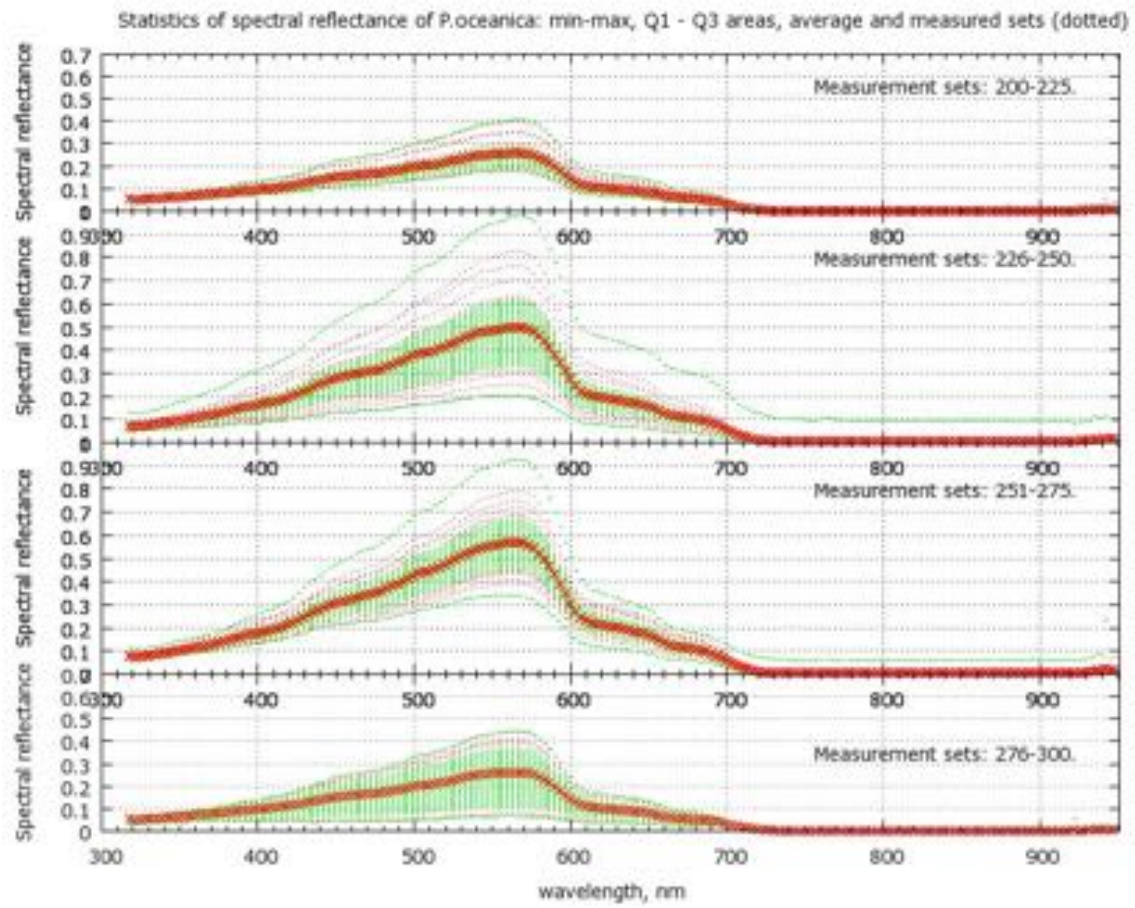

Figure 4.6: Statistical analysis of the spectral reflectance of P.oceanica: min-max, average values (red bold points), Q1-Q3 areas (green vertical dashed) and measured values (dotted): multiplot of measurement sets 200300. Gnuplot. Pages: $<23>,<31>,<35>$

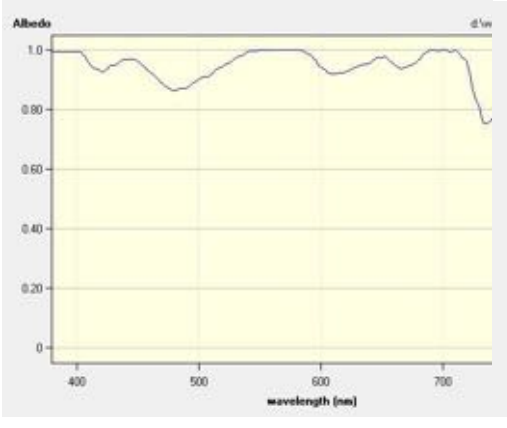

(a) Sand

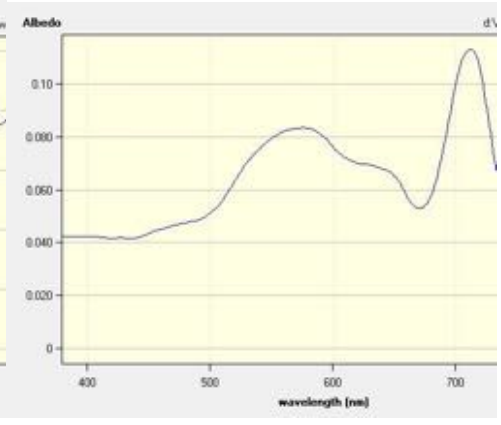

(b) P.oceanica

Figure 4.7: Bottom albedo of carbonate sand and P.oceanica, Agia Pelagia. Page: $<24>$

The graph is received in excel spreadsheet using mean values of spectral reflectance of sand (Fig.4.10) and seagrass (Fig.A.39), respectively, which have been calculated from measurements of radiance and irradiance received in Agia Pelagia bay. 


\subsubsection{Statistical analysis of the observational data and hypothesis testing}

The total amount of measured data was large and included following datasets made using hyperspectral radiometer Ramses: 350 measurement sets of P.oceanica reflectance for 14th Oct (Tab.A.28), 400 sets of P.oceanica reflectance for 15th Oct (Tab.A.11), 84 datasets for seawater reflectance with sediments, 105 datasets for seawater reflectance without sediments, 87 sets for spectral reflectance of carbonate sand. A statistical approach is evidently necessary for the proper processing of such amounts of data. The schematic view of the statistical approach used for the data processing can be seen on Fig. 3.8. Statistical pre-processing of large sets of serial data enables to generalize data by using the most typical and predicted values of spectral reflectance for further calculations, and to get rid of the extreme values, noise and errors. The statistical calculators were mainly made by means of GNU Regression, Econometrics and Time-series Library (GRETL) and SPSS. The Open Office was used for preliminary data view and preprocessing, and included following computations at each data set (for example, Fig.A.26) with summary outcome of mean, median, Q1 and Q3, standard deviation, min and max values (Tab.4.1, Tab.A.11). The statistical pre-processing and analysis were made to display the mean values of spectral reflectance, which were used for comparison with reflectance data of various seafloor cover types as well as seawater with and without sediment (e.g. Fig.A.16). In the statistical analysis of the raw observed data pool of the values of spectral reflectance (about 400 single measurements for P.oceanica, e.g. Tab.A.11), we summarize their complexity by concentrating on some simple numerical characteristics that they possess, i.e. parameters. Examples are the mean and variance of a probability distribution of measurements dataset (for example, Tab.A.5). We divided the total data pool into datasets of 25 measurements for more convenience and ease of use, both for P.oceanica and carbonate sand. The mean of a probability distribution of spectral reflectance describes the average value of the random variable over all of its possible realizations (appendices). Conceptually, there are an infinite number of such realizations, therefore parameters are not known to us. However, in the statistical analysis of the observed data our goal is to estimate these parameters using a finite amount of information available to us: fieldwork observations. Thus, we collected a number of realizations (a sample of 25 measurements for both sand and P.oceanica) and then estimate the statistical parameters (appendices).

Finally we analyzed about 400 datasets totally (example of carbonate sand on Fig.4.9, P.oceanica - on Fig.4.8) made during different days. Since the actual values that measured variables of spectral reflectance take on are not actually known before we observed them, they are random. Thus, we analyzed the statistical distribution of the spectral reflectance values of seafloor cover types using common mathematical formulae, implemented in GRETL software (Tab.A.3). Their probability expresses uncertainty about the possible values of the spectral reflectance of P.oceanica and sand, respectively. There is a distinction to be made between variables whose values are not yet observed (random variables) and those whose values have been observed (observations). Each time we observe the outcome of a random variable of spectral reflectance, we obtain an observation, which is hence no longer random. We applied various methods of statistical analysis towards data pool (some examples of the selected tables are in the appendices: Tab.A.18, Tab.A.25, Tab.A.23, 
Tab.A.24, Tab.A.29), in order to analyze the distribution of values of spectral reflectance of P.oceanica. A probability distribution, a mathematical statement about the possible values that the random observations of spectral reflectance can take on, displays the relative frequency with which each possible value of spectral reflectance is observed. The Least Absolute Deviations (LAD), a popular optimization technique, was used to show the main trend of the distribution of spectral reflectance values along the spectra (Tab.A.4). Non-linear logistic analysis is applied to specify and estimate a model of spectral distribution, in which the dependent variable (i.e. the value of spectral reflectance for each single observation) is not continuous, but discrete and independent for each case (Tab.A.12).

As the observations were made in a repeated way, we also analyzed the data pool using autocorrelation as well: Tab.A.19 and Tab.A.14 for P.oceanica and Tab.A.27 for carbonate sand. The autocorrelation, a crosscorrelation of an observed value with itself, made on two different days (14th and 15th October), shows the similarity between observations as a function of the time separation between them, as can be seen on Fig.A.32, Fig.A.31 and Fig.A.41, it is a useful tool for finding repeating patterns for a single value of observations, such as the presence of a periodic signal which has been buried under noise. The autocorrelation analysis has been performed using both SPSS and GRETL software (Fig.A.27). The method of least squares minimizes the sum of the squares of the errors made in solving every single observation made. We tried different approaches of the least squares methods: Tab.A.15, Tab.A.18, Weighted Least Squares (WLS): Tab.A.26, Ordinary Least Squares (OLS): Fig.A.15

To focus on the relationship between a dependent variable (each single observation of the spectral reflectance) and independent variables (three various depths: $0.5,1.5$ and 2.5 meters) we used the regression analysis, which enables modeling and analyzing values of the spectral reflectance at several depths: Tab.A.6, Tab.A.7, Tab.A.8. The summary of the values of spectral reflectance properties on various depths is presented on the Tab.A.10. The k-means cluster analysis has been used for partitioning observation sets into k clusters (Tab.A.19, Tab.A.20, Tab.A.21, Tab.A.22) in which each observation belongs to the cluster with the nearest mean. It enables to highlight the main areas of the location of values of spectral reflectance along the spectra. To estimate spectral density of optical measurements we used periodogram function (Tab.A.30), which corresponds to the general spectrum of the observations with representation of a variable quantity. Thus, the periodogram (Fig.A.40) of the series of observation highlights so-called dead spots of low power between the frequencies we wish to exclude (can be seen clearly at the end of the graphs, e.g. Fig.A.27) and the frequencies we want to retain (the general profile that lies in the 450-850 nm, Fig.A.29, enlarged part of $500-660 \mathrm{~nm})$.

The visualization of the data plotting was made by means of Gnuplot software, which enables fine drawing and advanced displaying of large amounts of serial data, ultimate control over graph properties, the simplicity of plotting and the ease of scripting (see Fig.4.8, appendices). The graphs illustrating spectral signatures of various seafloor cover types display the mean values and areas of quartiles (Q1 - Q3, Fig.A.38, and shaded Q-Q areas on graph, Fig. 4.6, Fig.4.9), which cover most probable data distribution (spectral reflectance) for each spectral band. In X-axis displayed are the areas of 400-950 nm in spectra, where the measurements were 
done; the y-axis was adjusted for the better visualization of the P.oceanica spectra: as its spectral values are mostly located in the lower part of the spectra (usually no more than $0.20 \mathrm{~nm}$, except for borders), we did not extend the y-scale up to 100 percent, in order to focus on the most necessary area of spectral values (Fig.4.9, Fig.4.3 and appendices). The mean values are highlighted using bold red points, as we used these values for plotting the final graph of P.oceanica spectra in Ligaria beach, Agia Pelagia.
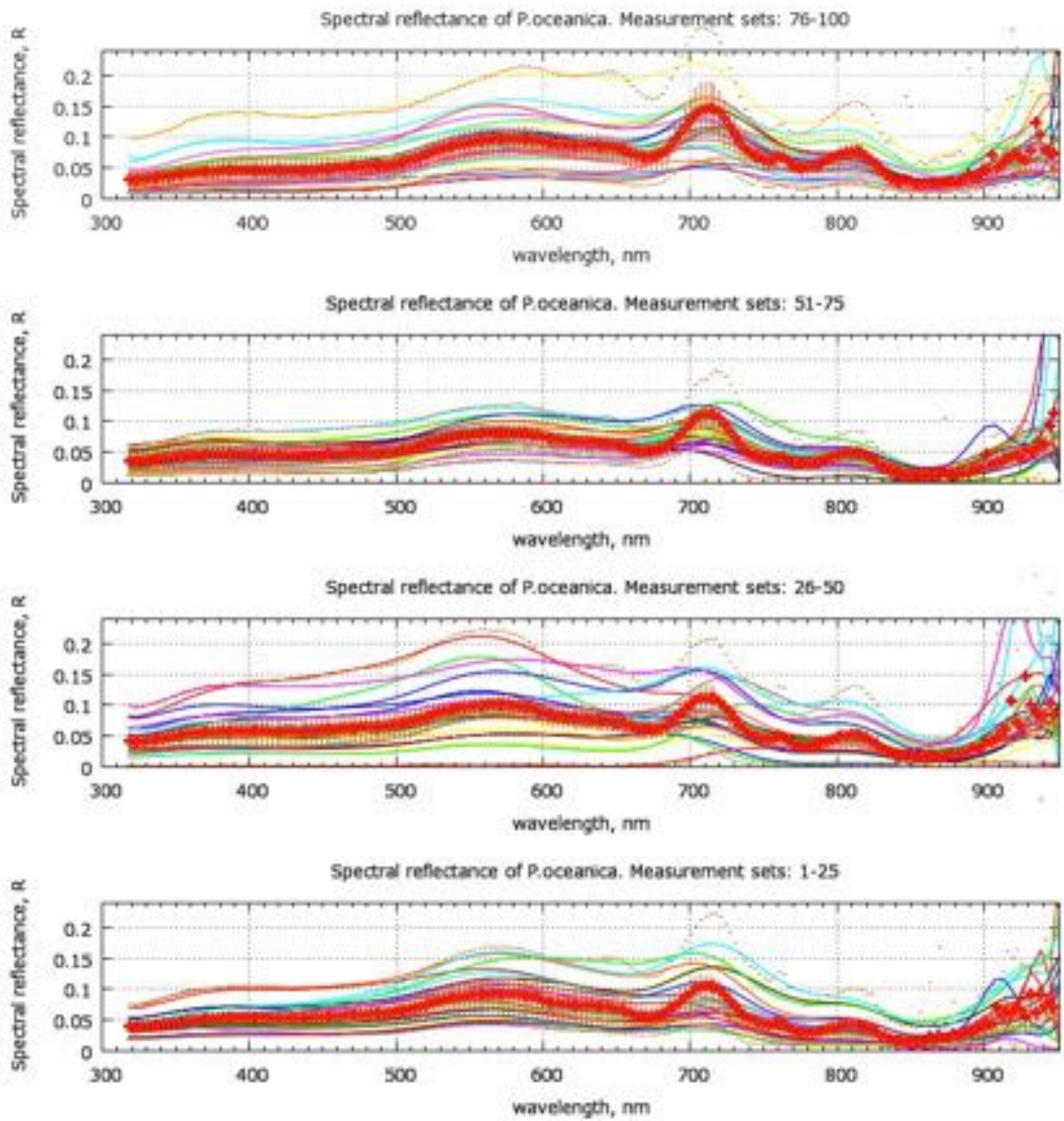

Figure 4.8: Multiplot of spectral reflectance of P.oceanica. Series 1-100. Shown mid-spread of the statistical quartiles Q1 and Q3 (vertical dashes) and mean value within the range (red bold dots). Gnuplot. Pages: $<23>$, $<44>,<50>$ 
A statistical hypothesis test has been applied for the making decision and controlling the wealth of the observational data of the hyperspectral measurements of the water reflectance. The received results are statistically significant if they are unlikely to have occurred by chance alone, according to a pre-determined threshold probability, the significance level. Therefore, we applied critical tests of significance to analyze the measured data according to their significant value. Answering the first research question, we suggest the following statement.
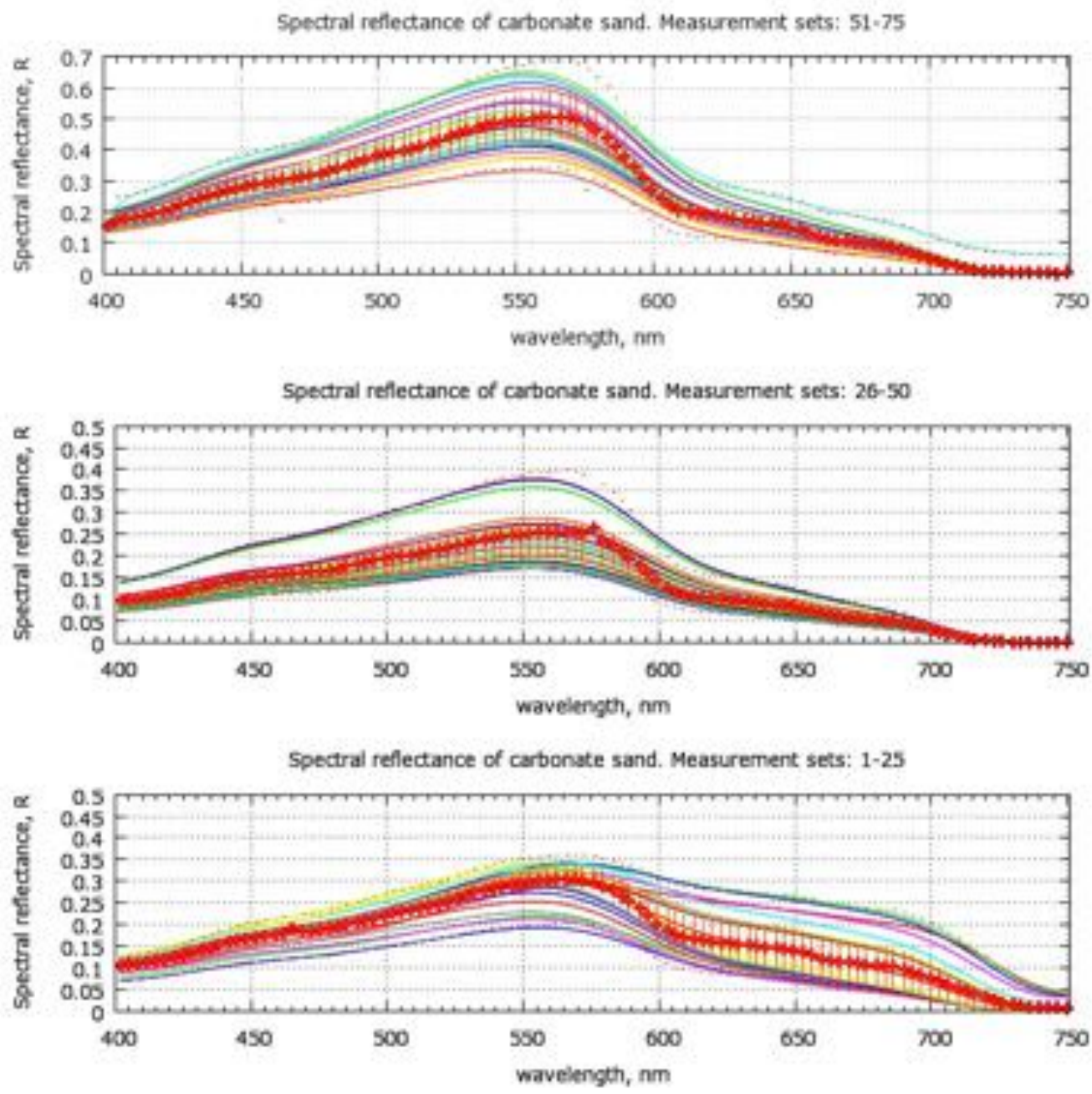

Figure 4.9: Multiplot of spectral reflectance of carbonate sand. Series 1-75. Shown mid spread of the statistical quartiles Q1 and Q3 (vertical dashes) and mean value within the range (red bold dots). Gnuplot. Pages: $<23>$, $<44>$

Answering the first research question, we suggest the following statement. If the Hypothesis $H_{o}$ is true, then the spectral distinguishability of the seagrass P.oceanica from other seafloor types (carbonate sand) is not 
changing with varying in-situ environmental conditions, $H_{o}: \mu 1=\mu 2=\mu 3=\ldots=\mu n$. The alternative Hypothesis $H_{a}$ claims the opposite statement: the spectral discernibility of the seagrass P.oceanica is distinctly changing with varying in-situ conditions, i.e. increasing depth, $H_{o}: \mu 1 \neq \mu 2 \neq \mu 3 \neq \ldots \neq \mu n$. Two statistical approaches have been tested for confirmatory data analysis and hypothesis testing.
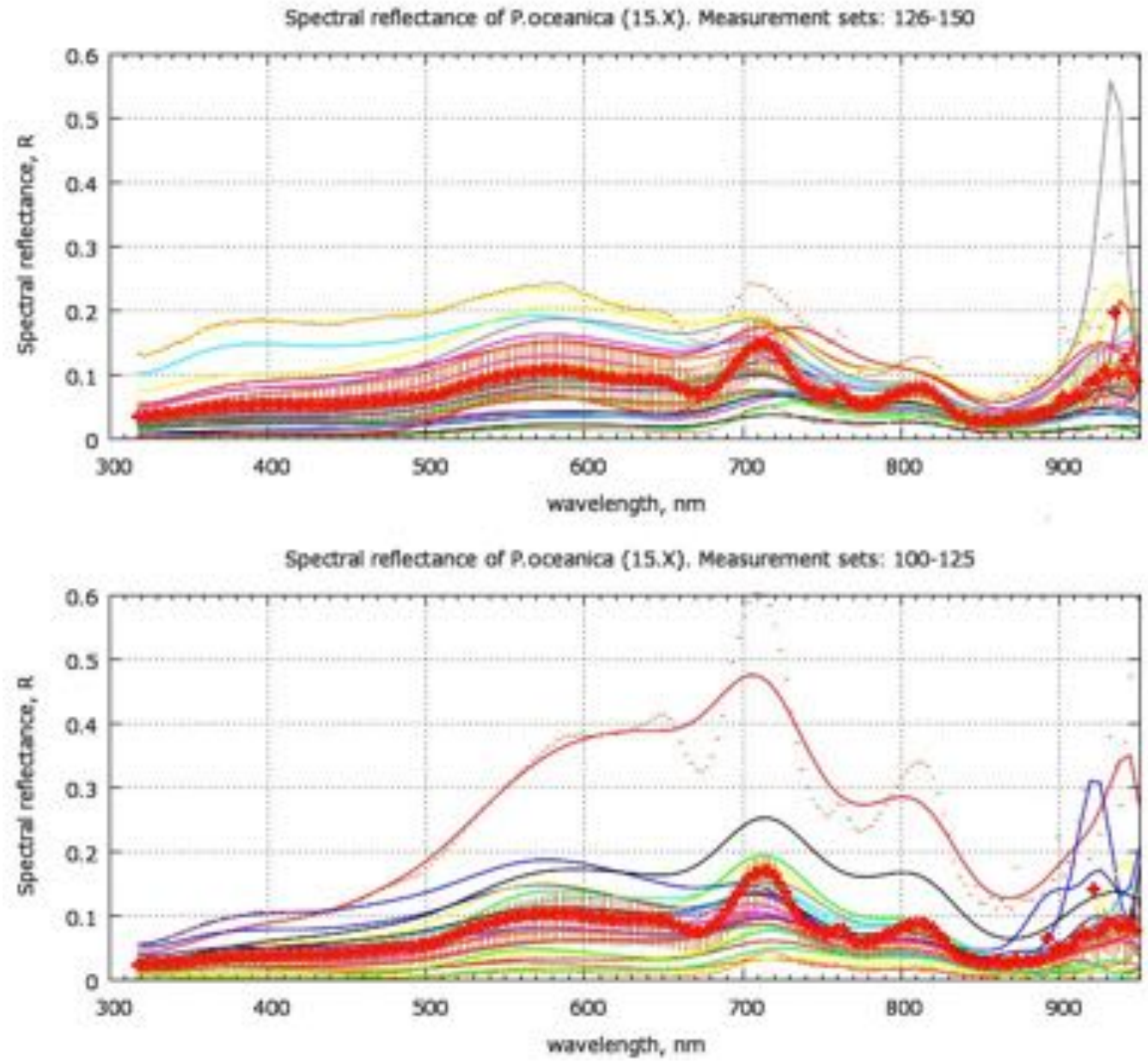

Figure 4.10: Multiplot of spectral reflectance of P.oceanica. Series 126-150. Shown mid-spread of the statistical quartiles Q1 and Q3 (vertical dashes) and mean value within the range (red bold dots). Gnuplot visualization. Pages: $<42>,<50>$

ANOVA-testing We applied ANOVA (ANalysis Of Variance) testing for the analysis of the probability of the spectral reflectance of P.oceanica to be more or less spectrally distinct from other seafloor cover types with changing depth. $\mathrm{W}$ are checking the statement Hypothesis $H_{o}$, is true, which is the spectral distinguishability of the seagrass P.oceanica from other seafloor types is not changing with varying in-situ conditions, $H_{o}: \mu 1=\mu 2=\mu 3=\ldots=\mu n$, which gives the following outcome. $\mathrm{P}\left(\right.$ reject $H_{o} \mid H_{o}$ is valid $)=$ 
$\mathrm{P}(\mathrm{X}>c \mid p=.05)$. where $\mathrm{c}$ comes for critical values and $\mathrm{p}=$ probability. The result $\mathrm{P}=.05$ is (Tab.A.9), hence, very small, which makes the statement of Hypothesis $H_{o}$ highly unlikely (less than 1 in a 10 chance). The one-way ANOVA highlighted a significant difference between data of spectral reflectances of P.oceanica and carbonate sand at different depths, and and proved spectral discernibility of seagrass P.oceanica from carbonate sand (Fig.5.1), i.e. true is the opposite statement: Hypothesis $H_{a}=$ the spectral discernibility of the seagrass P.oceanica is distinctly changing, and seagrass can be spectrally discriminated from carbonate sand with varying in-situ conditions, i.e. increasing depth, $H_{o}: \mu \neq \mu 2 \neq \mu 3 \neq \ldots \neq \mu n$. As a result of the statistical testing, we came to the following conclusion. The Hypothesis $H_{a}$ is true, which claims that the spectral discernibility of the seagrass P.oceanica is distinctly changing and can be discriminated from from other seafloor cover types (carbonate sand) with varying in-situ conditions, i.e. increasing depth, $H_{o}: \mu 1 \neq$ $\mu 2 \neq \mu 3 \neq \ldots \neq \mu$, which positively answers first research question. Statistical results are illustrated with Error bars made using Excel's vertical box and Whisker Charts (Box Plots). The graphs were plotted on the basis of the following statistical data calculated from the sampling measurements data: Tab.A.11, Tab.A.28, TabA.5.

Table 4.1: Statistical analysis of the measurements of spectral reflectance of P.oceanica (fragment). Page: $<44>$

\begin{tabular}{|c|c|c|c|c|}
\hline Statistical values & $\mathbf{3 1 8 . 1 9}$ & $\mathbf{4 1 8 . 3 4 4 8}$ & $\mathbf{5 1 8 . 8 3 6 1}$ & $\mathbf{6 1 9 . 3 6 6 2}$ \\
\hline \hline Mean & 0.034521 & 0.049235 & 0.076088 & 0.085287 \\
\hline St Dev & 0.019849 & 0.030338 & 0.042587 & 0.046569 \\
\hline Median & 0.033035 & 0.046197 & 0.07704 & 0.080277 \\
\hline Q1 & 0.019293 & 0.023706 & 0.045606 & 0.049468 \\
\hline Q3 & 0.042477 & 0.057934 & 0.092289 & 0.114191 \\
\hline Minimum & 0.007898 & 0.010087 & 0.021373 & 0.022691 \\
\hline Maximum & 0.076835 & 0.110906 & 0.18938 & 0.216231 \\
\hline 25th Pct & 0.019293 & 0.023706 & 0.045606 & 0.049468 \\
\hline 50th Pct & 0.013743 & 0.022491 & 0.031435 & 0.030808 \\
\hline 75th Pct & 0.009441 & -0.01174 & -0.01525 & -0.03391 \\
\hline Min & 0.011395 & 0.013618 & 0.024232 & 0.026777 \\
\hline Max & 0.034358 & 0.052972 & 0.097091 & 0.1 \\
\hline
\end{tabular}

The abbreviations stand for the following values: Mean: Average of the data to be plotted, AVERAGE data St Dev: Standard deviation, Standard Deviation (STDEV) data Median: Median of the data, MEDIANdata Calculating interquartile ranges: Q1=First quartile, PERCENTILE(data*0.25) and Q3=Third quartile, PERCENTILE(data*0.75) Minimum: Minimum value,MINdata Maximum: Maximum value, MAXdata 25th Pct: Plotting value of first quartile = Q1 50th Pct: Plotting value of median = Median-Q1 75th Pct: Plotting value of third quartile = Median-Q3 Min: Lower error bar length=Q1 - Minimum Max: Upper error bar length=Maximum - Q3 The statistical analysis is displayed on the Graph 1.1 which compares the spread in 


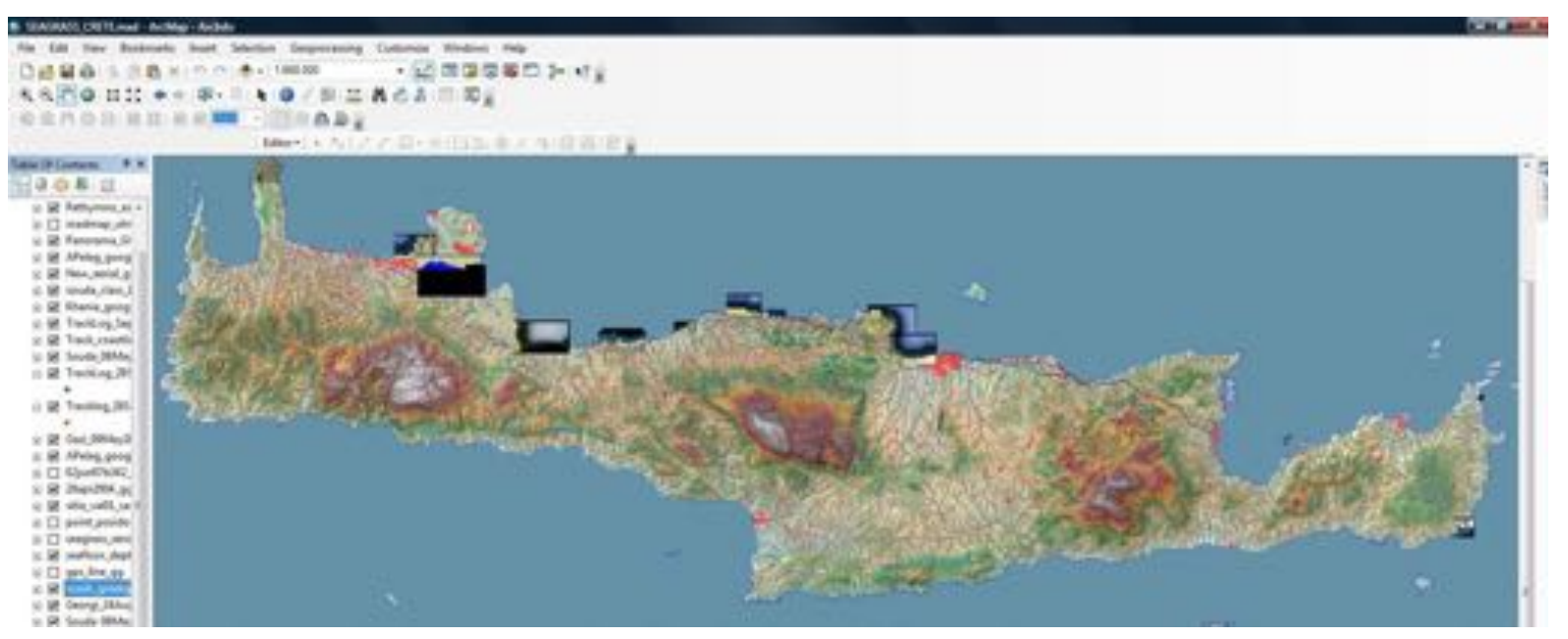

Figure 4.11: Google aerial images incorporated into the GIS project: fragment of ArcGIS layout. Page: $<51>$

sets of measurement data of spectral reflectance of under various environmental conditions (depth).

\subsubsection{Remote sensing application}

The in situ spectral reflectance data of P.oceanica and sand were used to model these seafloor cover types as the different sensors would percept them: MODIS, ASTER, MERIS, SeaWiFS and CZCS.

These sensors vary in technical characteristics and therefore, have different spectral sensitivity, which we briefly illustrated in a small summary table (Tab.2.1) These models simulate spectral views of the chosen sensors, how these sensors will "see" seagrass (Fig.4.1) and sand as pixels, with accepted default atmosphere and water column effects (given by WASI software). In such a way we defined an empirical upper limit to the discriminative potential of these sensors. The analysis of the remote sensing reflectance simulated by these sensors shows that the measured spectra of seagrass P.oceanica (Fig.4.8, Fig.4.10) were statistically different at most of the spectral bands (Fig.A.35, Fig.A.36), with a 95\% confidence level (p value $<0.05$ ). The $\mathrm{F}$ values of the test $(\mathrm{F}=8.477$ as on Tab.A.7) are greater than $\mathrm{F}$ critical value, which is 2.64 at 0.05 confidence level. This proves that broadband and hyperspectral sensors enable spectral discrimination of seagrass, i.e. $H_{o}: \mu 1 \neq \mu 2 \neq \mu 3 \neq \ldots \neq \mu n$. Therefore, we answer the second research question positively, i.e. broadband and hyperspectral sensors (Fig.4.4 and Fig.A.34) provide enough radiometric information for spectral discrimination of seagrass and can therefore be used for mapping of seagrass P.oceanica.

\subsection{GIS mapping of seagrass}

Data integration The integrated approach used in this research work has high potential as a means to monitor changes in seagrass landscape occurring in shallow waters over Crete area.

It encompasses the integration of high resolution aerial color Google Earth photography, spaceborne satel- 
lite imagery, assessment of spectral signatures using WASI software, image processing by means of Erdas Imagine (Fig.A.50, Fig.A.49) and Arc GIS based mapping. The use of GIS for data incorporation (Fig.4.11), storage, analyses, visualizing and mapping enables to analyze environmental changes within seagrass landscapes based on data from various sources: aerial and satellite images, geographically referenced maps of Crete island and results of images classification showing areas of seagrass distribution. The final mapping has been supported in ArcGIS through the data exporting, conversion and integration of various data in one GIS-project (Fig.4.11). Data collected during the fieldwork, imagery of the seagrass distribution are added into a GIS dataset for the assessment and spatial analysis.

Accuracy assessment We prepared the error confusion matrices (Fig.A.32 and Fig.A.33) using К (Kappa) statistics to assess and evaluate accuracy of the classification. The accuracy assessment has been done using Erdas Imaging function Classifier/Accuracy Assessment. In the Accuracy Assessment viewer we have chosen utility Edit in order to generate random points throughout the classified image, and then chosen the Create or add random points dialog. After the points were generated, we entered the class values for the reference points from the supervised classification. In order to perform a proper accuracy assessment we needed about 300 points so that we defined the number of points for the selection. From the option parameters for points distribution we have chosen "stratified random" as better representing the variables. Then we evaluated the location of the points and determined their class value, which was done with ground truth points from Google Earth aerial photos for various data and seafloor imagery and with reference to the signature file, to find the numeric value that has been assigned to each class previously. Finally, to print the errors matrix, we selected Accuracy Assessment viewer again and chosen there Report/ Options with turned on Error Matrix, Kappa Statistics and Accuracy Total. The error matrix is just comparing reference points of various seafloor cover types to the classified points (i.e. seagrass, carbonate sand, various land cover types on the coast). The Kappa coefficient takes into account chance agreement and thus, shows the reduction in errors generated by a classification process compared with the errors which could be received by a completely random classification in other words, it evaluates quality of the classification. The overall map accuracy by supervised classificationis $72 \%$ (Fig.A.33), which means that $72 \%$ of the pixels are classified to the correctly chosen seafloor cover type in case, and in case of unsupervised classification we received result of $64 \%$ (Fig.A.32) which proves that supervised classification is preferable method for seagrass mapping. 


\section{Discussion}

\subsection{Remote sensing for seagrass mapping}

An approach of the seagrass spectral analysis, monitoring and mapping has been taken in this work, which integrates various research techniques and tools, combining remote sensing methods of spectral analysis of the seafloor cover types, and knowledge of the ecology of P.oceanica, with the aim to develop a method of seagrass spectral optical discrimination for the seagrass mapping based on the aerial imagery classification.

In Chapter 1: Introduction we discusses main objective of this MSc thesis, which was to study possibilities of seagrass mapping, based on the application of the remote sensing measurement of the seawater optical properties using hyperspectral radiometers. The relationship between the optical properties (spectral reflectance) of the seafloor cover types and hydrological parameters of the environment has been studied in order to analyse limitations and capabilities of broadband and narrowband sensors under the conditions of altering environmental parameters. For the retrieval of hydrological parameters - seawater radiance, irradiance and spectral reflectance of various seafloor cover types, - spectral optical field measurements were carried out in 2009 at the testing sites in Agia Pelagia, Heraklion and Ligaria beach, Crete Island using Trios-RAMSES spectroradiometers.

Further in Chapter 1: 1.8 Research assumptions, we assume the constant values of the optical properties of the seawater, phytoplankton, total amount of suspended particles and solids, atmospheric conditions, as well as CDOM, which have been set up in modelling part of this work, during WASI simulations of various remote sensors.

The second Chapter 2: Seagrass monitoring: overview of literature and research resources starts from the review of the available research resources and then discusses various Radiative Transfer Models (RTM) for the simulation of water optical properties: a brief review of existing software tools and concludes with reported experience of the remote sensing application towards seagrass mapping: Review of multispectral imagery used for seagrass mapping. In section 2.2 of Chapter 2: Seagrass monitoring: overview of literature and research resources, Measuring optical properties of benthic vegetation: hyperspectral radiometers, Measuring water optical properties: hyperspectral radiometers, the Trios-RAMSES-ACC-UV and Trios-RAMSESARC spectroradiometers of Trios-RAMSES Hyperspectral Sensor series are described.

The instruments Trios-RAMSES have been used during the fieldwork measurements-2009 for the collection of the reflectance spectra. The Trios-RAMSES-ACC-UV measures spectra in the wavelength domain between $280 \mathrm{~nm}$ and 500nm, the Trios-RAMSES-ARC, suitable for UV and visible spectra, covers diapason of 320-950 nm with spectral accuracy of $0.3 \mathrm{~nm}$ (better than 6\%), typical saturation (at 200nm) of $1 \mathrm{Wm}^{-2} * n \mathrm{~m}^{-1} * s r^{-1}$ in 256 channels with a sampling interval of $3.3 \mathrm{~nm} /$ pixel and a Field Of View (FOV) is 7 degrees. The spectral reflectance of the seawater with and without sediments, respectively, was calculated by the ratio of the radiance and irradiance values.

The reflectance spectra of P.oceanica show (Fig.4.6, Fig.A.27, Fig.A.28, Fig.A.35, Fig.A.36) a values maxi- 
mum between $450 \mathrm{~nm}$ and $600 \mathrm{~nm}$, first, because of the chlorophyll absorption peak at 465 and 665nm (Fig. A.4), secondly, because of the weakening of CDOM (or Gelbstoff) in the blue part of the VIS spectrum, as it most strongly absorbs short wavelength light in blue to ultraviolet range, and finally, because the absorption of the seawater increases in the red part of the VIS spectra. The decrease in spectral reflectance values of P.oceanica after $660 \mathrm{~nm}$ (Fig.A.28) is caused by the second absorption peak of phytoplankton. The magnitude of the reflectance maximum slightly varies at single variables between about $8 \%$ and $12 \%$ (as on Fig.A.27) and is probably related to the individual pigmentation and colour composition of single leaves, their structure and geometric orientation, which naturally causes variations in radiance values.

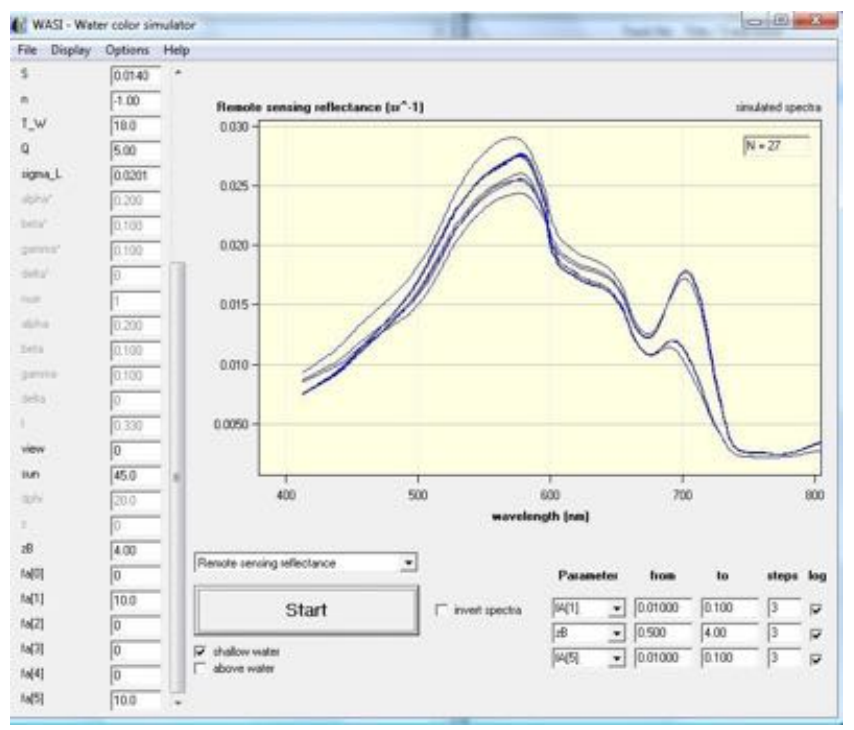

Figure 5.1: Spectral reflectance of P.oceanica and carbonate sand at different depths of 0.5-4.0m.

Modelled by WASI water color spectral simulation. Pages: $<34>,<38>,<31>,<49>$

The ecological variables, specific to the field environmental conditions, were factored into the WASI-based simulation models. Through the WASI simulation process, imitating spectral properties of P.oceanica and carbonate sand for various broadband and narrowband sensors, models were created that accounted for not only atmospheric conditions (i.e. sun zenith angle), but also height of water column, thus approaching it to the Mediterranean conditions, and chemical content of the seawater (i.e. amount of suspended particles, Gelbstoff, etc), which results in models of optical properties of "seawater with sediments" and "seawater without sediments".

The in-situ field large-scale matte-level level of seafloor monitoring was then upscaled to airborne Google Earth aerial imagery interpretation, to provide a meadow-level view of seagrass landscapes. An attempt of the small-scale mapping is designed on an example of Landsat satellite imagery. However, in upscaling to this third, small-scale mapping level further environmental variables need to be considered: health conditions of the seagrass, presence of other underwater vegetation (e.g. other seagrass species), hydrological 
specifications (e.g. direction and speed of currents, amplitude of tidal waves, etc), season, date and times of the image taken. Therefore, we focused on the first two levels in the current work. These different scale levels have been individually considered in terms of the seagrass spectral discernibility for monitoring and mapping, and have been brought together, to provide a roundup of the achieved results and an overview of what still has to be done in P.oceanica seagrass mapping by future researchers (see Recommendations).

In Chapter 3: Materials and methods, describing data collection, a videographic approach tested in previous works, has been applied during the summer fieldwork, when we captured imagery and video footage of the seafloor on several routes of the boat in the Ligaria beach.

The finding of Chapter 4, Results showed that the relationship between the spectral reflectance of various seafloor cover types was tied to depth, i.e. water column height. Thus, the results of the in-situ fieldwork measurements revealed that spectral reflectance of P.oceanica undergo alterations at depths of 0.5, 2.0 and 3.5m (Fig.4.5). The analysis of the spectral signatures of the seagrass P.oceanica and sand clearly shows (Fig.A.17) that seagrass has spectral reflectance much lesser than that of a carbonate sand, in general not increasing values of $10 \%$ reflectance in spectra of 500-600 nm, while sand has spectral reflectance approaching $33 \%$ in its highest values. These results indicate that seagrass P.oceanica can in general be detected and discriminated from other seafloor cover types (carbonate sand) with varying environmental conditions, i.e. water column height, by hyperspectral spectroradiometers (Trios-RAMSES), which positively answers the first research question of this thesis ("Is P.oceanica spectrally distinct from carbonate sand with varying in-situ conditions ?"). Further in Chapter 4, Results, studies of the broadband and narrowband sensors demonstrate that simulated spectra of the seagrass, made using WASI modeller, have the best results at CZCS scanner, especially devoted to the measurement of ocean color. The spectrum of P.oceanica reflectance, simulated for CZCS, covers the wavelength interval of $400-800 \mathrm{~nm}$, and is distinctive for various depths. Other remote sensors (MODIS, SeaWiFS) may also be used for the seagrass mapping, because their technical characteristics enable to spectrally discriminate P.oceanica seagrass from other seafloor cover types (Fig.4.4), particularly carbonate sand as tested in the current work. Therefore, the second research question of this MSc thesis ("Do broadband and hyperspectral sensors provide enough radiometric information for spectral discrimination of seagrass, and therefore, can be used for mapping of P.oceanica ?") is answered with "yes", and the most suitable sensor is the Coastal Zone Color Scanner CZCS.

The graphs showing optical properties of seawater with and without sediments (Fig.4.3, Fig.A.17, Fig.4.2) focused on spectral variability of the water with changed physical and chemical content. The alterations in the individual spectral signatures of single measurements (e.g. on Fig.4.8, Fig.A.35, Fig.4.10, Fig.A.37) reflect individual health properties of leaves: different nitrogen and chlorophyll content causing diverse colour pigmentation and light absorption, water content in leaves and plant physiological conditions, which vary across seagrass meadow, shoot morphology, etc. The differences in spectral reflectance values of the measurements taken on various days might have been caused by the impact of atmospheric conditions, such as solar radiation and sun illumination by different zenith angle. 
For further development of the remote sensing based monitoring and mapping of the seagrass and other seafloor cover types it is desirable to consider upscale mapping with concern to bathymetry. Studies of the substratum and underwater relief in a more detailed way, i.e. bathymetric properties of the testing sizes, gives information about seagrass landscape distribution, because changes in relief directly cause and reinforce the colonisation process of P.oceanica meadows. Thus, the depression and valleys in relief in general stimulate increase of the sedimentation process. In turn, it enables accumulation of necessary nutrient for seagrass plant growth, increases resource allocation to the seagrass roots for better exploitation of porewater nutrients by the P.oceanica shoots. As for patchiness in seagrass landscapes, besides natural reasons, the anthropogenic disturbances (e.g. ocean trawling) still remain a main cause for landscapes fragmentation.

\subsection{Upscale mapping of the seagrass landscapes}

Although ocean pelagic landscapes have a high degree of spatial variance and less structurally complex, comparing to the terrestrial ones, the landscape-level phenomena have similar features, and there are accepted definitions of landscapes elements within the seagrass meadows [124]. In general, the structure of seagrass landscape is simpler than that of the terrestrial ecosystems in biodiversity and complexity; however, seagrass landscapes show variation in spatial patterns over different special scales (Fig.5.2). The complexity of the landscape of seagrass meadow is shown by the measure of patches in size and shape, expressed in ratio of patch perimeter to area. The fragmentation of the seagrass landscapes is expressed in contiguity displaying patch aggregation within meadows.

The general principles of the hierarchy within the seagrass landscapes are based upon the quantitative analysis of the spatial patterns, consisted by components and separate elements. Thus, bunches of individual shoots construct patches, the first hierarchical level. Patches are arranged into discrete clumps of mattes (at a scale of centimeters to meters) which, in turn, make up beds with 1-100m in diameter. Finally, seagrass beds are arranged into meadows that may extend over kilometer-wide areas, historically defined as landscapes [124].

Besides spatial structure of the seagrass meadows, there are strong and complex patterns of depth zoning, specific to individual seagrass species, but such detailed classification goes beyond the scope of the current study. Unique feature of seagrass meadows, most characteristic for shallow areas, is dynamics of their landscapes. Homogeneous, continuous seagrass meadows can reach in size up to $40 m^{2}$ (Fig.3.10 a), however they are often interrupted by gaps and channels of open spaces generated by the complex, disturbing sedimentation processes, turbulence and turbidity regime of waters and landscape dynamics, which form gaps and channels within meadows, making them patchy-looking, i.e. diversified by separate mattes (Fig.3.10 b). The traditional definition for gap in vegetation cover is disturbance generated openings in either floral or faunal cover [24]. Formation and increase of these gaps within the mosaic of seagrass meadows is caused by

different reasons. The most probable drivers for the process of gaps formation within seagrass meadows are removal of interior vegetation, differential growth of seagrass meadows and increased sedimentation. Thus, 


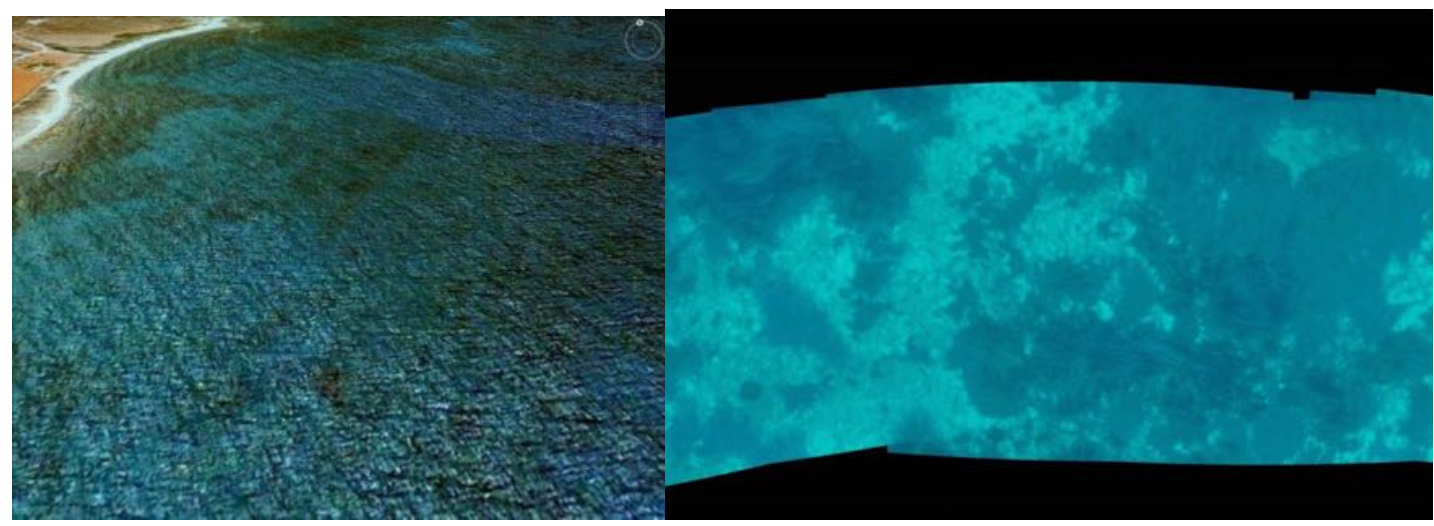

(a) Meadows of the seagrass. Source: Google

(b) Patches (mattes) of the seagrass. Source: in-situ Earth videometric measurements

Figure 5.2: Variations in spatial structure of the seagrass landscapes. Page: $<55>$

storms lead to severe deposition of sediments, burying parts of seagrass meadow, the same effect has movements and deposition of sediments during and after floods[9]. Increased nutrient sedimentation, especially phosphorus, were explored [63] as a potential mechanism for increasing patch dynamics and morphological plasticity within seagrass meadows. Finally, increasing the degree of fragmentation of the landscapes of P.oceanica meadows can be caused by the invasion of alien species, such as Cymodocea nodosa, Caulerpa prolifera, Caulerpa taxifolia. Invaders are in general strong colonizers comparing to native P.oceanica: they occupy much greater habitat space within the regressed meadows of stressed native seagrass [97]. However, on the northern coasts of Crete the only dominating seagrass species is P.oceanica. Morphological differences in scale of seagrass landscape formations, discussed above, cause need for the different-scale mapping. Therefore, the investigation of the seagrass meadows at different levels is performed using underwater videometric measurements, aerial and satellite imagery. 


\section{Conclusion}

The goal of this MSc research was to explore the perspectives, advantages and limitations of the narrowband and broadband sensors for the environmental mapping and monitoring of P.oceanica seagrass along the coasts of Crete Island. The research outcome demonstrated that the application of the remote sensing data from the broadband sensors is highly advantageous for the seagrass mapping, the spectral discrimination of P.oceanica from other seafloor cover types is possible at diverse and changing environmental conditions, and that P.oceanica is spectrally distinct from other seagrass species as well (Thalassia testudinum), Fig.2.6.

The RTM software is a powerful means for analyzing spectral signatures of various seafloor types and enabling simulations of data received from broadband and narrowband remote sensors.

The example of application of WASI RTM, given in this work, is an achievement of the research insight towards the spectral properties of P.oceanica and other bottom cover types, enabling to discriminate them from each other with changing environmental conditions. The research shows that spectral signatures of P.oceanica are distinct at various depths.

The methodology of the spectral discrimination of seafloor cover types is designed in the frame of this research and is based on the application of the remote sensing RTM techniques, data from broadband sensors, hyperspectral radiometers for measurements of optical properties of the seawater, categorical and continuous statistical analysis for the data processing and GIS raster based software for images visualization, classification and analysis. Technically, we used different software, adjusted for diverse research purposes, to manage, integrate and process data from various origin and resources, and finally to receive accurate research results. The marine coastal ecosystems are complex, constantly changing and developing. Using flexibility of GIS combined with remote sensing methods and application of data from broadband sensors is therefore advantageous for the monitoring of coastal areas. Besides Mediterranean area, the methodology of the seagrass environmental studies can be applied towards other shelf areas with dominating seagrass landscapes.

More than $50 \%$ of the world population lives within one $\mathrm{km}$ of the coast, which results in continued anthropogenic pressure on the coastal regions. Therefore, management of coastal resources and shelf zone protection become increasingly important nowadays, and require large-scale monitoring and mapping of the shelf areas as a vital instrument for the environmental assessment.

This research is a contribution to the development of the methodology of seagrass mapping with the aim of the environmental monitoring, and a case study of P.oceanica, an endemic Mediterranean seagrass species, dominating in underwater landscapes and ecosystems along the coasts of Crete Island. 


\section{Recommendations}

To make further studies of P.oceanica more effective we would suggest the following recommendations to be considered by the future researchers:

First: To extend the research area towards the eastern part of the Crete Island, in order to received more regular observations of the seagrass locations.

Second: To use different sources of imagery and thus, to increase the total collection of scenes covering the research area.

Third: To extend the temporal period of the imagery coverage, once the data are available. The current work only includes images covering short temporal period (ca 10-year); further estimation of the dynamics of P.oceanica along the coasts of Crete would increase our understanding of the long-scale temporal variations of the seagrass distribution.

Fourth: To apply various classifications methods for the available imagery in order to compare the results received by means of various techniques

Fifth: To simulate various environmental conditions while modelling optical properties of different seafloor cover types. Not only the depths and the chemical content of the seawater should be considered, but also other factors determining the effect of the ecology and health of P.oceanica.

Sixth: To consider seafloor geomorphology among other factors determining seagrass distribution. If possible, to find out bathymetric data for the research area, and to overlay them with existing images and maps, in order to analyse correlation between spatial distribution of seagrass P.oceanica and underwater relief along Cretan coasts.

Seventh: In upscaling to the small-scale mapping level further environmental variables need to be considered: health conditions of the seagrass (usually, indicated by the number of leaves per shoot), presence of other underwater vegetation, hydrology (e.g. direction and speed of currents, amplitude of tides and waves), season, date and times of the image taken.

Eighth: Other RTM software may be tested and the modelling outcomes compared.

Ninth Application of various open source GIS (ILWIS, GRASS) could be very useful for the validation of the cartographic results, assessment of accuracy and comparison of various classification methods.

Tenth: The analysis of the health indicators of the seagrass (such as number of leaves per shoot, biomass estimation within the single shot, etc) was not considered in the current work, as it would go beyond the scope of the MSc thesis. However, ecological investigations could be used for the assessment of the vulnerability of the seagrass meadows in various locations on Crete.

Eleventh: A flexible combination of the multi-scale mapping and results of the fieldwork measurements with GPS-referenced underwater footage would enable more profound analysis of the coastal environment on Crete. 


\section{Appendices}

\section{A appendices}

\section{A.1 Capturing aerial imagery from the Google Earth}

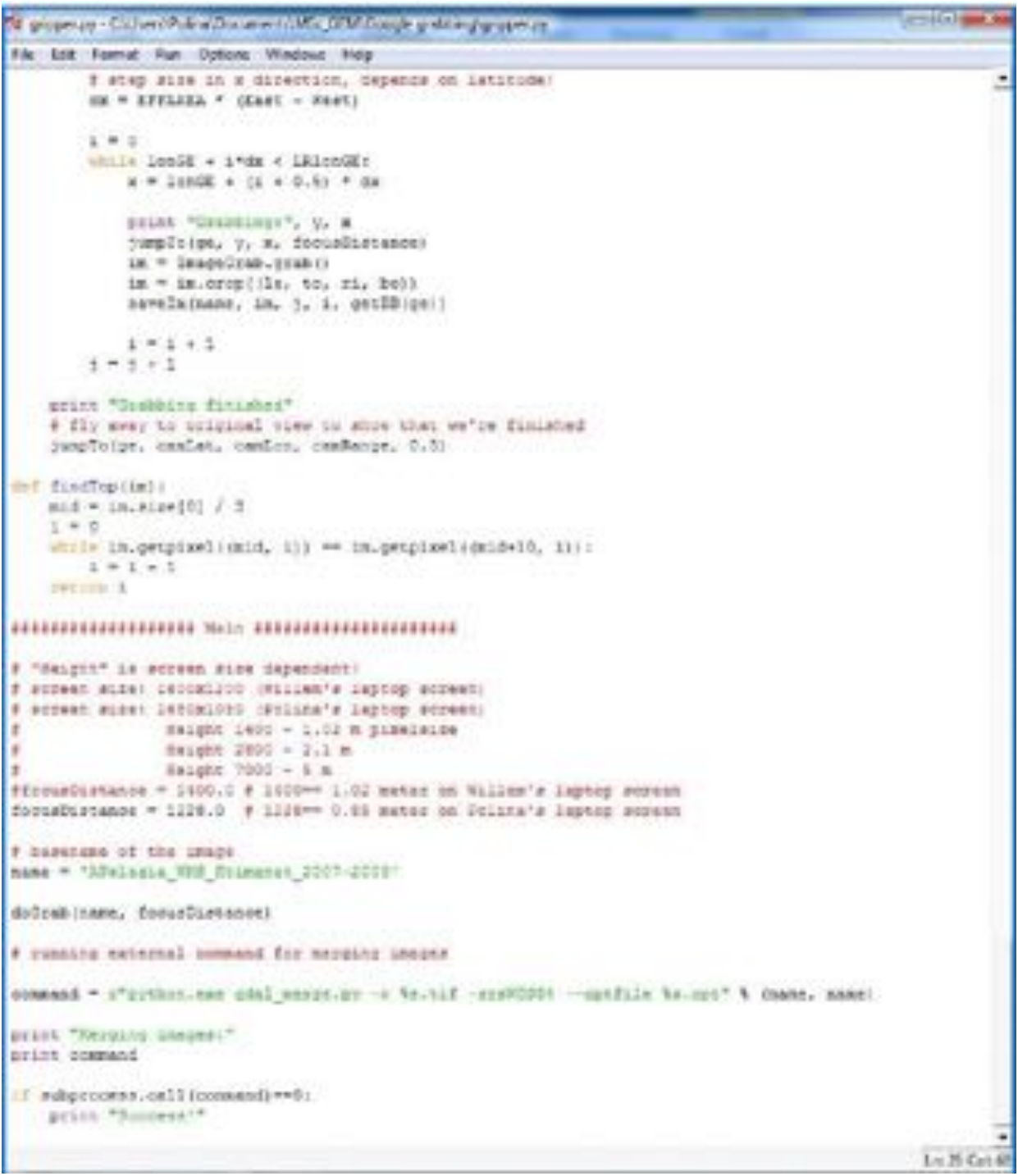

Figure A.1: Capturing aerial imagery from the Google Earth: grabbing process. Page: $<36>$ 


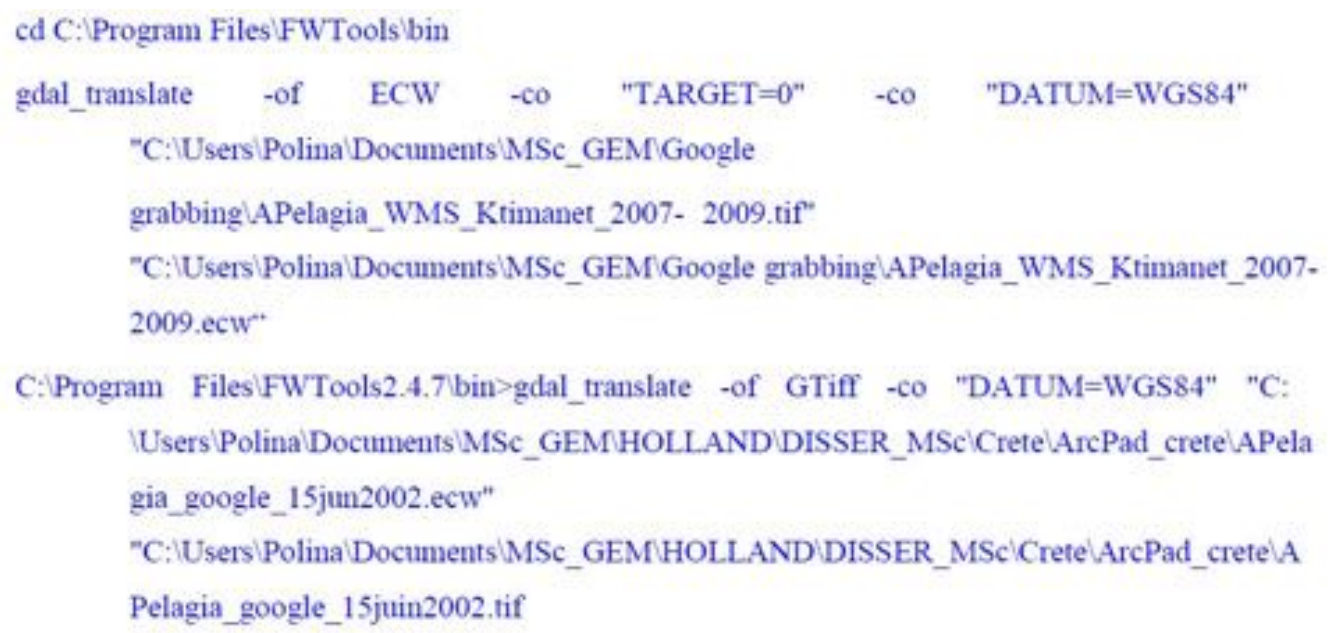

Figure A.2: Script command of FWTools enabling to reduce the size of the aerial images, from .tif to .ecw format. Page: $<36>$

\section{A.2 Illustrations of remote sensing principles used for seagrass monitoring}

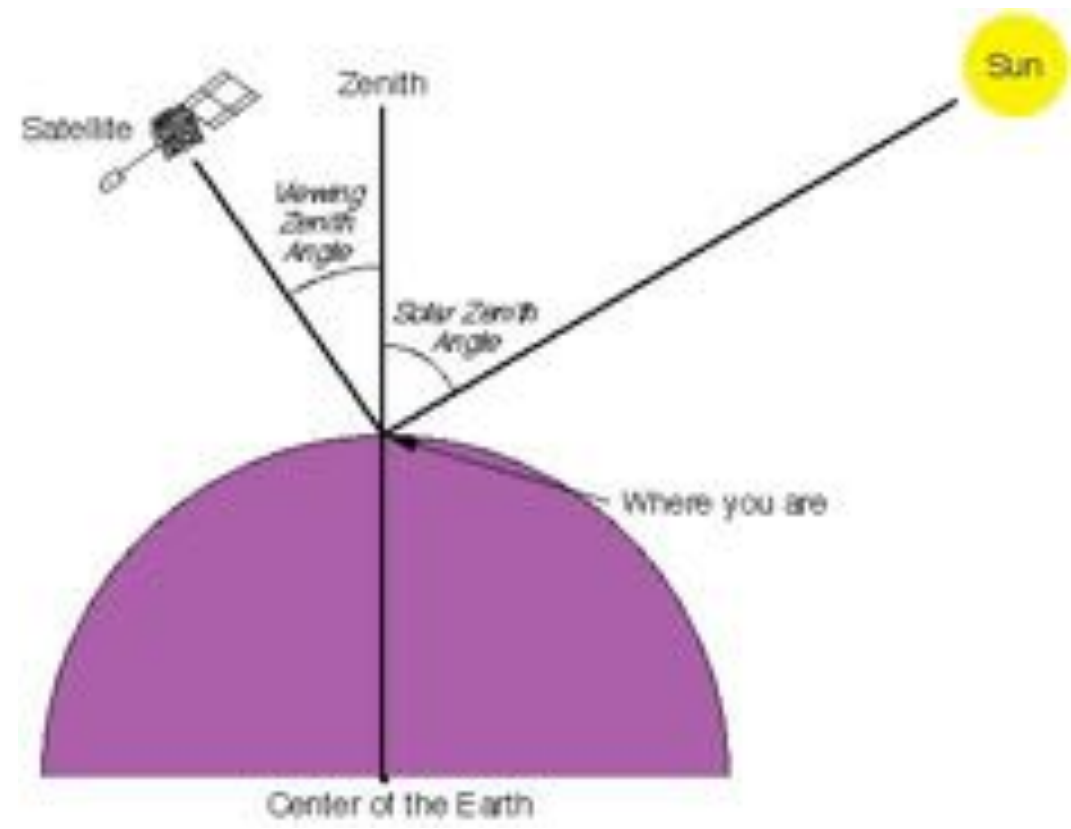

Figure A.3: Schematic illustration of the solar zenith angle and viewing zenith angle for observations from satellite-based instrument. Source: Support to Aviation Control Service (SACS). Page: $<10>$ 


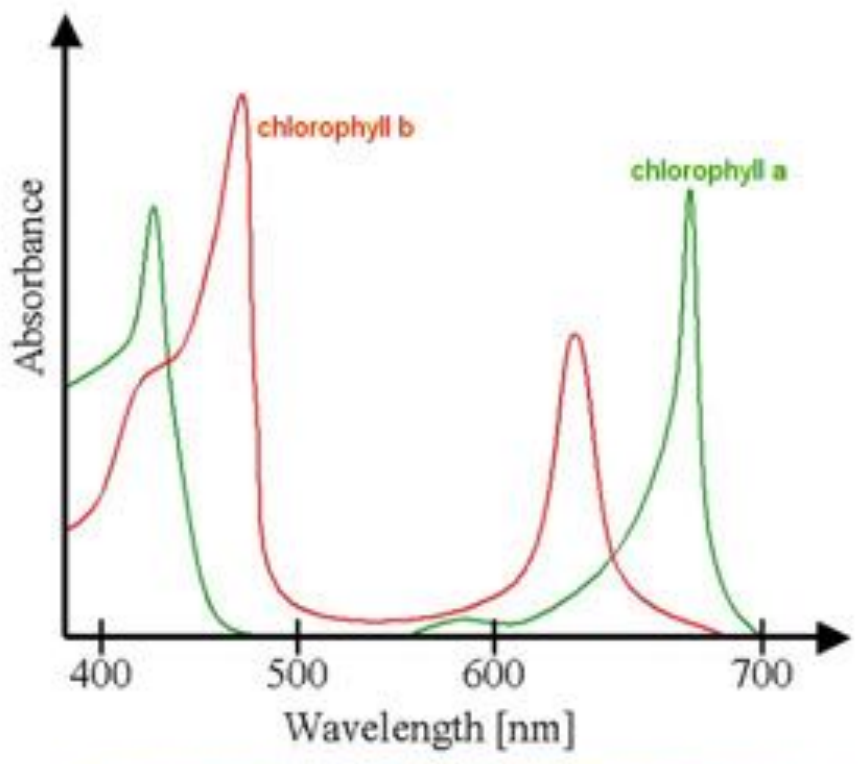

Figure A.4: Absorbance spectra of free chlorophyll a (green) and b (red) in a solvent. The spectra of chlorophyll molecules are slightly modified in vivo depending on specific pigment-protein interactions.

Source: Wikipedia.org. Page: $<53>$

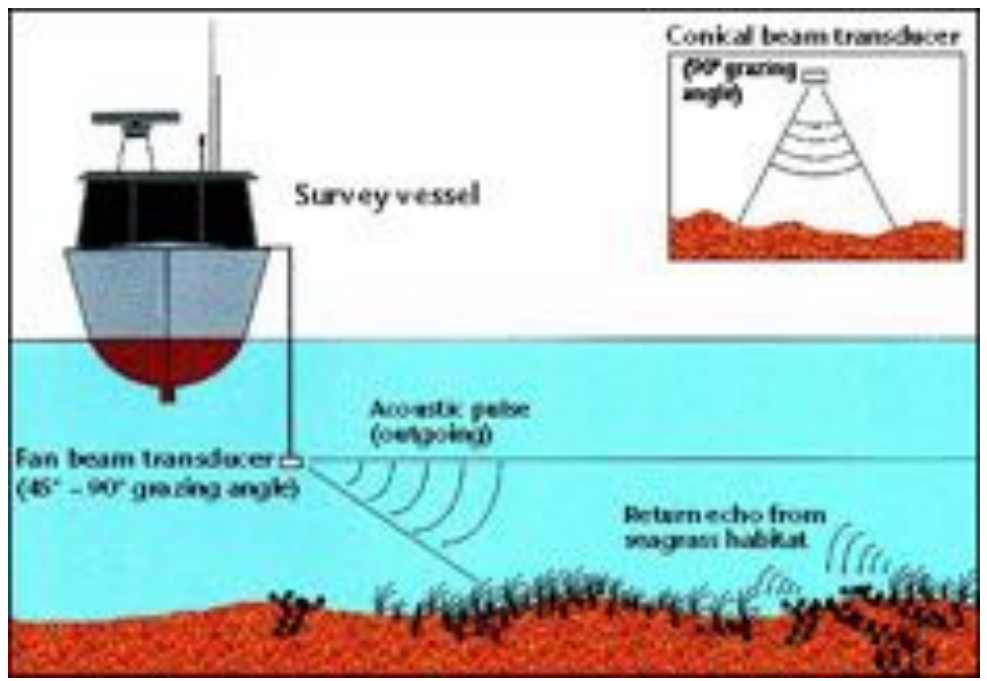

Figure A.5: Example of sonar beam acoustic systems used for mapping seagrasses habitat boundaries. Source: Reef Research. Page: $<17>$ 


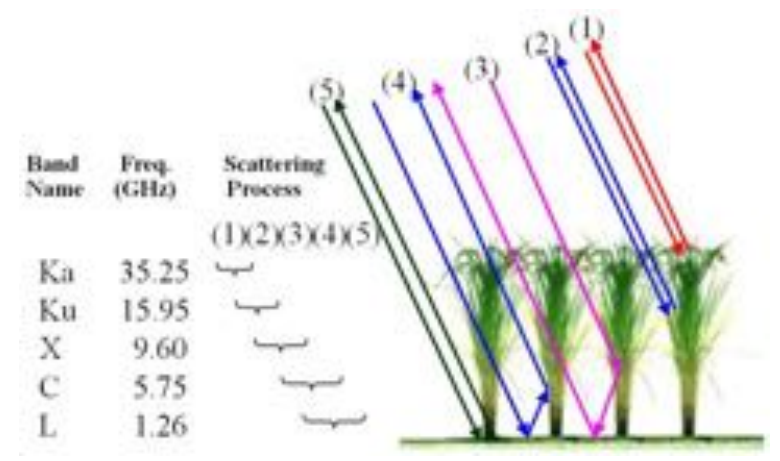

Figure A.6: Example of wave backscattering from the vegetation. Source: Yoshio Inoue. Page: $<11>$

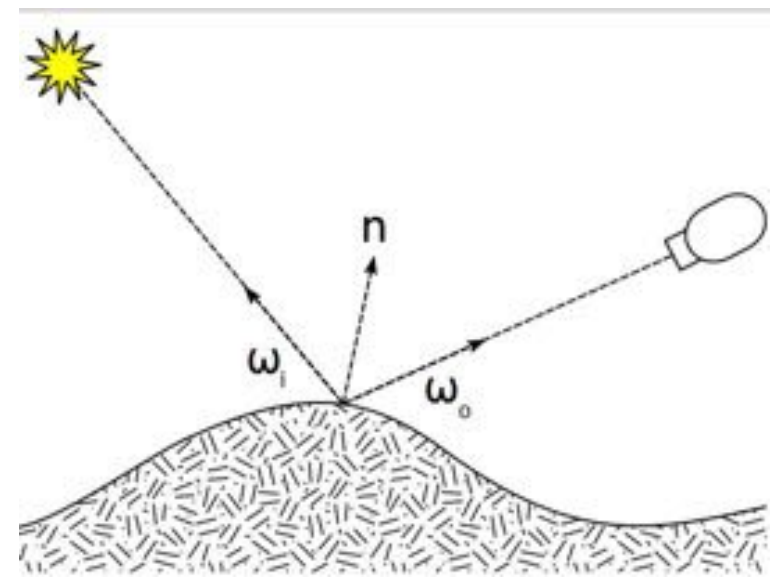

Figure A.7: BRDF is a ratio of reflected radiance along $\omega_{o}$ to the irradiance from direction $\omega_{i}$, all parameterized by azimuth angle $\phi$ and zenith angle $\theta$. Source: Wikipedia.org. Page: $<11>$ 


\section{A.3 Instrumental adjustment and tuning: Trios-RAMSES setup}

Table A.1: Attributes of the Trios-RAMSES hyperspectral radiometer and SAM during measurement sets. Selected examples (14. X, set 1 and 15.X, set 4). Page: <29>

\begin{tabular}{|c|c|c|}
\hline Parameters & 15 October, set 1 & 14 October, set 4 \\
\hline Version & 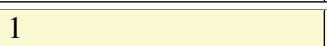 & 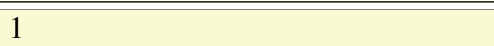 \\
\hline IDData & $\begin{array}{l}78 \mathrm{~B} 1-2009-10-15-08- \\
56-22-280-272\end{array}$ & 78B1-2009-10-14-15-15-59-342-726 \\
\hline IDDevice & SAM-820C & SAM-8204 \\
\hline IDDataType & SPECTRUM & SPECTRUM \\
\hline IDDataTypeSub1 & CALIBRATED & CALIBRATED \\
\hline DateTime & $2009-10-15$ 08:56:22 & $10 / 14 / 2009,15: 15: 59$ \\
\hline PositionLatitude & $35.2451=35^{\circ} 14^{\prime} 29.4354$ & $35.24752=35^{\circ} 14^{\prime} 51.072^{\prime \prime}$ \\
\hline PositionLongitude & $25.01269=25^{\circ} 0^{\prime} 45.6834^{\prime}$ & $25.0098=25^{\circ} 0 ’ 35.2794^{\prime \prime}$ \\
\hline Comment & P.oceanica & P.oceanica \\
\hline CommentSub1 & $0.5 \mathrm{~m}$ depth & $2.5 \mathrm{~m}$ depth \\
\hline CommentSub2 & diffuse & diffuse \\
\hline CommentSub3 & Agia Pelagia & Agia Pelagia site 2 , close to rocks \\
\hline IDMethodType & SAM Control & SAM Control \\
\hline MethodName & SAM-820C & SAM-8204 \\
\hline Mission & No Mission & No Mission \\
\hline MissionSub & 1 & 1 \\
\hline RecordType & 0 & 0 \\
\hline CalFactor & 1 & 1 \\
\hline IDDataBack & $\begin{array}{l}\text { DLAB-2008-02-06-14- } \\
13-18-865-675\end{array}$ & DLAB-2008-01-25-20-42-29-607-062 \\
\hline IDDataCal & $\begin{array}{l}\text { DLAB-2008-02-06-14- } \\
23-00-187-767\end{array}$ & DLAB-2008-01-28-08-40-24-220-395 \\
\hline IntegrationTime & 512 & 1024 \\
\hline P31 & -1 & -1 \\
\hline P31e & 0 & 0 \\
\hline PathLength & $+\mathrm{INF}$ & $+\mathrm{INF}$ \\
\hline RAWDynamic & 65535 & 65535 \\
\hline Temperature & $+\mathrm{NAN}$ & $+\mathrm{NAN}$ \\
\hline Unit1 & 0101 Wavelength $\mathrm{nm}$ & 11 Wavelength $\mathrm{nm}$ \\
\hline Unit2 & $\begin{array}{ll}03-06 & \text { Intensity } \\
\mathrm{mW} /(\mathrm{m} 2 \mathrm{~nm}) & \end{array}$ & 0303 Intensity $\mathrm{mW} /(\mathrm{m} 2 \mathrm{~nm} \mathrm{Sr})$ \\
\hline Unit3 & $\begin{array}{lll}\mathrm{f0}-06 & \text { Error } & \mathrm{mW} /(\mathrm{m} 2 \\
\mathrm{nm}) & & \\
\end{array}$ & 3-3 Error $\mathrm{mW} /(\mathrm{m} 2 \mathrm{~nm} \mathrm{Sr})$ \\
\hline Unit4 & f1-00 Status & f1-00 Status \\
\hline
\end{tabular}


Table A.2: Attributes of the Trios-RAMSES hyperspectral radiometer during measurement sets. Selected examples (15. X, set 1 and 14.X, set 4). Page: <29>

\begin{tabular}{|c|c|c|}
\hline Parameters & 14 October, set 1 & 15 October, set 4 \\
\hline Version & 1 & 1 \\
\hline IDData & $\begin{array}{l}\text { 78B1-2009-10-14-15- } \\
32-02-078-323\end{array}$ & 78B1-2009-10-15-10-36-02-217-136 \\
\hline IDDevice & SAM-820C & SAM-8204 \\
\hline IDDataType & SPECTRUM & SPECTRUM \\
\hline IDDataTypeSub1 & CALIBRATED & CALIBRATED \\
\hline DateTime & 2009-10-14 15:32:02 & 2009-10-15 10:36:02 \\
\hline PositionLatitude & $\begin{array}{l}35.24752= \\
35^{\circ} 14^{\prime} 51.072^{\prime}\end{array}$ & $35.245071=35^{\circ} 14^{\prime} 42.2556^{\prime \prime}$ \\
\hline PositionLongitude & $\begin{array}{l}25.0098= \\
25^{\circ} 0^{\prime} 35.2794 \prime\end{array}$ & $25.012661=25^{\circ} 0^{\prime} 45.5796^{\prime \prime}$ \\
\hline Comment & P.oceanica & P.oceanica \\
\hline CommentSub1 & 3.5m depth & $1.5 \mathrm{~m}$ depth \\
\hline CommentSub2 & diffuse & diffuse \\
\hline CommentSub3 & Agia Pelagia & Agia Pelagia site 1 , close to rocks \\
\hline IDMethodType & SAM Control & SAM Control \\
\hline MethodName & SAM-820C & SAM-8204 \\
\hline Mission & No Mission & No Mission \\
\hline MissionSub & 1 & 1 \\
\hline RecordType & 0 & 0 \\
\hline CalFactor & 1 & 1 \\
\hline IDDataBack & $\begin{array}{l}\text { DLAB-2008-02-06-14- } \\
13-18-865-675\end{array}$ & DLAB-2008-01-25-20-42-29-607-062 \\
\hline IDDataCal & $\begin{array}{l}\text { DLAB-2008-02-06-14- } \\
23-00-187-767\end{array}$ & DLAB-2008-01-28-08-40-24-220-395 \\
\hline IntegrationTime & 64 & 32 \\
\hline P31 & -1 & -1 \\
\hline P31e & 0 & 0 \\
\hline PathLength & $+\mathrm{INF}$ & $+\mathrm{INF}$ \\
\hline RAWDynamic & 65535 & 65535 \\
\hline Temperature & $+\mathrm{NAN}$ & $+\mathrm{NAN}$ \\
\hline Unit1 & 01-01 Wavelength $\mathrm{nm}$ & 01-01 Wavelength $\mathrm{nm}$ \\
\hline Unit2 & $\begin{array}{ll}03-06 & \text { Intensity } \\
\mathrm{mW} /(\mathrm{m} 2 \mathrm{~nm}) & \end{array}$ & 0303 Intensity $\mathrm{mW} /(\mathrm{m} 2 \mathrm{~nm} \mathrm{Sr})$ \\
\hline Unit3 & $\begin{array}{l}\text { f0-06 Error } \mathrm{mW} /(\mathrm{m} 2 \\
\mathrm{nm})\end{array}$ & f0-03 Error $\mathrm{mW} /(\mathrm{m} 2 \mathrm{~nm} \mathrm{Sr})$ \\
\hline Unit4 & f1-00 Status & f1-00 Status \\
\hline
\end{tabular}




\section{A.4 Types of seagrass structural patterns: Ligaria beach, Crete}

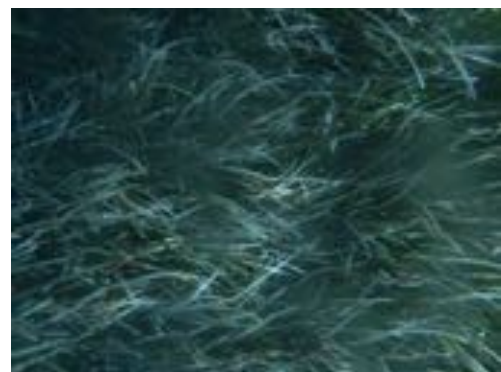

(a) Fragment of meadow

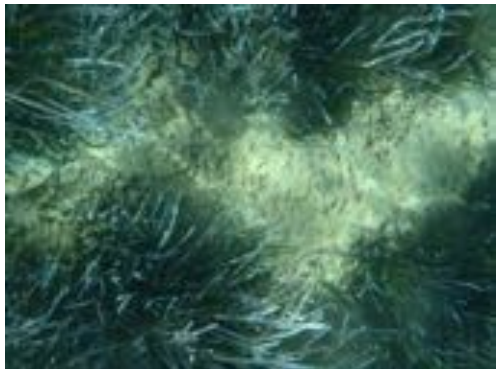

(b) Aggregated seagrass patch

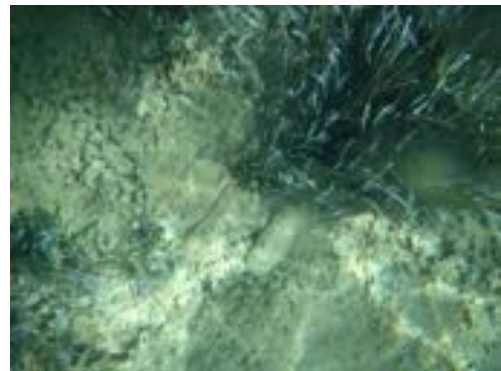

(c) Isolated patch of seagrass

Figure A.8: Types of seagrass structural patterns, Ligaria beach, Crete. Pages: $<28>,<31>$

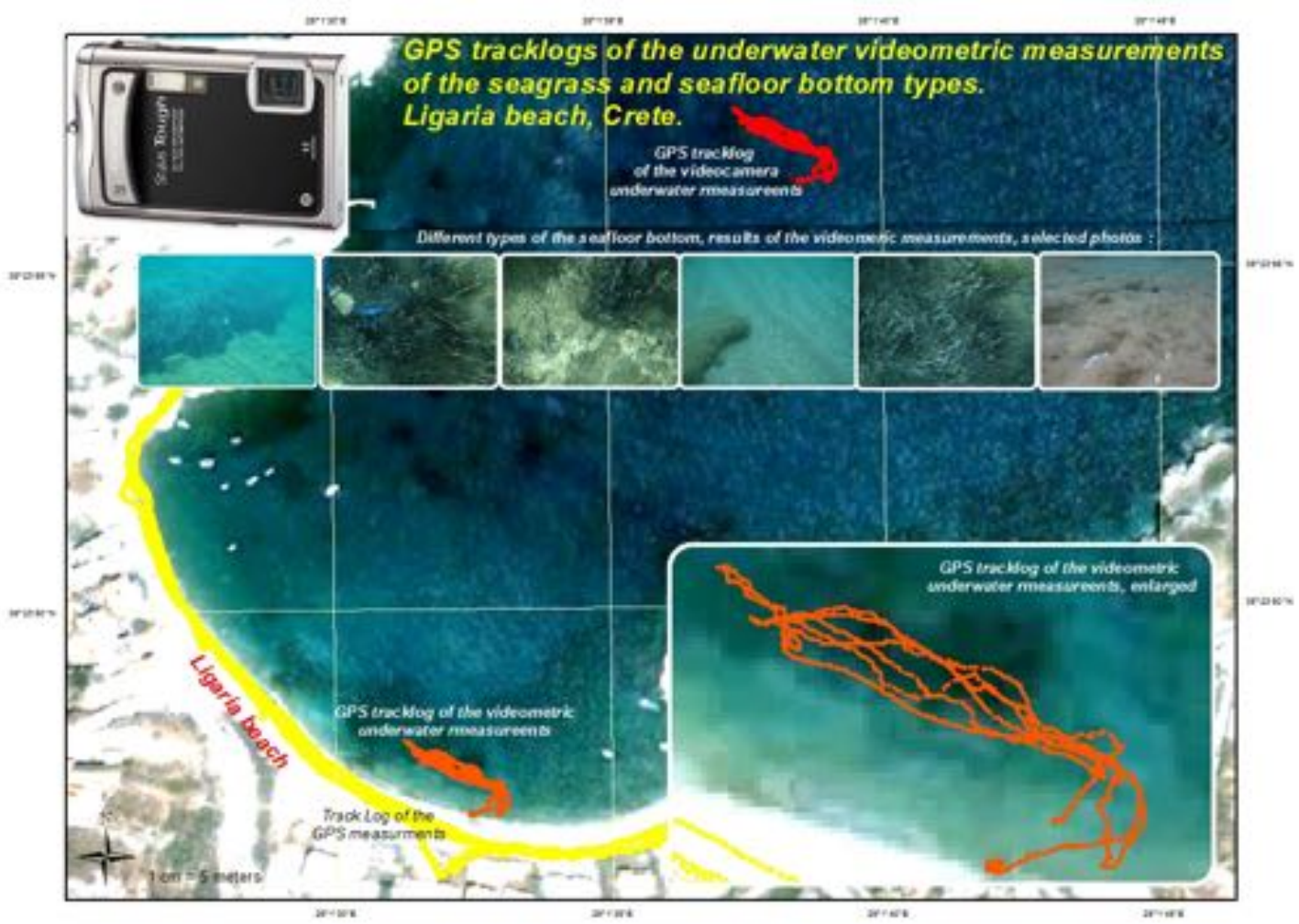

Figure A.9: Locations of the video measurements and GPS tracklogs, Ligaria. Pages: $<27>,<28>$ 
A.5 Results of videographic measurements: seafloor types on Crete island

A APPENDICES

\section{A.5 Results of videographic measurements: seafloor types on Crete island}

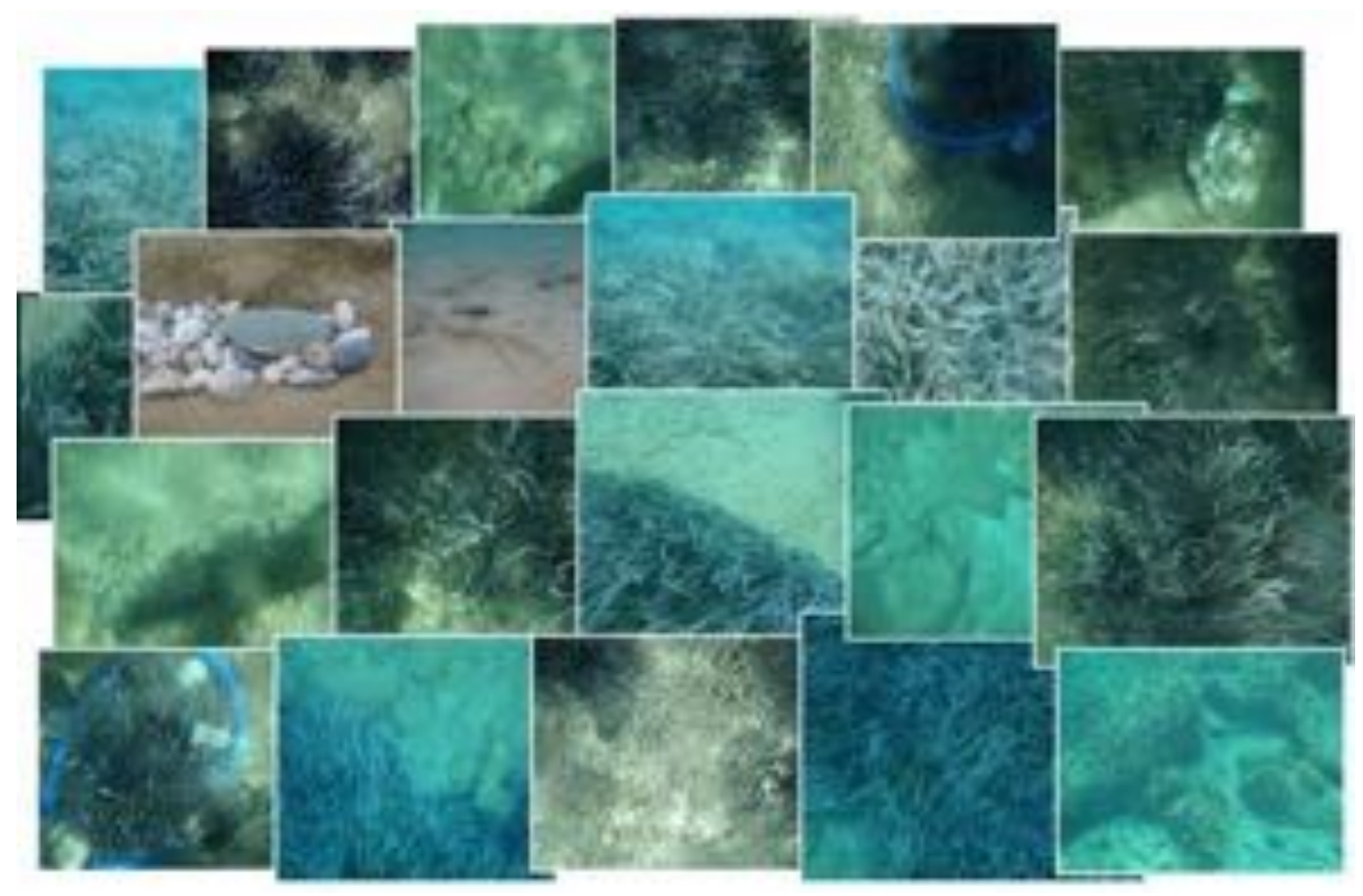

Figure A.10: Ligaria beach, Crete: seafloor types. Pages: $<31>,<42>$

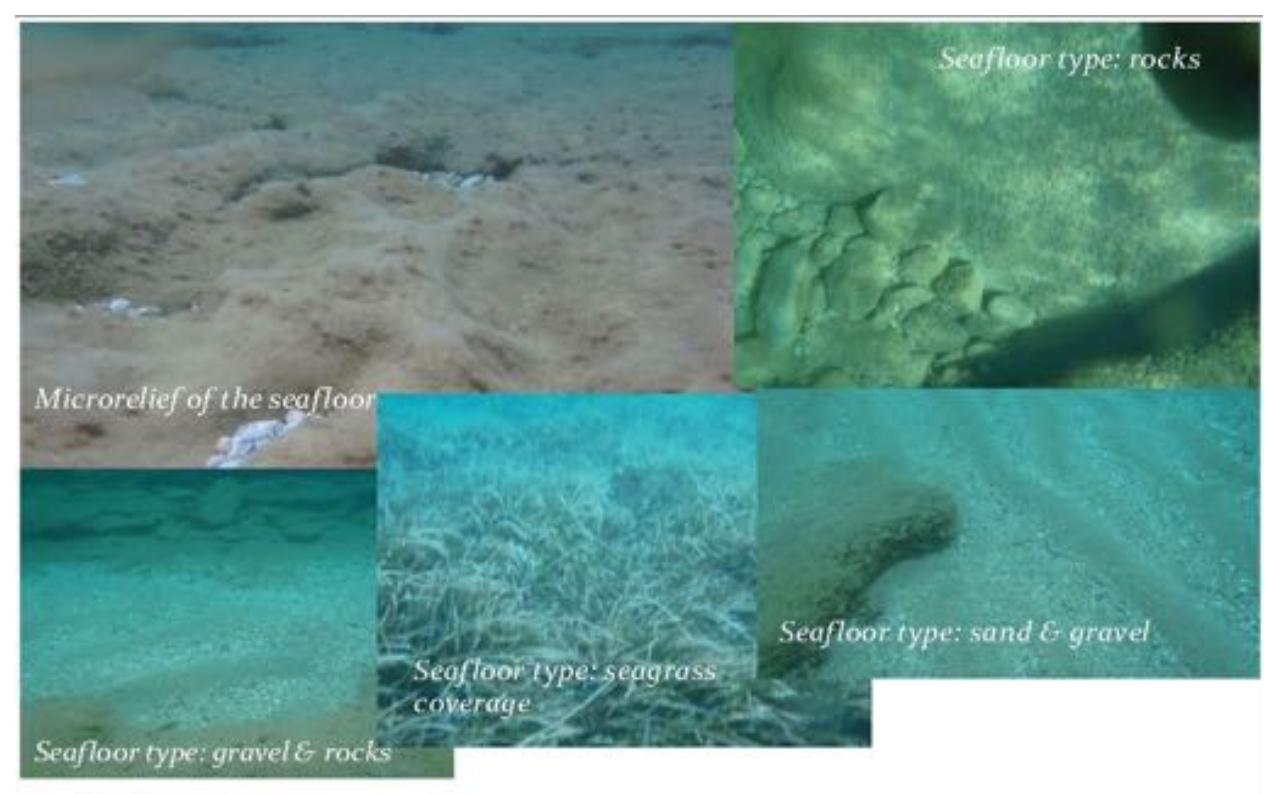

Figure A.11: Various seafloor types; Ligaria beach, Crete. Page: $<31>$ 


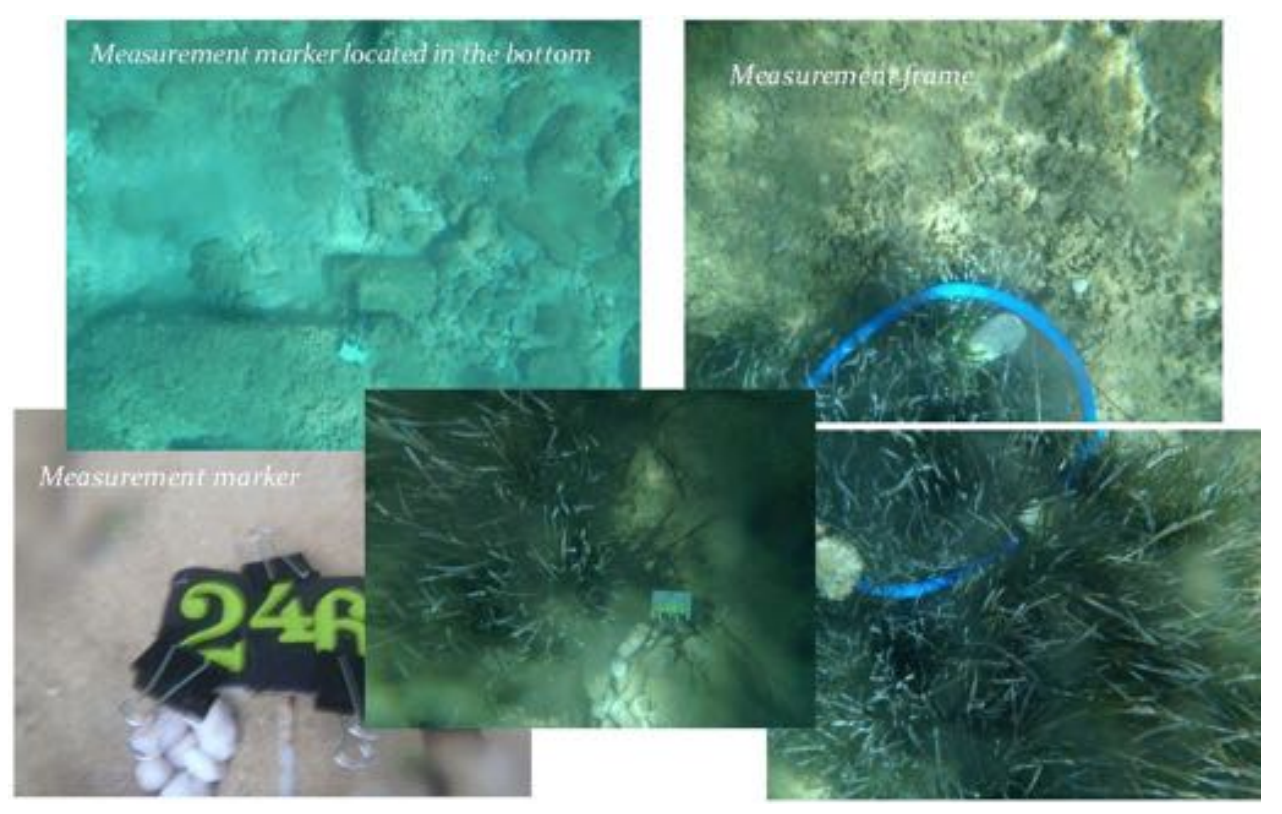

Figure A.12: Measurement underwater equipment. Page: $<28>$ 


\section{A.6 Data pre-processing}

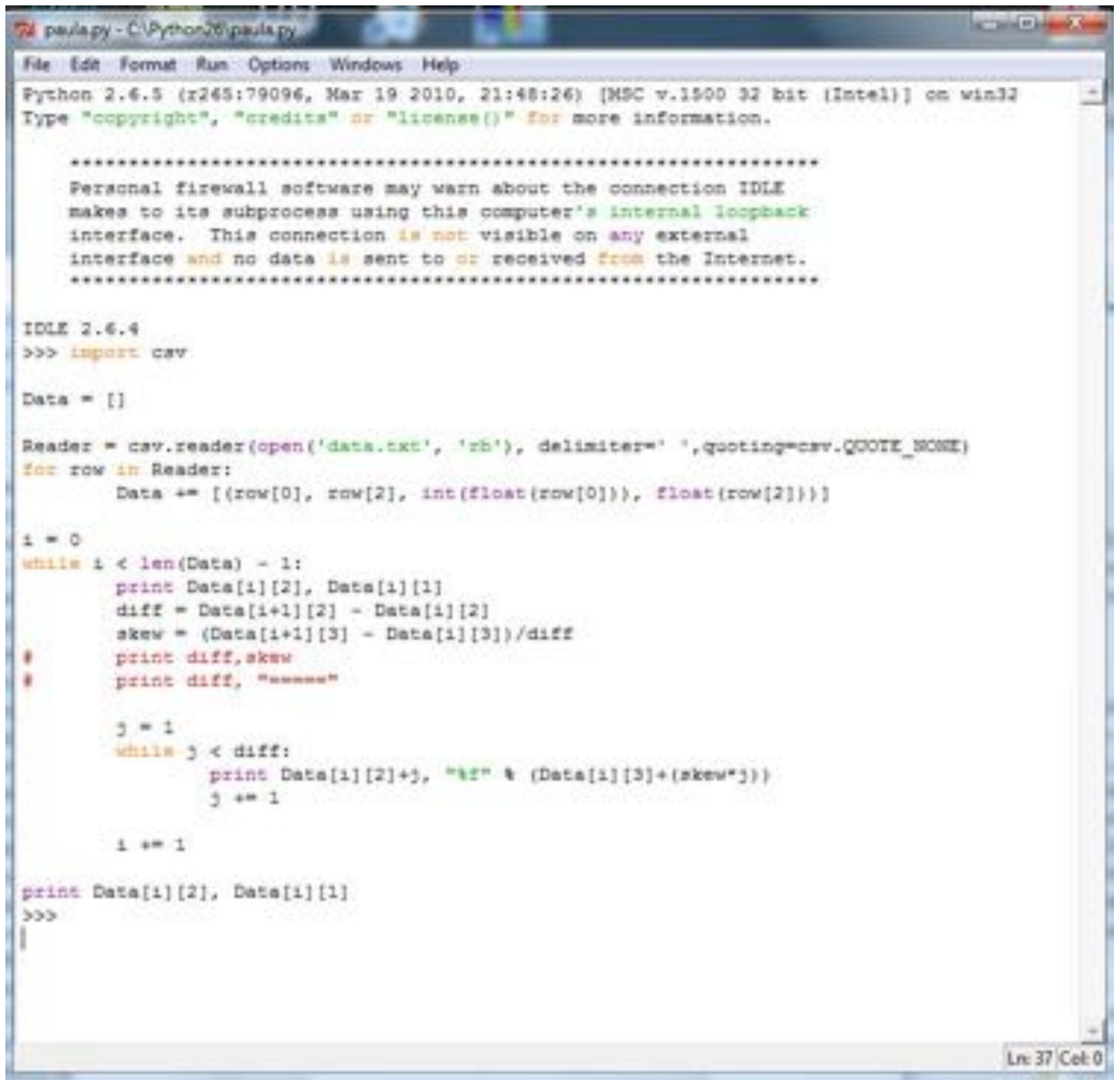

Figure A.13: Script written on Python, for the interpolation raw data of the Trios-RAMSES measurements. Page: $<31>$ 


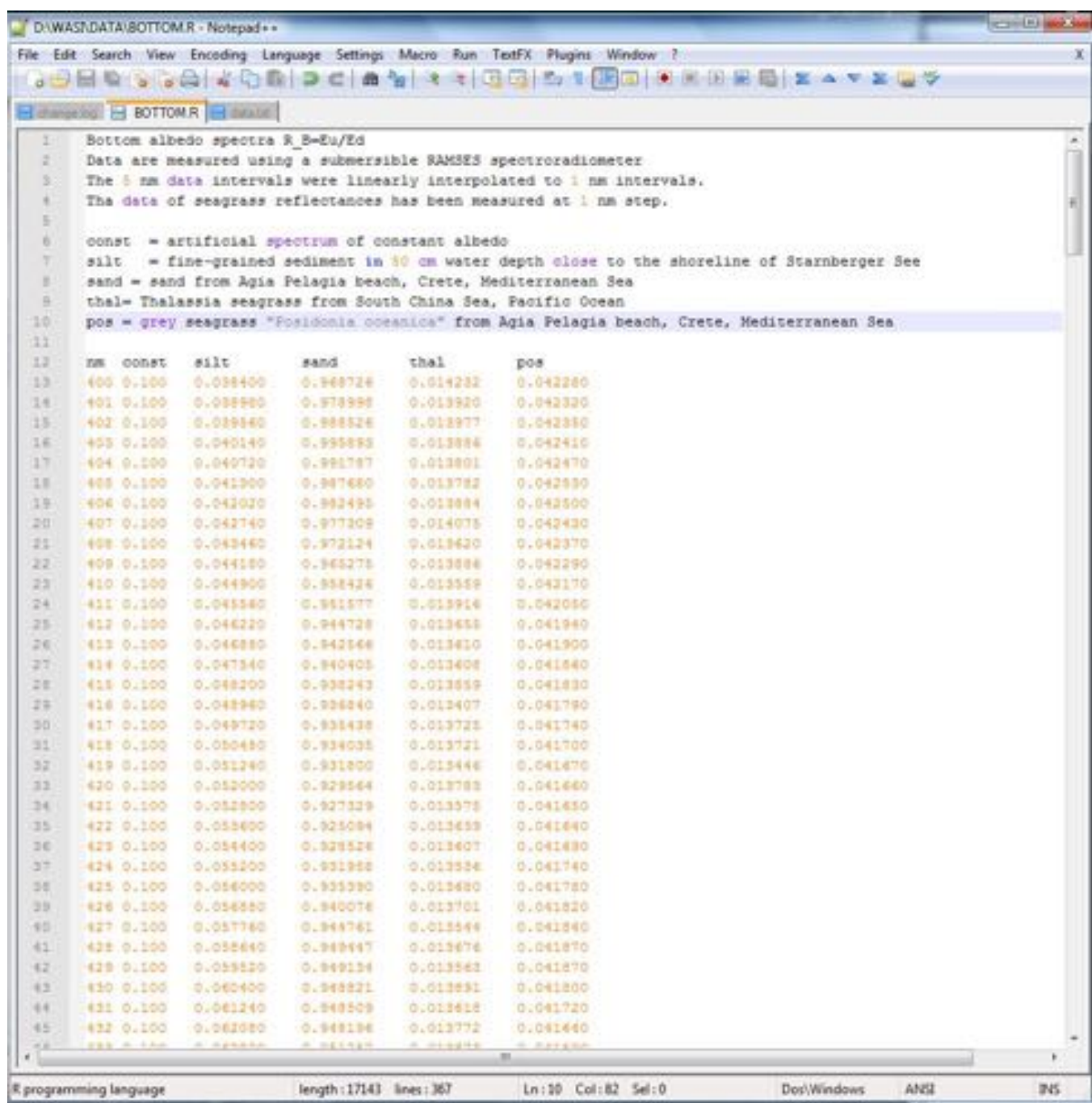

Figure A.14: Fragment of Bottom.R file: values of spectral measurements of the seagrasses (various species), sand, silt and artificial spectrum of constant albedo. Page: $<31>$ 


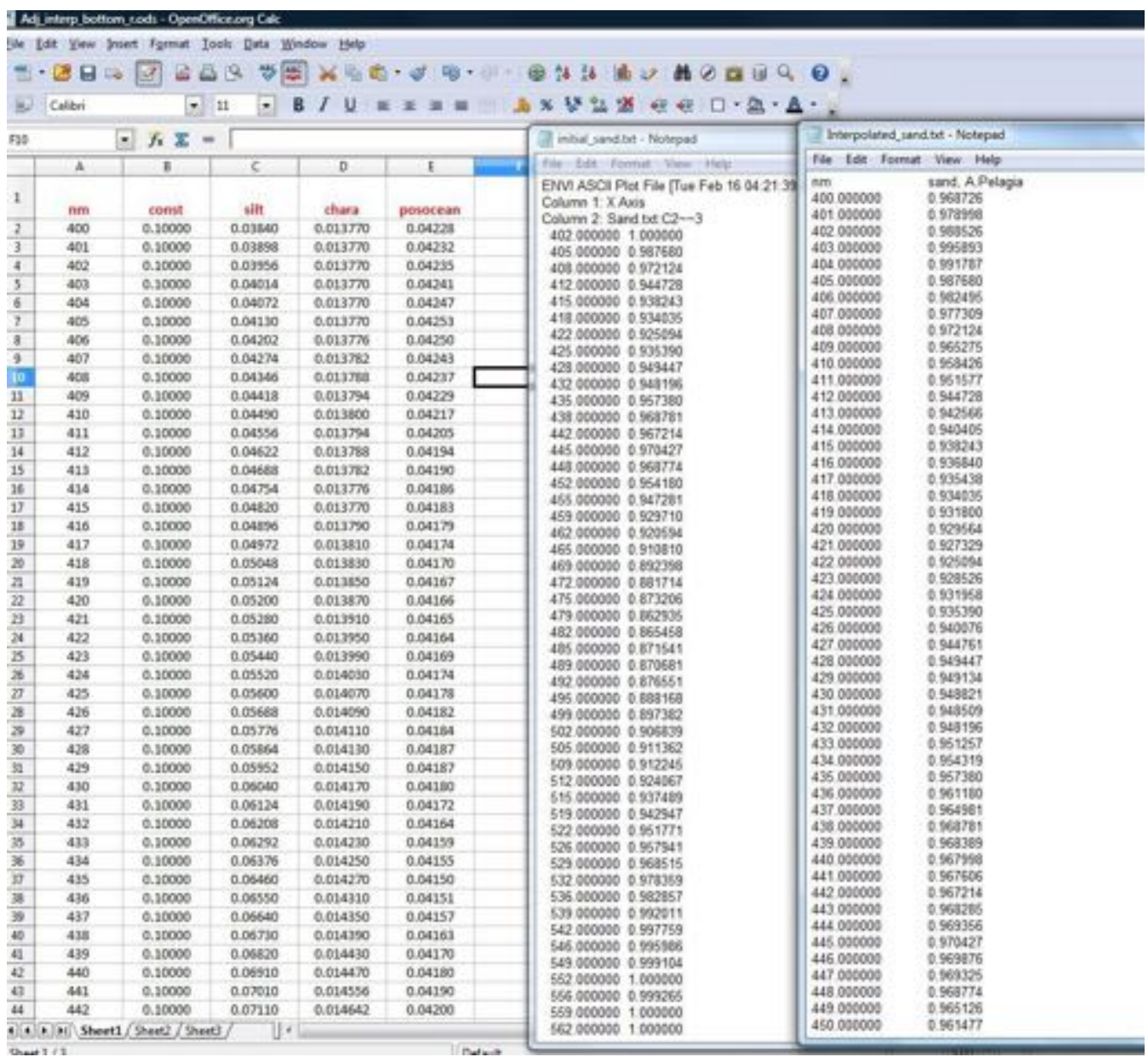

Figure A.15: Interpolation of the spectral measurements by means of Open Office. Page: $<31>$ 


\section{A.7 Data processing and statistical evaluation: measurements of the seafloor optical prop- erties.}

Table A.3: Basic mathematical formulae used for statistical analysis of the measurement set of the spectral reflectance. Page: $<44>$

\begin{tabular}{|c|c|}
\hline \hline Basic Statistics & Math Formulae \\
\hline \hline Mean & $\Sigma\left(x_{i} / n=\bar{x}\right)$ \\
\hline Variance & $\frac{1}{n-1} \Sigma\left(x_{i}-\bar{x}\right)=s_{x}^{2}$ \\
\hline Standard Deviation & $s=s^{2}$ \\
\hline Coefficient of Variation & $s / \bar{x}$ \\
\hline Skewness & $\frac{1}{n-1} \Sigma\left(x_{i}-\bar{x}\right) / s^{3}$ \\
\hline Excess Kurtosis & $\frac{1}{n-1} \Sigma\left(x_{i}-\bar{x}\right) / s^{4}-3$ \\
\hline
\end{tabular}

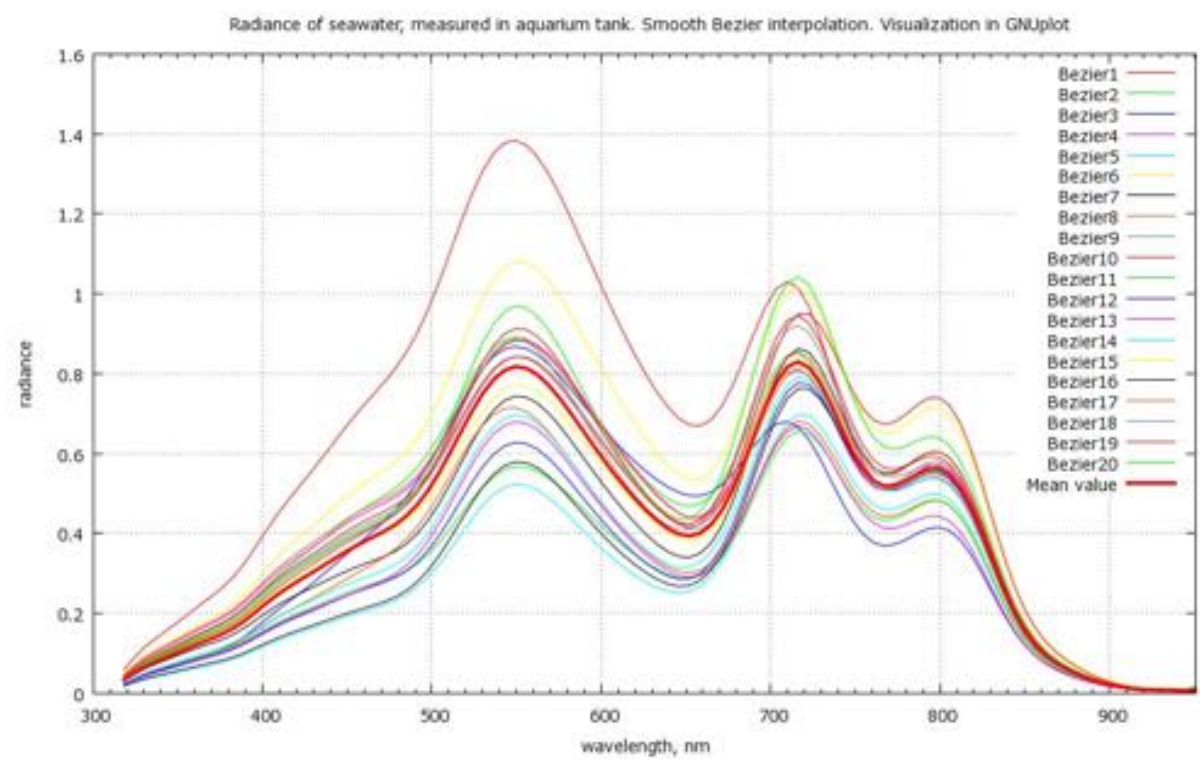

Figure A.16: Radiance of the seawater with sediments. Measured in aquarium tank. Bezier Interpolation. Gnuplot. Pages: $<32>,<44>,<29>$ 


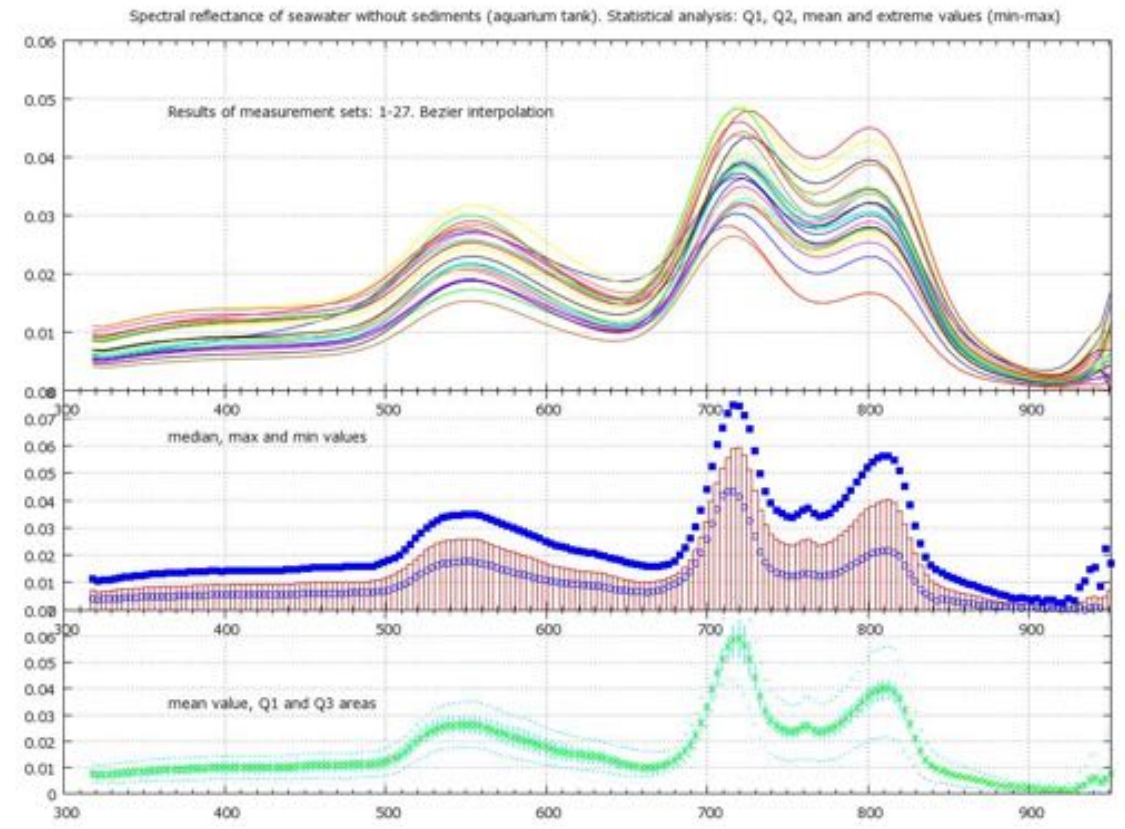

Figure A.17: Multiplot graph showing spectral reflectance of the seawater without sediments, measured in aquarium tank, Agia Pelagia district, Crete. Gnuplot. Two complimentary graphs below show the results of the statistical analysis. Pages: $<31>,<32>,<34>$

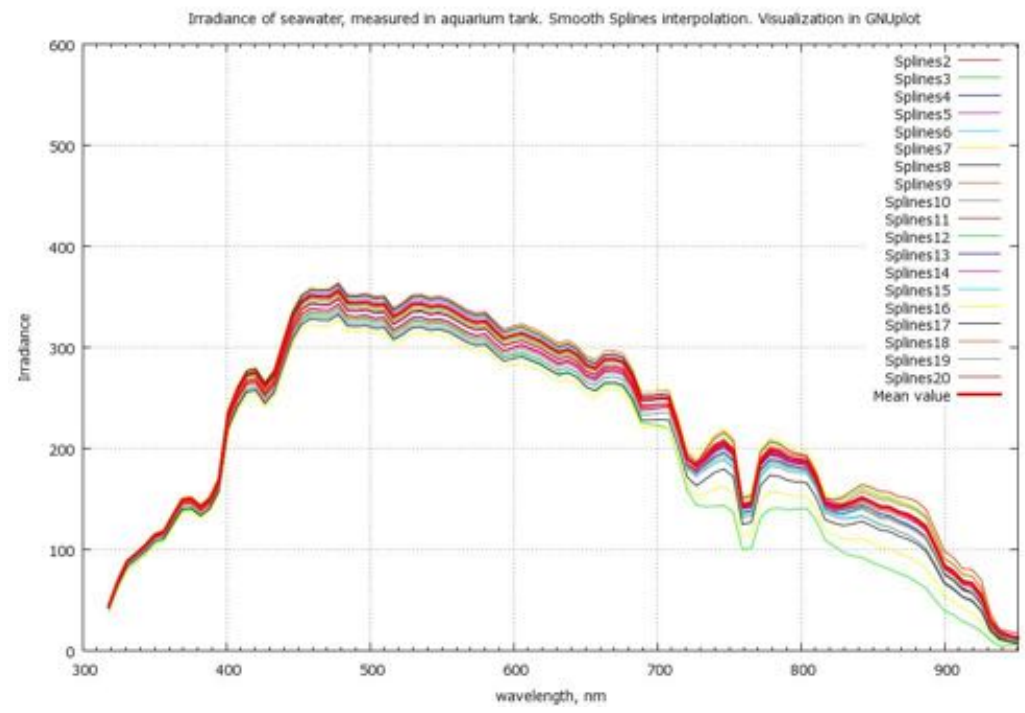

Figure A.18: Irradiance of the seawater, measured in aquarium tank. Smooth Splines interpolation. Visualization in Gnuplot. Page: $<38>$ 
Table A.4: Robust estimation of the seawater radiance (measured in aquarium tank, Heraklion): results of the least absolute deviation (LAD), Series:V16. Gretl. Page: $<45>$

Model 6: LAD, using observations 1:01-8:23 $(T=191)$

Dependent variable: v16

$\begin{array}{|ccccc|} & \text { Coefficient } & \text { Std. Error } & t \text {-ratio } & \text { p-value } \\ \text { const } & 0.738911 & 0.0862011 & 8.5719 & 0.0000 \\ \text { v1 } & -0.000775186 & 0.000114010 & -6.7993 & 0.0000\end{array}$

$\begin{array}{lrlr}\text { Median depend. var } & 0.227857 & \text { S.D. dependent var } & 0.205031 \\ \text { Sum absolute resid } & 30.22342 & \text { Sum squared resid } & 8.059632 \\ \text { Log-likelihood } & 28.74727 & \text { Akaike criterion } & -53.49454 \\ \text { Schwarz criterion } & -46.99000 & \text { Hannan-Quinn } & -50.85990\end{array}$

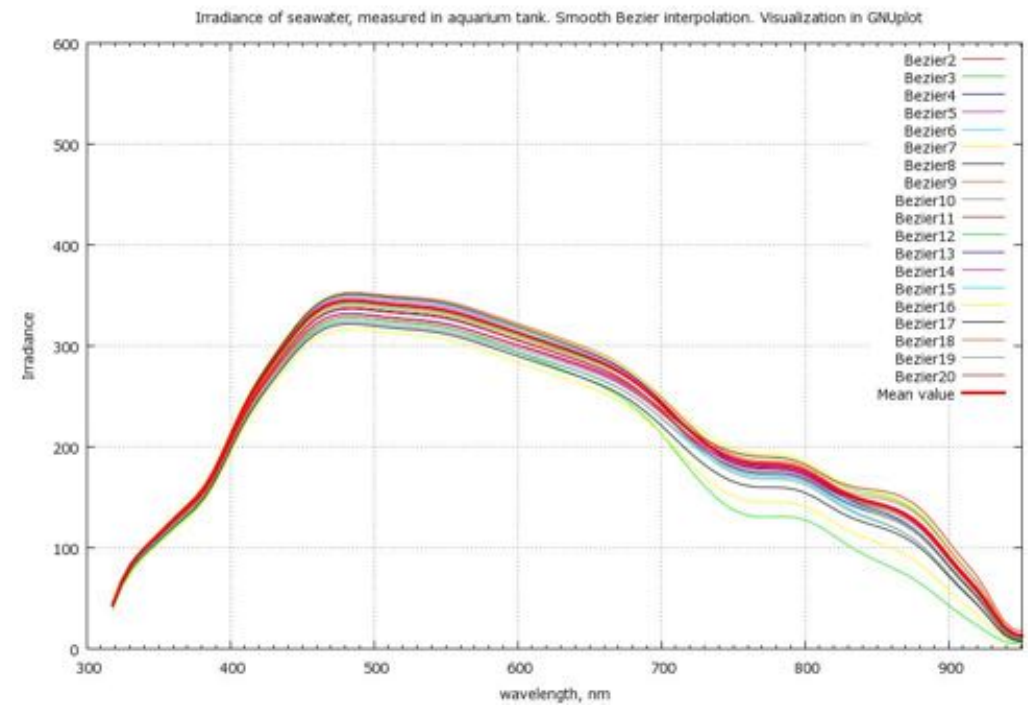

Figure A.19: Irradiance of the seawater, measured in aquarium tank. Smooth Bezier interpolation. Visualization in Gnuplot. Pages: $<32>,<29>$ 


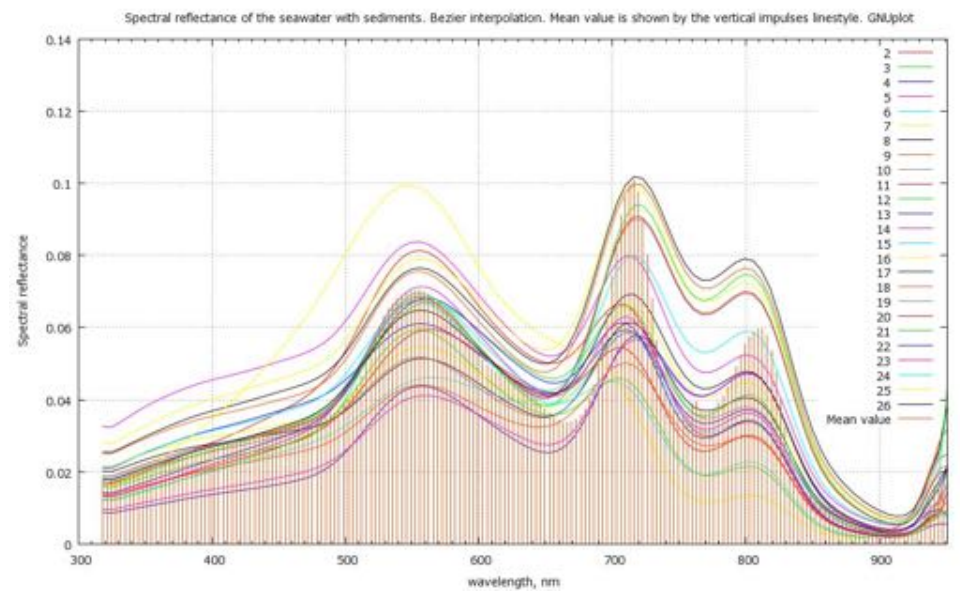

Figure A.20: Spectral reflectance of the seawater with sediments. Bezier interpolation. Mean value is shown by the vertical impulses linestyle. Gnuplot. Pages: $<32>,<38>$
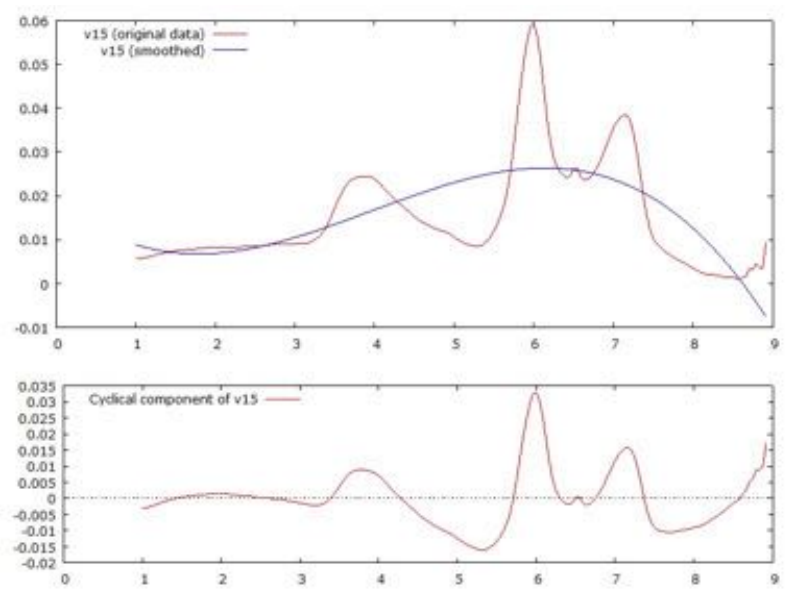

Figure A.21: Plot illustrating polynomial trend for spectral reflectance of seawater without sediments (Ligaria Beach), variable V15. Gretl modelling visualization. Page: $<32>$ 

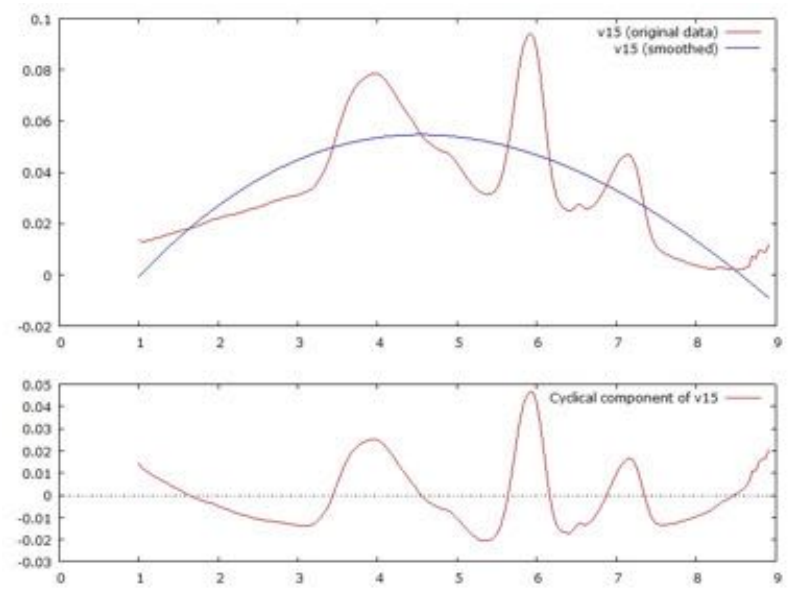

Figure A.22: Plot illustrating polynomial trend for spectral reflectance of seawater with sediments (Ligaria Beach), variable V15. Gretl modelling visualization. Page: $<32>$
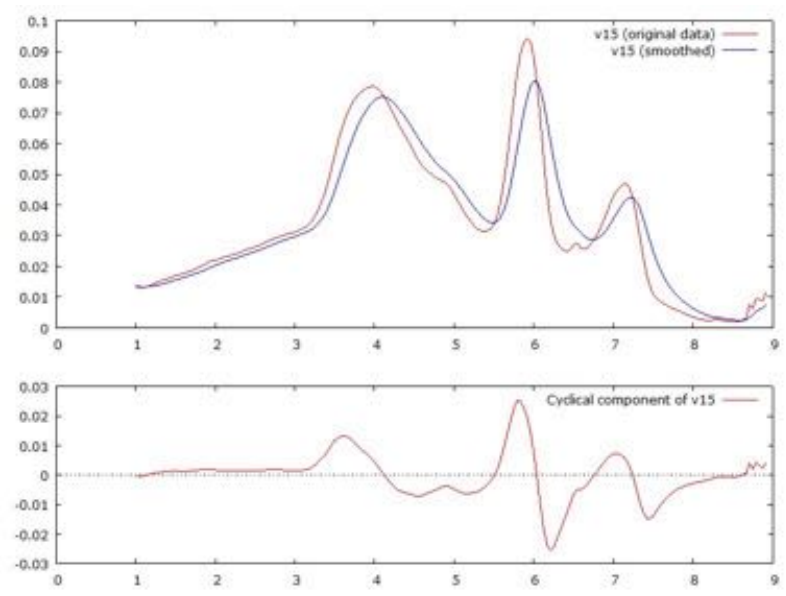

Figure A.23: Exponential moving average of spectral reflectance of seawater with sediments (Ligaria Beach), variable V15. Gretl modelling visualization. Page: $<32>$ 


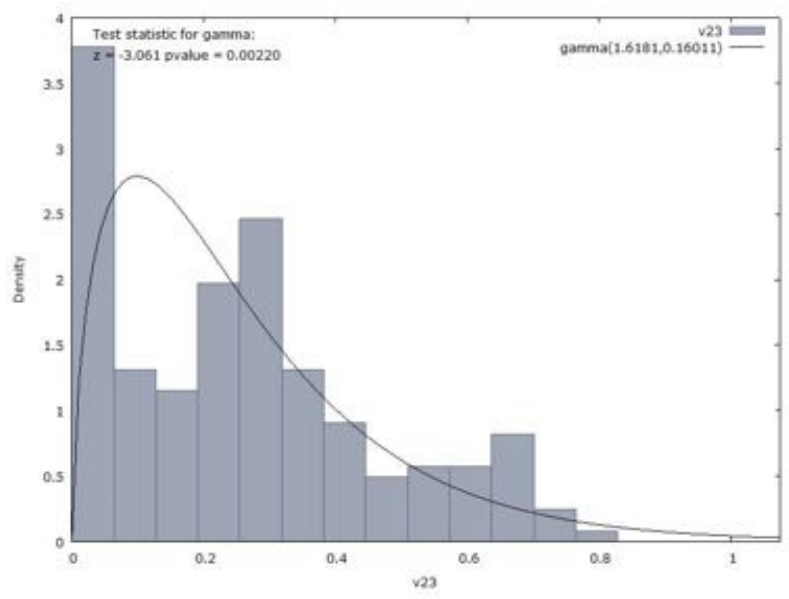

Figure A.24: Frequency normality test against gamma distribution: radiance of the seawater, measured in aquarium tank. Visualization in Gretl. Page: $<17>$

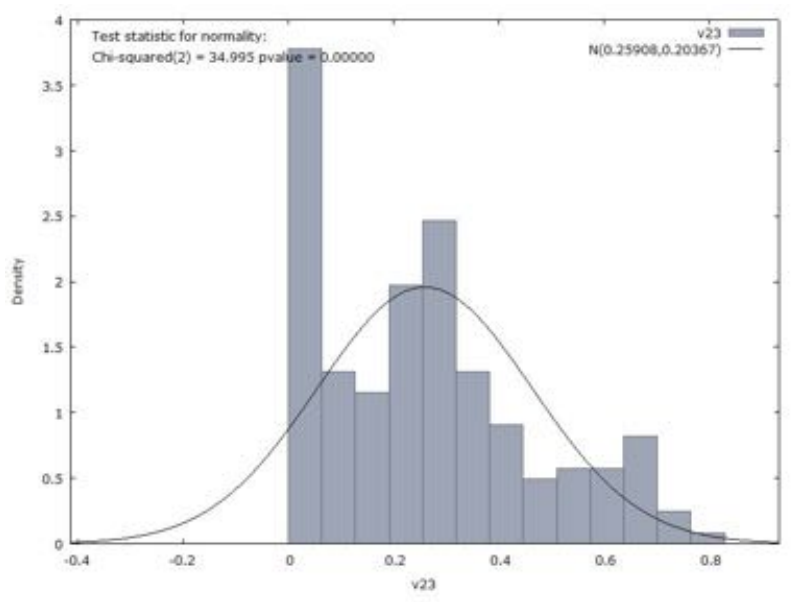

Figure A.25: Frequency normality test against normal distribution: radiance of the seawater, measured in aquarium tank. Visualization in Gretl. Page: $<17>$ 


\section{A.7.1 Data processing and statistical evaluation: P.oceanica}

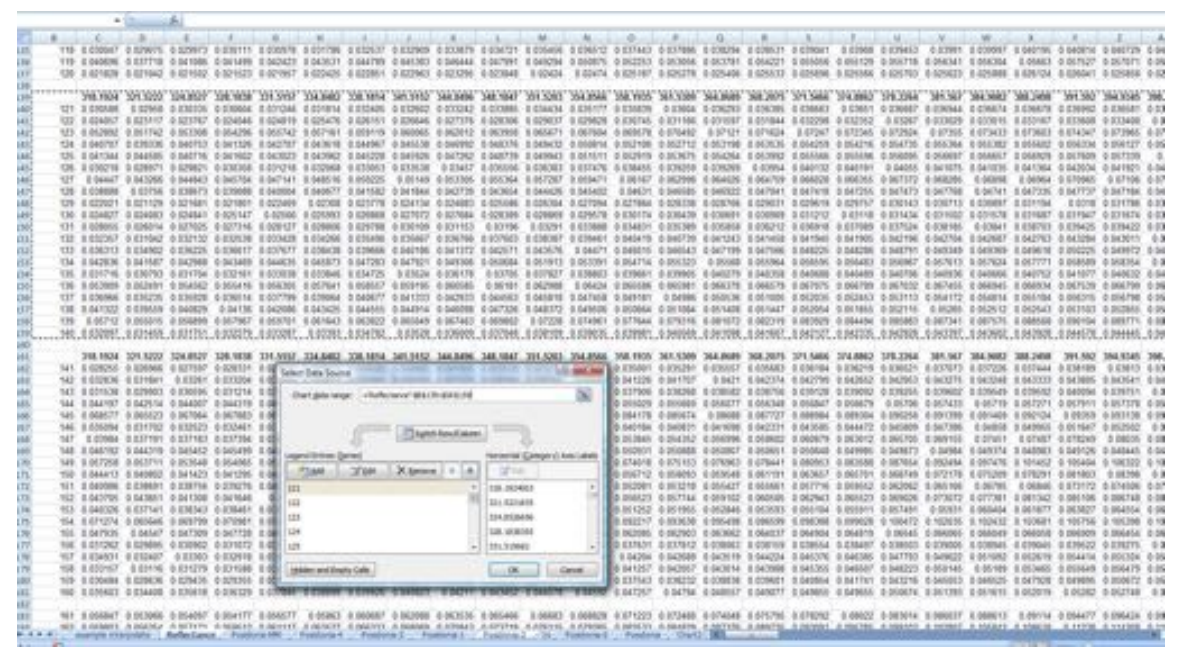

Figure A.26: Values of spectral reflectances of seagrass P.oceanica (fragment). Pages: $<32>,<44>$

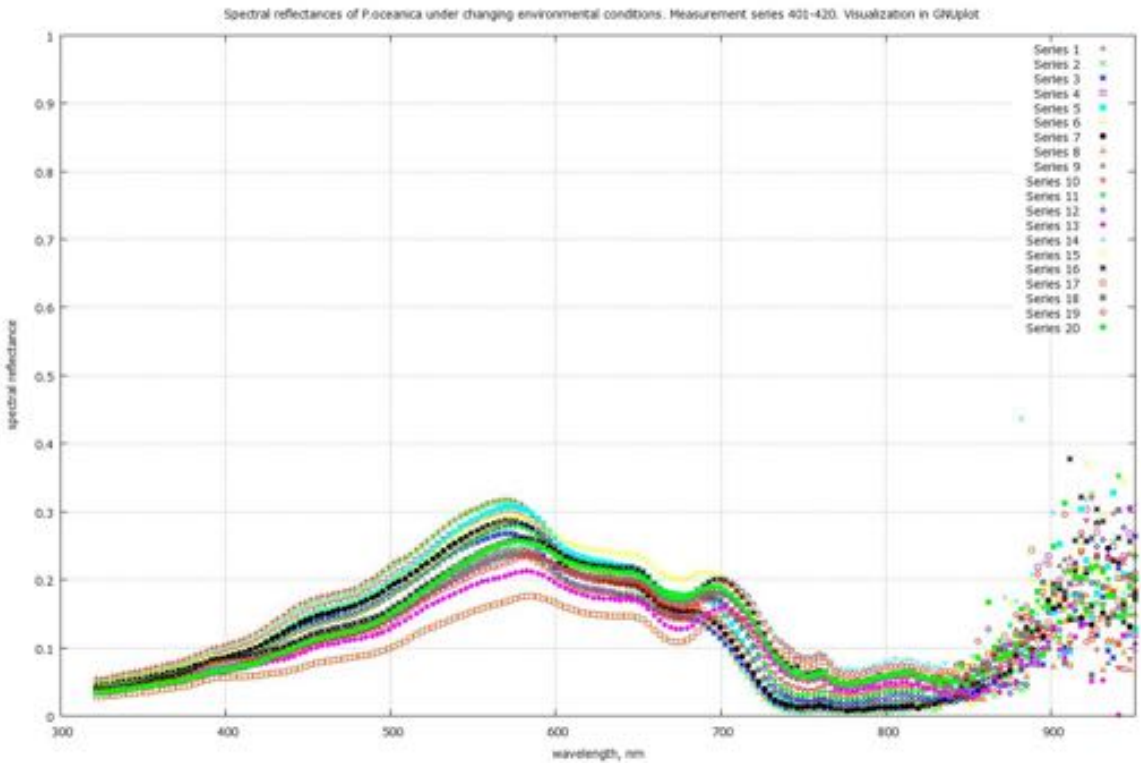

Figure A.27: Spectral reflectance of P.oceanica. Measurement series 401-420. Gnuplot. Pages: $<23>,<32>$, $<38>$ 


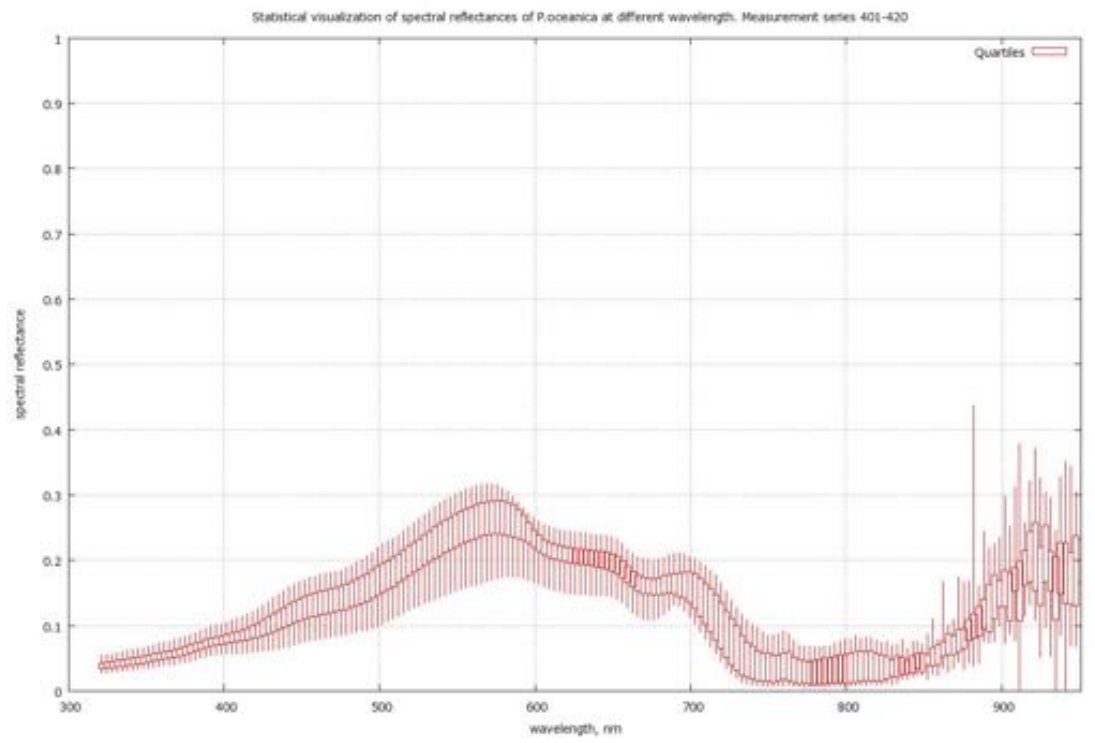

Figure A.28: Statistical analysis of the measurement data: spectral reflectance of the P.oceanica. Visualization of the interquartile ranging. Example of data set 401-420. Shown mid-spread of statistical quartiles Q1 and Q3, min and max values within the range. Gnuplot. Pages: $<23>,<38>$

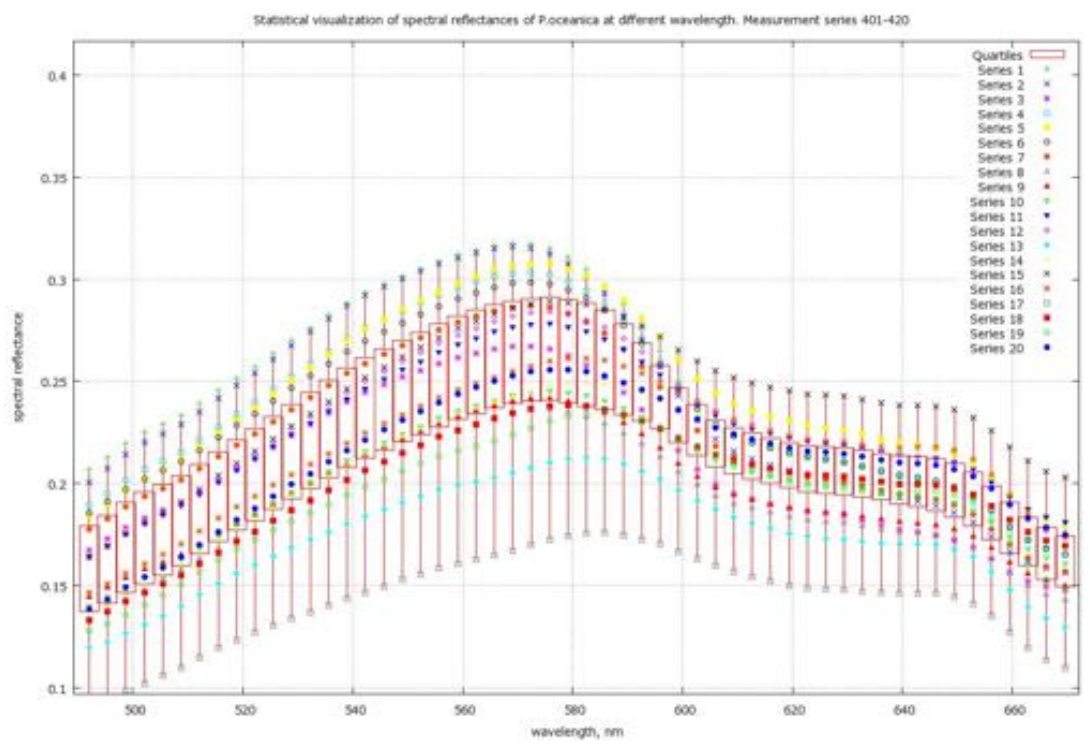

Figure A.29: Enlarged fragment of the statistical analysis of the measurement data. Example of data set 401-420. Visualization of the interquartile ranging and plotted together with measurement data. Gnuplot. Page: $<38>$ 
Table A.5: Results of the statistical analysis of spectral reflectance of P.oceanica, with average values (for sets 1 - 350). Generalisation up to step $20 \mathrm{~nm}$. Pages: $<44>,<49>$

\begin{tabular}{|c|c|c|c|c|c|c|}
\hline Wavelength, nm & mean & Q1 & $\min$ & Q3 & $\max$ & median \\
\hline 318.23354 & 0.030467 & 0.038907 & 0.029764 & 0.069762 & 0.116100 & 0.048984 \\
\hline 338.29900 & 0.033560 & 0.043030 & 0.032847 & 0.076252 & 0.128290 & 0.054334 \\
\hline 358.37932 & 0.039897 & 0.051320 & 0.039131 & 0.091143 & 0.154409 & 0.066354 \\
\hline 378.47247 & 0.045786 & 0.058849 & 0.045039 & 0.105993 & 0.177150 & 0.078339 \\
\hline 398.57640 & 0.052346 & 0.066859 & 0.051625 & 0.122328 & 0.201038 & 0.091905 \\
\hline 418.68905 & 0.058942 & 0.074842 & 0.058240 & 0.138984 & 0.226028 & 0.106207 \\
\hline 438.80838 & 0.070690 & 0.089761 & 0.069999 & 0.167825 & 0.267712 & 0.130580 \\
\hline 458.93235 & 0.080107 & 0.102089 & 0.079392 & 0.191424 & 0.304933 & 0.149762 \\
\hline 479.05891 & 0.086278 & 0.110348 & 0.085546 & 0.207940 & 0.332934 & 0.162881 \\
\hline 499.18600 & 0.098498 & 0.126592 & 0.097689 & 0.239161 & 0.380603 & 0.188192 \\
\hline 519.31159 & 0.110222 & 0.143976 & 0.109022 & 0.265948 & 0.421370 & 0.210237 \\
\hline 539.43363 & 0.125694 & 0.166156 & 0.124310 & 0.302678 & 0.475842 & 0.240492 \\
\hline 559.55006 & 0.131844 & 0.175865 & 0.130257 & 0.319385 & 0.503907 & 0.253726 \\
\hline 579.65885 & 0.12 & 0.166084 & 186 & 0.302078 & 0.485661 & 0.237873 \\
\hline 599.75794 & 0.077236 & 0.111113 & 0.075669 & 0.200557 & 0.343876 & 0.154016 \\
\hline 619.84529 & 0.057038 & 0.085386 & 0.055588 & 0.154781 & 0.281737 & 0.117003 \\
\hline 639.91885 & 0.050841 & 0.077438 & 0.049432 & 0.141810 & 0.265181 & 0.106188 \\
\hline 659.97657 & 0.038118 & 0.059971 & 0.036997 & 0.110774 & 0.223366 & 0.082411 \\
\hline 680.01641 & 0.032892 & 0.052265 & 0.032012 & 0.095789 & 0.198389 & 0.071686 \\
\hline 700.03633 & 0.034756 & 0.058426 & 0.033643 & 0.101504 & 0.215413 & 0.075789 \\
\hline 720.03426 & 0.026287 & 0.047084 & 0.025162 & 0.082940 & 0.193535 & 0.061184 \\
\hline 740.00817 & 0.009740 & 0.022355 & 0.010145 & 0.042861 & 0.132244 & 0.029414 \\
\hline 759.95601 & 0.008651 & 0.020234 & 0.009191 & 0.039371 & 0.128165 & 0.026558 \\
\hline 779.87573 & 0.006019 & 0.014157 & 0.006397 & 0.028320 & 0.100314 & 0.019322 \\
\hline 799.76528 & 0.008607 & 0.020030 & 0.009050 & 0.037323 & 0.118123 & 0.026535 \\
\hline 819.62263 & 0.008777 & 0.020295 & 0.009288 & 0.037598 & 0.118055 & 0.026799 \\
\hline 839.44571 & 0.002562 & 0.008010 & 0.002864 & 0.017472 & 0.076515 & 0.011432 \\
\hline 859.23249 & 0.002653 & 0.006921 & 0.002897 & 0.016121 & 0.070377 & 0.009889 \\
\hline 878.98091 & 0.002327 & 0.008080 & 0.002821 & 0.018625 & 0.082462 & 0.011617 \\
\hline 898.68893 & 0.004077 & 0.013098 & 0.004709 & 0.031217 & 0.101146 & 0.019767 \\
\hline 918.35451 & 0.006215 & 0.020162 & 0.007229 & 0.045213 & 0.199711 & 0.029950 \\
\hline 937.97559 & 0.005783 & 0.026132 & 0.007307 & 0.065475 & 0.195072 & 0.040848 \\
\hline 951.03058 & 0.002296 & 0.026581 & 0.002380 & 0.067924 & 0.265845 & 0.041463 \\
\hline
\end{tabular}


A APPENDICES

Table A.6: Model summary of the regression analysis: curve estimation and ANOVA table tested for single observations within one measurement set: spectral reflectance of P.oceanica. SPSS. Page: $<45>$

\begin{tabular}{|c|c|c|c|}
\hline \hline R & R square & Adjusted R square & Std. Error of the Estimate \\
\hline \hline .2771 & .077 & .068126692 & .462 \\
\hline
\end{tabular}

The independent variable is wavelength.

Table A.7: $A N O V A$ table: exponential curve estimation in the regression analysis, tested for single observations within one measurement set: spectral reflectance of P.oceanica. SPSS. Pages: $<45>,<50>$

\begin{tabular}{|c|c|c|c|c|c|}
\hline \hline & Sum of squares & df & Mean Square & $\mathrm{F}$ & Sig. \\
\hline \hline Regression & 1.810 & 1 & 1.810 & 8.477 & .004 \\
\hline Residual & 21.781 & 102 & .214 & & \\
\hline Total & 23.592 & 103 & & & \\
\hline
\end{tabular}

The independent variable is wavelength.

Table A.8: Coefficients of the regression analysis (exponential curve estimation) of the spectral reflectance of P.oceanica. SPSS. Page: $<45>$

\begin{tabular}{|c|c|l|c|c|c|}
\hline \hline & \multicolumn{2}{|c|}{ Unstandardized Coefficients } & \multicolumn{3}{|c|}{ Sig. } \\
& $\mathrm{B}$ & Std.Error & Stand. Coef. Beta & $\mathrm{t}$ & Sig. \\
\hline \hline wavelength & -.001 & .000 & -.277 & -2.912 & .004 \\
\hline constant & .464 & .121 & & 3.821 & .000 \\
\hline
\end{tabular}

The underlying process assumed is independence (white noise).

Based on the asymptotic chi-square approximation. 


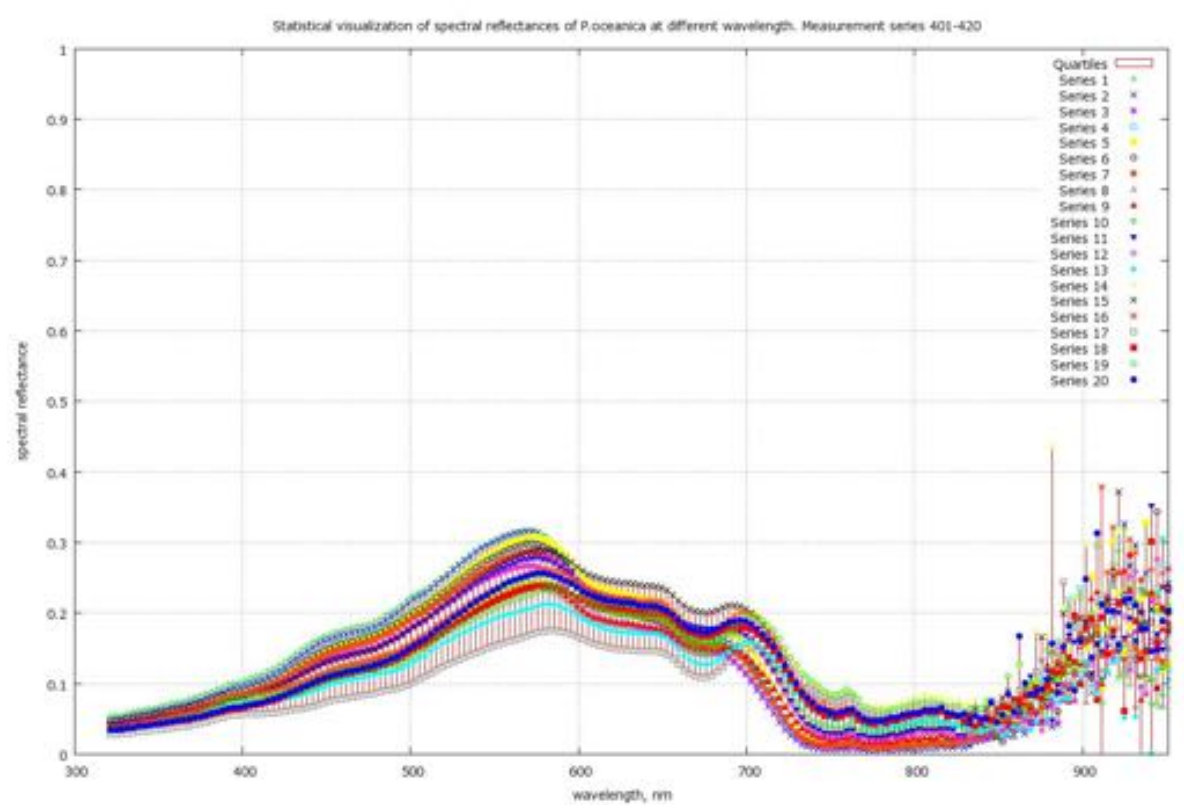

Figure A.30: Fragment of the statistical analysis of the P.oceanica reflectance. Example of data set 401-420. Visualization of the measured data together with statistical values: interquartile ranging, medians, means. Gnuplot. Pages: $<23>,<32>,<29>$

Table A.9: Results of the ANOVA one-way analysis: results of the single factor (depth) testing of the radiance of P.oceanica at various depths: $0.5,1.5$ and 2.5 meters. SPSS. Page: $<31>$

\begin{tabular}{|c|c|c|c|c|c|c|}
\hline \hline Source of Variation & SS & df & MS & F & P value & F crit \\
\hline Between Groups & 373841.7048 & 2 & 186920.8524 & 407.85359 & 1.11677 & 3.01153 \\
\hline Within Groups & 261233.1668 & 570 & 458.3038014 & & & \\
\hline Total & 635074.8716 & 572 & & & & \\
\hline
\end{tabular}

P more than .05, which means that there is a significant difference in radiance of P.oceanica at three different depth $(0.5,1.5$ and 2.5$)$. 
Table A.10: Summary of the ANOVA one-way analysis: results of the single factor (depth) testing of the radiance of P.oceanica at various depths: $0.5,1.5$ and 2.5 meters. SPSS. Page: $<31>$

\begin{tabular}{|c|c|c|c|c|}
\hline \hline Groups & Count & Sum & Average & Variance \\
\hline \hline Column 1 & 191 & 760.126692 & 3.9797209 & 18.6948046 \\
\hline Column 2 & 191 & 4527.214218 & 23.7026922 & 251.4863978 \\
\hline Column 3 & 191 & 12465.19972 & 65.2628257 & 1104.7302015 \\
\hline
\end{tabular}

$\mathrm{P}>0.05$, which means that there is a significant difference in radiance of P.oceanica at three different depth $(0.5,1.5$ and 2.5$)$.

Table A.11: Results of the statistical analysis of spectral reflectance of P.oceanica, sets 1-350). Wavelength step: $3 \mathrm{~nm}$. Measured on Agia Pelagia beach, 15th October. Pages: $<31>,<44>,<49>$

\begin{tabular}{|c|c|c|c|c|c|c|}
\hline wl & mean & Q1 & $\min$ & Q3 & $\max$ & median \\
\hline 318.23354 & 0.030467 & 0.038907 & 0.029764 & 0.069762 & 0.116100 & 0.048984 \\
\hline $\mathbf{3 2 1 . 5 7 6 6 6}$ & 0.028129 & 0.037310 & 0.027965 & 0.066572 & 0.110918 & 0.046450 \\
\hline 324.92025 & 0.030163 & 0.038570 & 0.029502 & 0.068216 & 0.114120 & 0.047710 \\
\hline 328.26428 & 0.030457 & 0.038936 & 0.029789 & 0.069098 & 0.116080 & 0.048574 \\
\hline 331.60876 & 0.031407 & 0.040192 & 0.030731 & 0.071247 & 0.119681 & 0.050299 \\
\hline $\mathbf{3 3 4 . 9 5 3 6 7}$ & 0.032480 & 0.041545 & 0.031781 & 0.073494 & 0.123651 & 0.051941 \\
\hline 338.29900 & 0.033560 & 0.043030 & 0.032847 & 0.076252 & 0.128290 & 0.054334 \\
\hline 341.64474 & 0.034067 & 0.043938 & 0.033356 & 0.077587 & 0.131152 & 0.055506 \\
\hline 344.99089 & 0.035346 & 0.045272 & 0.034616 & 0.080212 & 0.135395 & 0.057653 \\
\hline 348.33743 & 0.036199 & 0.046719 & 0.035465 & 0.082716 & 0.139829 & 0.059655 \\
\hline 351.68436 & 0.037336 & 0.048027 & 0.036587 & 0.085062 & 0.144101 & 0.061509 \\
\hline 355.03166 & 0.038611 & 0.049598 & 0.037852 & 0.087963 & 0.149193 & 0.063835 \\
\hline 358.37932 & 0.039897 & 0.051320 & 0.039131 & 0.091143 & 0.154409 & 0.066354 \\
\hline 361.72735 & 0.040712 & 0.052408 & 0.039951 & 0.093252 & 0.157952 & 0.068034 \\
\hline $\mathbf{3 6 5 . 0 7 5 7 2}$ & 0.041541 & 0.053517 & 0.040782 & 0.095491 & 0.161650 & 0.069682 \\
\hline 368.42442 & 0.042378 & 0.054625 & 0.041622 & 0.097634 & 0.164944 & 0.071524 \\
\hline 371.77346 & 0.043682 & 0.056205 & 0.042926 & 0.100782 & 0.169458 & 0.074006 \\
\hline 375.12281 & 0.044525 & 0.057191 & 0.043779 & 0.102916 & 0.172533 & 0.075888 \\
\hline 378.47247 & 0.045786 & 0.058849 & 0.045039 & 0.105993 & 0.177150 & 0.078339 \\
\hline $\mathbf{3 8 1 . 8 2 2 4 3}$ & 0.047361 & 0.060698 & 0.046615 & 0.109681 & 0.182421 & 0.081219 \\
\hline 385.17269 & 0.048457 & 0.062067 & 0.047717 & 0.112447 & 0.186097 & 0.083586 \\
\hline $\mathbf{3 8 8 . 5 2 3 2 2}$ & 0.049503 & 0.063533 & 0.048767 & 0.115361 & 0.190440 & 0.086143 \\
\hline 391.87402 & 0.051271 & 0.065536 & 0.050529 & 0.119310 & 0.196618 & 0.089165 \\
\hline 395.22508 & 0.052033 & 0.066436 & 0.051298 & 0.121231 & 0.199547 & 0.090884 \\
\hline 398.57640 & 0.052346 & 0.066859 & 0.051625 & 0.122328 & 0.201038 & 0.091905 \\
\hline 401.92796 & 0.053246 & 0.067963 & 0.052517 & 0.124750 & 0.204926 & 0.093940 \\
\hline 405.27975 & 0.054472 & 0.069505 & 0.053749 & 0.127847 & 0.209718 & 0.096463 \\
\hline 408.63176 & 0.055492 & 0.070692 & 0.054773 & 0.130382 & 0.213406 & 0.098620 \\
\hline 411.98399 & 0.056331 & 0.071703 & 0.055621 & 0.132628 & 0.216692 & 0.100545 \\
\hline 415.33642 & 0.057682 & 0.073235 & 0.056976 & 0.135758 & 0.221309 & 0.103354 \\
\hline 418.68905 & 0.058942 & 0.074842 & 0.058240 & 0.138984 & 0.226028 & 0.106207 \\
\hline 422.04186 & 0.060504 & 0.076815 & 0.059805 & 0.142833 & 0.231707 & 0.109487 \\
\hline 425.39485 & 0.062547 & 0.079376 & 0.061847 & 0.147773 & 0.238892 & 0.113584 \\
\hline 428.74801 & 0.064817 & 0.082141 & 0.064115 & 0.153137 & 0.246681 & 0.118126 \\
\hline 432.10132 & 0.066664 & 0.084493 & 0.065967 & 0.157743 & 0.253230 & 0.122093 \\
\hline
\end{tabular}


Table A.8: Spectral reflectance of P.oceanica (continued from previous page)

\begin{tabular}{|c|c|c|c|c|c|c|}
\hline wl & mean & Q1 & $\min$ & Q3 & $\max$ & median \\
\hline 435.45478 & 0.068616 & 0.086926 & 0.067925 & 0.162414 & 0.259765 & 0.126092 \\
\hline 438.80838 & & & & 0.167825 & 0.267712 & 100 \\
\hline 442.16211 & 701 & 092360 & 72010 & 0.172808 & 75027 & 134721 \\
\hline 445.51596 & 0.074550 & 0.094801 & .073855 & 0.177420 & 282203 & 0.138517 \\
\hline 448.86992 & 0.076196 & 0.096995 & 0.075496 & 0.181512 & 0.288621 & 0.141853 \\
\hline 452.22397 & 0.077581 & 0.098795 & 0.076876 & 0.184975 & 0.294309 & 0.144634 \\
\hline 455.57812 & 0.079009 & 0.100624 & 0.078296 & 0.188516 & 0.300251 & 0.147486 \\
\hline 458.93235 & & 0.10 & & 0.191424 & & \\
\hline 462.28665 & & 103609 & & 0.194453 & & \\
\hline 465.64102 & 0.082366 & 105087 & 0.081658 & 0.197331 & .314862 & .154601 \\
\hline 468.99543 & 0.083316 & 0.106273 & 0.082589 & 0.199757 & 0.319033 & 0.156521 \\
\hline 472.34990 & 0.084192 & 0.107427 & 0.083464 & 0.202075 & .323294 & 0.158350 \\
\hline 475.70439 & 122 & 0.108714 & 1392 & 0.204674 & 802 & 50310 \\
\hline 479.05891 & & 48 & & 0.207940 & & 881 \\
\hline 482.41344 & & 712 & & 0.212533 & 090 & 5595 \\
\hline 485.76798 & 064 & 295 & & 585 & & 644 \\
\hline 489.12252 & 0.091822 & 0.117678 & 0.091073 & 0.222210 & 55070 & 0.174440 \\
\hline 492.47704 & & 0.120058 & 0.092835 & 0.226915 & 1882 & 0.178261 \\
\hline 495.83154 & & 0.12 & & 0.232757 & & $\overline{979}$ \\
\hline 499.18600 & & 92 & 0.0 & 0.239161 & 03 & 192 \\
\hline 502.54043 & 97 & 43 & 0 . & 918 & 52 & 036 \\
\hline 505.89480 & 34 & 69 & 39 & 0.246962 & 456 & 0.194588 \\
\hline 509.24911 & & 22 & & 0.249966 & 001 & 0.196947 \\
\hline 512.60336 & & 0.136069 & & 523 & & 0556 \\
\hline 515.9 & & 307 & & 0.259986 & & 238 \\
\hline 519.3 & & 0.1 & & 0.265948 & & 237 \\
\hline $\mathbf{5 2 2 . 6 6 5 5 7}$ & 891 & 090 & 50 & 0.272217 & 485 & 5339 \\
\hline 526.01943 & 799 & 266 & & .278942 & 0382 & 0.220946 \\
\hline 529.37318 & & 0.156156 & 0.117302 & 0.285384 & 045 & 0.226407 \\
\hline 532.72680 & & 0.159690 & & 491 & 964 & 1403 \\
\hline 536.0 & & & & & & 144 \\
\hline 539.4 & & & & 0.3 & & 492 \\
\hline 542.78681 & & 24 & 97 & 0.306828 & 311 & 0.243819 \\
\hline 546.13983 & 93 & 170255 & 5944 & 0.309747 & 7098 & 0.246131 \\
\hline 549.49267 & 0.12 & 0.171844 & 887 & 0.312256 & 1208 & 0.248155 \\
\hline 552.84533 & & 0.173 & & 0.31 & 23 & 0.249936 \\
\hline 556. & & & & & & 1984 \\
\hline 559.5 & & & & & & \\
\hline 562.90211 & & & 79 & 0.320731 & 658 & 511 \\
\hline 566.25394 & 944 & 176786 & 0.130273 & 0.321450 & 0.508802 & 0.254761 \\
\hline 569.60554 & 139 & 176171 & 456 & 0.320617 & 508657 & 0.253650 \\
\hline 572.95690 & 0.12 & 0.174497 & 0.127627 & 0.317523 & 0.50 & 0.250781 \\
\hline 576.30800 & & & & 578 & & 45834 \\
\hline & & & & & & 873 \\
\hline 583.00943 & & & & 0.289985 & 10 & 0.227889 \\
\hline 586.35972 & & 0.152038 & & 0.275585 & 0.449536 & 0.216026 \\
\hline 589.70973 & 0.102719 & 0.142758 & 0.101038 & 0.258779 & 0.425248 & 0.201868 \\
\hline 593.05945 & 0.094713 & 0.132871 & 0.093063 & 0.240383 & 0.399506 & 0.186687 \\
\hline 596.40885 & 0.086028 & 0.121987 & 0.084416 & 0.220594 & 0.372134 & 0.170438 \\
\hline 599.75794 & & 113 & & 0.200557 & 876 & 0.154016 \\
\hline 603.10670 & 0.070071 & 0.102079 & 0.068539 & 0.183962 & 0.320865 & 0.140543 \\
\hline
\end{tabular}


Table A.8: Spectral reflectance of P.oceanica (continued from previous page)

\begin{tabular}{|c|c|c|c|c|c|c|}
\hline wl & mean & Q1 & $\min$ & Q3 & $\max$ & median \\
\hline 606.45513 & 0.064972 & 0.095380 & 0.063465 & 0.172189 & 0.304973 & 0.131080 \\
\hline 609.80321 & & & & 164 & 5132 & \\
\hline 613.15094 & .059707 & .088656 & 0.058235 & .160355 & 39194 & 121614 \\
\hline 616.49830 & 0.058283 & 0.086915 & 0.056821 & 0.157314 & 85336 & .119161 \\
\hline 619.84529 & 0.057038 & 0.085386 & 0.055588 & 0.154781 & 0.281737 & 0.117003 \\
\hline 623.19189 & 0.055996 & 0.084129 & 0.054556 & 0.152697 & 0.278854 & 0.115243 \\
\hline 626.53811 & 0.055200 & 0.083282 & 0.053763 & 0.151068 & 0.277016 & 0.113879 \\
\hline 629.88392 & & & & 0.14 & & \\
\hline 633.22932 & & 860 & 869 & 147176 & & \\
\hline 636.57430 & 0.052033 & 0.079147 & 0.050611 & 0.144415 & 68135 & 0.108222 \\
\hline 639.91885 & 0.050841 & 0.077438 & 0.049432 & 0.141810 & 0.265181 & 0.106188 \\
\hline 643.26296 & 0.049737 & 0.075977 & 0.048336 & 0.139466 & 63239 & 0.104485 \\
\hline 646.60662 & 0.02 & 0.074330 & 076 & 0.136488 & 0596 & 2251 \\
\hline 649.94982 & & $0.0 \%$ & & 0.132376 & 761 & 096 \\
\hline 653.29255 & 0 & 0.068866 & 59 & 126637 & 247 & 730 \\
\hline 656.63481 & 0.0 & 0.064447 & & 661 & 539 & 686 \\
\hline 659.97657 & 0.0 & 0.059971 & 997 & 0.110774 & 223366 & 0.082411 \\
\hline 663.31784 & 0.035847 & 0.056353 & 8750 & 0.104541 & 2843 & 0.077616 \\
\hline 666.65861 & & 0.0 & & 0.100476 & & 4622 \\
\hline 669.9 & & & & 06 & & 881 \\
\hline 673.3 & & 33 & 94 & 0.09 & 744 & 021 \\
\hline 676.67777 & 897 & 0.051894 & 003 & 0.095851 & 7694 & 0.071600 \\
\hline 680.01641 & & 265 & & 789 & 389 & 686 \\
\hline 683.35451 & & & & 053 & & 2478 \\
\hline 686.69203 & & & & 0.09 & & \\
\hline 690.0 & & & & 0.0 & & 20 \\
\hline 693.36536 & 0.0 & 0.05 & 29 & 0.100112 & 708 & 4967 \\
\hline 696.70114 & 595 & 0.05 & 554 & 994 & 198 & 0.075367 \\
\hline 700.03633 & 156 & 0.058426 & & 0.101504 & 413 & 0.075789 \\
\hline$\overline{703.37090}$ & & 0.058 & & 0.101601 & 5696 & 75467 \\
\hline 706. & & & & & & \\
\hline 710. & & & & & & \\
\hline 713.37085 & & & 58 & 0.09 & 402 & 8982 \\
\hline 716.70288 & 935 & 0.050808 & 789 & 0.089359 & 2502 & 0.066018 \\
\hline 720.03426 & & 0.047084 & 162 & 0.082940 & 535 & 0.061184 \\
\hline 723.36497 & 0.0 & 0.041962 & & 0.075244 & 363 & 350 \\
\hline 726.6 & & & & 83 & & 522 \\
\hline 730.02435 & & & & & & \\
\hline 733.35299 & 7 & 0.02 & & 0.05 & 592 & 0.036934 \\
\hline 736.68094 & .010923 & 0.024633 & 0.011200 & 0.046727 & 0.138634 & 0.032350 \\
\hline 740.00817 & 0.009740 & 0.022355 & 145 & 0.042861 & 2244 & 0.029414 \\
\hline 743.33467 & 0.008848 & 0.020756 & 0.009299 & 0.040084 & 0.127367 & 0.027450 \\
\hline & & & & 166 & & 9956 \\
\hline$\overline{749.98548}$ & & & & & & \\
\hline 753.30975 & & & & 0.035542 & 242 & 967 \\
\hline$\overline{756.63327}$ & 0.007777 & 0.018797 & 273 & 0.036601 & 0.119191 & 0.024621 \\
\hline 759.95601 & 0.008651 & 0.020234 & 0.009191 & 0.039371 & 0.128165 & 0.026558 \\
\hline 763.27797 & 0.008355 & 0.020033 & 0.008883 & 0.038779 & 0.126589 & 0.026439 \\
\hline 766.59914 & 0.007232 & 0.017224 & 0.007708 & 0.033862 & 0.113056 & 0.022658 \\
\hline 769.91951 & & & & 0.02 & 584 & 0.020196 \\
\hline 773.23907 & 0.006016 & 0.014264 & 0.006407 & 0.028277 & 0.100504 & 0.019270 \\
\hline
\end{tabular}

xxvi

MSc Thesis

"Seagrass mapping and monitoring along the coasts of Crete, Greece" 
Table A.8: Spectral reflectance of P.oceanica (continued from previous page)

\begin{tabular}{|c|c|c|c|c|c|c|}
\hline wl & mean & Q1 & $\min$ & Q3 & $\max$ & median \\
\hline 776.55781 & 0.005801 & 0.013966 & 0.006189 & 0.027876 & 0.099265 & 0.019096 \\
\hline 779.87573 & & & & 0.028320 & 00314 & \\
\hline 783.19280 & 6136 & 014643 & 6524 & 0.028946 & 01978 & 978 \\
\hline 786.50903 & 0.006559 & 0.015475 & 0.006967 & 0.030261 & 104960 & .021034 \\
\hline 789.82440 & 0.007038 & 0.016900 & 0.007440 & 0.031880 & 0.107764 & 0.022351 \\
\hline 793.13891 & 0.007598 & 0.017699 & 0.008021 & 0.033662 & 0.111651 & 0.023996 \\
\hline 796.45254 & 0.008137 & 0.018912 & 0.008556 & 0.035621 & 0.114760 & 299 \\
\hline 799.76528 & & 30 & & 323 & & \\
\hline 803.07713 & & .020935 & 544 & 0.038749 & 6699 & 598 \\
\hline 806.38808 & 0.009299 & 0.021600 & 0.009772 & 0.039865 & 22278 & 0.028669 \\
\hline 809.69811 & 0.009526 & 0.022082 & 0.009994 & 0.040470 & 0.124400 & 0.029071 \\
\hline 813.00722 & 0.009575 & 0.022239 & 0.010086 & 0.040394 & 0.124681 & 0.029112 \\
\hline 816.31539 & 0.0 & 0.021517 & 572 & 0.039929 & 390 & 8547 \\
\hline 819.62263 & & 0.020295 & & 0.037598 & & 799 \\
\hline 822.92891 & & 0.017661 & & 0.034147 & & 239 \\
\hline 826.23423 & 397 & 0.015734 & & 0.030561 & & 328 \\
\hline 829.53858 & 0.0 & 0.013286 & 0.006340 & 0.026347 & .095980 & 0.018276 \\
\hline 832.84195 & & 0.010824 & & 0.022895 & 0.087424 & 5291 \\
\hline 836.14433 & & 0.0 & & 0.0 & & 090 \\
\hline 839.44571 & & 10 & & 472 & & 432 \\
\hline 842.74608 & & 22 & 94 & 18 & & 511 \\
\hline 846.04544 & 121 & 0.007283 & 442 & 689 & 570 & 195 \\
\hline 849.34376 & & 35 & & & & 9926 \\
\hline 852.64105 & & 0.00 & & & & 824 \\
\hline 855.93730 & & & & & & 103 \\
\hline 859.23249 & & 0.0 & & 0.0 & & 889 \\
\hline 862.52661 & & 0.006846 & 0.0 & 0.016677 & 344 & 9943 \\
\hline 865.81966 & 508 & .007308 & 0.0 & 5406 & 265 & 0.010239 \\
\hline 869.11162 & & & & 118 & & 382 \\
\hline 872.40249 & & 89 & & 0.0 & 487 & 688 \\
\hline 875.6 & & & & & & 912 \\
\hline 878.9 & & & & & & \\
\hline 882.26844 & & 0.00 & 0.0 & 0.019452 & 564 & 996 \\
\hline 885.55484 & 940 & 0.008588 & 400 & 0.021344 & 0.080998 & 0.012489 \\
\hline 888.84010 & & 0.00 & & 0.022626 & 9420 & 0.013547 \\
\hline 892.12421 & & 0.01 & 0.0 & 0.02 & 97 & 324 \\
\hline 716 & & & & & & 328 \\
\hline 898.6 & & & & & & \\
\hline 901.96953 & & 0.01 & & 0.032824 & 000 & 0.020699 \\
\hline 905.24894 & 0.004167 & .014798 & 0.004249 & 0.034899 & 0.135645 & 0.022265 \\
\hline 908.52716 & 0.003891 & .015616 & 0.002986 & 0.037403 & 8828 & 0.024065 \\
\hline 911.80416 & 0.00 & 0.018706 & 306 & 0.043272 & 375 & 0.027328 \\
\hline & & & & & & 7234 \\
\hline & & & & & & 950 \\
\hline 921.62783 & & & & 0.047785 & & 0.032131 \\
\hline 924.89991 & 0.0 & 0.019678 & 957 & 0.051741 & 0.127093 & 0.032278 \\
\hline 928.17074 & 0.002955 & 0.021413 & 0.004277 & 0.053042 & 0.266342 & 0.035277 \\
\hline 931.44030 & 0.002679 & 0.023349 & 0.004029 & 0.057574 & 0.225003 & 0.036074 \\
\hline 0859 & 0.003446 & 3229 & 0.00 & 0.059098 & 0.549439 & 0.037722 \\
\hline 559 & & 132 & & 0.065475 & 072 & 0.040848 \\
\hline 941.24130 & 0.005209 & 0.024892 & 0.006147 & 0.058814 & 0.281685 & 0.039602 \\
\hline
\end{tabular}

xxvii

MSc Thesis

"Seagrass mapping and monitoring along the coasts of Crete, Greece" 
Table A.8: Spectral reflectance of P.oceanica (continued from previous page)

\begin{tabular}{|l|l|l|l|l|l|l|}
\hline wl & mean & Q1 & min & Q3 & max & median \\
\hline 944.50571 & 0.003354 & 0.025994 & 0.004299 & 0.064521 & 0.232462 & 0.041118 \\
\hline $\mathbf{9 4 7 . 7 6 8 8 1}$ & 0.003156 & 0.023476 & 0.003813 & 0.059536 & 0.246006 & 0.037035 \\
\hline $\mathbf{9 5 1 . 0 3 0 5 8}$ & 0.002296 & 0.026581 & 0.002380 & 0.067924 & 0.265845 & 0.041463 \\
\hline
\end{tabular}

Table A.12: Nonlinear model: results of the logistic analysis of the seawater radiance with sediments (15.X.), Series:V16. Gretl. Page $<44>$

Model 2: Logistic, using observations 1:01-8:23 $(T=191)$

Dependent variable: v16

$$
\hat{y}=1 /\left(1+e^{-X \hat{\beta}}\right)
$$

\begin{tabular}{|c|c|c|c|c|} 
& Coefficient & Std. Error & $t$-ratio & p-value \\
const & 1.58324 & 0.407258 & 3.8876 & 0.0001 \\
v1 & -0.00512630 & 0.000615503 & -8.3286 & 0.0000
\end{tabular}

Statistics based on the transformed data:

$\begin{array}{lrll}\text { Sum squared resid } & 462.8481 & \text { S.E. of regression } & 1.564906 \\ R^{2} & 0.268481 & \text { Adjusted } R^{2} & 0.264610 \\ F(1,189) & 69.36634 & \text { P-value }(F) & 1.63 \mathrm{e}-14 \\ \text { Log-likelihood } & -355.5467 & \text { Akaike criterion } & 715.0935 \\ \text { Schwarz criterion } & 721.5980 & \text { Hannan-Quinn } & 717.7281 \\ \hat{\rho} & 0.980662 & \text { Durbin-Watson } & 0.020351\end{array}$

Statistics based on the original data:

Mean dependent var $\quad 0.262542 \quad$ S.D. dependent var 0.205031

Sum squared resid 10.80565 S.E. of regression 0.239108 
Table A.13: Results of the autocorrelation analysis of the measurement set 1-16 of the spectral reflectance of P.oceanica (15.X.), Series:V3. SPSS. Page $<45>$

\begin{tabular}{|c|c|c|c|c|c|}
\hline \hline \multirow{2}{*}{ Lag } & Autocorrelation & Std error(a) & \multicolumn{3}{|c|}{ Box-Ljung Statistic } \\
& Value & df & Sig (b) \\
\hline \hline 1 & .844 & .071 & 141.324 & 1 & .000 \\
\hline 2 & .816 & .071 & 273.208 & 2 & .000 \\
\hline 3 & .799 & .071 & 400.323 & 3 & .000 \\
\hline 4 & .780 & .071 & 522.217 & 4 & .000 \\
\hline 5 & .723 & .070 & 627.372 & 5 & .000 \\
\hline 6 & .700 & .070 & 726.581 & 6 & .000 \\
\hline 7 & .745 & .070 & 839.623 & 7 & .000 \\
\hline 8 & .624 & .070 & 919.336 & 8 & .000 \\
\hline 9 & .584 & .070 & 989.540 & 9 & .000 \\
\hline 10 & .562 & .069 & 1054.920 & 10 & .000 \\
\hline 11 & .522 & .069 & 1111.681 & 11 & .000 \\
\hline 12 & .464 & .069 & 1156.693 & 12 & .000 \\
\hline 13 & .475 & .069 & 1204.314 & 13 & .000 \\
\hline 14 & .463 & .069 & 1249.726 & 14 & .000 \\
\hline 15 & .401 & .069 & 1283.916 & 15 & .000 \\
\hline 16 & .389 & .068 & 1316.427 & 16 & .000 \\
\hline
\end{tabular}

The underlying process assumed is independence (white noise).

Based on the asymptotic chi-square approximation.

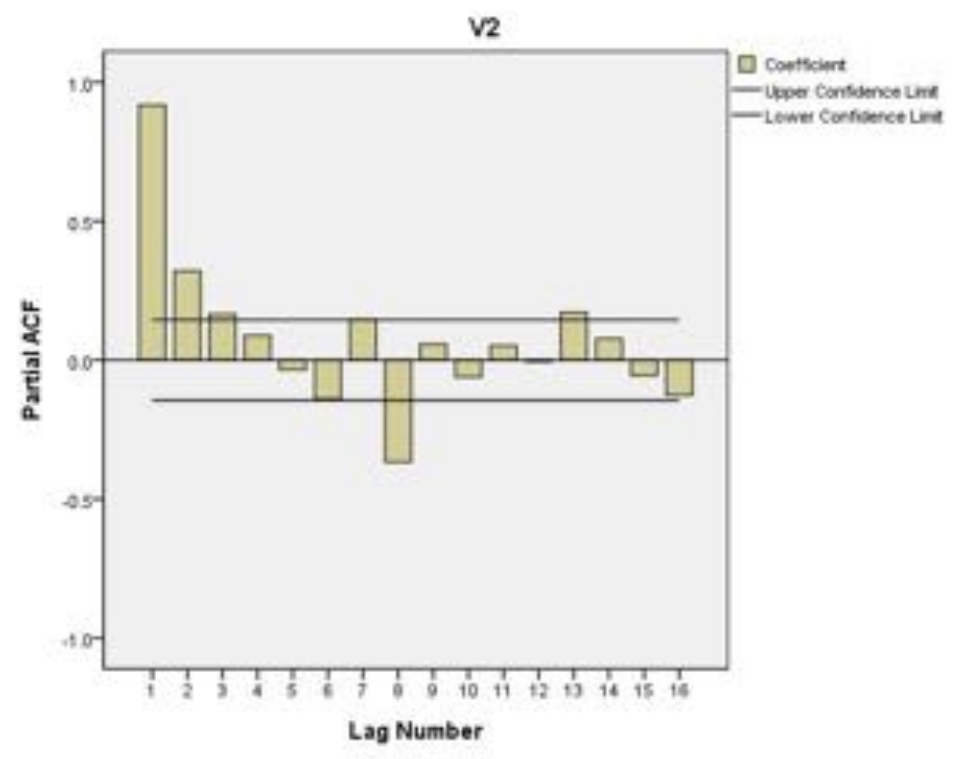

Figure A.31: Partial correlation analysis of the measurement set 1-16 of the spectral reflectance of P.oceanica (15.X.). Visualization in SPSS. Page: $<45>$ 


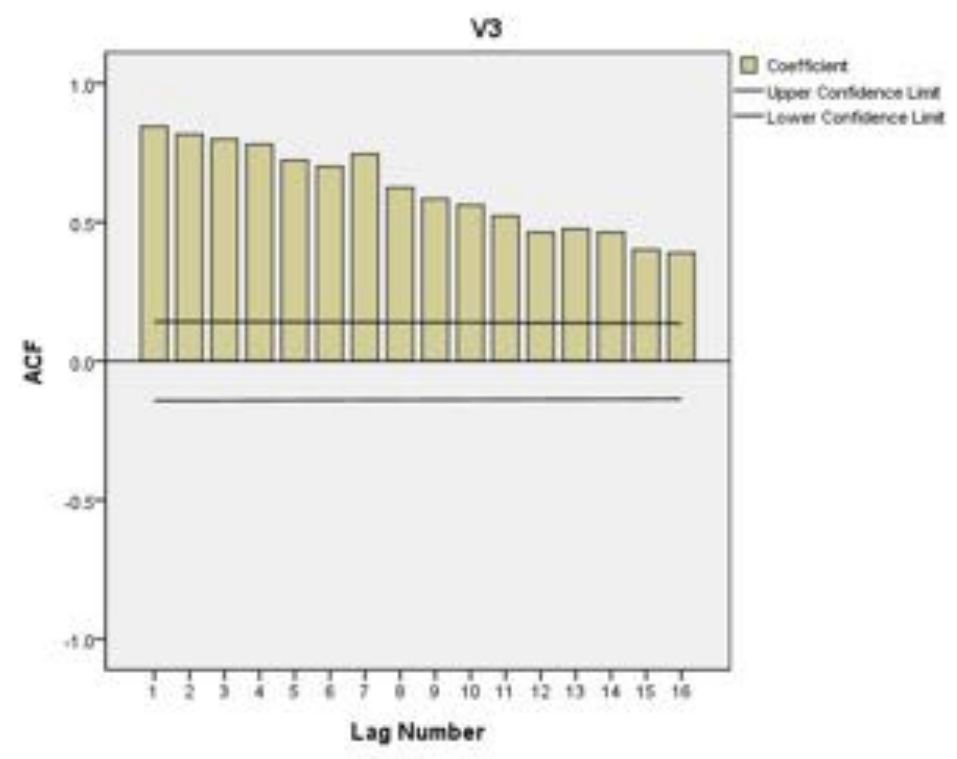

Figure A.32: Autocorrelation analysis of the measurement set 1-16 of the spectral reflectance of P.oceanica (15.X.). Visualization in SPSS. Page: $<45>$

Table A.14: Results of the partial autocorrelation analysis of the measurement set 1-16 of the spectral reflectance of P.oceanica (15.X.), Series:V3. SPSS. Page: $<44>$

\begin{tabular}{|c|c|c|}
\hline \hline Lag & Partial Autocorrelation & Std error \\
\hline \hline 1 & .844 & .072 \\
\hline 1 & .358 & .072 \\
\hline 3 & .217 & .072 \\
\hline 4 & .125 & .072 \\
\hline 5 & -.093 & .072 \\
\hline 6 & .003 & .072 \\
\hline 7 & .310 & .072 \\
\hline 8 & -.403 & .072 \\
\hline 9 & -.117 & .072 \\
\hline 10 & .033 & .072 \\
\hline 11 & -.104 & .072 \\
\hline 12 & .023 & .072 \\
\hline 13 & .246 & .072 \\
\hline 14 & -.164 & .072 \\
\hline 15 & .084 & .072 \\
\hline 16 & .152 & .072 \\
\hline
\end{tabular}


Table A.15: Ordinary Least Squares: results of the $O L S$ analysis of the measurement set 326-350 of the spectral reflectance of P.oceanica (15.X.). Gretl. Page: $<45>$

Model 2: OLS, using observations 326-350

Dependent variable: v20

\begin{tabular}{ccccc} 
& Coefficient & Std. Error & $t$-ratio & p-value \\
const & 0.414957 & 0.0299342 & 13.8623 & 0.0000 \\
v1 & -0.000441803 & $4.52185 \mathrm{e}-005$ & -9.7704 & 0.0000 \\
\hline \hline
\end{tabular}

$\begin{array}{lrlr}\text { Mean dependent var } & 0.134005 & \text { S.D. dependent var } & 0.140653 \\ \text { Sum squared resid } & 2.497416 & \text { S.E. of regression } & 0.114951 \\ R^{2} & 0.335585 & \text { Adjusted } R^{2} & 0.332070 \\ F(1,189) & 95.46076 & \text { P-value }(F) & 1.65 \mathrm{e}-18 \\ \text { Log-likelihood } & 143.1678 & \text { Akaike criterion } & -282.3357 \\ \text { Schwarz criterion } & -275.8311 & \text { Hannan-Quinn } & -279.7010\end{array}$




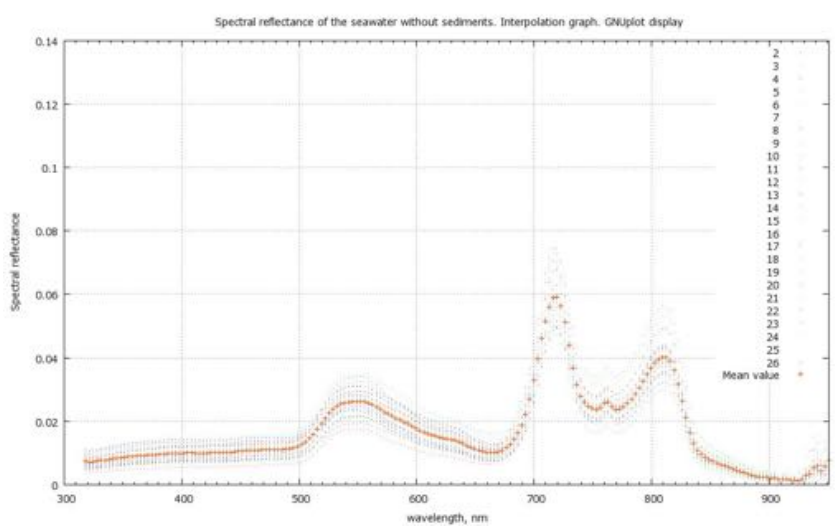

Figure A.33: Spectral reflectance of the seawater without sediments. Interpolation graph. Gnuplot display. Page: $<38>$

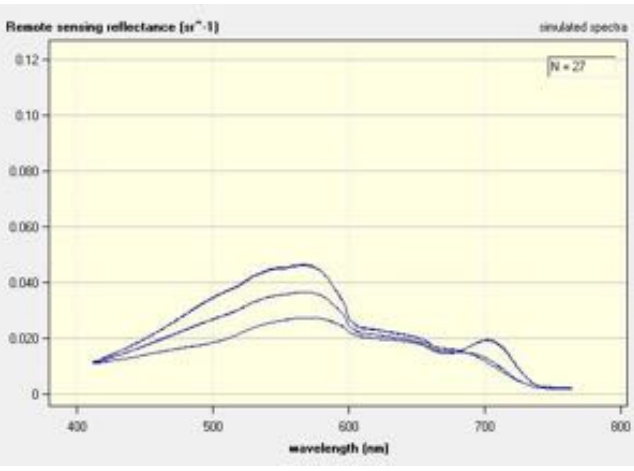

(a) CZCS

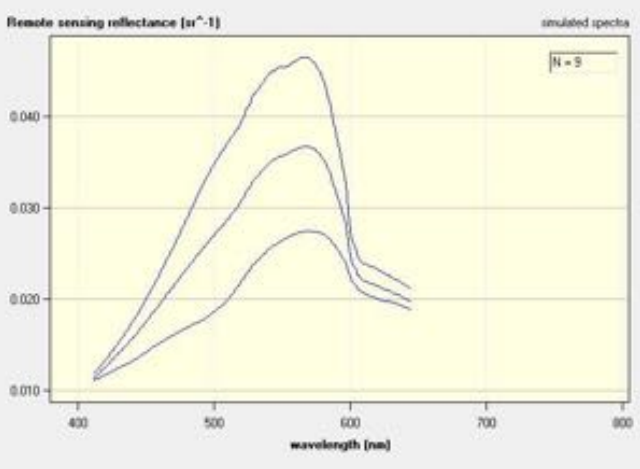

(c) MODIS

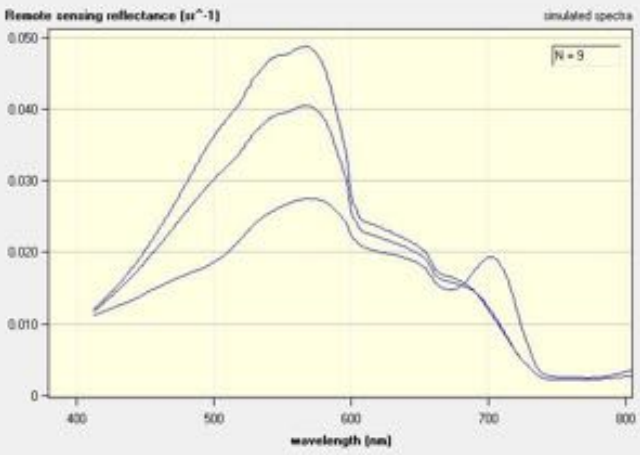

(b) MERIS

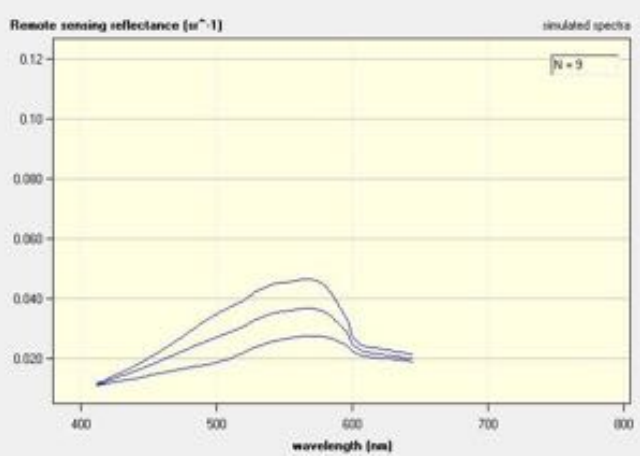

(d) SeaWiFS

Figure A.34: WASI-simulated remote sensing reflectance of P.oceanica at various sensors. Pages: $<40>,<50>$ 
Table A.16: Summary statistics of measurements set: 301-325.

Example of selected variables 12-22. Gretl. Page: $<44>$

Summary Statistics, using the observations 301-325

\begin{tabular}{|c|c|c|c|c|}
\hline Variable & Mean & Median & Minimum & Maximum \\
\hline v12 & 0.221475 & 0.139032 & 0.00101700 & 0.780730 \\
v13 & 0.217074 & 0.139285 & 0.00108700 & 0.754430 \\
\hline v14 & 0.167442 & 0.110878 & 0.000348000 & 0.575242 \\
v15 & 0.155908 & 0.111737 & 0.0125650 & 0.483602 \\
\hline v16 & 0.158329 & 0.111647 & 0.0101590 & 0.498096 \\
v17 & 0.167575 & 0.111349 & 0.000836000 & 0.579004 \\
\hline v18 & 0.125868 & 0.0863670 & 0.000662000 & 0.417701 \\
\hline v19 & 0.179261 & 0.117898 & 0.000935000 & 0.612021 \\
\hline v20 & 0.141302 & 0.0932400 & 0.000714000 & 0.478343 \\
v21 & 0.228822 & 0.143105 & 0.00149500 & 0.800529 \\
\hline v22 & 0.174892 & 0.114994 & 0.000343000 & 0.592146 \\
\hline \hline Variable & Std. Dev. & Coef.Var. & Skewness & Ex. kurtosis \\
\hline v12 & 0.246134 & 1.11134 & 0.930598 & -0.393370 \\
\hline v13 & 0.239324 & 1.10250 & 0.910879 & -0.440017 \\
v14 & 0.181797 & 1.08573 & 0.884089 & -0.466508 \\
\hline v15 & 0.151811 & 0.973718 & 0.796534 & -0.646866 \\
\hline v16 & 0.155834 & 0.984241 & 0.832126 & -0.587890 \\
\hline v17 & 0.182383 & 1.08837 & 0.901570 & -0.435120 \\
\hline v18 & 0.134253 & 1.06662 & 0.820573 & -0.603688 \\
\hline v19 & 0.195217 & 1.08901 & 0.873615 & -0.515800 \\
\hline v20 & 0.152787 & 1.08128 & 0.863700 & -0.525357 \\
\hline v21 & 0.252696 & 1.10434 & 0.924172 & -0.408867 \\
\hline v22 & 0.189797 & 1.08523 & 0.858809 & -0.546215 \\
\hline & & & & \\
\hline
\end{tabular}


Table A.17: Summary of the table with values of the spectral reflectance of P.oceanica measured on three different depths, R. Page: $<31>$

\begin{tabular}{|c|c|c|c|}
\hline \hline wl & X0.5m & X1.5m & X2.5m \\
\hline \hline Min. :318.2 & Min. :0.00000 & Min. : 0.7792 & Min. :0.005096 \\
\hline 1st Qu.:476.9 & 1st Qu.:0.03398 & 1st Qu.:14.4084 & 1st Qu.:0.091878 \\
\hline Median :636.1 & Median :0.10955 & Median :22.4621 & Median :0.269328 \\
\hline Mean :635.6 & Mean :0.11392 & Mean :19.6899 & Mean :0.301121 \\
\hline 3rd Qu.:794.5 & 3rd Qu.:0.17198 & 3rd Qu.:25.8785 & 3rd Qu.:0.431055 \\
\hline Max. :950.9 & Max. :0.32937 & Max. :30.9573 & Max. :0.981314 \\
\hline
\end{tabular}

From: DepthData <- read.table(file="Three-Depths.dat", sep="”, header=T); summary(DepthData)

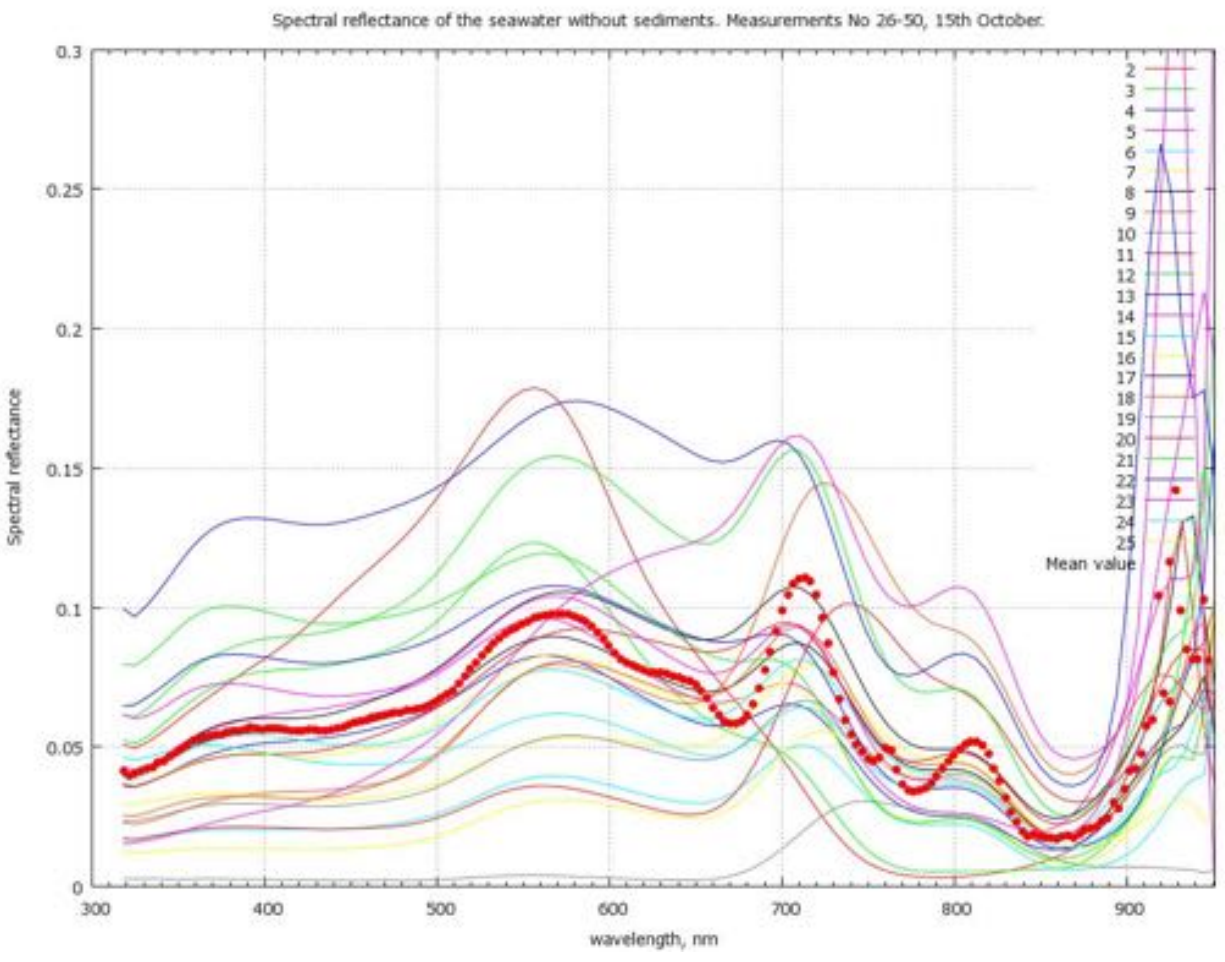

Figure A.35: Spectral reflectance of P.oceanica. Measurement series 25-50.

Gnuplot display. Pages: $<23>,<32>,<50>$ 


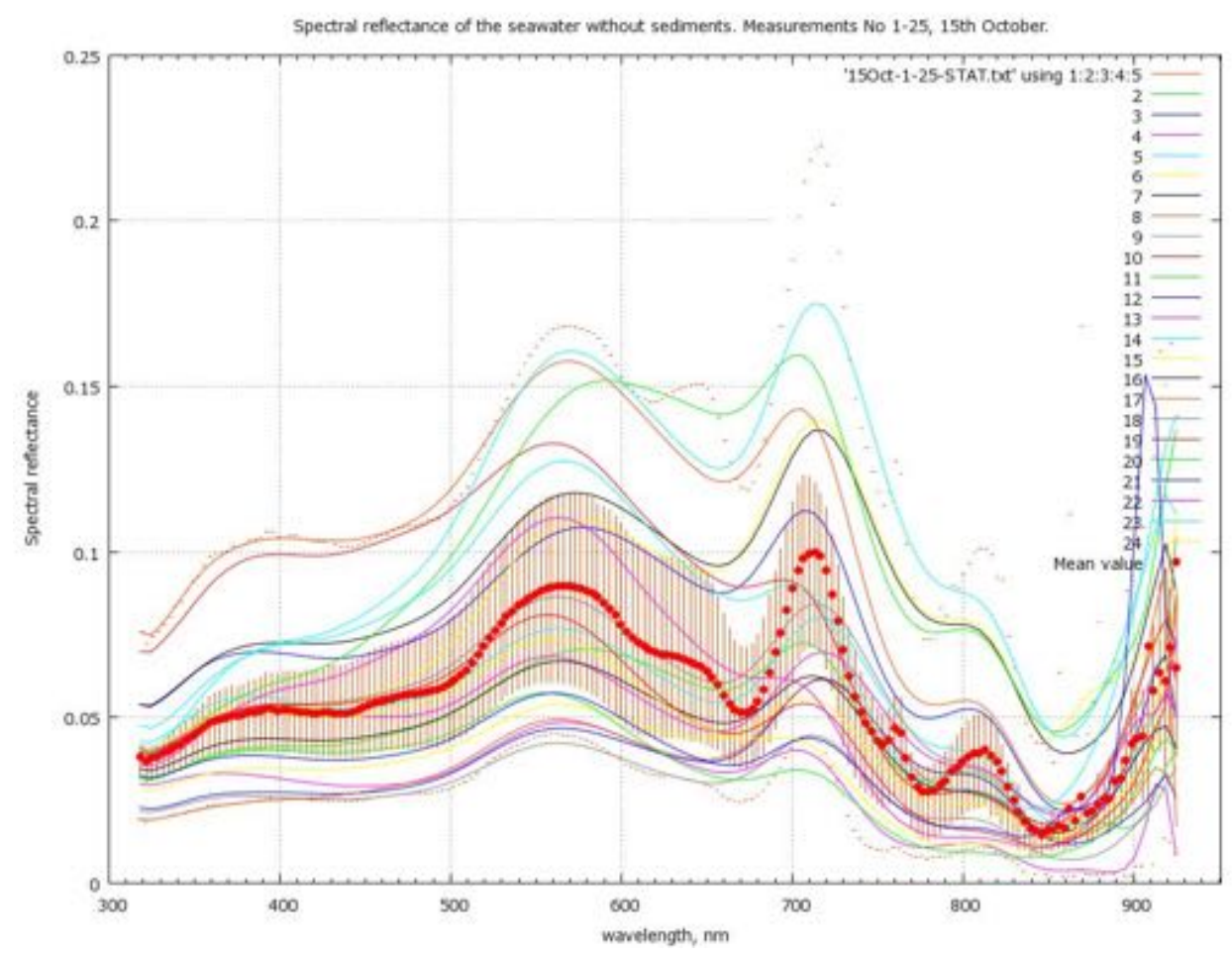

Figure A.36: Remote sensing reflectance of P.oceanica. Series 1-25.

Shown midspread of the statistical quartiles Q1 and Q3 (vertical dashes) and mean value within the range.

Gnuplot. Page: $<23>,<50>$ 
Table A.18: Two-Stage Least Squares: results of the TSLS analysis of the measurement set 1-191 of the spectral reflectance of P.oceanica (15.X.). Gretl. Page: $<44>$

Model 1: TSLS, using observations 1-191

Dependent variable: const

Instrumented: v17

Instruments: v12

$\left|\begin{array}{ccccc} & \text { Coefficient } & \text { Std. Error } & z & \text { p-value } \\ \text { v17 } & 6.88502 & 0.527503 & 13.0521 & 0.0000\end{array}\right|$

$\begin{array}{lrll}\text { Mean dependent var } & 1.000000 & \text { S.D. dependent var } & 0.000000 \\ \text { Sum squared resid } & 97.51535 & \text { S.E. of regression } & 0.716407 \\ \text { Log-likelihood } & -237.5799 & \text { Akaike criterion } & 477.1598 \\ \text { Schwarz criterion } & 480.4121 & \text { Hannan-Quinn } & 478.4771\end{array}$

Hausman test -

Null hypothesis: OLS estimates are consistent

Asymptotic test statistic: $\chi^{2}(1)=13.2834$

with $\mathrm{p}$-value $=0.000267768$

Weak instrument test -

First-stage $F(1,190)=16670.2$

Table A.19: Initial Cluster Centers: results of the $K$-means analysis of the measurement set 201-236 of the spectral reflectance of P.oceanica (15.X.). SPSS. Pages: $<29>,<44>$

\begin{tabular}{|c|c|c|c|c|c|}
\hline \hline & \multicolumn{2}{|c|}{ Cluster } & & \multicolumn{2}{c|}{ Cluster } \\
& 1 & 2 & & 1 & 2 \\
\hline \hline V2 & .353010 & .000644 & V16 & .240091 & .000374 \\
\hline V3 & .271519 & .000394 & V17 & .270306 & .000435 \\
\hline V4 & .273594 & .000644 & V18 & .196188 & .000211 \\
\hline V5 & .406525 & .000527 & V19 & .301486 & .000370 \\
\hline V6 & .344973 & .000509 & V20 & .178575 & .000328 \\
\hline V7 & .395117 & .000646 & V21 & .231708 & .000440 \\
\hline V8 & .254642 & .000352 & V22 & .186493 & .000365 \\
\hline V9 & .288881 & .000267 & V23 & .261761 & .000418 \\
\hline V10 & .191850 & .000255 & V24 & .282032 & .000264 \\
\hline V11 & .249462 & .000323 & V25 & .190709 & .000375 \\
\hline V12 & .209622 & .000414 & V26 & .177432 & .000206 \\
\hline V13 & .218312 & .000206 & V27 & .195104 & .000268 \\
\hline V14 & .177432 & .000268 & V28 & .256630 & .000386 \\
\hline V15 & .184836 & .000223 & V29 & .283744 & .000436 \\
\hline & & & V30 & .406525 & .000646 \\
\hline
\end{tabular}


Table A.20: Iteration History(a): results of the $K$-means analysis of the measurement set 201-236 of the spectral reflectance of P.oceanica (15.X.). SPSS. Page: $<44>$

\begin{tabular}{|c|c|c|}
\hline \hline & \multicolumn{2}{|c|}{ Change in Cluster } \\
Iteration & 1 & 2 \\
\hline \hline 1 & .326 & .206 \\
\hline 2 & .024 & .010 \\
\hline 3 & .008 & .003 \\
\hline 4 & .000 & .000 \\
\hline
\end{tabular}

Convergence achieved due to no or small change in cluster centers. The maximum absolute coordinate change for any center is .000. The current iteration is 4 . The minimum distance between initial centers is 1.435 .

Table A.21: Number of Cases in each Cluster: results of the K-means analysis of the measurement set 201-236 of the spectral reflectance of P.oceanica (15.X.). SPSS. Page: $<44>$

\begin{tabular}{|c|c|}
\hline \hline Cluster 1 & 55.000 \\
\hline Cluster 2 & 136.000 \\
\hline Valid & 191.000 \\
\hline Missing & .000 \\
\hline
\end{tabular}

Table A.22: Final Cluster Centers: results of the $K$-means analysis of the measurement set 201-236 of the spectral reflectance of P.oceanica (15.X.). SPSS. Page: $<45>$

\begin{tabular}{|c|c|c|c|c|c|}
\hline \hline & \multicolumn{2}{|c|}{ Cluster } & & \multicolumn{2}{c|}{ Cluster } \\
& 1 & 2 & & 1 & 2 \\
\hline \hline V2 & 0.265141 & 0.046966 & V16 & 0.181395 & 0.033191 \\
\hline V3 & 0.202643 & 0.036088 & V17 & 0.202698 & 0.036614 \\
\hline V4 & 0.20699 & 0.037789 & V18 & 0.149364 & 0.028217 \\
\hline V5 & 0.298975 & 0.052158 & V19 & 0.225452 & 0.040193 \\
\hline V6 & 0.25915 & 0.045968 & V20 & 0.135163 & 0.025506 \\
\hline V7 & 0.293508 & 0.049314 & V21 & 0.175176 & 0.031866 \\
\hline V8 & 0.193292 & 0.036402 & V22 & 0.142295 & 0.027148 \\
\hline V9 & 0.215848 & 0.038738 & V23 & 0.19514 & 0.034553 \\
\hline V10 & 0.147798 & 0.027489 & V24 & 0.214946 & 0.038321 \\
\hline V11 & 0.188955 & 0.034031 & V25 & 0.14585 & 0.027665 \\
\hline V12 & 0.157947 & 0.029319 & V26 & 0.134787 & 0.024912 \\
\hline V13 & 0.165877 & 0.029961 & V27 & 0.149217 & 0.028326 \\
\hline V14 & 0.137149 & 0.02626 & V28 & 0.193388 & 0.034999 \\
\hline V15 & 0.140563 & 0.026211 & V29 & 0.214436 & 0.038433 \\
\hline & & & V30 & 0.299183 & 0.053451 \\
\hline
\end{tabular}


Table A.23: Results of the tobit analysis with censored dependent variable (2) from the selected dataset Series 151-175 of the s.reflectance of P.oceanica. Gretl. Page: $<44>$

Model 2: Tobit, using observations 1:01-8:23 $(T=191)$

Dependent variable: v12

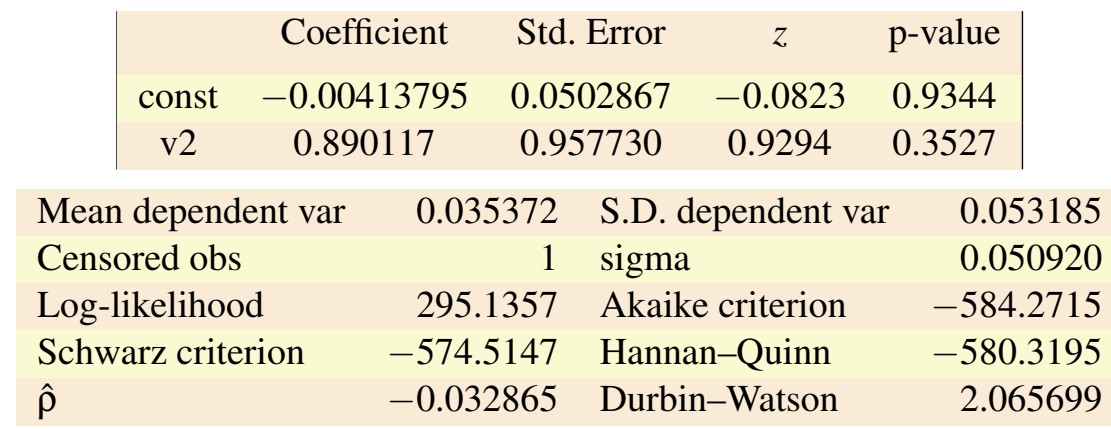

Test for normality of residual -

Null hypothesis: error is normally distributed

Test statistic: $\chi^{2}(2)=190.404$

with $\mathrm{p}$-value $=4.51226 \mathrm{e}-042$

Table A.24: Results of the Prais-Winsten estimation applied towards variables 15 from the selected dataset 151175 of the spectral reflectance of P.oceanica. Gretl. Page: $<44>$

Model 3: Prais-Winsten, using observations 1:01-8:23 $(T=191)$

Dependent variable: $\mathrm{v} 12$

$$
\hat{\rho}=-0.0343656
$$

$\begin{array}{|ccccc|} & \text { Coefficient } & \text { Std. Error } & t \text {-ratio } & \mathrm{p} \text {-value } \\ \text { const } & -0.00498439 & 0.00977709 & -0.5098 & 0.6108 \\ \text { v2 } & 0.912742 & 0.205904 & 4.4328 & 0.0000\end{array} \mid$

Statistics based on the rho-differenced data:

$\begin{array}{lrll}\text { Mean dependent var } & 0.035372 & \text { S.D. dependent var } & 0.053185 \\ \text { Sum squared resid } & 0.490951 & \text { S.E. of regression } & 0.050967 \\ R^{2} & 0.086511 & \text { Adjusted } R^{2} & 0.081678 \\ F(1,189) & 19.67163 & \text { P-value }(F) & 0.000016 \\ \hat{\rho} & -0.001888 & \text { Durbin-Watson } & 2.003741\end{array}$



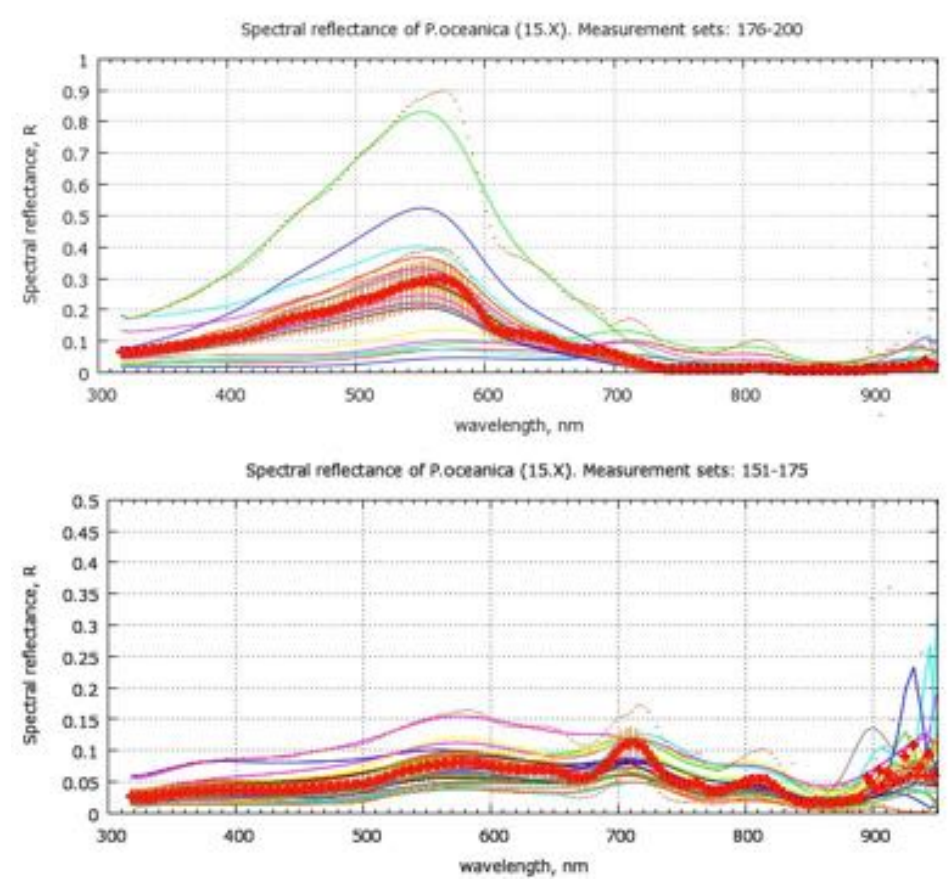

Figure A.37: Multiplot of spectral reflectance of P.oceanica. Series 151-200. Shown mid-spread of the statistical quartiles Q1 and Q3 (vertical dashes) and mean value within the range (red bold dots). Gnuplot visualization. Pages: $<31>,<42>$

Table A.25: Results of the Principal Components Analysis: measurement variables 1-7 from the selected dataset 301-325 of the spectral reflectance of P.oceanica (15.X.). Gretl. Page: <44>

Eigenanalysis of the Correlation Matrix

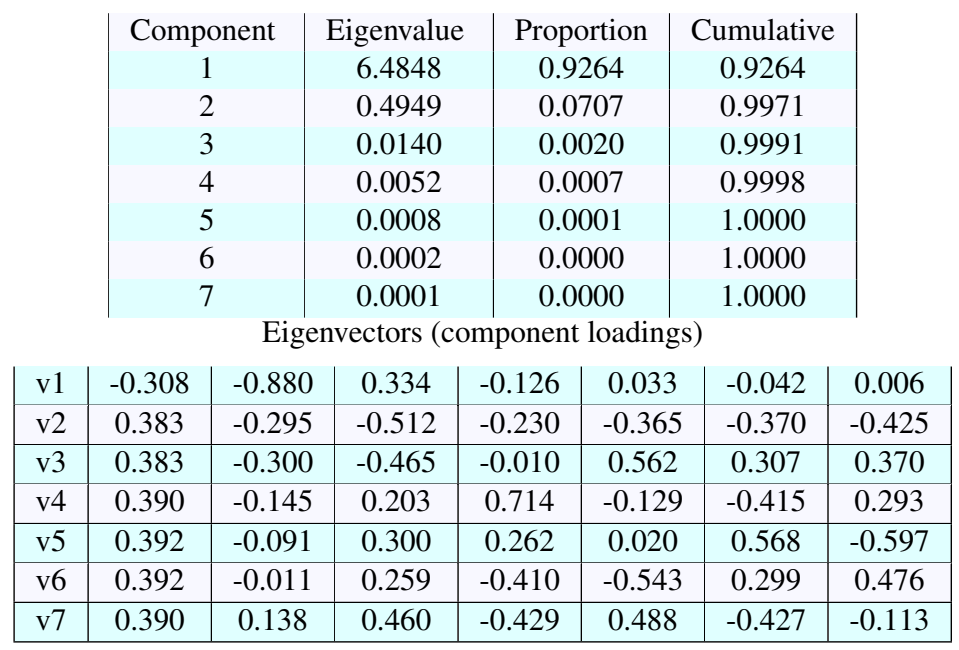


Table A.26: Results of the Weighted Least Squares Analysis applied towards variables 12-20 from the selected dataset 301-325 of the spectral reflectance of P.oceanica. Gretl. Page: $<45>$

Model 1: WLS, using observations 1-95

Dependent variable: v20

Variable used as weight: v12

\begin{tabular}{|c|c|c|c|c|} 
& Coefficient & Std. Error & $t$-ratio & $\mathrm{p}$-value \\
const & 0.239525 & 0.0771338 & 3.1053 & 0.0025 \\
v1 & 0.000120809 & 0.000147131 & 0.8211 & 0.4137
\end{tabular}

Statistics based on the weighted data:

\begin{tabular}{|lrlr} 
Sum squared resid & 0.290924 & S.E. of regression & 0.055930 \\
\hline$R^{2}$ & 0.007197 & Adjusted $R^{2}$ & -0.003478 \\
$F(1,93)$ & 0.674200 & P-value $(F)$ & 0.413691 \\
\hline Log-likelihood & 140.1579 & Akaike criterion & -276.3158 \\
\hline Schwarz criterion & -271.2081 & Hannan-Quinn & -274.2519 \\
\hline
\end{tabular}

Statistics based on the original data:

Mean dependent var 0.136154 S.D. dependent var 0.149193

Sum squared resid $\quad 5.689669$ S.E. of regression $\quad 0.247344$ 


\section{A.7.2 Data processing and statistical evaluation: carbonate sand}

Table A.27: Results of the autocorrelation analysis of the measurement set 51-75 of the spectral reflectance of carbonate sand, Gretl. Page: $<44>$

\begin{tabular}{|c|c|c|c|c|c|c|}
\hline LAG & $\mathrm{ACF}$ & & PACF & & Q-stat & [p-value] \\
\hline 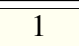 & 0.9851 & $* * *$ & 0.9851 & **** & 104.8293 & {$[0.000]$} \\
\hline 2 & 0.9657 & $* * *$ & -0.1598 & $* * *$ & 206.5423 & {$[0.000]$} \\
\hline 3 & 0.9420 & $* * *$ & -0.1337 & $* * *$ & 304.2787 & {$[0.000]$} \\
\hline 4 & 0.9144 & $* * *$ & -0.1107 & $* * *$ & 397.2949 & {$[0.000]$} \\
\hline 5 & 0.8835 & $* * *$ & -0.0905 & $* * *$ & 484.9833 & {$[0.000]$} \\
\hline 6 & 0.8495 & $* * *$ & -0.0732 & $* * *$ & 566.8791 & {$[0.000]$} \\
\hline 7 & 0.8131 & $* * *$ & -0.0565 & $* * *$ & 642.6707 & {$[0.000]$} \\
\hline 8 & 0.7748 & $* * *$ & -0.0423 & $* * *$ & 712.1933 & {$[0.000]$} \\
\hline 9 & 0.7350 & $* * *$ & -0.0317 & $* * *$ & 775.4114 & {$[0.000]$} \\
\hline 10 & 0.6941 & $* * *$ & -0.0280 & $* * *$ & 832.3807 & {$[0.000]$} \\
\hline 11 & 0.6524 & $* * *$ & -0.0221 & $* * *$ & 883.2508 & {$[0.000]$} \\
\hline 12 & 0.6103 & $* * *$ & -0.0197 & $* * *$ & 928.2405 & {$[0.000]$} \\
\hline 13 & 0.5679 & $* * *$ & -0.0170 & $* * *$ & 967.6289 & {$[0.000]$} \\
\hline 14 & 0.5256 & $* * *$ & -0.0162 & $* * *$ & 1001.7381 & {$[0.000]$} \\
\hline 15 & 0.4835 & $* * *$ & -0.0154 & $* * *$ & 1030.9237 & {$[0.000]$} \\
\hline 16 & 0.4418 & $* * *$ & -0.0172 & $* * *$ & 1055.5584 & {$[0.000]$} \\
\hline 17 & $0.4 \mathrm{v} 004$ & $* * *$ & -0.0196 & $* * *$ & 1076.0231 & {$[0.000]$} \\
\hline 18 & $0.35 \mathrm{v} 94$ & $* * *$ & -0.0216 & $* * *$ & 1092.7041 & {$[0.000]$} \\
\hline 19 & 0.3189 & $* * *$ & -0.0224 & $* * *$ & 1105.9911 & {$[0.000]$} \\
\hline 20 & 0.2788 & $* * *$ & -0.0269 & $* * *$ & 1116.2679 & [0.000] \\
\hline
\end{tabular}

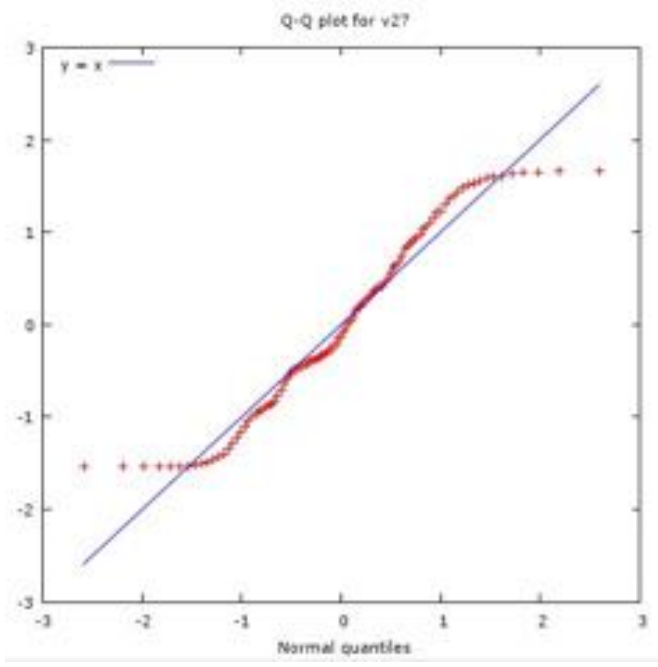

Figure A.38: Normal Q-Q plot: estimated versus observed values of the measurement of carbonate sand, variable 27. Series 51-75. Gretl modelling visualization. Page: $<45>$ 
Table A.28: Results of the statistical analysis of spectral reflectance of carbonate sand, with average values (for sets 1-3). Wavelength step: $3 \mathrm{~nm}$. Measured on Agia Pelagia beach, 14th October. Pages: $<44>,<49>$

\begin{tabular}{|c|c|c|c|c|c|c|}
\hline wl & in & Q1 & mean & Q3 & $\max$ & median \\
\hline 402 & .091522 & 0.108252 & 0.119264 & 0.125199 & 0.156262 & 0.120855 \\
\hline 405 & 0.094129 & 0.111507 & 0.126390 & 0.139560 & 0.174126 & 0.124623 \\
\hline 408 & 0.096608 & .114474 & 129816 & 0.143488 & 0.178780 & 0.127983 \\
\hline 412 & 703 & .117396 & & 0.147164 & & 82 \\
\hline 415 & 101803 & .120880 & 137375 & 0.151792 & .189039 & 35571 \\
\hline 418 & 105012 & 0.124746 & 141910 & 0.156937 & 0.195073 & 0.140136 \\
\hline 422 & 108640 & 0.129140 & 0.147168 & 0.162721 & 0.202021 & 0.145337 \\
\hline 425 & 113279 & .134815 & 0.153679 & 0.169999 & 0.210668 & 0.151906 \\
\hline 428 & 0.118544 & 0.141149 & 0.160985 & 0.178059 & 0.220194 & 9402 \\
\hline 432 & 22987 & 0.146844 & 59 & 518 & 341 & \\
\hline 435 & 11 & 0.1 & 174248 & 0.192960 & 370 & \\
\hline 438 & & 3310 & 1427 & 0.201169 & .246705 & $\overline{0044}$ \\
\hline 442 & 136621 & 0.163674 & 0.187881 & 0.208310 & 0.255343 & 0.186472 \\
\hline 445 & 140316 & 0.168266 & 0.193508 & 0.214558 & 0.262974 & 0.192106 \\
\hline 448 & 22 & & 0.1 & 703 & 568 & 6709 \\
\hline 452 & 15 & 0. & & 770 & 73 & 367 \\
\hline 455 & 0 & 31 & 47 & 926 & 78 & 052 \\
\hline 459 & 149944 & 0.180646 & .208895 & 0.230917 & 0.284950 & 0.207175 \\
\hline 462 & 978 & 0.183204 & .212228 & 0.234461 & 0.289839 & 0.210556 \\
\hline 465 & .136264 & 0.184985 & 0.214436 & 0.238727 & 4286 & 3490 \\
\hline 469 & 48 & & & 237 & 04 & \\
\hline 472 & & & & 769 & & \\
\hline 475 & 0 & & 00 & 279 & 77 & 16 \\
\hline 479 & 11 & 12 & 8849 & 810 & 9961 & 4984 \\
\hline 482 & 0.164012 & 0.2 & 0.232478 & 7229 & 555 & 0.230599 \\
\hline 485 & 72 & & & & & $\overline{110}$ \\
\hline 489 & 0 & & & & & \\
\hline 492 & 0 & & & & & \\
\hline 495 & 0 & & 0.2 & 6469 & 048 & 243 \\
\hline 499 & 09 & 74 & 43 & 200 & 896 & 0.263884 \\
\hline 502 & & & 417 & 563 & 8882 & 0.269139 \\
\hline 505 & 0 & & & 379 & & 281 \\
\hline 509 & 9 & & & 46 & & 0.2 \\
\hline 512 & & & & & & \\
\hline 515 & & & & & & \\
\hline 519 & 39 & 81 & 0.294768 & 29524 & 0.398796 & 0.291707 \\
\hline 522 & 0.208548 & 0.259760 & 0.301397 & 0.337066 & 0.407969 & 0.298231 \\
\hline 526 & 0.213382 & 0.266241 & 0.308821 & 5426 & 0.418276 & 0.305397 \\
\hline 529 & & & & 749 & 329 & 2514 \\
\hline 532 & & & & & & 122 \\
\hline 536 & & & & & & \\
\hline 539 & & & & 0.376082 & 0.455017 & \\
\hline 542 & & 0. & 0.3 & 0.381589 & 0.461345 & 0.3 \\
\hline 546 & 0.235193 & 0.296532 & 0.343224 & 0.385560 & 0.465598 & 0.338854 \\
\hline 549 & 0.236680 & 0.299381 & 0.345918 & 0.388909 & 0.469140 & 0.341256 \\
\hline 552 & 69 & 0.3 & 97 & 858 & 296 & 3234 \\
\hline 556 & & & & & 36 & 633 \\
\hline 55 & & & & & 0.47 & \\
\hline 562 & 0 & & & 0.400054 & 0.48 & 0.348 \\
\hline
\end{tabular}


Table A.29: Spectral reflectance of carbonate sand (continued from previous page)

\begin{tabular}{|c|c|c|c|c|c|c|}
\hline wl & $\min$ & Q1 & mean & Q3 & max & median \\
\hline 566 & 0.240416 & 0.308874 & 0.355162 & 0.401224 & 0.481897 & 0.348929 \\
\hline 569 & 0.238748 & 0.307064 & 0.353688 & 0.400427 & 0.480263 & 0.347042 \\
\hline 572 & 0.235026 & 0.302640 & 0.349433 & 0.395980 & 0.475648 & 0.342958 \\
\hline 576 & 0.212260 & 0.294628 & 0.340050 & 0.386378 & 0.466085 & 0.334751 \\
\hline 579 & 0.219835 & 0.283193 & 0.329664 & 0.375185 & 0.450895 & 0.324215 \\
\hline 583 & 0.208955 & 0.268530 & 0.314599 & 0.359047 & 0.432720 & 0.308769 \\
\hline 586 & 0.196370 & 0.252380 & 0.296960 & 0.338330 & 0.411550 & 0.290283 \\
\hline 589 & 0.181828 & 0.233326 & 0.276049 & 0.316609 & 0.386565 & 0.267500 \\
\hline 593 & 0.166276 & 0.212916 & 0.253544 & 0.293790 & 0.359268 & 0.243094 \\
\hline 596 & 0.149323 & 0.191055 & 0.229373 & 0.267668 & 0.331353 & 0.217166 \\
\hline 599 & 0.132182 & 0.169324 & 0.205072 & 0.241088 & 0.303079 & 0.191137 \\
\hline 603 & 0.117895 & 0.151271 & 0.185181 & 0.219420 & 0.280528 & 0.170074 \\
\hline 606 & 0.107449 & 0.138360 & 0.171146 & 0.203897 & 0.264634 & 0.155317 \\
\hline 609 & 0.101008 & 0.130206 & 0.162388 & 0.194168 & 0.254754 & 0.146269 \\
\hline 613 & 0.097084 & 0.125265 & 0.157073 & 0.188174 & 0.248485 & 0.140671 \\
\hline 616 & 0.094383 & 0.121987 & 0.153592 & 0.184349 & 0.244702 & 0.137070 \\
\hline 619 & 0.092105 & 0.119159 & 0.150566 & 0.180848 & 0.241217 & 0.134371 \\
\hline 623 & 0.090017 & 0.116792 & 0.147899 & 0.177856 & 0.238265 & 0.131097 \\
\hline 626 & 0.088364 & 0.114636 & 0.145734 & 0.175448 & 0.236222 & 0.128638 \\
\hline 629 & 0.086562 & 0.112565 & 0.143418 & 0.173135 & 0.233625 & 0.126183 \\
\hline 633 & 0.084448 & 0.109785 & 0.140489 & 0.170056 & 0.230251 & 0.123296 \\
\hline 636 & 0.082208 & 0.106766 & 0.137216 & 0.166497 & 0.226502 & 0.119990 \\
\hline 639 & 0.079925 & 0.103852 & 0.134122 & 0.162951 & 0.222721 & 0.116886 \\
\hline 643 & 0.077879 & 0.101395 & 0.131468 & 0.159978 & 0.219899 & 0.114099 \\
\hline 646 & 0.075563 & 0.098621 & 0.128409 & 0.156518 & 0.216573 & 0.110812 \\
\hline 649 & 0.072328 & 0.095004 & 0.124254 & 0.151735 & 0.212143 & 0.106456 \\
\hline 653 & 0.068455 & 0.089876 & 0.118539 & 0.145085 & 0.205574 & 0.100544 \\
\hline 656 & 0.063138 & 0.083138 & 0.110767 & 0.135900 & 0.196204 & 0.092816 \\
\hline 660 & 0.057899 & 0.076562 & 0.102919 & 0.126826 & 0.186379 & 0.085030 \\
\hline 663 & 0.054237 & 0.071651 & 0.097286 & 0.120346 & 0.179417 & 0.079514 \\
\hline 666 & 0.051717 & 0.068781 & 0.093827 & 0.116423 & 0.175195 & 0.076101 \\
\hline 670 & 0.050172 & 0.066690 & 0.091590 & 0.113854 & 0.172561 & 0.073923 \\
\hline 673 & 0.048823 & 0.064991 & 0.089610 & 0.111550 & 0.170358 & 0.071985 \\
\hline 676 & 0.047230 & 0.063165 & 0.087474 & 0.109078 & 0.167774 & 0.069807 \\
\hline 680 & 0.045818 & 0.061108 & 0.085168 & 0.106421 & 0.165049 & 0.067486 \\
\hline 683 & 0.044262 & 0.058946 & 0.082783 & 0.103630 & 0.162579 & 0.065041 \\
\hline 686 & 0.041986 & 0.055955 & 0.079361 & 0.099441 & 0.158648 & 0.061599 \\
\hline 690 & 0.040081 & 0.051396 & 0.074010 & 0.092741 & 0.152034 & 0.055896 \\
\hline 693 & 0.034783 & 0.045555 & 0.067241 & 0.084820 & 0.143195 & 0.050116 \\
\hline 696 & 0.030094 & 0.039507 & 0.060070 & 0.076166 & 0.133838 & 0.043600 \\
\hline 700 & 0.025499 & 0.033281 & 0.052660 & 0.066929 & 0.124164 & 0.036937 \\
\hline 703 & 0.020752 & 0.027050 & 0.045008 & 0.057197 & 0.113843 & 0.030173 \\
\hline 706 & 0.016243 & 0.021080 & 0.037529 & 0.047681 & 0.103394 & 0.023549 \\
\hline 710 & 0.012303 & 0.015914 & 0.030791 & 0.038860 & 0.093244 & 0.017834 \\
\hline 713 & 0.007533 & 0.011641 & 0.025113 & 0.031338 & 0.084822 & 0.013233 \\
\hline 716 & 0.006371 & 0.008236 & 0.020172 & 0.024328 & 0.077202 & 0.009214 \\
\hline 720 & 0.004247 & 0.005386 & 0.015711 & 0.018057 & 0.069074 & 0.006121 \\
\hline 723 & 0.002773 & 0.003524 & 0.012159 & 0.012999 & 0.061638 & 0.003836 \\
\hline 726 & 0.001812 & 0.002194 & 0.009537 & 0.009237 & 0.055408 & 0.002543 \\
\hline 730 & 0.001248 & 0.001453 & 0.007627 & 0.006800 & 0.049434 & 0.001739 \\
\hline 733 & 0.000801 & 0.001018 & 0.006264 & 0.004722 & 0.044850 & 0.001208 \\
\hline
\end{tabular}


Table A.29: Spectral reflectance of carbonate sand (continued from previous page)

\begin{tabular}{|l|l|l|l|l|l|r|}
\hline wl & min & Q1 & mean & Q3 & max & median \\
\hline 736 & 0.000192 & 0.000855 & 0.005279 & 0.003743 & 0.042097 & 0.000954 \\
\hline 740 & 0.000471 & 0.000718 & 0.004811 & 0.003055 & 0.039099 & 0.000816 \\
\hline 743 & 0.000506 & 0.000644 & 0.004419 & 0.002901 & 0.037332 & 0.000740 \\
\hline 746 & 0.000211 & 0.000582 & 0.004282 & 0.002898 & 0.036089 & 0.000715 \\
\hline 750 & 0.000318 & 0.000557 & 0.003937 & 0.002175 & 0.033962 & 0.000667 \\
\hline
\end{tabular}

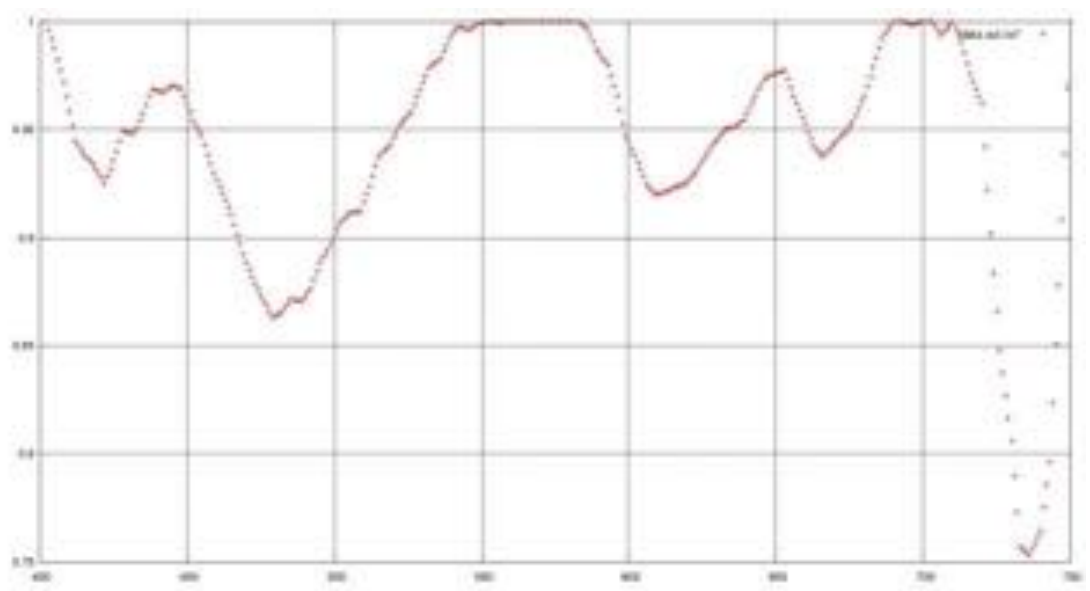

Figure A.39: Spectral reflectance of carbonate sand on A.Pelagia beach. Results of single measurement set made by spectroradiometer Trios-RAMSES. Gnuplot. Pages: $<31>,<42>$

Table A.29: Results of the Quantile estimates: measurements 51-75 of the spectral reflectance of carbonate sand, Gretl. Page: $<44>$

Model 2: Quantile estimates, using observations 1:01-5:09 $(T=105)$

Dependent variable: v27

$$
\tau=0.5
$$

Asymptotic standard errors assuming IID errors

\begin{tabular}{ccccc}
$* * *$ & Coefficient & Std. Error & $t$-ratio & $\mathrm{p}$-value \\
const & 0.837827 & 0.0386417 & 21.6820 & 0.0000 \\
v1 & -0.00111120 & $6.60949 \mathrm{e}-005$ & -16.8122 & 0.0000 \\
\hline \hline
\end{tabular}

\begin{tabular}{lrlr} 
Median depend. var & 0.191024 & S.D. dependent var & 0.135439 \\
Sum absolute resid & 8.625039 & Sum squared resid & 1.370360 \\
Log-likelihood & 84.64508 & Akaike criterion & -165.2902 \\
Schwarz criterion & -159.9822 & Hannan-Quinn & -163.1393 \\
\hline
\end{tabular}


Table A.30: Results of the periodogram for v30 of the measurement set 51-75 of the spectral reflectance of carbonate sand, Gretl. Page: $<45>$

\begin{tabular}{|c|c|c|c|c|c|c|c|}
\hline omega & $\begin{array}{l}\text { scaled fre- } \\
\text { quency }\end{array}$ & periods & $\begin{array}{l}\log \\
\text { spectral } \\
\text { density }\end{array}$ & omega & $\begin{array}{l}\text { scaled fre- } \\
\text { quency }\end{array}$ & periods & $\begin{array}{l}\log \\
\text { spectral } \\
\text { density }\end{array}$ \\
\hline 0.05984 & 1 & 105.00 & -1.2466 & 1.61568 & 27 & 3.89 & -11.111 \\
\hline 0.11968 & 2 & 52.50 & -5.8761 & 1.67552 & 28 & 3.75 & -11.170 \\
\hline 0.17952 & 3 & 35.00 & -4.0657 & 1.73536 & 29 & 3.62 & -11.208 \\
\hline 0.23936 & 4 & 26.25 & -7.1031 & 1.79520 & 30 & 3.50 & -11.461 \\
\hline 0.29920 & 5 & 21.00 & -6.1742 & 1.85504 & 31 & 3.39 & -11.380 \\
\hline 0.35904 & 6 & 17.50 & -7.2772 & 1.91488 & 32 & 3.28 & -11.686 \\
\hline 0.41888 & 7 & 15.00 & -8.7802 & 1.97472 & 33 & 3.18 & -11.624 \\
\hline 0.47872 & 8 & 13.13 & -7.6806 & 2.03456 & 34 & 3.09 & -11.724 \\
\hline 0.53856 & 9 & 11.67 & -8.4848 & 2.09440 & 35 & 3.00 & -11.818 \\
\hline 0.59840 & 10 & 10.50 & -8.5764 & 2.15423 & 36 & 2.92 & -11.805 \\
\hline 0.65824 & 11 & 9.55 & -9.4643 & 2.21407 & 37 & 2.84 & -12.002 \\
\hline 0.71808 & 12 & 8.75 & -9.0868 & 2.27391 & 38 & 2.76 & -11.930 \\
\hline 0.77792 & 13 & 8.08 & -9.3608 & 2.33375 & 39 & 2.69 & -12.010 \\
\hline 0.83776 & 14 & 7.50 & -9.9332 & 2.39359 & 40 & 2.63 & -12.124 \\
\hline 0.89760 & 15 & 7.00 & -9.6836 & 2.45343 & 41 & 2.56 & -12.190 \\
\hline 0.95744 & 16 & 6.56 & -10.00 & 2.51327 & 42 & 2.50 & -12.248 \\
\hline 1.01728 & 17 & 6.18 & -9.8994 & 2.57311 & 43 & 2.44 & -12.306 \\
\hline 1.07712 & 18 & 5.83 & -10.188 & 2.63295 & 44 & 2.39 & -12.323 \\
\hline 1.13696 & 19 & 5.53 & -10.197 & 2.69279 & 45 & 2.33 & -12.353 \\
\hline 1.19680 & 20 & 5.25 & -10.467 & 2.75263 & 46 & 2.28 & -12.420 \\
\hline 1.25664 & 21 & 5.00 & -10.505 & 2.81247 & 47 & 2.23 & -12.382 \\
\hline 1.31648 & 22 & 4.77 & -10.641 & 2.87231 & 48 & 2.19 & -12.487 \\
\hline 1.37632 & 23 & 4.57 & -10.906 & 2.93215 & 49 & 2.14 & -12.433 \\
\hline 1.43616 & 24 & 4.38 & -10.957 & 2.99199 & 50 & 2.10 & -12.609 \\
\hline 1.49600 & 25 & 4.20 & -10.785 & 3.05183 & 51 & 2.06 & -12.410 \\
\hline 3.11167 & 52 & 2.02 & -12.477 & & & & \\
\hline
\end{tabular}

Number of observations $=105$ 


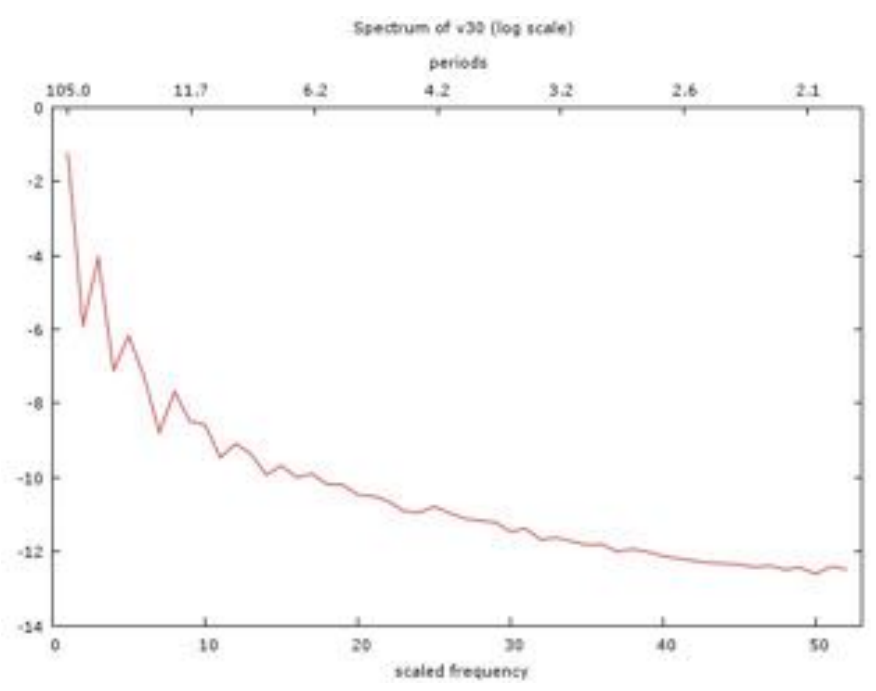

Figure A.40: Plot illustrating periodogram for v30 from measurements of carbonate sand, series 51-75. Gretl modelling visualization. Page: $<45>$
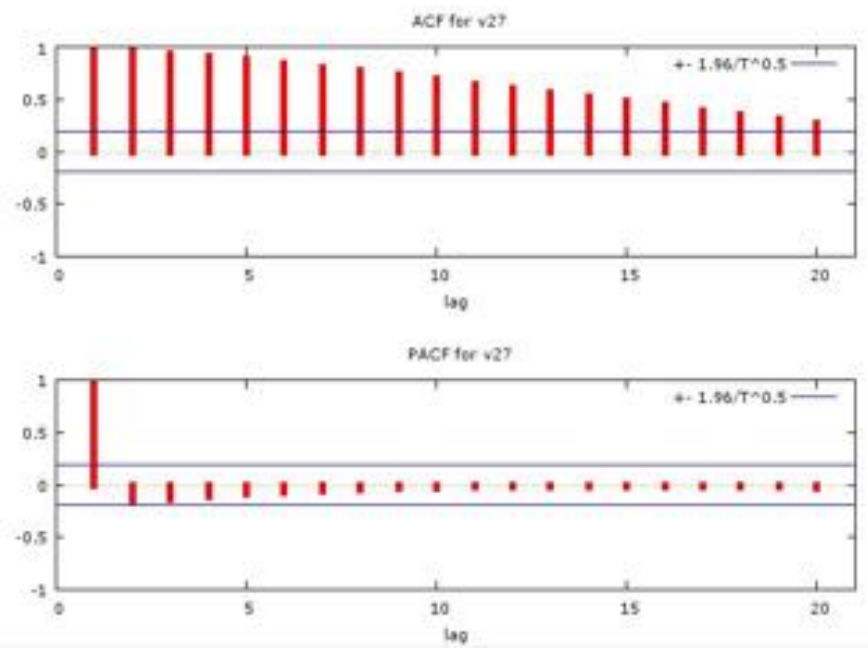

Figure A.41: Graph of the autocorrelation analysis of the measurements of carbonate sand. Series 51-75, variable 27. Gretl visualization. Page: $<44>$ 
A.8 Satellite and aerial images covering research area of Crete Island: selected examplAs APPENDICES

\section{A.8 Satellite and aerial images covering research area of Crete Island: selected examples}

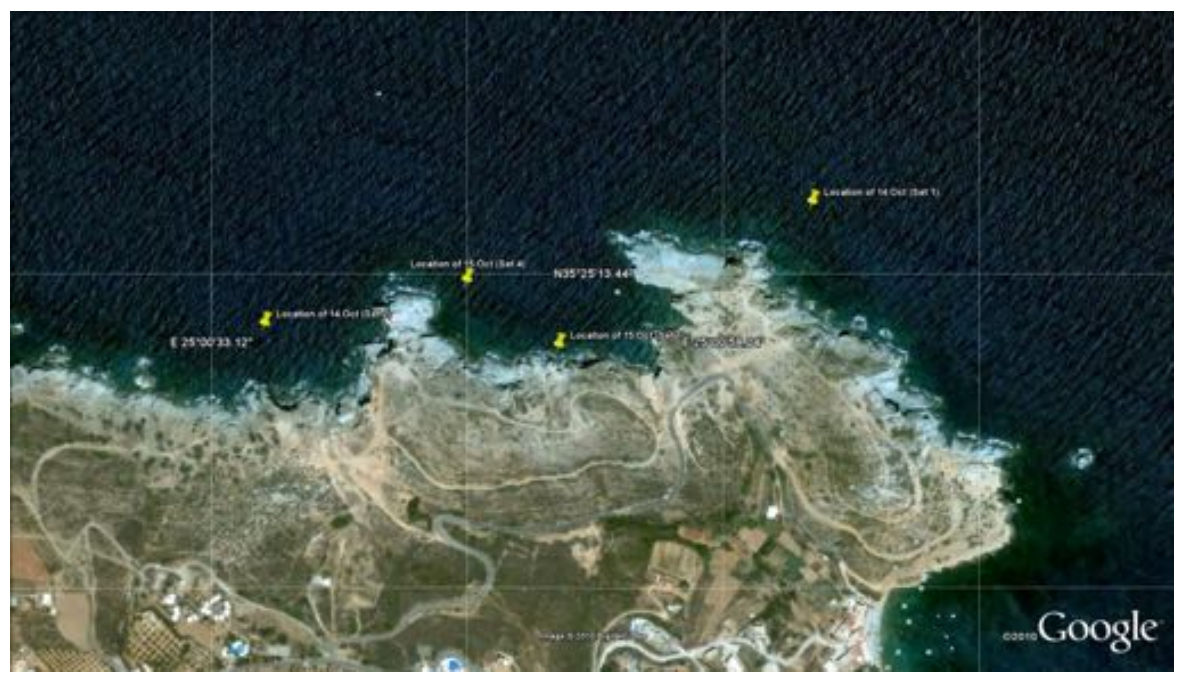

Figure A.42: Locations of selected measurements, visualization on Google Earth. Page: $<36>$

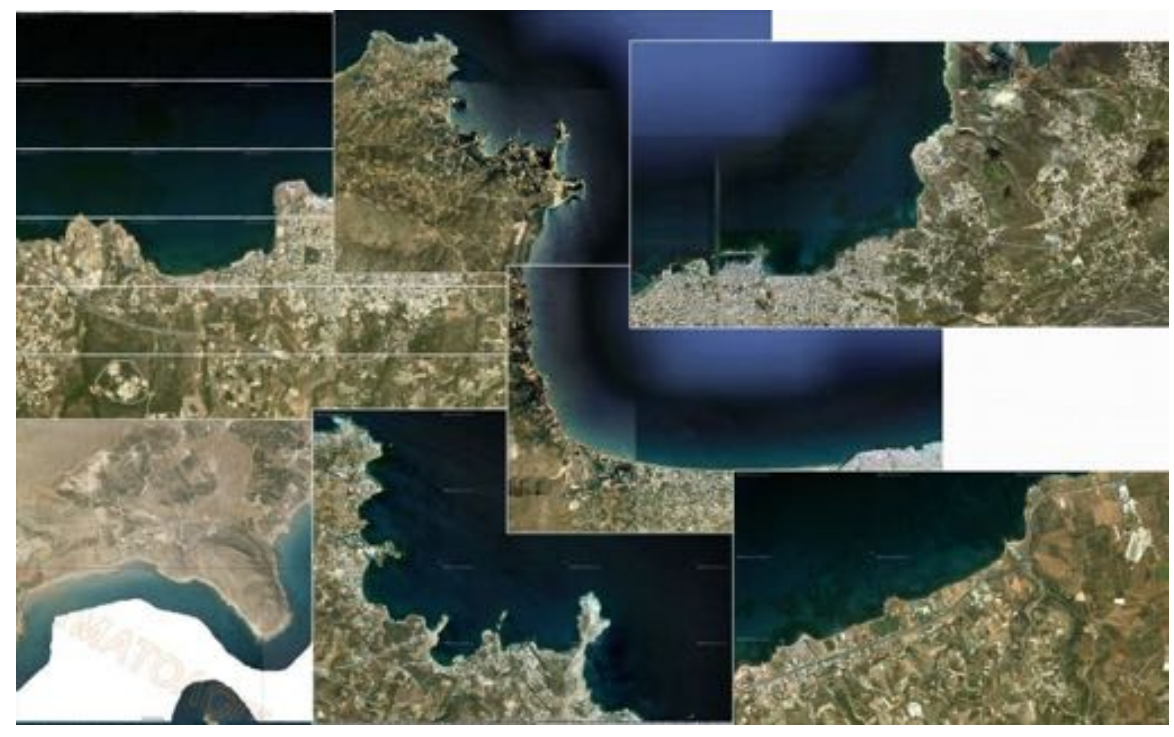

Figure A.43: Random mosaic of selected aerial Google Earth images. Pages: $<29>,<36>$ 
A.8 Satellite and aerial images covering research area of Crete Island: selected examplAs APPENDICES

Table A.31: Available broadband Landsat satellite images covering the research area of Crete Island. Page: $<29>$

\begin{tabular}{|c|c|c|c|}
\hline No & Image cource & Data & Name \\
\hline 1 & Landsat ETM+ & 2005/May/04 & $\begin{array}{l}\text { WRS2p181r035L71181035-035- } \\
\text { 20050504-ETM-GLS2005 }\end{array}$ \\
\hline 2 & Landsat TM & 2006/Nov/07 & $\begin{array}{l}\text { WRS2p181r036L5181036-036- } \\
\text { 20061107-TM-GLS2005 }\end{array}$ \\
\hline 3 & Landsat ETM+ & 2005/Apr/25 & $\begin{array}{l}\text { WRS2p182r035L71182035-035- } \\
\text { 20050425-ETM-GLS2005 }\end{array}$ \\
\hline 4 & Landsat ETM+ & 2000/Jul/09 & $\begin{array}{l}\text { WRS2p181r036-7dx-20000709-ETM- } \\
\text { GLS2000 }\end{array}$ \\
\hline 5 & Landsat TM & 1987/Jun/10 & $\begin{array}{l}\text { LandsatWRS2p183r035p183r035-5dx- } \\
\text { 19870610-TM-GLS1990 }\end{array}$ \\
\hline 6 & $\begin{array}{l}\text { Landsat ETM+/ Earth } \\
\text { Sat }\end{array}$ & 1999/Aug/08 & $\begin{array}{l}\text { 071-261Mosaic-LandsatN-35N-35- } \\
\text { 35ETM-EarthSat-MrSID-19990808- } \\
20020624\end{array}$ \\
\hline 7 & $\begin{array}{l}\text { Landsat ETM+/ Earth } \\
\text { Sat }\end{array}$ & 1999/Aug/08 & $\begin{array}{l}\text { 071-260Mosaic-LandsatN-35N-35- } \\
\text { 30ETM-EarthSat-MrSID-19990808- } \\
20020617\end{array}$ \\
\hline 8 & Landsat ETM+ & 2000/Jun/30 & $\begin{array}{l}\text { WRS2p182r036-7x-20000630-ETM- } \\
\text { EarthSat }\end{array}$ \\
\hline 9 & $\begin{array}{l}\text { Landsat MSS / Earth } \\
\text { Sat }\end{array}$ & 1975/Jul/26 & $\begin{array}{l}\text { LandsatWRS1p196r35-2m-19750726- } \\
\text { MSS-EarthSat }\end{array}$ \\
\hline 10 & Landsat TM / Earth Sat & 1987/Jun/10 & $\begin{array}{l}\text { 012-807LandsatWRS2p183r35-5t- } \\
\text { 19870610-TM-EarthSat }\end{array}$ \\
\hline 11 & Landsat ETM+ & 2000/Jun/30 & $\begin{array}{l}\text { LandsatWRS2p182r036-7dx- } \\
\text { 20000630-ETM-GLS2000 }\end{array}$ \\
\hline 12 & Landsat ETM+ & 2005/Apr/09 & $\begin{array}{l}\text { LandsatWRS2p182r036L71182036- } \\
\text { 036-20050409-ETM-GLS2005 }\end{array}$ \\
\hline
\end{tabular}




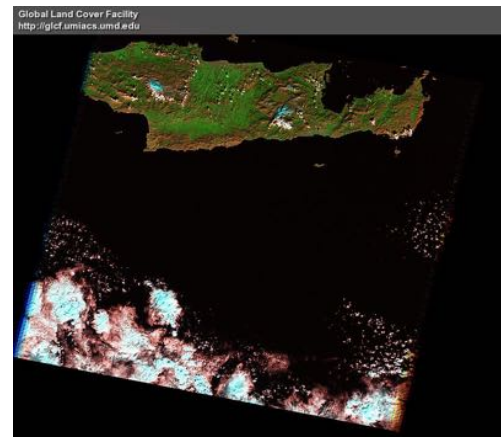

(a) Landsat 2006-11-07-TM

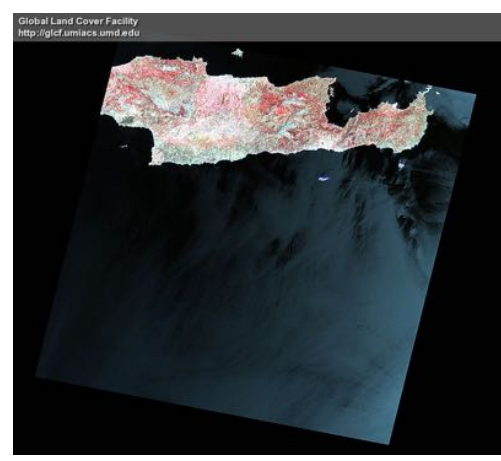

(d) Landsat 2000-07-09 ETM

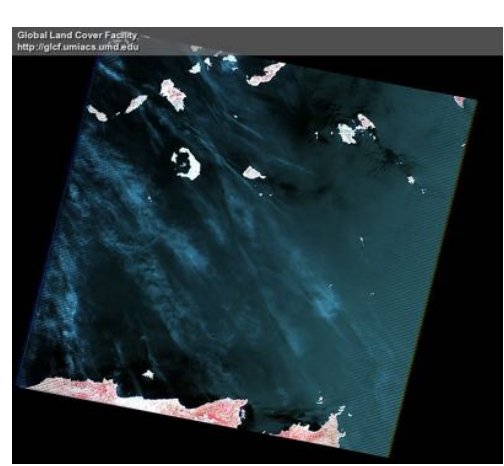

(g) Landsat-2005-05-04-ETM

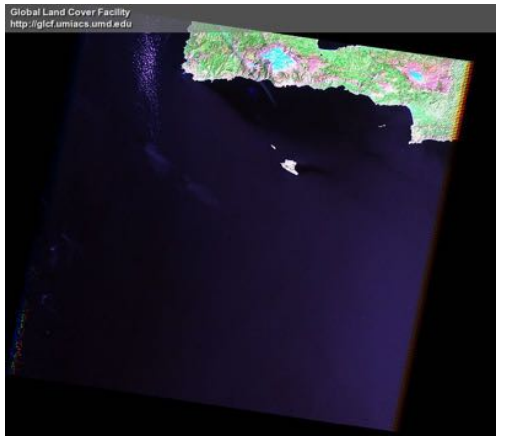

(b) Landsat-2005-04-09

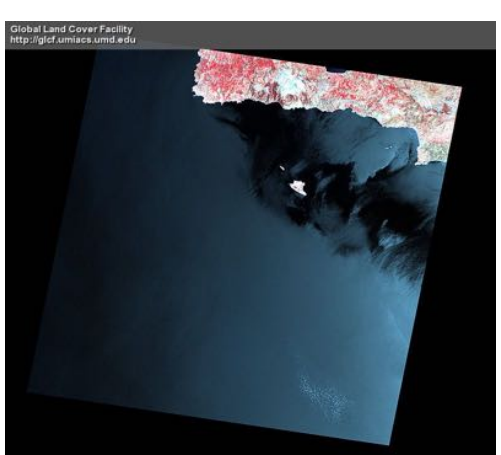

(e) Landsat 2000-06-30 ETM

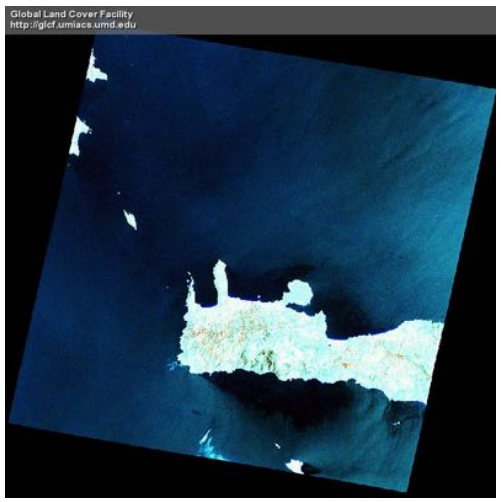

(h) Landsat-1975-07-26

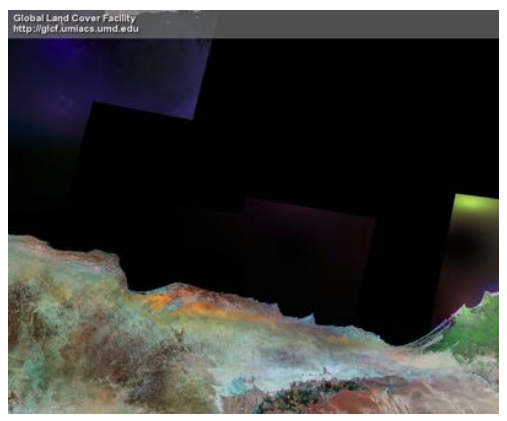

(j) Landsat-ETM-99-08-08

xlix

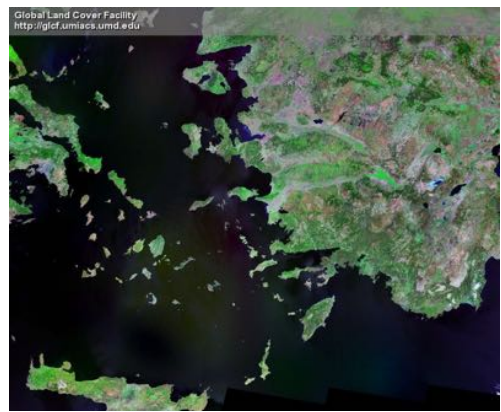

(c) Mosaic-Landsat- ETM-199908-08

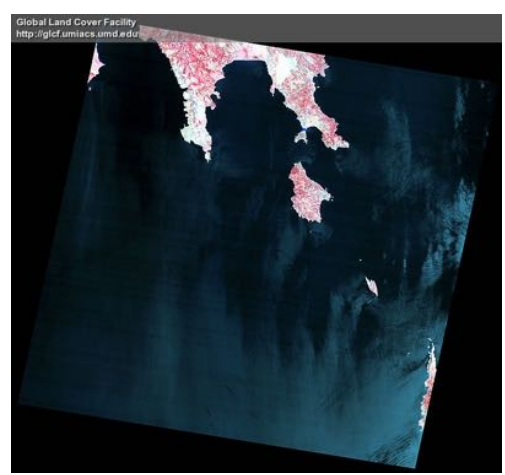

(f) Landsat 1987-06-10-TM

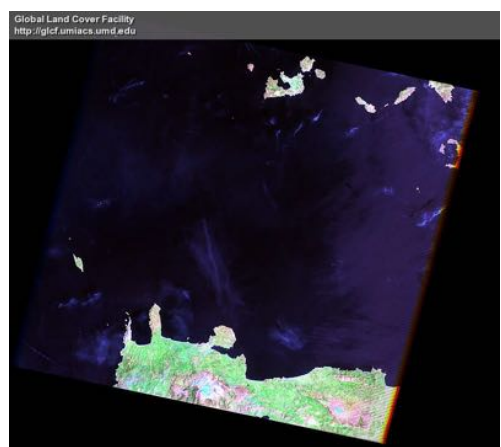

(i) Landsat TM

Figure A.44: Langdsat imagery, Crix Seagrass mapping and monitoring along the coasts of Crete, Greece" 


\section{A.9 Analysis and classification of the satellite and aerial images}

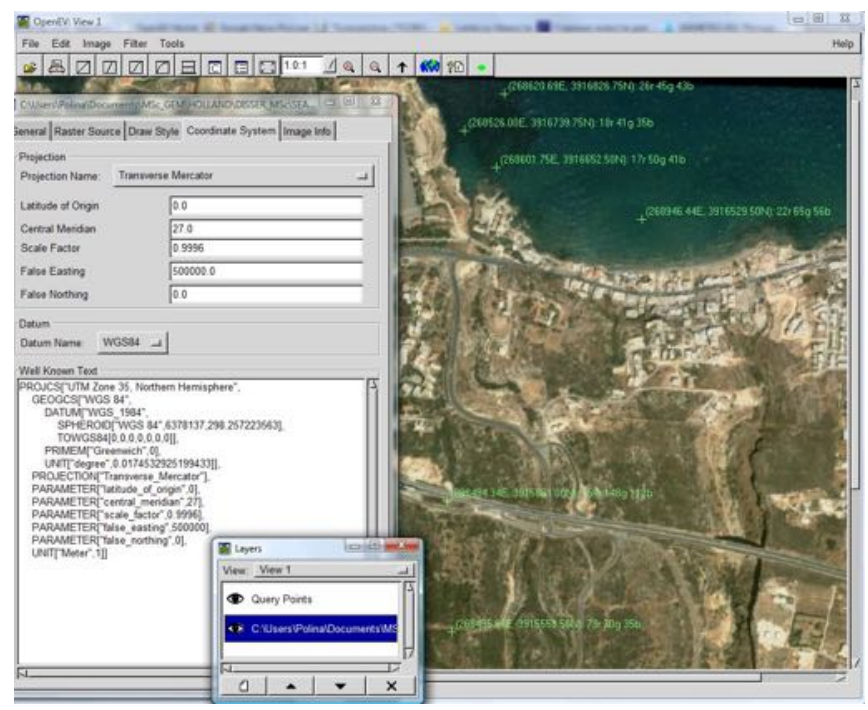

Figure A.45: The point querying shows the selected points and their coordinates within the area of seagrass meadow (green). OpenEV.Page: $<29>$

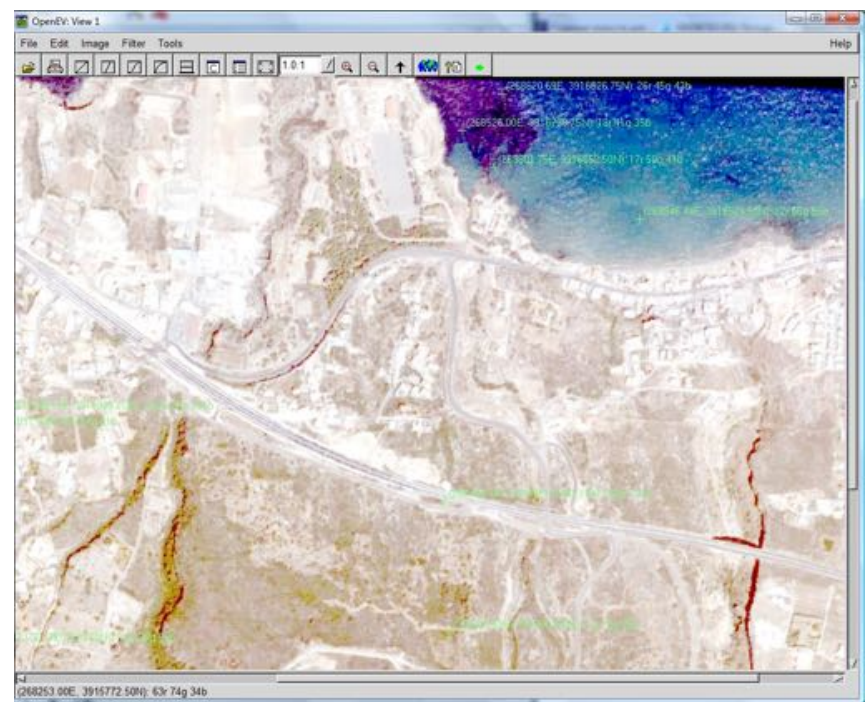

Figure A.46: Logarithmic Enhancement to Raster, applied to the aerial Google Earth image: the seagrass meadow seen as a bright spot of purple color. OpenEV. Page: $<29>$ 


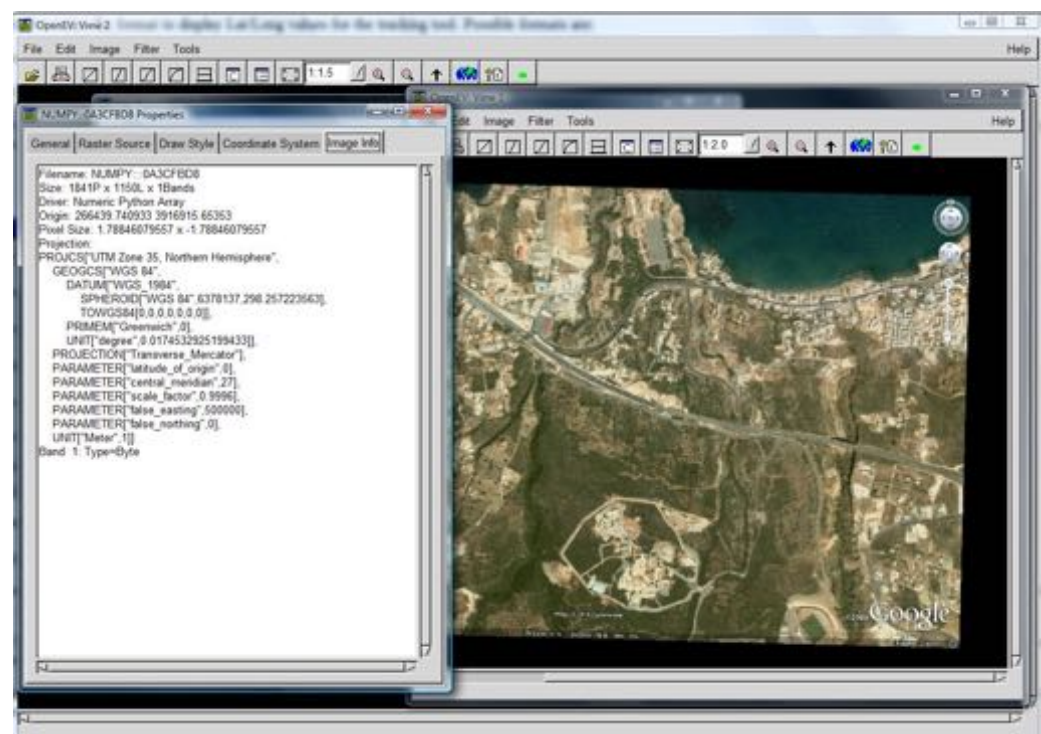

Figure A.47: Raster properties dialog: visualization and spatial info about the image (projection UTM, zone 35, datum WGS-84, etc.) OpenEV). Page: $<29>$

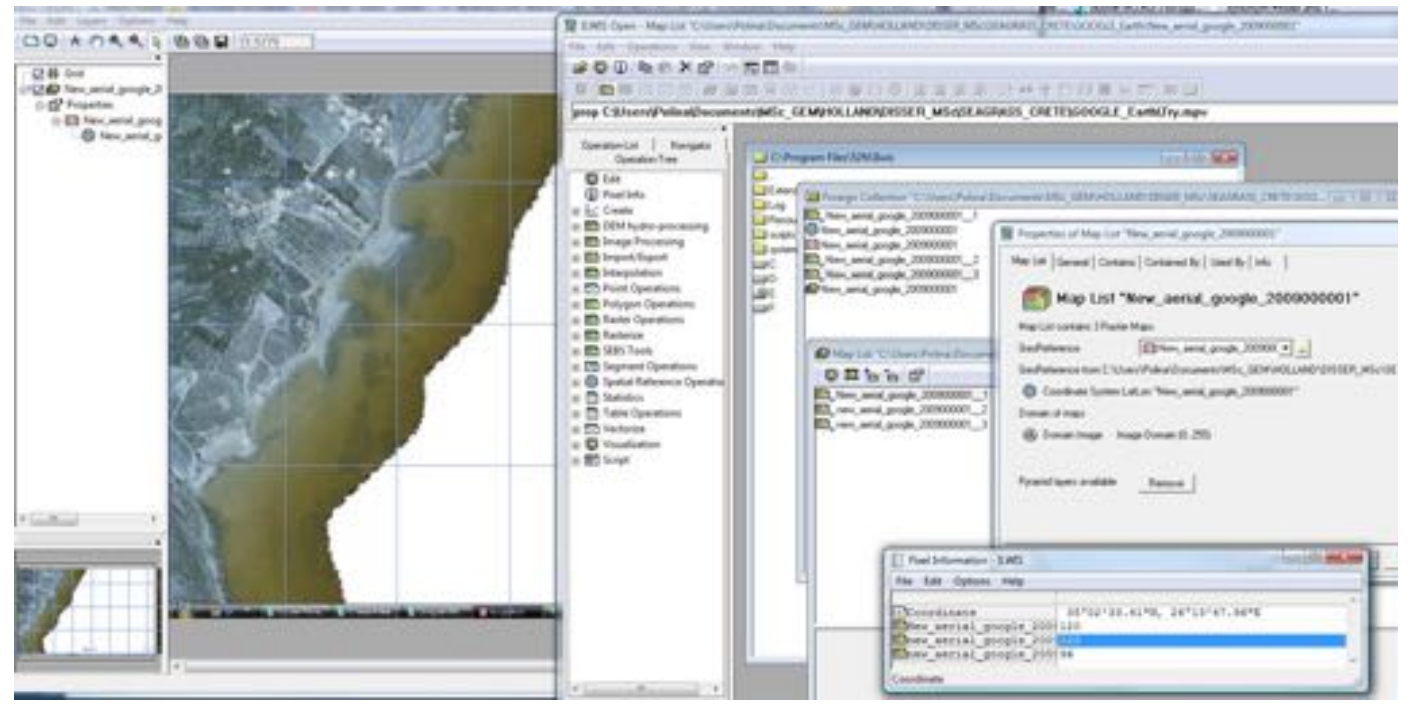

Figure A.48: Color composite image composed of 3 images of Cretan shelf, Google Earth. ILWIS. Page: <29> 


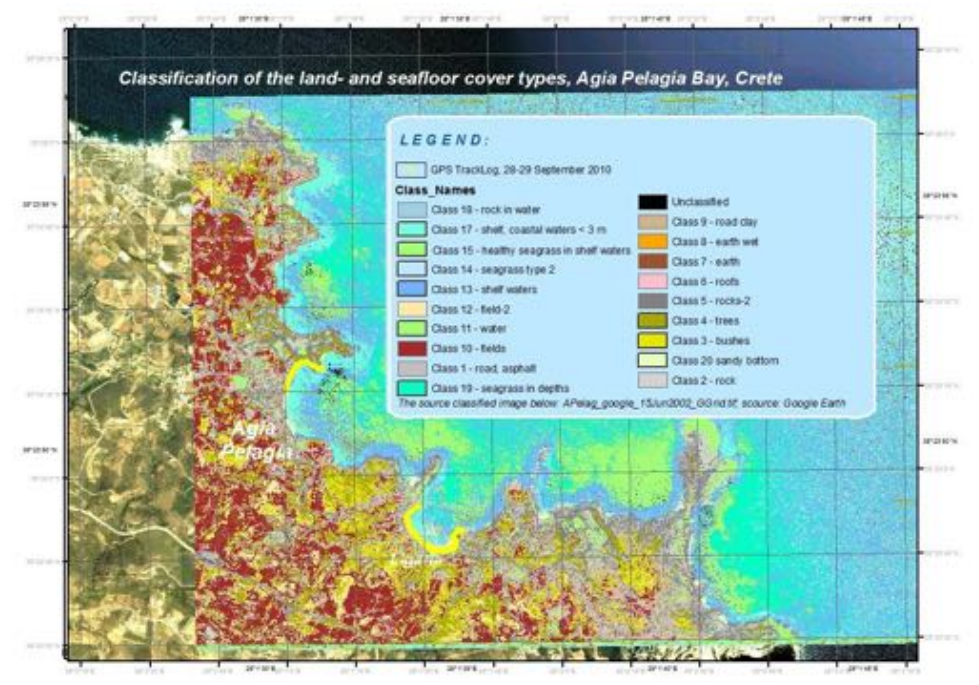

Figure A.49: Results of the image unsupervised classification of the seafloor cover types and land structure, Agia Pelagia; raster layer read into the ArcGIS project. Page: $<55>$

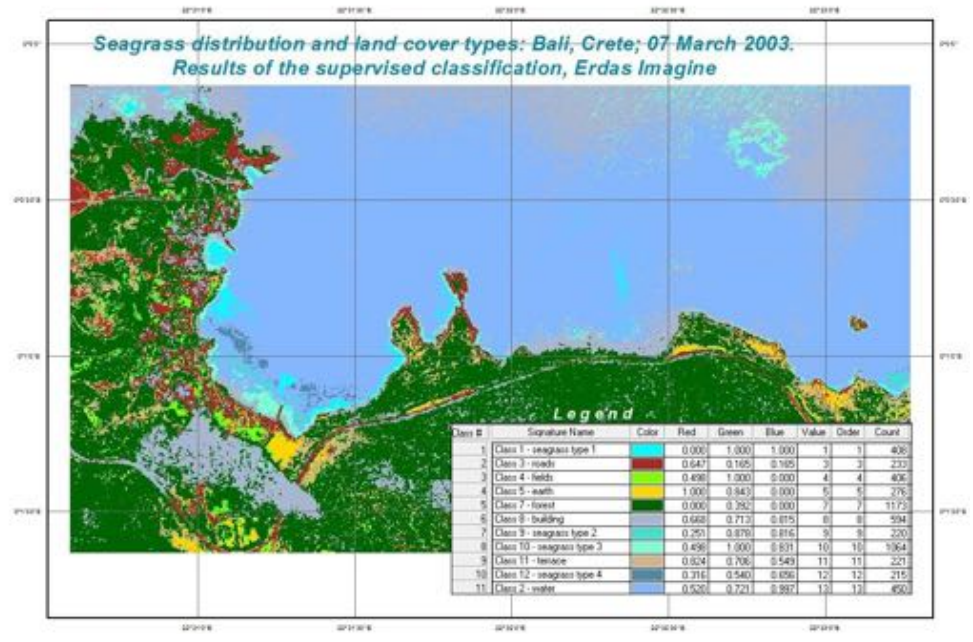

Figure A.50: Results of the image supervised classification in Erdas Imagine: seagrass distribution in Bali area, Crete. Pages: $<55>,<$ liv $>$ 


\section{A.10 Accuracy assessment}

Table A.32: Confusion Matrix-1, between the classified Google Earth aerial image and fieldwork data, for Fig.A.49. Page: $<51>$

\begin{tabular}{|c|c|c|c|c|c|c|c|c|c|c|c|c|c|c|c|c|c|}
\hline $\begin{array}{l}\text { Correctly } \\
\text { classified }\end{array}$ & 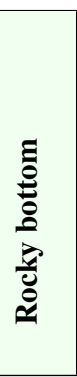 & 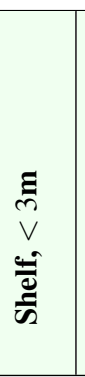 & 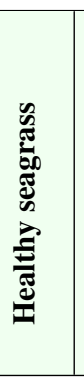 & 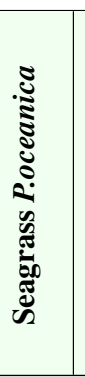 & 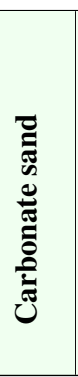 & 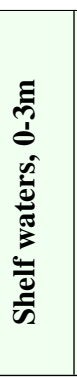 & 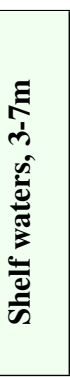 & 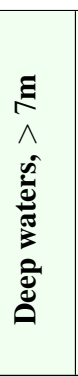 & 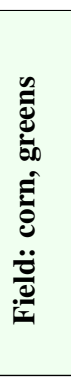 & 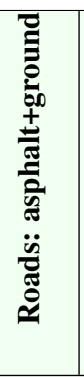 & 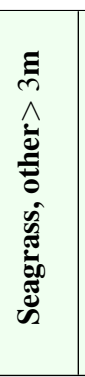 & 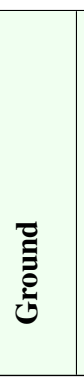 & 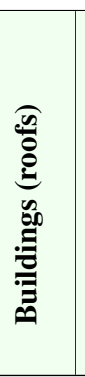 & 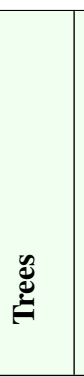 & 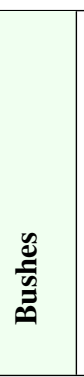 & $\stackrel{\bar{\pi}}{0}$ & 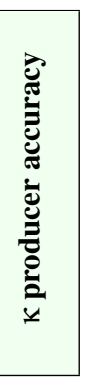 \\
\hline $\begin{array}{l}\text { Rocky } \\
\text { bottom }\end{array}$ & 14 & 2 & 0 & 0 & 3 & 0 & 0 & 0 & 0 & 1 & 0 & 2 & 0 & 1 & 1 & 24 & 0.58 \\
\hline Shelf, $<3 \mathbf{m}$ & 0 & 12 & 0 & 3 & 1 & 2 & 0 & 0 & 1 & 0 & 0 & 0 & 1 & 0 & 0 & 20 & 0.60 \\
\hline $\begin{array}{l}\text { Healthy sea- } \\
\text { grass }\end{array}$ & 0 & 1 & 10 & 3 & 2 & 0 & 0 & 0 & 1 & 0 & 2 & 0 & 0 & 0 & 0 & 19 & 0.52 \\
\hline $\begin{array}{l}\text { Seagrass } \\
\text { P.oceanica }\end{array}$ & 0 & 1 & 1 & 13 & 0 & 1 & 0 & 0 & 1 & 0 & 2 & 0 & 0 & 1 & 1 & 21 & 0.62 \\
\hline $\begin{array}{l}\text { Carbonate } \\
\text { sand }\end{array}$ & 2 & 0 & 0 & 0 & 16 & 0 & 0 & 0 & 0 & 0 & 0 & 2 & 0 & 0 & 0 & 20 & 0.80 \\
\hline $\begin{array}{l}\text { Shelf wa- } \\
\text { ters, } 0-3 \mathrm{~m}\end{array}$ & 0 & 3 & 0 & 0 & 0 & 9 & 2 & 0 & 0 & 0 & 0 & 0 & 0 & 0 & 0 & 14 & 0.64 \\
\hline $\begin{array}{l}\text { Shelf wa- } \\
\text { ters, } 3-7 \mathrm{~m}\end{array}$ & 1 & 2 & 0 & 0 & 0 & 3 & 8 & 1 & 0 & 0 & 0 & 0 & 0 & 0 & 0 & 15 & 0.53 \\
\hline $\begin{array}{l}\text { Deep wa- } \\
\text { ters, }>7 \mathrm{~m}\end{array}$ & 1 & 1 & 0 & 0 & 1 & 2 & 3 & 16 & 0 & 0 & 1 & 0 & 0 & 0 & 0 & 25 & 0.64 \\
\hline $\begin{array}{l}\text { Fields: corn, } \\
\text { greens }\end{array}$ & 0 & 0 & 0 & 0 & 0 & 0 & 0 & 0 & 14 & 0 & 0 & 0 & 0 & 3 & 4 & 21 & 0.66 \\
\hline $\begin{array}{l}\text { Roads: as- } \\
\text { phalt+ground }\end{array}$ & 1 & 0 & 0 & 0 & 1 & 0 & 0 & 0 & 0 & 5 & 2 & 0 & 0 & $\sigma$ & 0 & 9 & 0.55 \\
\hline $\begin{array}{l}\text { Seagrass, } \\
\text { other }>3 \mathbf{m}\end{array}$ & 0 & 0 & 0 & 3 & 0 & 0 & 0 & 0 & 0 & 0 & 24 & 2 & 0 & 1 & 1 & 31 & 0.77 \\
\hline Ground & 1 & 0 & 0 & 0 & 0 & 0 & 0 & 0 & 0 & 0 & 0 & 11 & 3 & 1 & 1 & 17 & 0.65 \\
\hline $\begin{array}{l}\text { Buildings } \\
\text { (roofs) }\end{array}$ & 0 & 0 & 0 & 0 & 2 & 0 & 0 & 0 & 0 & 0 & 0 & 0 & 9 & 2 & 3 & 16 & 0.56 \\
\hline Trees & 0 & 0 & 2 & 0 & 0 & 0 & 0 & 0 & 0 & 0 & 0 & 0 & 0 & 7 & $J$ & 12 & 0.58 \\
\hline Bushes & 0 & 0 & 0 & 0 & 0 & 0 & 0 & 0 & 0 & 0 & 0 & 0 & 0 & 2 & 4 & 6 & 0.66 \\
\hline Total & 20 & 22 & 13 & 22 & 26 & 17 & 13 & 17 & 17 & 6 & 31 & 17 & 13 & 18 & 18 & 270 & \\
\hline $\begin{array}{l}\text { K user's ac- } \\
\text { curacy }\end{array}$ & 0.70 & 0.55 & 0.77 & 0.59 & 0.62 & 0.53 & 0.62 & 0.94 & 0.82 & 0.83 & 0.77 & 0.65 & 0.69 & 0.39 & 0.22 & - & 0.64 \\
\hline
\end{tabular}

Overall Kappa $(\kappa)$ accuracy is calculated using the formula: $\sum A / N$, where $\mathrm{A}$ is number of correctly mapped points (172) and $\mathrm{N}$ is the total number of points (270). Thus, according to the results we received overall accuracy $=172 / 270=0.6370$, which is $64 \%$. Overall $\kappa$ accuracy for unsupervised classification $=\mathbf{6 4 \%}$.

Users accuracy (Reliability of classes) varies between 0.22 and 0.94 depending on class, which proves that supervised classification (see next table: Tab.A.33 ) has better results for seagrass mapping than the unsupervsied classification. Producer accuracy lies in interval between 0.52-0.77 according to class as well. 
Table A.33: Confusion Matrix-2, between the classified Google Earth aerial image and fieldwork data, for

Fig.A.50. Page: $<51>$

\begin{tabular}{|c|c|c|c|c|c|c|c|c|c|c|c|c|c|}
\hline 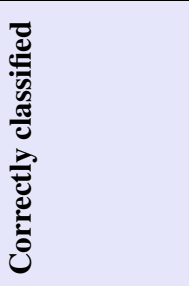 & 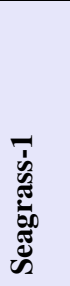 & $\begin{array}{l}\mathscr{n} \\
\stackrel{\mathscr{g}}{\simeq}\end{array}$ & $\frac{0}{\frac{0}{2}}$ & 氞 & 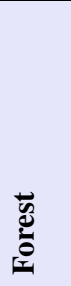 & 包 & 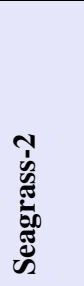 & 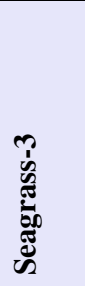 & & 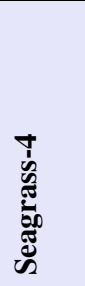 & $\frac{\bar{m}}{3}$ & हَّ & 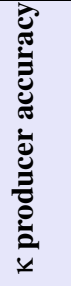 \\
\hline $\begin{array}{l}\text { Seagrass } \\
\text { P.oceanica }\end{array}$ & 22 & 0 & 0 & 0 & 0 & 0 & 2 & 1 & 0 & 1 & 1 & 27 & 0.81 \\
\hline Roads & 0 & 18 & 0 & 3 & 1 & 2 & 0 & 0 & 0 & 0 & 0 & 24 & 0.75 \\
\hline Fields & 0 & 1 & 10 & 0 & 3 & 0 & 0 & 0 & 1 & 0 & 0 & 15 & 0.66 \\
\hline Earth & 0 & 1 & 1 & 13 & 0 & 1 & 0 & 0 & 1 & 0 & 0 & 17 & 0.76 \\
\hline Forest & 0 & 1 & 1 & 1 & 9 & 0 & 0 & 0 & 1 & 0 & 0 & 13 & 0.69 \\
\hline Buildings & 0 & 0 & 2 & 0 & 1 & 24 & 0 & 0 & 1 & 0 & 0 & 28 & 0.85 \\
\hline Seagrass-2 & 3 & 0 & 0 & 0 & 0 & 0 & 33 & 2 & 0 & 2 & 2 & 42 & 0.78 \\
\hline Seagrass-3 & 1 & 0 & 0 & 0 & 0 & 0 & 1 & 27 & 0 & 1 & 1 & 31 & 0.87 \\
\hline Terrace & 0 & 2 & 3 & 1 & 0 & 1 & 0 & 0 & 19 & 0 & 0 & 26 & 0.73 \\
\hline Seagrass-4 & 1 & 0 & 0 & 0 & 0 & 0 & 2 & 2 & 0 & 37 & 1 & 43 & 0.86 \\
\hline Water & 2 & 0 & 0 & 0 & 0 & 0 & 1 & 1 & 0 & 1 & 14 & 19 & 0.74 \\
\hline Total & 29 & 23 & 17 & $\overline{18}$ & 14 & 28 & 39 & 33 & 23 & 42 & 19 & 285 & 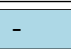 \\
\hline $\begin{array}{l}\text { К user's ac- } \\
\text { curacy }\end{array}$ & 0.76 & 0.78 & 0.59 & 0.72 & 0.64 & 0.86 & 0.85 & 0.82 & 0.83 & 0.88 & 0.74 & - & 0.72 \\
\hline
\end{tabular}

Overall Kappa $(\kappa)$ accuracy is calculated using the formula: $\sum A / N$, where $\mathrm{A}$ is number of correctly mapped points (226) and $\mathrm{N}$ is the total number of points (285). Thus, according to the results we received overall accuracy $=226 / 285=0.79298$, which is $72 \%$. Overall $\kappa$ accuracy for supervised classification $=\mathbf{7 2 \%}$.

Users accuracy (Reliability of classes) varies between 0.59 and 0.88 depending on class.

Producer accuracy lies in interval between $0.66-0.87$ according to class as well. 


\section{A.11 Research general workflow}

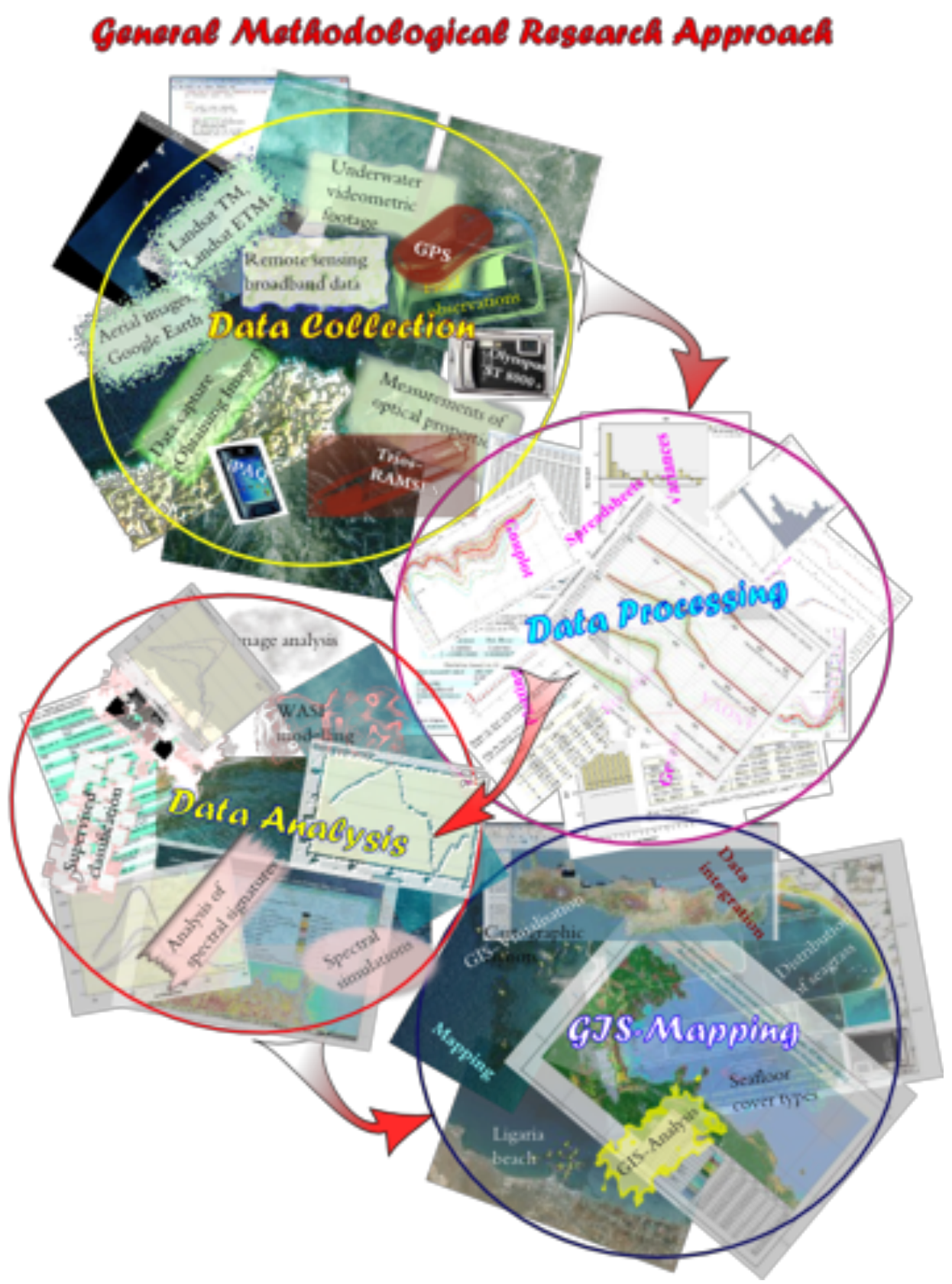

Figure A.51: General methodological research approach. Inkscape. Page: $<11>$ 


\section{A.12 Some snapshots of the working process}

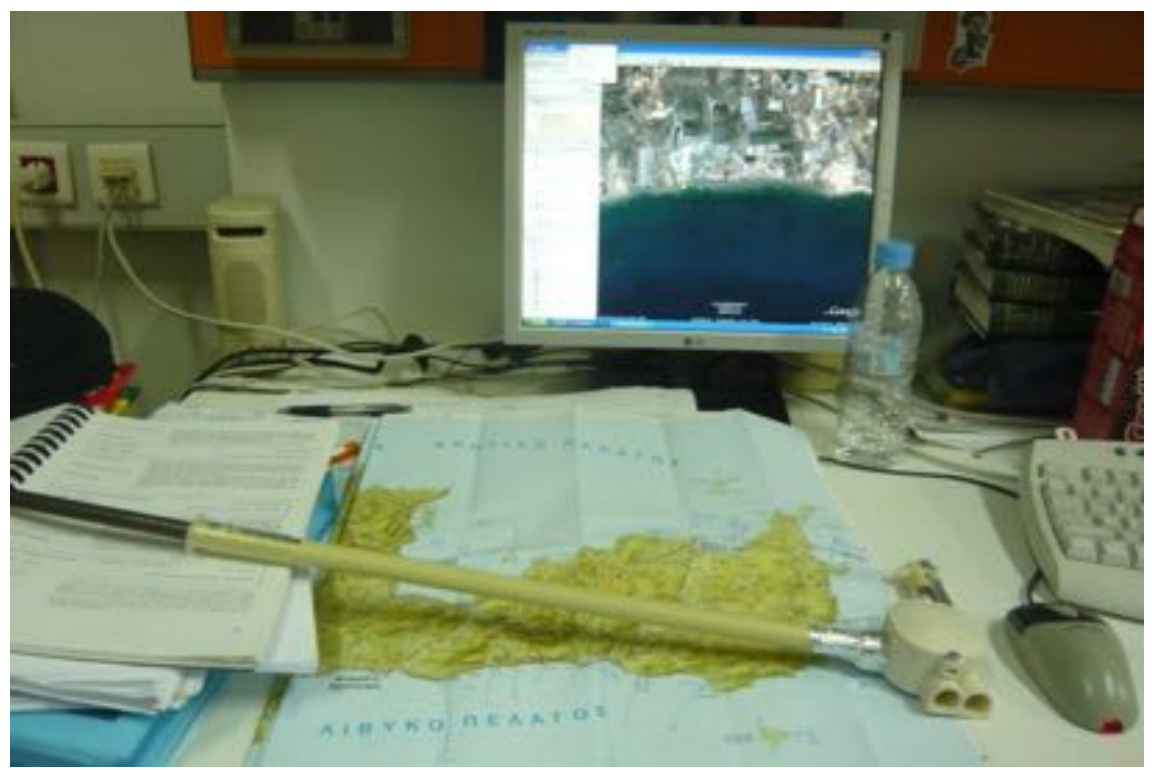

Figure A.52: Google Earth aerial imagery grabbing, Heraklion, the University of Crete. Pages: $<36>,<11>$

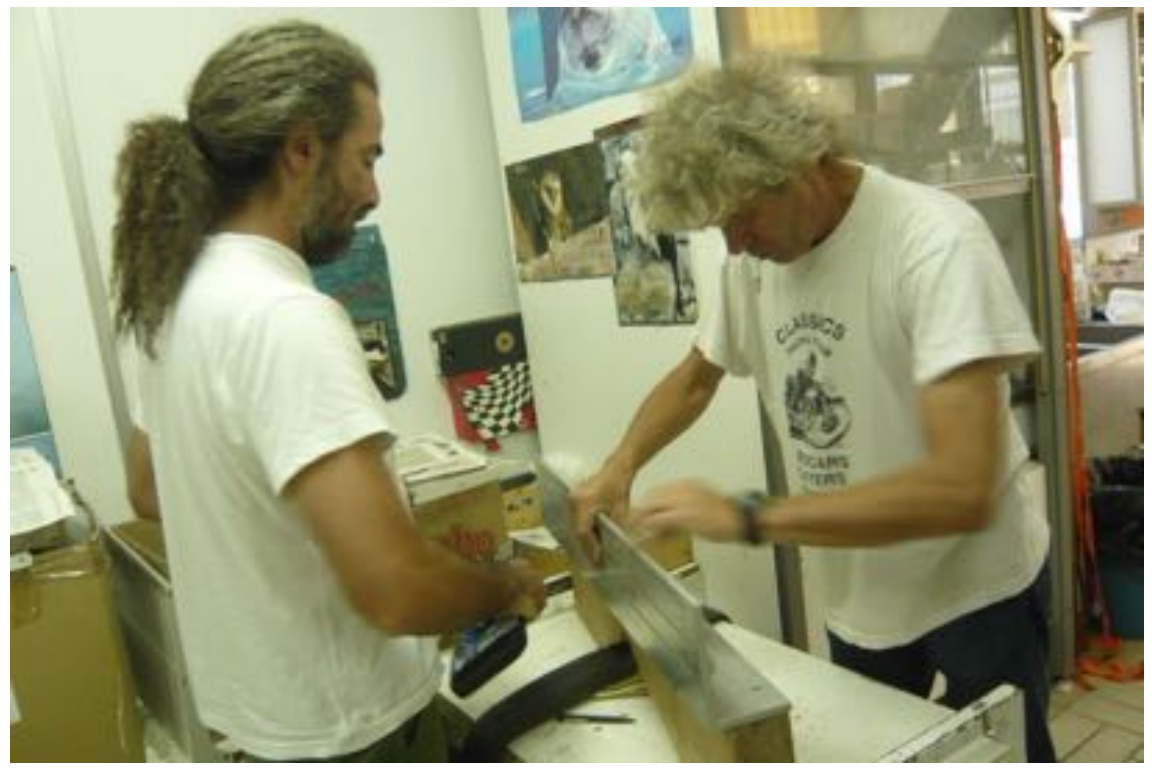

Figure A.53: Adjusting waterproof Olympus cameras for underwater seafloor videometric measurements. Dr. Petros Lymberakis (left) and Dr. Bert Toxopeus (right). Pages: $<27>,<28>$ 


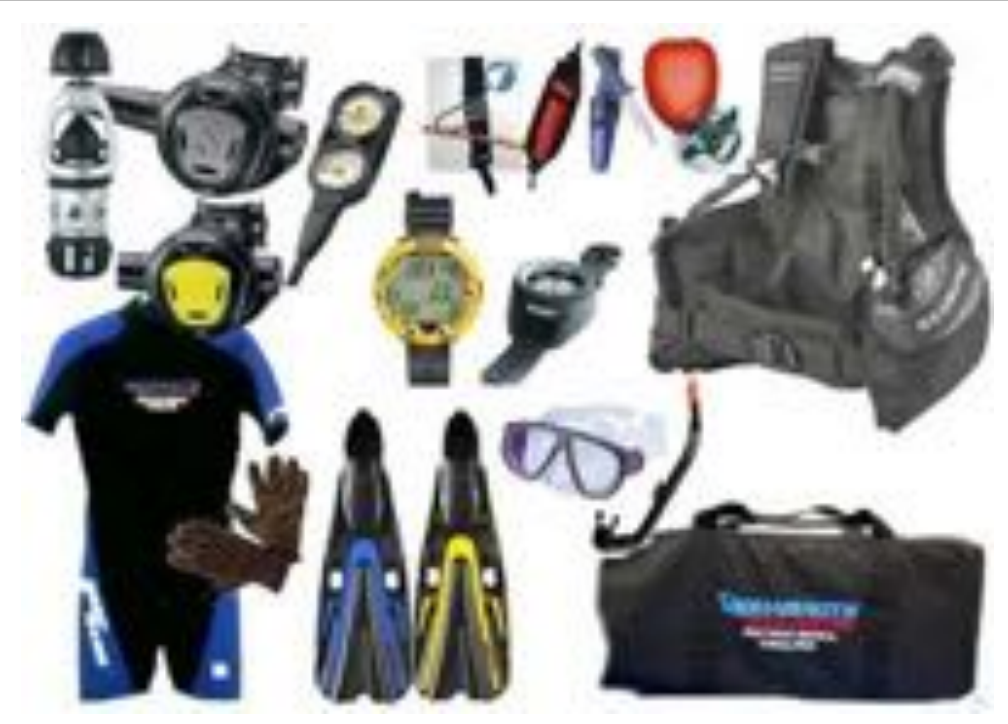

Figure A.54: SCUBA gear diving equipment necessary for seagrass monitoring. Source: Aquanauts.com. Pages: $<17>,<27>$

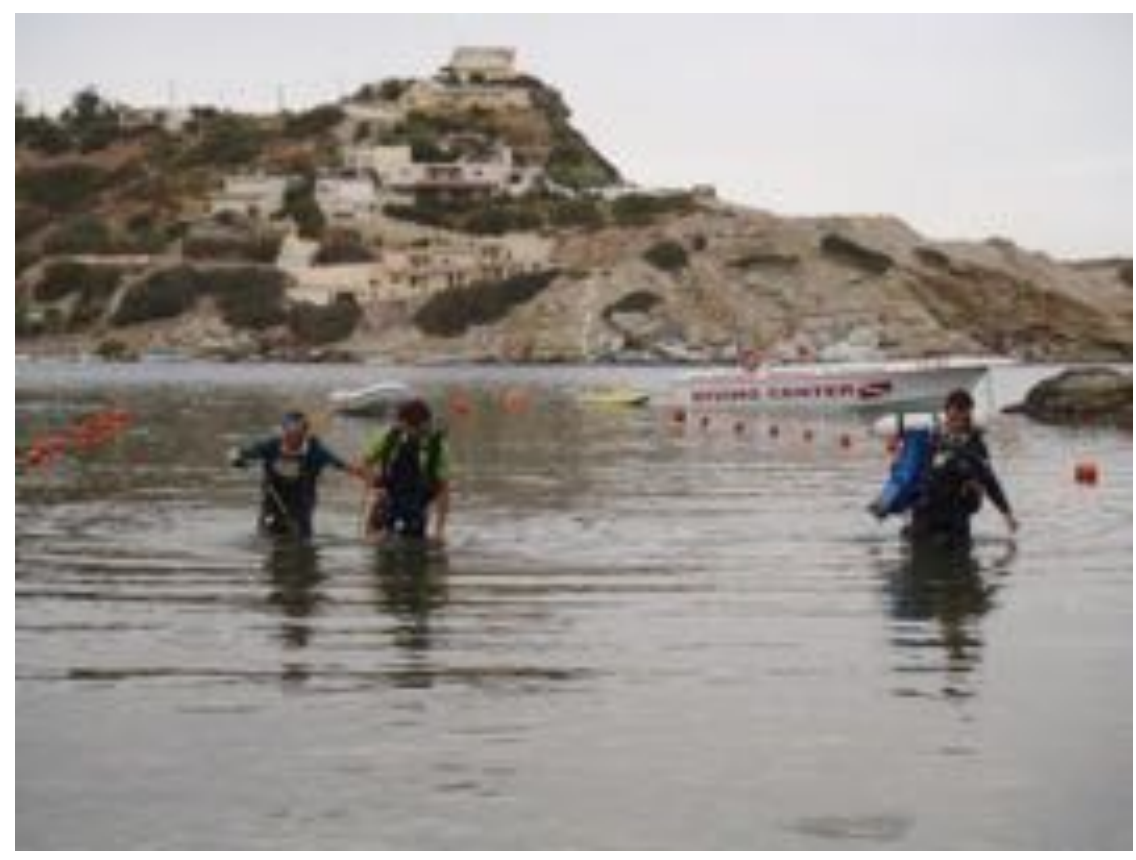

Figure A.55: ... and it's me, learning diving skills on Ligaria beach, Crete, 2010. On the photo: left. Page: $<27>$ 


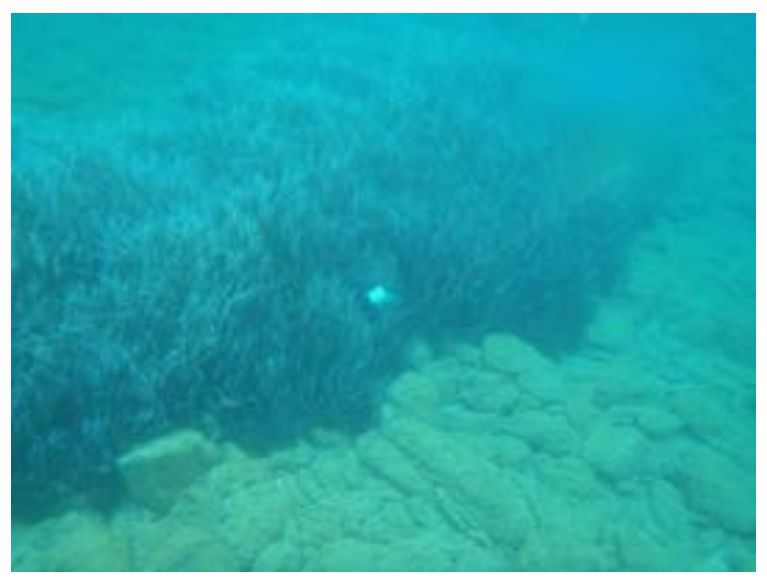

Figure A.56: Sticking marker into the sea bottom in matte of P.oceanica for depth measurements. Page: $<26>$

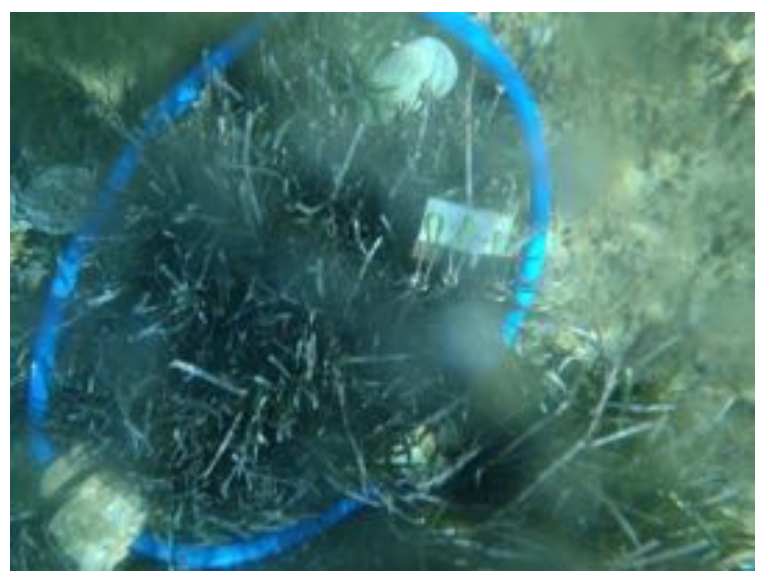

Figure A.57: Placing the $0.5 \mathrm{~m}$ circle and depth marker in the mattte of P.oceanica for photo capture. Page: $<28>$

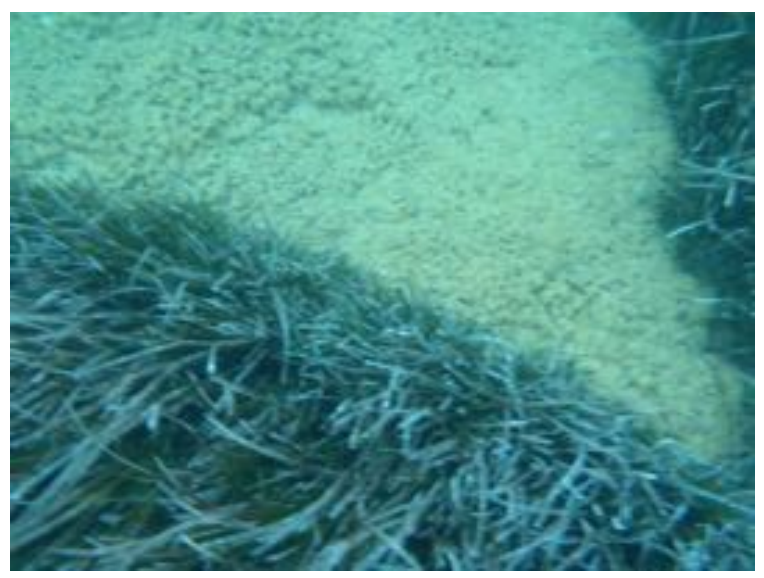

Figure A.58: Monitoring different seafloor cover types: mattte of P.oceanica vs carbonate sand. Ligaria beach. Page: $<28>$ 


\section{References}

[1] Ackleson S. 2003. Light in shallow waters: A brief research review. Limnol. Oceanogr., 48(1, part 2), 2003, 323328. American Society of Limnology and Oceanography, Inc. 14

[2] Alcoverro T., Romero J., Duarte C.M., Lopez N. 1997. Spatial and temporal variations in nutrient limitation of seagrass Posidonia oceanica growth in the NW Mediterranean. Marine ecology Progress Series.Vol.146: 155-161. 4

[3] Amoutzopoulou-Schina H. and Haritonidis S. 2005. Distribution and phenology of the marine phanerogam Posidonia oceanica in the Pagassitikos Gulf, Greece. Journal of Biological Research 4: 203 211, 2005 J. 2

[4] Arai K. and Tonooka H. 2005. Radiometric Performance Evaluation of ASTER VNIR, SWIR and TIR IEEE Transactions on Geoscience and Remote Sensing, Vol. 43, No. 12, Dec. 2005. 21

[5] Ardizzone G.D., Belluscio A. and Maiorano L. 2006. Long-term change in the structure of a Posidonia oceanica landscape and its reference for a monitoring plan. Marine Ecology. ISSN 0173-9565. 18

[6] Ball D., Soto-Berelov M., Young P. and Coots A. 2009. Baywide Seagrass Monitoring Program Historical Seagrass Mapping. Fisheries Victoria Technical Report Series No. 70.19

[7] Barille L., Robin M., Harin N., Bargain A., Patrick L. 2009. Increase in seagrass distribution at Bourgneuf Bay (France) detected by spatial remote sensing. Aquatic Botany. 19

[8] Bakran-Petricioli T., Antonic O., Bukovec D., Petricioli D., Janekovic I., Krizan J., Kusan V. and Dujmovic S. 2006. Modelling spatial distribution of the Croatian marine benthic habitats. Ecological Modelling 191, 96105. 18

[9] Bell S.S., Robbins B.D. and Jensen S.L. 1999. Gap Dynamics in a Seagrass Landscape. SpringerVerlag. Ecosystems (1999) 2: 493504. 56

[10] Bierwirth P. N., Lee T. J. and Burne R. V. 1993. Shalow sea-floor reflectance and water depth derived by unmixing multispectral imagery. Photogrammetric Engineering and Remote Sensing, vol. 59, No. 3, March, pp. 331-338. 20

[11] Blake S., Roob R. and Patterson E. 2000. Seagrass mapping of Victoria's Minor Inlets. Marine and Freshwater Resources Institute Report No. 28. 4

[12] Borum J., Duarte C.M., Krause-Jensen D. and Greve T.M. 2004. European seagrasses: an introduction to monitoring and management. The M and MS project. ISBN: 87-89143-21-3. Internet version: Available at Seagrasses.org 5

[13] Brown C.J., Cooper K.M., Meadows W.J., Limpenny D.S., Rees H.L. 2002. Small scale mapping of sea bed assemblages in the eastern English Channel using sonar and remote sampling techniques. Estuarine Coastal and Shelf Science, 54, 263-278. 11

[14] Boudouresque C.F., Meinesz, A., Fresi, E. and Gravez, V., 1989. 2nd International Workshop on Posidonia oceanica Beds. G.I.S. Posidonie, Oceanica, 2, 322 pp. 5 
[15] Bharathi A.M., Kumar S.C., Kalliappan S. 2003. Target Identification in multispectral images using in-situ hyperspectral reflectance. The Geospatial Resource Portal. Remote Sensing. gisdevelopment 22

[16] Buia M.C. and Mazzella L. 1991. Reproductive phenology of the Mediterranean seagrasses Posidonia oceanica (L.) Delile, Cymodocea nodosa ( Ucria) Aschers., and Zostera noltii Hornem. Aquatic Botany, 40 (1991) 343-362. Elsevier Science Publishers B.V., Amsterdam. 6

[17] Butler 1987. Marine resource mapping: an introductory manual. 24

[18] Cappo M., Alongi D.M., Williams D. and Duke N. 1995. A Review and Synthesis of Australian Fisheries Habitat Research: Major threats, issues and gaps in knowledge of coastal and marine fisheries habitats. Fisheries Research and Development Corporation. 3

[19] Carter G.A., Criss G.A., Blossom G.A. and Biber P.D. 2008. Decadal-Scale Changes in Coverage on the Mississippi Barrier Islands, Northern Gulf of Mexico. precedings.nature.com 18

[20] Calvo S., Ciraolo G. and Loggia G. la. 2003. Monitoring Posidonia oceanica meadows in a Mediterranean coastal lagoon (Stagnone, Italy) by means of neural network and ISODATA classification methods. INT. J. REMOTE SENSING, 2003, VOL. 24, NO. 13, 270327167

[21] Cambridge M.L., Kendrick G.A. 2009. Contrasting responses of seagrass transplants (Posidonia australis) to nitrogen, phosphorus and iron addition in an estuary and a coastal embayment. Journal of Experimental Marine Biology and Ecology. 371, 3441. 3

[22] Choo, C.K. 2006. Save our Seahorses. First Edition. sosmalaysia 11

[23] Clark, R.N., 1999. Spectroscopy of rocks and minerals and principles of spectroscopy. In: A.N. Rencz (ed.). Manual of Remote Sensing, Chapter 1, John Wiley and Sons, New York. 3-58. 11

[24] Connell J.H. 1978. Diversity in tropical rain forests and coral reefs. Science 199:1302 10. 55

[25] Dehouck A., Martiny N., Froidefond J.-M., Sénéchal N. 2008. In-Water Reflectance Spectra Measured On Board a Jet-Ski Across a Complex Nearshore Zone of Case-2 Waters during the ECORS Experiment. Manuscript published in "Ocean Optics XIX, Barga: Italie (2008)” 18

[26] Dekker A.G., Brando V.E., Anstee J.M. 2005. Retrospective seagrass change detection in a shallow coastal tidal Australian lake. Remote Sensing of Environment 97:415-433. 7

[27] Dekker A., Brando V.E., Anstee J.M. 2005. Remote Sensing of Seagrass Ecosystems: Use of Spaceborne and Airborne Sensors. SVNL083-Larkum. 20

[28] Di Carlo G. 2004. The natural recolonisation process of the seagrass Posidonia oceanica (L.) Delile after the introduction of the Italo-Algerian methane pipeline in the SW Mediterranean sea.5

[29] Diaz-Almela E., Marbà N., Alvarez E., Santiago R., Holmer M., Grau A., Danovaro R., Argyrou M., Karakassis I., Duarte C.M. 2006. Benthic inputs as predictors of seagrass (Posidonia oceanica) fish farm-induced decline. arxiv.org 3 
[30] Dierssen H. and Zimmerman R.C. 2003. Ocean color remote sensing of seagrass and bathymetry in the Bahamas Banks by high-resolution airborne imagery. Limnol. Oceanogr., 48(1, part 2), 2003, 444455, by the American Society of Limnology and Oceanography. 21

[31] Dixon R., editor. 2005. Watching the Seagrass Grow a guide for community seagrass monitoring in $N S W(2 n d E d)$. Reference manual . The Community Environment Network, Ourimbah. 3

[32] Duarte, C.M. 2002. The future of seagrass meadows. Environmental Conservation 29 (2), 192206. 3

[33] Dumay O., Fernandez C. and Pergent G. 2002. Primary production and vegetative cycle in Posidonia oceanica when in competition with the green algae Caulerpa taxifolia nd Caulerpa racemosa. J.Mar. Biol. Ass. UK, 82, 379-387. 1

[34] Dural B. 2010. Phenological observations on Posidonia oceanica (L.) Delile medows along the coast of Akkum (Sgack Bay, Aegean Sea, Turkey). J. Black Sea/Mediterranean Environment, Vol. 16 (1): 133-144. 6

[35] Edwards A.J. (ed.) 2000. Remote Sensing handbook for tropical coastal management. UNESCO 6

[36] Ferguson R.L. and Karl Korfmacher K. 1997 Remote sensing and GIS analysis of seagrass meadows in North Carolina, USA. Aquatic Botany 58 (1997) 241-258. 20

[37] Fletcher R.S., Pulich Jr. W. and Hardegree B. 2009. A Semiautomated Approach for Monitoring Landscape Changes in Texas Seagrass Beds from Aerial Photography. Coastal Education and Research Foundation, doi: 10.2112/07-0882.1 21

[38] Fornes A., Basterretxea G., Orfila A., Jordi A., Alvarez A. and Tintore J. 2006. Mapping Posidonia oceanica from IKONOS. ISPRS Journal of Photogrammetry and Remote Sensing 60 (2006) 315322. 7

[39] Francour, P., Magreau, J.F., Mannoni, P.A., Cottalorda, J.M., Gratiot, J., 2006.Management guide for Marine Protected Areas of the Mediterranean Sea, Permanent Ecological Moorings. Universite de Nice-Sophia Antipolis and Parc National de Port-Cros, Nice, 68 pp. 5

[40] Francour P., Ganteaume A. and M. Poulain. 1999. Effects of boats anchoring in Posidonia oceanica seagrass beds in the Port-Cross National Park (north-western Mediterranean Sea). Aquatic conservation: Marine and Freshwater Ecosystems: 9: 391-400. 3

[41] Fyfe S.K. 2003. Spatial and temporal variation in spectral reflectance: Are seagrass species spectrally distinct? Limnology and Oceanography 48: 464479. 7

[42] Fyfe S.K. 2004. Hyperspectral studies of New South Wales with particular emphasis on the detection of light stress in Eelgrass Zostera capricorni. PhD Thesis. The University of Wollongong. Research Online, University of Wollongong Thesis Collection 7

[43] Gege P. 2004. The water color simulator WASI: an integrating software tool for analysis and simulation of optical in situ spectra. Computers and Geosciences 30 (2004) 523532. 38

[44] Gege, P. 2005. The Water Colour Simulator WASI. User manual for version 3. DLR Internal Report IB 564-01/05, 83 pp. 38 
[45] Gobert S., Cambridge, M. L., Velimirov, B., Pergent, G., Lepoint, G., Bouquegneau J.-M., Dauby, P., Pergent-Martini, C., Walker, D. I.. 2006. Biology of Posidonia. In Larkum A.W.D., Orth, R.J., Duarte C.M. (eds.), Seagrasses: Biology, ecology and conservation. Springer Verlag, Berlin, Pages 387408. 3

[46] Gobert S., Defawe O., Lepoint G., Demoulin V. and Bouquegneau J.-M. 2001. Anthesis effects on Posidonia oceanica (L.) Delile phenology in the Bay of Calvi (Corsica, Mediterranean Sea). Hydrobiologia 455: 121125. 6

[47] Green, E.P., Mumby P.J., Edwards A.J., and Clark C.D., 1996. A review of remote sensing for the assessment and management of tropical coastal resources. Coast. Manag., 24(1):1-40. 7

[48] Green E.P., Short F.T. 2003. World Atlas of Seagrasses. University of California Press, Berkeley, USA. 2

[49] Guidetti P. 2008. Population dynamics of the seagrass Posidonia oceanica for evaluating meadow health status: a study case using reconstruction techniques. Laboratory of Zoology and Marine Biology, DiSTeBA, CoNISMa, University of Lecce. 5

[50] Gullstroom M., Lunden B., Bodin M., Kangwe J., Ohman M.C., Mtolera M.S.P. and Bjork M. 2006. Assessment of changes in the seagrass-dominated submerged vegetation of tropical Chwaka Bay (Zanzibar) using satellite remote sensing. Estuarine, Coastal and Shelf Science 67 (2006) 399-408. 20

[51] Haag S.M., Kennish M., Sakowicz G.P. 2008. Seagrass Habitat Characterization in Estuarine Waters of the Jacques Cousteau National Estuarine Research Reserve Using Underwater Videographic Imaging Techniques. Journal of Coastal Research, SI(55), 171 179. West Palm Beach (Florida), ISSN 0749-0208. 7

[52] Den Hartog, C. 1970. The Seagrasses of the World. North Holland Publishing Company, Amsterdam, 275 pp. 31 plates. 35

[53] Den Hartog, C., 1977. Structure, function, and classification in seagrass communities. In: C.P. McRoy and C. Helfferich (Editors), Seagrass Ecosystems: a Scientific Perspective. Marcel, New York, pp. 89121. 2

[54] Heege T., Bogner A., Pinnel N. 2003. Mapping of submerged aquatic vegetation with a physically based process chain. Proc. Remote Sensing, September 8-12 2-3/ Barcelona, Spain. Ed. by Kramer E. The International Society for Optical Engineering, Vol.5233. 21

[55] Hirose K., Syoji M., Hang H.T.M., Anh N.H., Triet T. and Nam V.N. 2004. Satellite data application for mangrove management. International Symposium on Geoinfomatics for Spatial Infrastructure Development in Earth and Allied Sciences. 21

[56] Hochberg, E.J., Atkinson, M.J. 2003a. Capabilities of remote sensors to classify coral, algae, and sand as pure and mixed spectra. Remote Sensing of Environment 85, 174189. 23

[57] Hochberg, E.J., Atkinson, M.J., Andréfouët, S., 2003b. Spectral reflectance of coral reef bottomtypes worldwide and implications for coral reef remote sensing. Remote Sensing of Environment 85, 159173. 17 
[58] Hogarth P. 2007. The Biology of Mangroves and Seagrasses. Oxford University Press. 1

[59] Holmer M., Marbà N., Lamote M. and Duarte C. 2009Deterioration of Sediment Quality in Seagrass Meadows (Posidonia oceanica) Invaded by Macroalgae (Caulerpa sp.). Estuaries and Coasts (2009) 32:456466 DOI 10.1007/s12237-009-9133-4 1

[60] Holmer M., Argyrou M., Dalsgaard T., Danovaro R., Diaz-Almela E., Duarte C., Frederiksen M., Grau A., Karakassis I., Marbà N., Mirto S., Pérez M., Pusceddu A., Tsapakis M., 2008 Effects of fish farm waste on Posidonia oceanica meadows: Synthesis and provision of monitoring and management tools. Marine Pollution Bulletin 56 (2008) 16181629. 3

[61] Iverson R.L. and Bittaker H.F. 1986. Seagrass Distribution and Abundance in Eastern Gulf of Mexico Coastal Waters. Estuarine, Coastal and Shelf Science, 22, 577-602. 17

[62] Jackson J., Nemeth D.J. 2007. A New Method to Describe Seagrass Habitat Sampled During Fisheries-Independent Monitoring. Estuaries and Coasts Vol. 30, No. 1, p. 171178 February 2007 7

[63] Jensen S. and Bell S.S. 2001. Seagrass growth and patch dynamics: cross-scale morphological plasticity. Plant Ecology 155: 201217, 2001. 56

[64] Jensen J.R., Rutchey K., Koch M.S., Narumalani S. 1995. Inland wetland change detection in the everglades water conservation area 2 a using a time-series of normalized remotely-sensed data. Photogrammetric Eng Remote Sensing 61: 1992097

[65] Jerlov N.G. 1952. Influence of suspended and dissolved matter on the transparency of sea water. Wiley online Library. Tellus Volume 5, Issue 1, Published online: 2010. 14

[66] Kalinowski A. and Oliver S. 2004 ASTER Mineral Index Processing Manual. Remote Sensing Applications. Geoscience Australia 21

[67] Kelly, M.G., 1980. Remote sensing of seagrass beds, Handbook of Seagrass Biology: An Ecosystem Perspective (R.C. Phillips and C.P. McRoy, editors), Garland STPM Press, New York, N.Y., pp. 69-86. 6

[68] Kendrick G.A., Hegge B.J., Wyllie A., Davidson A., Lord D.A.. 2000. Changes in Seagrass Cover on Success and Parmelia Banks, Western Australia Between 1965 and 1995. Estuarine, Coastal and Shelf Science, 50:341-353. 7

[69] Kirk J.T.O. 1994. Light and photosynthesis in aquatic ecosystems, pp 1509. University Press, Cambridge, UK. 19

[70] Kirkman H. 1996. Baseline and Monitoring Methods for Seagrass Meadows. Journal of Environmental Management (1996) 47, 191201. 11

[71] Kuo J., McComb A.J., 1989. Seagrass taxonomy, structure and development. In: Larkum A.W.D., McComb A.J., Shepherd J., eds. Biology of seagrasses: a treatise on the biology of seagrasses with special reference to the Australian region. Elsevier, The Netherlands: 6-73. 2 
[72] Leoni V., Pasqualini V., Pergent-Martini C., Vela A., Pergent G. 2006. Morphological responses of Posidonia oceanica to experimental nutrient enrichment of the canopy water. Journal of Experimental Marine Biology and Ecology xx (2006) xxxxxx. 3

[73] Leoni V., Pasqualini V., Pergent-Martini C., Vela A., Pergent G. 2007. Physiological responses of Posidonia oceanica to experimental nutrient enrichment of the canopy water. Journal of Experimental Marine Biology and Ecology 349, 7383. 3

[74] Leoni V., Vela A., Pasqualini V., Pergent-Martini C., Pergent G. 2008. Effects of experimental reduction of light and nutrient enrichments $(N$ and $P)$ on seagrasses: a review. Aquatic Conservation: Marine and Freshwater Ecosystems, 18: 202220. 3

[75] Lewis M. 2001. Discriminating Vegetation with Hyperspectral Imagery - What is Possible? ieeexplore.ieee.org Proceedings, International Geoscience and Remote Sensing Symposium, 9-13 July 2001, Sydney, Australia. ISBN 0-7803-7031-7 18

[76] Louchard E.M., Reid R.P., Stephens F.C., Davis C.O., Leathers R.A., Downes T.V. 2003. Optical remote sensing of benthic habitats and bathymetry in coastal environments at Lee Stocking Island, Bahamas: A comparative spectral classification approach. Limnology and Oceanography (2003) 48:511-521. 18

[77] Luque A. and Templado J.A. 2004. Praderas y bosques marinos de Andalucia Consejeria de Medio Ambiente, Junta de Andalucia (in press). 5

[78] Lyzenga D.R. 1981. Remote sensing of bottom reflectance and water attenuation in shallow water using aircraft and Landsat data. International Journal of Remote Sensing 2, 71-82. 7

[79] Maffione R.A. and Dana D.R. 1997 Instruments and methods for measuring the backward-scattering coefficient of ocean waters. Optical Society of America 39

[80] Maffione R.A. 2001a. Evolution and Revolution in Measuring Ocean Optical Properties. Oceanography, Vol.14, No.3. 14

[81] Maffione R.A. 2001b.Hyperspectral Optical Properties, Remote Sensing, and Underwater Visibility. Hydro-Optics, Biology, and Instrumentation Laboratories. 15

[82] Malthus T.J. and Karpouzli E. 2003. Integrating field and high spatial resolution satellite based methods for monitoring shallow submersed aquatic habitats in the Sound of Eriskay, Scotland, UK. Int Journal Remote Sensing 24: 25852593. 7

[83] Matarrese R., Acquaro M., Morea A., Tijani K., Chiaradia M.T. 2008. Applications of remote sensing techniques for mapping Posidonia oceanica meadows. Geoscience and Remote Sensing Symposium. ISBN:978-1-4244-2807-6. 12

[84] Matarrese R., Acquaro M., Morea A., Khalid T., Chiaradia M.T. 2006 Applications of remote sensing techniques for mapping Posidonia oceanica meadows. International Geoscience and Remote Sensing Symposium 6 
[85] McKenzie L.J., Campbell S.J. 2002. Manual for Community (citizen) Monitoring of Seagrass Habitat. Western Pacific Edition. Marine Plant Ecology Group, QDPI, Northern Fisheries Centre, Cairns. 43 pp. 1

[86] McKenzie L.J., Campbell S.J. and Roder C.A. 2003. Seagrass-Watch: Manual for Mapping and Monitoring Seagrass Resources by Community (citizen) Volunteers. 2nd Edition. QFS, NFC, Cairns. 100pp. 6

[87] McKenzie L.J. 2003. Guidelines for the rapid assessment of seagrass habitats in the Western Pacific. Marine Plant Ecology Group, QDPI, Northern Fisheries Centre, Cairns, seagrasswatch 17

[88] McKenzie L.J., Campbell S.J. and F.Lasi 2006. Seagrasses and Mangroves. In: Green A.P., Lokani W., Atu P., Ramonia P., Thomas P. and Almanmy J. (eds). 2006 Solomon Islands Marine Assessment. Technical report of survey conducted May 13 to June 17 2004. The Nature Conservancy, Indo-Pacific Resource Centre. Report No 1/06 4

[89] McKenzie L.J. and Yoshida R. 2007. Seagrass-Watch: Guidelines for Monitoring Seagrass Habitats in the Fiji Islands. Proceeding of a training workshop. Corpus Christi Teachers College Laucala Bay, Suva, Fiji, 16th June 2007. Seagrass-Watch HQ Cairns, 42pp. 4

[90] McKenzie L.J. 2008. Seagrass-Watch. Proceedings of a Workshop for Mapping and Monitoring Seagrass Habitats in North East Arnhem Land, Northern Territory. 18-20 October 2008. Seagrass-Watch HQ, Cairns, 49pp. 1

[91] McKenzie L.J., Yoshida R. 2009. Seagrass Watch. Proceedings of a Workshop for Monitoring Seagrass Habitats in Indonesia. The Nature Conservancy, Coral Triangle Centre, Sanur, Bali, Indonesia. 34

[92] Meinesz, A., Lefevre, J.R., Astier, J.M., 1991. Impact of coastal development on the infralittoral zone along the south-eastern Mediterranean shore of continental France. Marine Pollution Bullettin 23, 343347. 3

[93] Mellors J. and McKenzie L. 2009(a). Seagrass-Watch: Guidelines for Monitoring Seagrass Habitats. Proceedings of a workshop held on Thursday Island, Torres Strait 4-8.03.2009. 18

[94] Mellors J. and McKenzie L. 2009(b). Seagrass-Watch: Seagrass Monitoring Guidelines for Torres Strait Communities. Meer Island. Proceedings of a workshop held on Meer Island, Torres Strait 1415 September 2009. 58 pp. 4

[95] Micheli C., Paganin P., Peirano A., Caye, G., Meinesz A. and Bianchi C.N. 2005. Genetic variability of Posidonia oceanica (L.) Delile in relation to local factors and biogeographic patterns. Aquatic Botany 82 (2005) 2102213

[96] Montefalcone M. 2009.Ecosystem health assessment using the Mediterranean seagrass Posidonia oceanica: A review. Ecological indicators 5956045

[97] Montefalcone M., Albertelli G., Morri C. and Bianchi C.N. 2010. Patterns of wide-scale substitution within meadows of the seagrass Posidonia oceanica in NW Mediterranean Sea: invaders are stronger than natives. Aquatic Conserv: Mar. Freshw. Ecosyst. 20: 507515. 56 
[98] Montefalcone M., Albertelli G., Bianchi C.N., Mariani M., Morri C. 2006. A new synthetic index and a protocol for monitoring the status of Posidonia oceanica meadows: a case study at Sanremo (Ligurian Sea, NW Mediterranean). Aquatic Conservation: Marine and Freshwater Ecosystems, 16, 2942. 11

[99] Mount R. 2003. The application of digital aerial photography to shallow water seabed mapping and monitoring how deep can you see? Coastal GIS 2003: and integrated approach to Australian coastal issues, 7th - 8th July 2003. Wollongong, University of Wollongong, pp. 139-156. 7

[100] Mumby P.J., Green E.P., Edwards A.J. and Clark C.D. 1999. The cost-effectiveness of remote sensing for tropical coastal resources assessment and management. Journal of Environmental Management Volume 55, Issue 3, March 1999, Pages 157-166 19

[101] Mumby, P.J. and Edwards A.J. 2002. Mapping marine environments with IKONOS imagery: Enhanced spatial resolution can deliver greater thematic accuracy. Remote Sensing of Environment, 82,24825721

[102] Mumby P.J., Skirving W., Strong A.E., Hardy J.T., LeDrew E.F., Hochberg E.J., Stumpf R.P. and David L.T. 2004. Remote sensing of coral reefs and their physical environment. Marine Pollution Bulletin, 48:219-228. 14

[103] Nagelkerken I., van der Velde G., Gorissen M.W., Meijer G.J., vant Hofc T. and Den Hartog C. 2000. Importance of Mangroves, Seagrass Beds and the Shallow Coral Reef as a Nursery for Important Coral Reef Fishes, Using a Visual Census Technique. Estuarine, Coastal and Shelf Science 51, 3144 doi:10.1006/ecss.2000.0617 2

[104] Noralez S. 2010. Exploring the Limits of Mapping Seagrass. A case study for P. oceanica. MSc Thesis. ITC. Netherlands. 30

[105] Norris J.G., Wyllie-Echeverria S., Mumford T., Bailey A. and Turner T. 1997. Estimating basal area coverage of subtidal seagrass beds using underwater videography. Aquatic Botany 58 (1997) 269-287 30

[106] SPOT, Official Website SPOT 20

[107] Orth R.J., Carruthers T.J.B., Dennison W.C., Duarte C.M., Fourqurean J.W., Heck Jr.K. L., Hughes A. R., Kendrick G. A., Kenworthy W. J., Olyarnik S., Short F.T., Waycott M. and Williams S. L. 2006. A Global Crisis for Seagrass Ecosystems. Vol. 56 No. 12, BioScience 987. 4

[108] Palandro D., Andréfouët S., Muller-Karger F. E., Dustan Ph., Hu Ch., and Hallock P. 2003. Detection of changes in coral reef communities using Landsat-5 TM and Landsat-7 ETM+data. Can. J. Remote Sensing, Vol. 29, No. 2, pp. 201209. 21

[109] Pasqualini V., Pergent-Martini C. and Pergent, G. 1998(a). Use of remote sensing for the characterization of the Mediterranean coastal environment the case of Posidonia oceanica. Journal of Coastal Conservation 4: 59-66, 1998, EUCC; Opulus Press Uppsala. 24

[110] Pasqualini V., Pergent-Martini C., Clabaut P., Pergent G. 1998(b). Mapping of Posidonia oceanica using aerial photographs and side scan sonar: Application off the island of Corsica (France). Estuarine Coastal Shelf Sci 47:359367. 7 
[111] Pasqualini V., Pergent-Martini C., Pergent G. 1999. Environmental impact identification along the Corsican coast (Mediterranean Sea) using image processing. Aquatic Botany, 65:311-320. 7

[112] Pasqualini V., Pergent-Martini C., Clabaut P., Marteel H., and Pergent G. 2001. Integration of Aerial Remote Sensing, Photogrammetry, and GIS Technologies in Seagrass Mapping. Photogrammetric Engineering and Remote Sensing Vol. 67, No. 1, January 2001, pp. 99-105. 7

[113] Pasqualini V., Pergent-Martini C., Pergent G., Agreila M., Skoufas G., Sourbes L. and Tsirika A. 2005. Use of SPOT 5 for mapping seagrasses: An application to Posidonia oceanica. Remote Sensing of Environment, 94:39-45. 20

[114] Peneva E., Griffith J.A. and Carter G.A. 2008. Seagrass Mapping in the Northern Gulf of Mexico using Airborne Hyperspectral Imagery: A Comparison of Classification Methods. Journal of Coastal Research, Number 244:850-856. 2008. Published By: Coastal Education and Research Foundation DOI: $10.2112 / 06-0764.122$

[115] Peneva E.I., Griffith J.A. and Carter G.A. 2007. Mapping seagrass distribution on Horn Island, MS using hyperspectral imagery. ecn.purdue.edu 22

[116] Pergent G. 1990. Lepidochronological analysis of the seagrass Posidonia oceanica (L.) Delile: a standardized approach. Aquatic Botany, 37 (1990) 39-54 39 Elsevier Science Publishers B.V., Amsterdam - Printed in The Netherlands 5

[117] Pergent-Martini C., Pasqualini V., Ferrat L. and Pergent G. 2006. Ecological Data in Integrated Coastal Zone Management: Case Study of Posidonia oceanica Meadows Along the Corsican Coastline (Mediterranean Sea). Environ Manage (2006) 38:889895 DOI 10.1007/s00267-005-0056-y. 7

[118] Pergent-Martini C., Leoni V., Pasqualini V., Ardizzone G.D., Balestri E., Bedini R., Belluscio A., Belsher T., Borg J., Boudouresque C.F., Boumaza S., Bouquegneau J.-M., Buia M.C., Calvo S., Cebrian J., Charbonnel E., Cinelli F., Cossu A., Di Maida G., Dural B., Francour P., Gobert S., Lepoint G., Meinesz A., Molenaar H., Mansour H.M., Panayotidis P., Peirano A., Pergent G., Piazzi L., Pirrotta M., Relini G., Romero J., Sanchez-Lizaso J.L., Semroud R., Shembri P., Shili A., Tomasello A., Velimirov B. 2005. Descriptors of Posidonia oceanica meadows: Use and application. Ecological Indicators 5, 213230. 3

[119] Phinn S., Roelfsema C., Dekker A., Brando V.E., Anstee J.M. 2008. Mapping seagrass species, cover and biomass in shallow waters: An assessment of satellite multi-spectral and airborne hyperspectral imaging systems in Moreton Bay (Australia). Remote Sensing of Environment, 112:3413-3425. 22

[120] Ralph P.J., Macinnis-Ng C.M.O., Frankart C. 2005. Fluorescence imaging application: effect of leaf age on seagrass photokinetics. Aquatic Botany 81 (2005) 6984. 7

[121] Rasib A.W. and Hashim M. 1997. Mapping Seagrass From Satellite Remote Sensing Data. Proceedings of Asian Conference on Remote Sensing. eprints.utm.my 20

[122] Ribed P.S. 2002. Submarine vegetation studies using remote sensing: importance in beach measurements. Journal of Environmental Protection and Ecology, 3 No 4, 953-958 (2002) 7

[123] Richardson L.L., LeDrew Ellesworth F. 2006. Remote Sensing of Aquatic Costal Ecosystems Processes. Springer. Science and Management Applications. 18 
[124] Robbins B.D., Bell S.S. 1994. Seagrass landscapes: a terrestrial approach to the marine subtidal environment. TREE vol.9, no 8, doi:10.1016/0169-5347(94)90041-8 55

[125] Sabins F. 1997. Remote Sensing, Principles and Interpretation. W.H. Freeman and Company, New York. 21

[126] Schmidt K. and Skidmore A.K. 2003. Spectral discrimination of vegetation types in a coastal wetland. Remote Sensing of Environment. 85:92-108. 22

[127] Schmieder K. 1997. Littoral zone - GIS of Lake Constance: a useful tool in lake monitoring and autecological studies with submersed macrophytes. Aquatic Botany 58 (1997) 333-346 17

[128] Schultz S.T. 2008. Seagrass monitoring by underwater videography: Disturbance regimes, sampling design, and statistical power. Aquatic Botany 88 (2008) 228238. 18

[129] Short F.T. and Coles R.G. (eds). 2001. Global Seagrass Research Methods, p 482. Elsevier Publishing Co., Amsterdam 7

[130] Shortis M., Harvey E., Seager J. 2007. A Review of the Status and Trends in Underwater Videometric Measurement. SPIE Conference 6491, Videometrics IX,IS and T/SPIE Electronic Imaging, San Jose, California, U.S.A., 28 January1 February 200727

[131] Stephens F.C., Louchard E.M., Reid R.P., Maffione R.A. 2003. Effects of microalgal communities on reflectance spectra of carbonate sediments in subtidal optically shallow marine environments. Limnology and Oceanography, 48:535-546. 18

[132] Thorhaug, A., Richardson, A. D. and Berlyn, G.P. 2007. Spectral reflectance of the seagrasses: Thalassia testudinum, Halodule wrightii, Syringodium filiforme and five marine algae. International Journal of Remote Sensing, 28: 7, 1487 1501. 7

[133] Toole D.A., Siegel D.A., Menzies D.W., Neumann M.J. and Smith R.C. 2000. Remote-sensing reflectance determinations in the coastal ocean environment: impact of instrumental characteristics and environmental variability. Applied Optics 39(3), 456-469. 41

[134] Vahtmae E., Kutser T., Martin G., Kotta J., 2006. Feasibility of hyperspectral remote sensing for mapping benthic macroalgal cover in turbid coastal waters - a Baltic Sea case study. Remote Sensing of Environment (2006) 101:342-351. 18

[135] Vahtmae E. and Kutser T. 2007. Mapping bottom type and water depth in shallow coastal waters with satellite remote sensing. Journal of Coastal Research, SI 50 (Proceedings of the 9th International Coastal Symposium), 185 189. Gold Coast, Australia, ISSN 0749.020823

[136] Villegas P. P. 2006. Magnitude of herbivory in Posidonia oceanica (L.) Delile and factors responsible for spatial variation. Available on web: tesisenxarxa 17

[137] Wabnitz C.C., Andréfouët S., Torres-Pulliza D., Müller-Karger F. E. and Kramer P.A., 2008. Regionalscale seagrass habitat mapping in the Wider Caribbean region using Landsat sensors: Applications to conservation and ecology. Remote Sensing of Environment Vol. 112, Issue 8, 15 August 2008, Pages 3455-3467 Earth Observations for Marine and Coastal Biodiversity and Ecosystems Special Issue. 20 
[138] Walker, D.I., 1989. Methods for monitoring seagrass habitat. Proceedings Rep. Workshop, 20-22 June 1988, Melbourne, Australia, VIMS Working Paper 18, pp. 1-26. 7

[139] Werdell P.J. and Roesler C.S. 2003. Remote assessment of benthic substrate composition in shallow waters using multispectral reflectance. Limnol. Oceanogr., 48 (1, part 2), 55756718

[140] Yang Ch., Yang D., Cao W., Zhao J., Wang G., Sun Zh., Xu Zh., Kumar M. S. R. 2010. Analysis of seagrass reflectivity by using a water column correction algorithm. International Journal of Remote Sensing. 31: 17, 4595 4608. 32 


\section{Index of People}

Acquaro M., $\mathrm{f}$

Agreila M., i

Albertelli G., g, h

Alcoverro, T., a

Almanmy J., g

Alongi D.M., $\mathrm{b}$

Alvarez A., c

Alvarez E., b

Amoutzopoulou-Schina, H., a

Andréfouët S., d, h, j

Anh N.H., d

Anstee J.M., i, b

Antonic, O., a

Arai, K., a

Ardizzone G.D., i, a

Argyrou M., b, e

Astier, J.M., g

Atkinson, M.J., d

Atu P., g

Bailey A., h

Bakran-Petricioli, T., a

Balestri E., i

Ball, D., a

Bargain, A., a

Barille, L., a

Basterretxea G., c

Bedini R., i

Bell S.S., a, e, j

Belluscio A., i, a

Belsher T., i

Berlyn, G.P., j

Bharathi A.M., b

Bianchi C.N., g, h

Biber P.D., b

Bierwirth, P. N., a

Bittaker H.F., e

Bjork M., d

Blake, S., a

Blossom G.A., b

Bodin M., d

Bogner A., d

Borg J., i
Borum, J., a

Boudouresque C.F., i, a

Boumaza S., i

Bouquegneau J.-M., i, d

Brando V.E., i, b

Brown, C.J., a

Buia M.C., i, b

Bukovec, D., a

Burne, R.V., a

Butler, b

Calvo S., i, b

Cambridge M.L., d, b

Campbell S.J., g

Cao W., k

Cappo, M., b

Carruthers T.J.B., $\mathrm{h}$

Carter G.A., i, b

Caye, G., g

Cebrian J., i

Charbonnel E., i

Chiaradia M.T., $\mathrm{f}$

Choo, C.K., b

Cinelli F., i

Ciraolo G., b

Clabaut P., i, h

Clark C.D., d, h

Clark, R.N., b

Coles R.G., j

Connell J.H., b

Cooper, K.M., a

Coots, A., a

Cossu A., i

Cottalorda, J.M, c

Criss G.A., b

Dalsgaard T., e

Dana D.R., $f$

Danovaro R., b, e

Dauby, P., d

David L.T., h

Davidson A., e

Davis C.O., $\mathrm{f}$ de Bie C.A.J.M., vii

Defawe O., d

Dehouck A., b

Dekker A.G., i, b

Demoulin V., d

Den Hartog C., d, h

Dennison W.C., h

Di Carlo G., b

Di Maida G., i

Diaz-Almela E., b, e

Dierssen H., c

Dixon R., c

Downes T.V., f

Duarte C.M., c, d, a, b, e, h

Dujmovic, S., a

Duke N., b

Dumay O., c

Dural B., i, c

Dustan Ph, h

Edwards A.J., c, d, h

Ferguson R.L., c

Fernandez C., c

Ferrat L., i

Fletcher R.S., c

Fornes A., c

Fourqurean J.W., h

Francour P., i, c

Frankart C., i

Frederiksen M., e

Fresi, E., a

Froidefond J.-M., b

Fyfe S.K., c

Ganteaume A., c

Gege P., vii, c

Gobert S., i, d

Gorissen M.W., h

Gratiot, J., c

Grau A., b, e

Gravez, V, a

Green A.P., g

Green E.P., d, h 
Greve, T.M, a

Griffith J.A., i

Guidetti P., d

Gullstroom M., d

Haag S.M., d

Hallock P., h

Hang H.T.M., d

Hardegree B., c

Hardy J.T., h

Harin, N., a

Haritonidis, S., a

Harvey E., j

Hashim M., i

Heck Jr.K. L., h

Heege T., d

Hegge B.J., e

Helfferich C., d

Hirose K., d

Hochberg E.J., d, h

Hogarth P., e

Holmer M., b, e

$\mathrm{Hu}$ Ch., h

Hughes A. R., h

Iverson R.L., e

Jackson J., e

Janekovic, I., a

Jensen J.R., e

Jensen S.L., a, e

Jerlov N.G., e

Jordi A., c

Kalinowski A., e

Kalliappan S., b

Kangwe J., d

Karakassis I., b, e

Karpouzli E., f

Kelly, M.G., e

Kendrick G.A., b, e, h

Kennish M., d

Kenworthy W. J., h

Khalid T., $\mathrm{f}$

Kirk J.T.O., e

Kirkman H., e
Koch M.S., e

Korfmacher Karl K., c

Kotta J., j

Kramer E., d

Kramer P.A., j

Krause-Jensen, D., a

Krizan, J., a

Kumar M. S. R., k

Kumar S.C., b

Kuo J., e

Kusan, V., a

Kutser T., j

Lamote M., e

Larkum A.W.D, d

Larkum A.W.D., e

Lasi, F., g

Leathers R.A., $f$

LeDrew E.F., i, h

Lee, T. J., a

Lefevre, J.R., g

Lemenkov, P., vi, vii

Lemenkova, P., ii

Leoni V., i, f

Lepoint G., i, d

Lewis M., $f$

Limpenny, D.S., a

Loggia G. la, b

Lokani W., g

Lopez, N., a

Lord D.A., e

Louchard E.M., f, j

Lunden B., d

Luque A., f

Lymberakis, P., vii, lvi

Lyzenga D.R., $\mathrm{f}$

Müller-Karger F. E., j

Macinnis-Ng C.M.O., i

Maffione R.A., f, j

Magreau, J.F., c

Maiorano, L., a

Malthus T.J., $\mathrm{f}$

Mannoni, P.A., c

Mansour H.M., i
Marbà N., b, e

Mariani M., h

Marteel H., i

Martin G., j

Martiny N., b

Matarrese R., f

Mazzella L., b

McComb A.J., e

McKenzie L.J., g

McRoy, C.P., d, e

Meadows, W.J., a

Meijer G.J, h

Meinesz A., i, a, g

Mellors J., g

Menzies D.W., j

Micheli C., g

Mirto S., e

Molenaar H., i

Montefalcone M., g, h

Morea A., f

Morri C., g, h

Mount R., h

Mtolera M.S.P., d

Muller-Karger F. E., h

Mumby P.J., d, h

Mumford T., h

Nagelkerken I., h

Nam V.N., d

Narumalani S., e

Nemeth D.J., e

Neumann M.J., j

Nieuwenhuis, W., vii

Noralez S., h

Norris J.G., h

Ohman M.C., d

Oliver S., e

Olyarnik S., h

Orfila A., c

Orth R.J., d, h

Pérez M, e

Paganin P., g

Palandro D., h

Panayotidis P., i 
Pasqualini V., i, f, h

Patrick, L., a

Patterson, E., a

Peirano A., i, g

Peneva E.I., i

Pergent G., i, c, d, f, h

Pergent-Martini C., i, d, f, h

Petricioli, D., a

Phillips, R.C., e

Phinn S., i

Piazzi L., i

Pinnel N., d

Pirrotta M., i

Poulain M., c

Pulich Jr. W., c

Pusceddu A., e

Ralph P.J., i

Ramonia P., g

Rasib A.W., i

Rees, H.L., a

Reid R.P., f, j

Relini G, i

Ribed P.S., i

Richardson L.L., i

Richardson, A.D., j

Robbins B.D., a, j

Robin, M., a

Roder C.A., g

Roelfsema C., i

Roesler C.S., $\mathrm{k}$

Roge-Wiśniewska, M., ii

Romero J., i, a

Roob, R., a

Rutchey K., e
Sénéchal N., b

Sabins F., j

Sakowicz G.P., d

Sanchez-Lizaso J.L., i

Santiago R., b

Schmidt K., j

Schmieder K., j

Schultz S.T., j

Seager J., j

Semroud R., i

Shembri P., i

Shepherd J., e

Shili A., i

Short F.T, h

Short F.T., d, j

Shortis M., j

Siegel D.A., j

Skidmore A.K., ii, j

Skirving W., h

Skoufas G., i

Smith R.C., j

Soto-Berelov, M., a

Sourbes L., i

Stephens F.C., f, j

Strong A.E., h

Stumpf R.P., h

Sun Zh., k

Syoji M., d

Templado J.A., $f$

Thomas P., g

Thorhaug, A., j

Tijani K., f

Tintore J., c

Tomasello A., i
Tonooka, H., a

Toole D.A., j

Torres-Pulliza D., j

Toxopeus, A.G., ii, vii, lvi

Triet T, d

Tsapakis M., e

Tsirika A., i

Turner T., h

Vahtmae E., j

van der Velde G., h

vant Hofc T., h

Vela A., $\mathrm{f}$

Velimirov B., i, d

Venus, V., ii, vii

Villegas P. P., j

Wabnitz C.C., j

Walker, D.I., d, k

Wang G., k

Waycott M., h

Werdell P.J., k

Williams D., b

Williams S.L., h

Wyllie A., e

Wyllie-Echeverria S., h

Xu Zh., k

Yang Ch., k

Yang D., vii, k

Yoshida R., g

Young, P., a

Zhao J., k

Zimmerman R.C., c 


\section{Index of Concepts}

Algae, 3

Data, 8

collection, 25

integration, 50

measurements pool, 44

pre-processing, 30

processing, 34

statistical analysis, 44

ANOVA, 48

autocorrelation, 45

average, 49

cross-correlation, 45

Gretl, 44

hypothesis testing, 47

$\mathrm{k}$-means cluster analysis, 45

LAD, 45

least squares, method of, 45

median, 49

non-linear logistic analysis, 45

observations, series of, 45

periodogram, 45

probability distribution, 45

quartiles Q1-Q3, 45

SPSS, 44

standard deviation, 49

Student-t testing, 32

variables, 44

Remote sensing, 17

aerial imagery

GoogleEarth, 36

GPS, 18

hyperspectral imagery, 22

application, 22

spectral bands, 22

multispectral imagery, 20

ASTER, 21, 50

CASI, 20

CZCS, 50

IKONOS, 20

Landsat ETM+, 20

Landsat TM, 20
MERIS, 50

MODIS, 50

Quickbird, 21

SeaWiFS, 50

SPOT, 20

Terra sensor, 21

spectral measurements, 18

underwater videography, 18

Research, 6

approach, 11

assumptions, 10

objective, 8

general, 9

specific, 9

problem, 6

questions, 9

hypothesis, 9

Seagrasses, 1

P.oceanica, 5

distribution, 5

environmental adaptation, 6

morphology, 5

phenology, 6

anthropogenic impacts on, 4

distribution of, 2

ecological vulnerability, 3

global monitoring, 13

global species, 2

global surveys, 13

Mediterranean species, 2

natural impacts on, 4

spatial structure, 55

Seawater optical properties, 14

hyperspectral measurements, 15

irradiance, 15

radiance, 15

RTM, 15

6SV1, 16

CRTM, 16

KOPRA, 16

MODTRAN, 16

RRTM, 16 
RTTOV-9, 16

WASI, 16, 34, 42, 51

spectral reflectance, 18,19

spectral diapason, 19 spectroradiometers, 15

Trios-RAMSES, 15

Software used, xv 